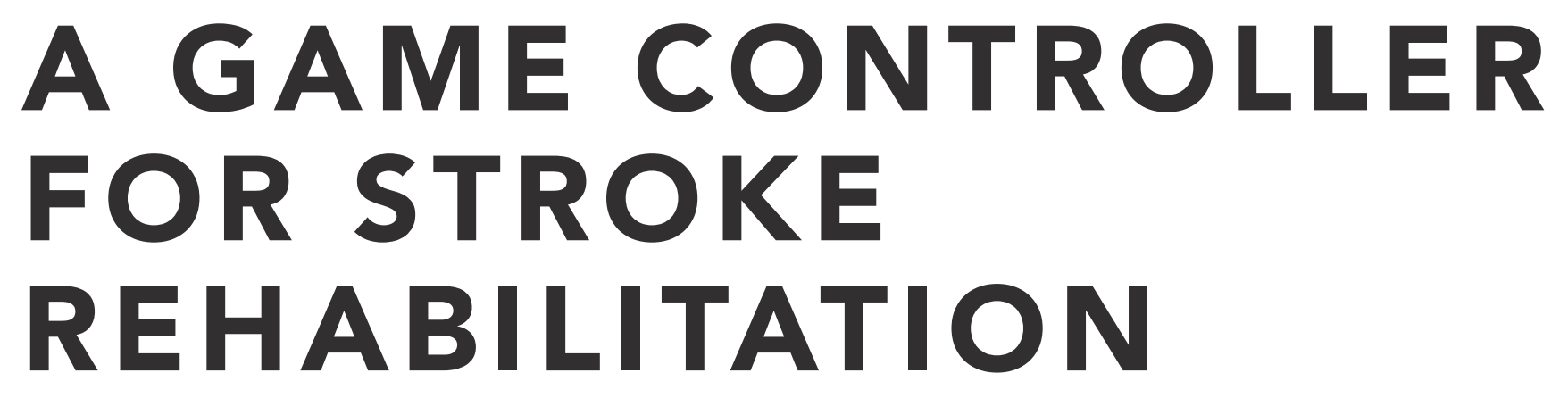

WILLIAM DUNCAN 



\section{A Game Controller for Stroke Rehabilitation}

\section{By William Thomas Duncan}

A 90-point thesis submitted to the Victoria University of Wellington in partial fulfillment of the requirements for the degree of Master of Design Innovation in Industrial Design.

Victoria University of Wellington, School of Design.

2017 


\section{DEDICATION}


To my Parents 
ACKNOWLEDGEMENTS 
Dr. Edgar Rodriguez-Ramirez. Your guidance and advice has been invaluable throughout this research.

My research partner Scott Brebner. Its been a pleasure collaborating with you. The adventures will surely be missed.

The clinicians and participants involved with this project, with a special mention to Dr Nada Signal and Dr Brian Robinson.

My design peers, I couldnt have asked for a better team to navigate the peaks and troughs of post-graduate research.

Finally, a special thank you to my better half Georgie, as well as my family for their love and support. 

ABSTRACT 
Successful stroke rehabilitation relies on early, long-term, repetitive and intensive treatment. Repetitions conducted during clinical rehabilitation are significantly lower than that suggested by physiotherapeutic literature to relearn lost motor capabilities. This leaves patients to achieve this quantity in their home environment. Exercises can be monotonous and repetitive, making it difficult to maintain patient motivation. Exergames have been promoted for use in the home to make rehabilitation entertaining, increasing patients engagement with their therapy. Marketed exergaming systems for lower limb rehabilitation are hard to find, and none as of yet, facilitate Strength for Task Training (STT), a novel physiotherapeutic method for lower limb stroke rehabilitation. Strength for Task Training involves performing brief but intensive strength training (priming) prior to task-specific training to promote neural plasticity and maximise the gains in locomotor ability.

This research investigates how the design of a game controller for lower limb stroke rehabilitation can facilitate unsupervised STT to compliment clinical contact time.

The game controller was developed as part of a complete exergaming system designed to specifically facilitate STT. This involved working closely with co-researcher Scott Brebner who designed the exergame media. A user centered design approach was followed to include clinicians and stroke patients in the design process. This ensured the design aligned with the functional requirements of STT and the contextual needs of the patient. Workshops with stroke clinicians and neurophysiologists pointed to the specific areas of STT that a designed system could address. An iterative design process was used to develop, compare and improve concepts through testing with participants and clinicians. User testing involved participants using the game controller to interact with the digital game.

The final output was a prototype pair of smart shoes with an attachable weighted sole. The design used removable sensors to translate lower limb movement into ingame interactions. The design of the shoes and weighted sole provided a simple and safe way to engage in unsupervised STT. Research findings suggest that while not all of the STT therapy can be incorporated in an unsupervised and home-based exergame system, there are some essential elements that can. Adaptable hardware was found to be integral to facilitating intensive priming. Barriers to use can be reduced through considering the diverse physiological and cognitive abilities of stroke patients and aesthetic consideration can help create a meaningful game controller that promotes its use in the home. 


\section{TABLE OF CONTENTS}

Dedication

Acknowledgements

viii

Abstract

Introduction

1) Background Research

Stroke, Lower Limb Rehabilitation and Exergames. 7

Adaptability

Exergames in the Home

Ergonomics and Usability When Designing for Stroke Patients. 16

Designing for the Domestic Environment

Summary of Background Criteria

2) Methodology

3) Design Research

A Clinician's Perspective

Personas

4) Final Design Criteria

5) Design Research...

Selected Technology

Defining the Intervention 
Revised Design Concepts

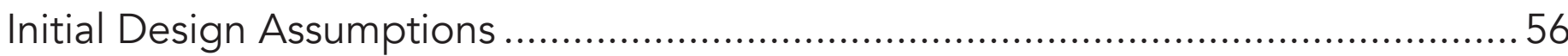

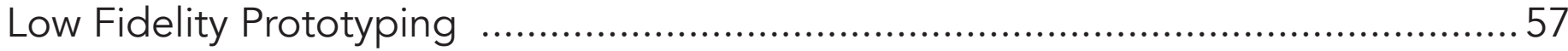

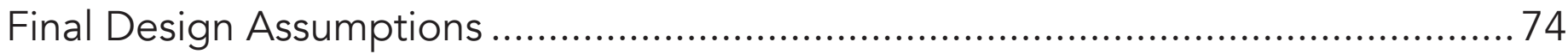

6) Testing \& Assessment .............................................79

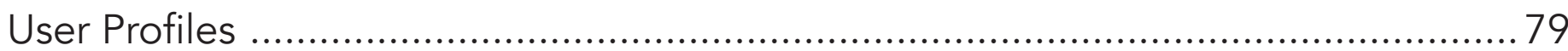

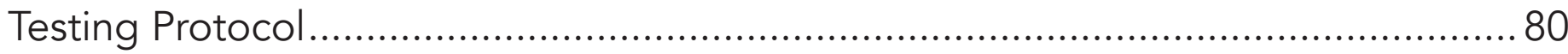

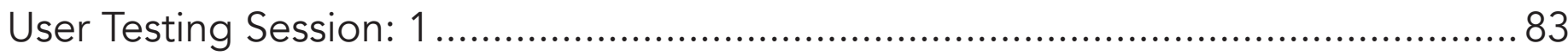

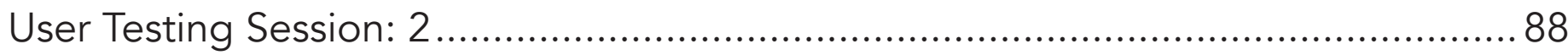

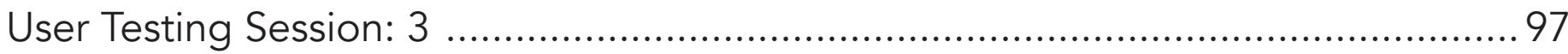

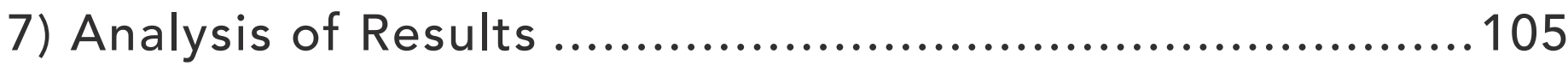

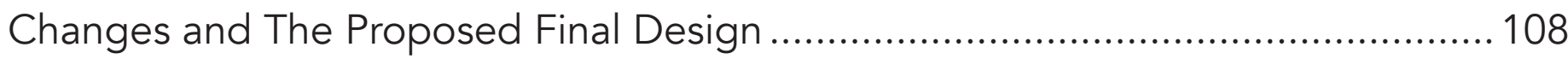

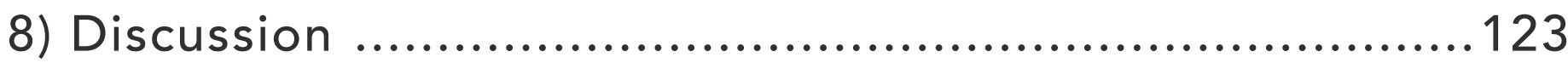

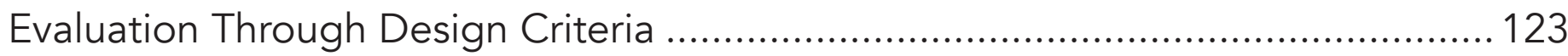

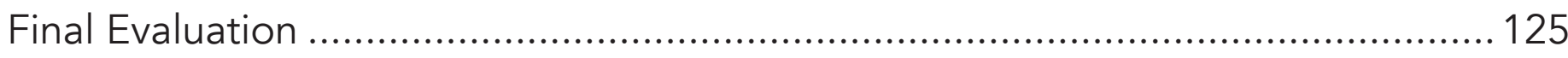

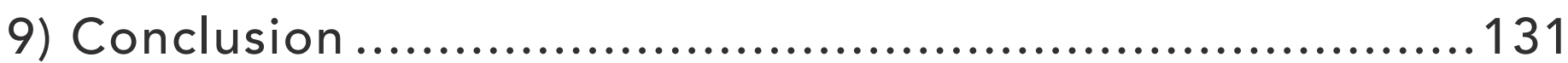

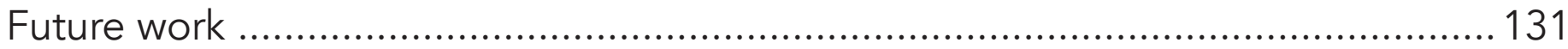

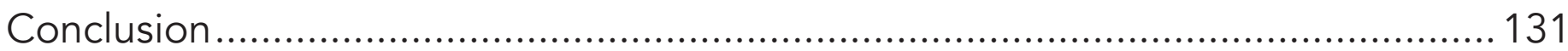

References ................................................................. 136

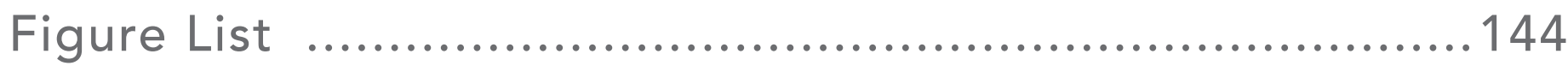

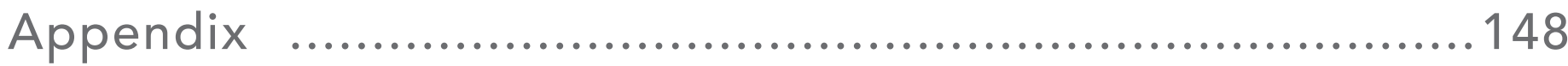





\section{INTRODUCTION}


With over 15 million cases worldwide every year (WHO, n.d.), strokes are a leading cause of serious long-term disability. Physical impairments following stroke include muscle weakness, a restricted range of motion, and reduced force generation (Jack et al., 2001; Mozaffarian et al., 2015). Up to $75 \%$ of people affected by stroke have lower limb mobility limitations (Duncan et al., 2005; Jack et al., 2001). The World Health Organisation (WHO) has highlighted the need for home health care that calls for rehabilitative devices, self monitoring tools and self-management skills, thus enabling clients and their families to self-manage their conditions at home where appropriate (WHO, 2002).

Success for stroke rehabilitation relies on early, intensive, long term repetitive treatment (Burke et al., 2009). With the increasing population access to clinicians is becoming restricted which means that the majority of rehabilitation must take place in the home (clinician 1, personal communication, August 10, 2015). However, although abundantly prescribed by clinicians, as little as 31\% of patients perform these exercises correctly and consistently (Shaughnessy et al., 2006, p. 16).

Recent studies show that systems of rehabilitative devices with incorporated digital games for exercising (exergames), improve patient engagement with their home based therapies. This has promoted beneficial patient outcomes for different long term conditions, including upper limb stroke rehabilitation (Bainbridge, Bevans, Keeley \& Oriel, 2010; Hijmans et al., 2011). However, there is a lack of commercialized lower limb stroke rehabilitation exergames for use in the home setting.

Strength for Task Training (STT) is a novel approach to physiotherapeutic lower limb rehabilitation that aims to improve locomotion through a combination of strength and task training (Signal, 2014, p. 249). STT is currently performed in a clinical therapy setting, however there is a need for the patient to be able to perform this therapy from home.

There currently exists an opportunity for the development of a game controller, as part of an exergame for a home based lower limb rehabilitation system that facilitates unsupervised strength for task training. As an adjunct to clinical rehabilitation, this system could help promote a higher volume of dose of therapy, optimise recovery of lower limb function and reduce the load on the public health system. 




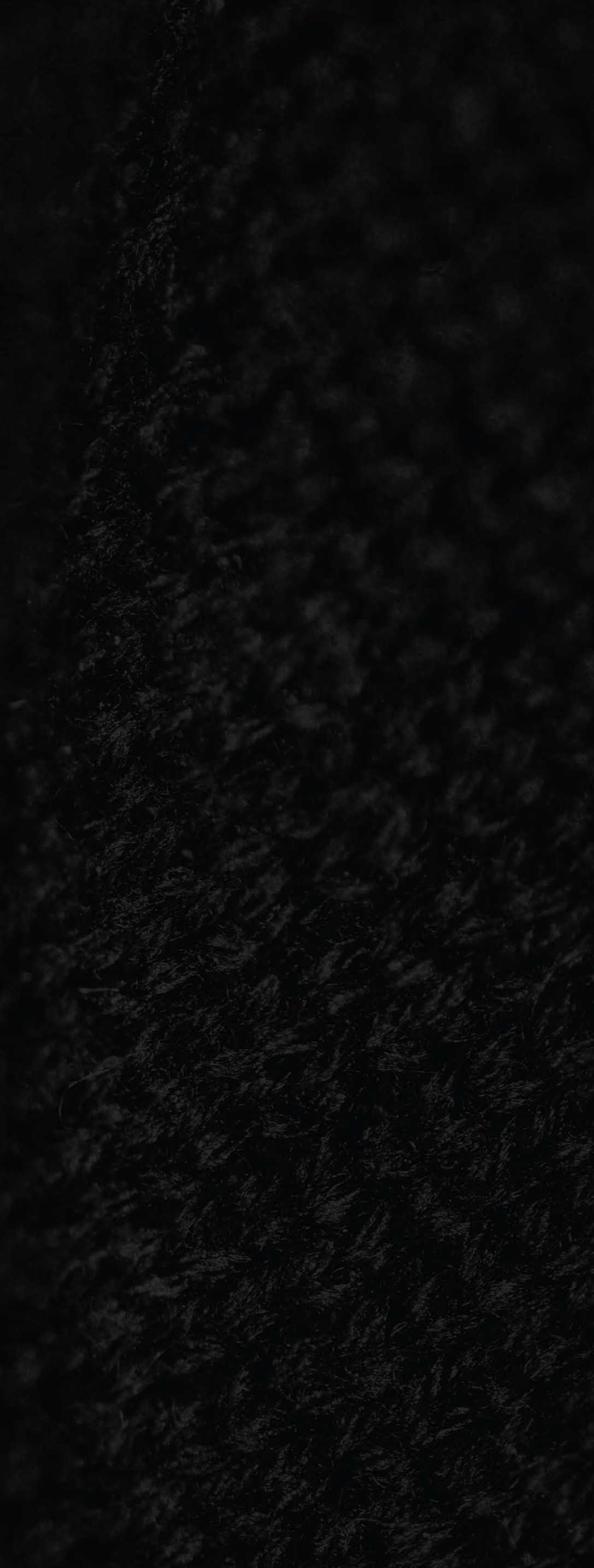




\section{BACKGROUND RESEARCH}

\section{"DESIGN DEPENDS LARGELY ON CONSTRAINTS" -}

\section{CHARLES EAMES}

This chapter investigates how and why exergames for stroke rehabilitation are suggested to be effective in providing positive outcomes for stroke patients and how Strength for Task Training (STT) has the potential to increase patients locomotion. Exploration of these factors informed initial criteria for the design of a controller, as part of a wider exergame system, that facilitates unsupervised lower limb stroke rehabilitation. Ergonomic and usability needs, as well as requirements for use in the home, helped form contextual design criteria. Current marketed exergaming systems were also referenced to discuss which elements are successful/unsuccessful and what the industry is failing to address. This chapter is broken down into themes to create criteria that informed the design process. It is important to remember that an exergame is constructed of two components, the hardware and the media. Although this research focuses on the hardware (game controller) the relationship between the hardware and the media will be addressed holistically to develop a specific and succinct exergaming system.

\section{Stroke, Lower Limb Rehabilitation and Exergames}

Suffering a stroke often results in hemiplegia (muscle paralysis) or hemiparesis (muscle weakness) down one side of the body; affecting the person's ability to perform day to day tasks and activities, subsequently compromising their independence (Alankus et al., 2010, p. 2114). Strokes occur when clots or bleeding prevent the flow of blood to the brain. This starves cells of oxygen causing subsequent damage to an area of the brain. This damage breaks down neural pathways in the brain meaning those who survive a stroke often experience cognitive, visual and motor impairments (Alankus et al., 2010, p. 2113). Neural plasticity is the brain's ability to build new connections between neurons (Kliem, 2011, p. 522). Encouraging neural plasticity in the brain, as well as learning to use existing redundant neural pathways is the goal of stroke rehabilitation. These require intensive, repetitive training to regain the loss of motor control (Alankus et al., 2010; Burke et al., 2009).

Clinical lower limb rehabilitation is often time consuming and expensive. Due to the growing prevalence of strokes, there is a paradigm emerging where there are too many patients and not enough clinicians (clinician 1, personal communication, August 10, 2015). This requires patients to practice their therapy at home unsupervised by their clinician. Although abundantly prescribed by clinicians, as little as $31 \%$ of patients perform these exercises correctly and consistently (Shaughnessy et al., 2006, p. 16). Rehabilitative exergames use exercise as the means of interaction with a video game (Sinclair et al., 2007) and are considered to improve patients' engagement with their prescribed therapies (Bainbridge, Bevans, Keeley \& Oriel, 2010; Hijmans et al., 2011). Exergames offer a motivating and stimulating intervention to the monotony of home based rehabilitation (Alankus et al., 2010, p. 2113). When engaged with their prescribed exercises, the patient is more likely to be 
consistent in their rehabilitation programme. This increases functional improvement during and after rehabilitation, promoting more effective recovery (Bright et al., 2015, p. 643).

On reviewing current marketed exergaming systems that promoted home based rehabilitation, only one was found to be targeted specifically towards lower limb stroke rehabilitation (YouRehab, 2015). A broader amount of exergames claimed to focus on improving the gait and balance of patients' who have suffered a stroke or traumatic brain injury (Fritz, Peters, Merlo \& Donley, 2013; Gil-Gomez et al., 2011; LuqueMoreno et al., 2015) as well as systems specifically designed for upper-limb stroke rehabilitation (Alankus et al., 2010; Levin, Weiss, Keshner, 2015; Shirzad et al., 2015).

\section{Strength for Task Training}

The focus of lower limb rehabilitation is on regaining the stroke patient's mobility. Hemiplegia or hemiparesis following stroke impede the survivor's ability to walk, subsequently restricting their movement around their home and community (Perry et al., 1995). Locomotive impedance is varied following stroke. Walking ability of patients can range from being able to walk independently through to wheelchair assisted or unable to walk at all (Perry et al., 1995). Lower limb rehabilitation exercises are structured using different variables to suit the patient's mobility.

The two restrictions of locomotion after a stroke are muscle weakness and impairment to the connections between the brain and limbs. Strength training is a clinically stable intervention that aims to improve muscle strength, endurance and/or power (Signal, 2014 , p. 13). Strength training increases the muscles' ability to complete the movements that are integral to the task of walking but has very limited translation to the coordination of executing these movements together to perform the task of walking (Signal, 2014, p. 125). Task specific training involves the repetitious practice of lower limb locomotor movements that are required to walk.
This repetition of task exercises promotes plasticity but has only limited results without the strengthening of the muscles involved with the task (Signal, 2014, p. 304). It is also worth noting that task training is adopted by contemporary exergames to provide salient interactions (Brunner et al., 2014, p. 3). These are interactions, which the user finds tangible to tasks they perform in everyday life. These task based exercises become stimulating in an exergaming environment, motivating the user to perform multiple repetitions (Brunner et al., 2014, p. 4).

Strength for Task Training (STT) is a novel approach to lower limb stroke rehabilitation. STT combines strengthening the muscles that are used to perform locomotion (e.g. strengthening plantarflexors and hip flexors to increase walking speed), with task specific movements promoting neural plasticity. Neural plasticity finds new pathways or rebuilds obsolete ones in the brain. These pathways establish the connection between the brain and subsequent muscle movement. Relearning these movements helps the patient attain better locomotion (Signal, 2014, p. 304).

Priming is the term given to the strengthtraining element of the exercise. This involves the strengthening of the muscles whilst getting the patient to exert themselves as much as possible. This exertion makes the strength training intensive and creates corticomotor excitability. This primes the neural pathways in the brain so when followed promptly with task specific training the brain is better equipped to promote neural plasticity (Signal, 2014, p. 47). Priming requires different forms of strength training for each exercise, typically involving lifting a weight or using a resistance band applied to the lower-limbs followed quickly by a taskbased activity using the same muscle groups (Signal, 2014, p. 53).

To prime effectively, the strength-training exercise must be intensive. Load is applied to the affected limb to promote intensive movement. Load, in the form of weight or resistance is prescribed by the patient's 
clinician based on their assessment of locomotive ability. The load is changed gradually as the patient progresses to ensure the strength exercises remain intensive.

Neural excitement begins to decrease within minutes of strength training. It is therefore important that the time between the priming and task training is prompt (Signal, 2014, p. 47).

Just like priming, task based exercises must also be intensive to promote improvement. The progression of exercises ensures that high volumes of task repetitions are completed at optimal intensity. Intensity is maintained by increasing the complexity of each task. Tasks must be designed to mimic real world motor skills. This ensures that the task movements are relevant to promoting better locomotion (Signal, 2014, p. 46).

The task training component is progressed across nine parameters at the discretion of the physiotherapist:

- Part/Whole Task

- Speed Accuracy

- Sensory Availability

- Biomechanical Challenge

- Cognitive Attention

- Physical Attention

- Environment

- Blocked vs. Random

(Signal, 2014, p. 53)

The complexity associated with facilitating all of these parameters within an exergaming system was beyond the scope of this project. The focus of the hardware would aim to promote intensive task training through progression of part and whole tasks. The media would also attempt to keep the tasktraining component intensive by increasing the accuracy and speed of the movements the user would be required to perform.

STT is made up of seven different activities. These engage all the muscle groups and tasks involved in locomotion. The seven exercises are conducted within a 60 minute sessions one after another in a circuit with small 30 second breaks in between. In a clinical setting the exercises require specific equipment or environmental requirements.

\section{Strength for Task Training Exercises (Signal, 2014, pg. 53)}

Strength Component (Priming) // Task Component

1. Toe Ups (Dorsiflexors/Evertors) // Obstacles Aim: Strengthen muscles for foot clearance

2. Hip Flexors // Walking \& Stepping Aim: Strengthen muscles at the front of the hip

3. Hip Abduction // Sideways Walking \& Stepping Aim: Strengthen muscles at the sides of the hip muscles

4. Quadriceps (Seated Leg Press) // Standing Up \& Sitting Down Aim: Strengthen muscles at the front of the thigh

5. Hip Extensors // Stairs \& Steps Aim: Strengthen buttock muscles

6. Hamstrings // Backwards Walking \& Stepping Aim: Strengthen hamstring muscles at the back of the thigh

7. Plantarflexors (Supine Leg Press) // Fast Walking \& Slopes Aim: Strengthen calf muscles 


\section{Equipment}

1 Resistance Bands

Rotary Hip Machine

3

Ankle brace connected to a resistance band

4

Leg Press Machine

5

Westminster Pulley

6

Westminster Pulley
Leg press machine

\section{Motion}

Use resistance band to lock knees together. Hold ankles together then pull toes of both feet up simultaneously and hold.

Bring knee forward and upward
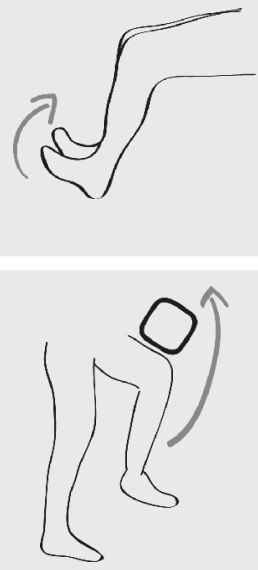

Move leg sideways away from mid-line

Push weight through foot to straighten the knee

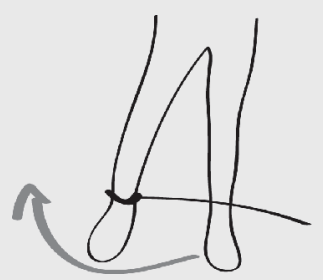

With Westminster Pulley attached at the ankle, keep knee straight and move leg backwards.
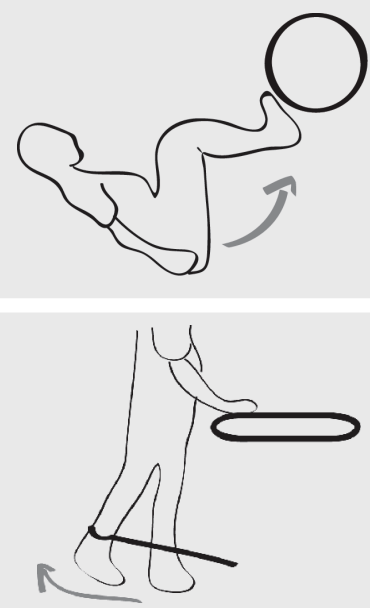

With pulley attached in front, keep the hip still and bend the knee

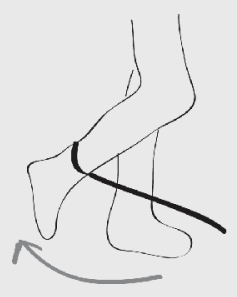

Push weight through toes to raise the heel

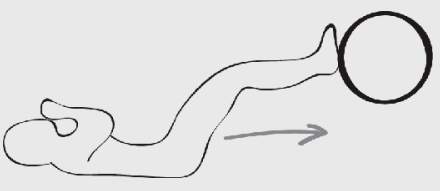




\section{Task Training Component}

\section{Transition}

\begin{tabular}{|c|c|}
\hline $\begin{array}{c}\text { Detach ankle } \\
\text { strap and } \\
\text { resistance }\end{array}$ & $\begin{array}{l}\text { Obstacles (cones, } \\
\text { hurdles, small mats) }\end{array}$ \\
\hline $\begin{array}{l}\text { Step off Rotary } \\
\text { Hip Machine }\end{array}$ & $\begin{array}{c}\text { Obstacles (rails to hold } \\
\text { onto, lines to walk } \\
\text { along, mats to step } \\
\text { over) }\end{array}$ \\
\hline $\begin{array}{c}\text { Detach ankle } \\
\text { strap and } \\
\text { resistance } \\
\text { band }\end{array}$ & Stepping Board \\
\hline $\begin{array}{c}\text { Get off Leg } \\
\text { Press Machine }\end{array}$ & Seat \\
\hline $\begin{array}{c}\text { Detach ankle } \\
\text { strap }\end{array}$ & Stepping Board \\
\hline $\begin{array}{c}\text { Detach ankle } \\
\text { strap }\end{array}$ & Stepping Board \\
\hline $\begin{array}{c}\text { Get off leg } \\
\text { press machine }\end{array}$ & Sloped Surface \\
\hline
\end{tabular}

Walk around the room navigating around, stepping over and stepping on obstacles.

\section{Motion}

Forwards walking while holding onto railing, walking along a

straight line and stepping over objects.
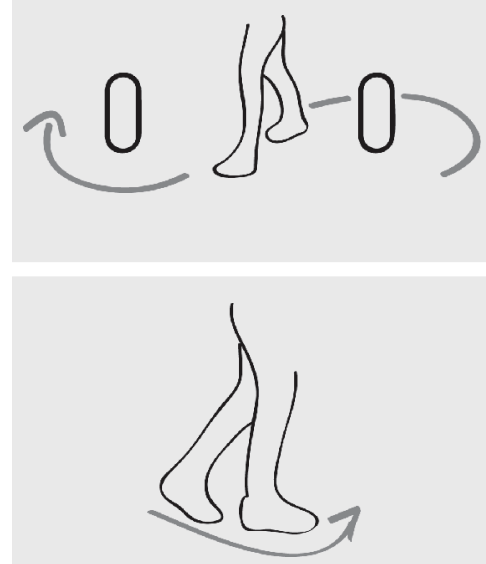

Sideways Stepping

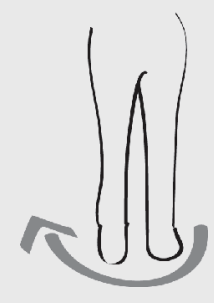

Stand up \& sit down

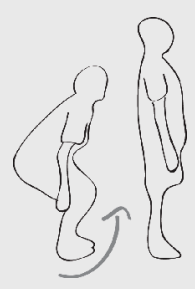

Step up and over

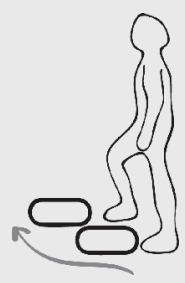

Step forward and back.

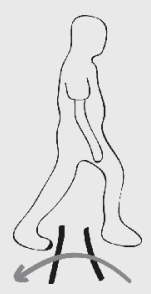

Walking fast and walking up a slope 


\section{Modifications and Progressions (Signal N, 2014, p. 55)}

- Part \& Whole task - Task training can be progressed increasing the complexity of the movement. The clinician might start the patient with the simple task exercise of side stepping. The clinician can then modify the task as the user progresses to side-stepping then pivoting. These part task/whole task modifications can also be used to tailor the component to the patient's ability level.

- Speed of Task - Increasing the speed of the task intensifies the exercise for the patient, as it requires faster processing, reaction and movement times.

- Accuracy - Increasing the accuracy promotes the learning of fine motor skills.

- Sensory Availability - Restricting the use of sensory input, such as getting visual feedback of your legs moving when trying to walk, can help develop the use of other sensors for this task. This simulates real world situations where the patient might not be able to constantly get visual feedback.

- Biomechanical Challenge Changing the support given during an exercise such as a walking frame or leaning on a table/sitting down, creates intensity as it changes the base of support. Increasing the range of motion required to complete a task whilst still having the same base of support also works.

- Cognitive Attention - Introduction of secondary cognitive tasks to help make locomotive movements more autonomous.
- Physical Attention - Introduction of secondary physical tasks to help make locomotive movements more autonomous.

- Environment - Make the environment more complex and variable.

- Blocked vs. Random - Another modification for more advanced users will be to mix up the movements rather than repeating them one after another.

Initial criteria can be derived from these core components of STT. This will help frame the exergame system as a home based intervention and guide the design of the game controller.

\section{Criteria:}

- The design should allow strength for task-training movements to act as inputs for playing an exergame by allowing movements to be tracked in $3 d$ space

- The design should enable the user to perform priming exercises through the application of load to the affected limb

- The design should provide an option of applying and increasing the weight of the lower limb during priming to make the exercises intensive

- The design should provide an option of applying and changing resistance bands to the lower limb during priming to make the exercises intensive

- The design should allow the user to perform priming and task exercises without being constrained by the game controller The design should enable the user to perform part and whole tasks 


\section{Adaptability}

Adaptability in rehabilitation is the practitioner's ability to change the difficulty, intensity, and complexity of a task to suit the patient's evolving needs (clinician 2, personal communication, August 10, 2015). Motor effects following stroke vary from patient to patient (Flores et al., 2008). If

the difficulty of the exercise is not matched and adapted to the patient's ability level, the patient can become frustrated, bored and fatigued (Levin et al., 2015). This can generate poorer outputs from patients when compared to exergames that are identified to be adaptable (Luque-Moreno et al., 2015, p. 4). Successful exergames must present the ability to change the difficulty manually or automatically through modifying in-game parameters (Alankus et al., 2010; Flores et al., 2008), adapting the difficulty to the needs of the patient, making the games motivating, engaging, and enjoyable (Levin et al., 2015). Jintronix is a VR exergaming system that uses Microsoft Kinect as the means of interaction. The game allows the clinician to change the size and position of objects that are interacted with in the virtual environment (Levin et al., 2015) keeping the patient motivated to play. Similarly, the eBaVIIR system that is played using Wii Balance Board where the clinician changes the difficulty and duration of the exercise, however only in a clinical setting (Gil-Gomez et al., 2011). Alankus et al. (2010, p. 2120) found the difficulty must also change automatically responsive to the patients ingame successes or failures (p. 2120). Patient's playing the exergames developed by Alankus et al., (2010, p. 2115) using webcams and Wii Remotes were found to be challenged and become board less easily. Game controllers should encourage use at different stages of recovery (Alankus et al., 2010, p. 2119). An exergame controller, which adapts to the varying degrees of locomotive abilities, would reduce the ephemerality of the system and appeal to a wide demographic of patients.
A review of medical journals featuring reviews of exergames seldom found information about hardware physically adapting to the patient's progress. Contemporary clinical interventions for lower limb stroke rehabilitation include ways for the therapist to change the difficulty of a task. Weight and resistance is modified to physically challenge the patient (Signal, 2014, p.13), however only the media is able to be adapted to the patient's progress (Alankus et al., 2010; Flores et al., 2008; Levin et al., 2015; Gil-Gomez et al., 2011). This suggests adaptability as a hardware design feature is yet to be explored. Interviews with stroke clinicians 1 and clinician 3 confirmed that further research is needed into how exergame hardware can facilitate adaptability (personal communication, October 10, 2015).

Criteria:

- The design should adapt to the patient's progress

- The design should adapt to different stages of recovery

\section{Exergames in the Home}

Designing exergames for use in the home requires different criteria than in a clinical setting. Adapting exergames for a domestic environment calls for design solutions that can be afforded by a wide demographic, easy enough to set up and trouble shoot, and portable enough to be accommodated in small living environments.

Interactive clinical rehabilitation systems such as Robot Assisted Haptic Controllers use expensive purpose-built software and hardware (Goodman et al., 2014), and can require significant space and assistance from third parties (Martin et al., 2014). With the largest demographic of stroke patients being over 65 years of age, this technology 
is not realistic in a domestic environment. Applicable price points have been achieved by exergames that re-purpose commercial video game technology. Microsoft Kinect (Nahid Norouzi-Gheidari \& Levin, 2014), Wii Balance Boards (Gil-Gómez et al., 2011) and Wii Remotes (Alankus et al., 2007, 2119) are examples of successful and affordable exergame controllers (Fritz et al., 2013). Both these systems are mass-produced for a universal market. Adapting these for niche exergame demographics results in affordable hardware with widespread availability (Gil-Gómez et al., 2011, p.2). However, the ubiquity of these controllers also becomes a limitation. These off the shelf systems are unable to accommodate the specific functional, ergonomic and aesthetic requirements needed to facilitate STT in the home.

Exergame controllers must accurately track the movement of the user for interacting with the game. Inaccurate tracking of patient's movements can lead to false feedback, frustrating the patient and/or promoting incorrect movements. Microsoft Kinect was found to have several accuracy issues when used to track the lower limbs and in inconsistent lighting conditions. Xu Xu (2015) found that accuracy levels when tracking a patient's gait were inconsistent. Hore (2014) also found that lighting conditions also inhibited the ability of Kinect to perform accurately. In comparison, wearable sensor networks made up of two or more accelerometer, gyroscope and magnetometer-based sensors have been shown to provide accurate motion tracking of three dimensional movement (Mortazavi et al., 2014; Whitehead et al., 2011). When considering the inconsistencies of light levels within the home, a more accurate means of interaction should be considered like wearable sensor-based hardware that does not require consistent light levels.

Exergaming systems that are intuitive and uncomplicated in how they are set up and used allow a more seamless integration into the home. Gerling et al., (2010) calls for the need for exergame systems to minimise the number of steps required for interaction to reduce the cognitive load on the user. Microsoft Kinect integrates seamlessly with a laptop or xbox (Hore, 2014, p. 32); Nintendo Wii's Balance Board and hand controllers; Playstation's Eyetoy and Move interact with small consoles that are easily setup and implemented in a domestic environment (Fritz et al., 2013, p. 222). These systems are however, all dependent on computers and consoles which restrict play to the area they are set up in. In contrast to this, mobile gaming is becoming affordable and accessible (Görgü et al., 2012). Mobile devices such as smartphones or tablets could be a point of departure away from the static platforms of the commercial consolebased exergames. Mortazavi et al., (2014) has shown that by combining relatively low cost wireless sensor networks with a tablet display, ubiquitous exergame systems can be created that facilitate the same successes of console-based systems. This novel

\section{This content is unavailable. Please consult the print version for access.}

figure 1.2 - Jintronix in Use

\section{This content is unavailable. Please consult the print version for access.}

figure 1.3 - Wii Balance Board in Use 
combination of technology allows the user virtually unlimited freedom of portability, promoting mobile use as the patient's mobility increases. In relation to lower limb stroke rehabilitation, this ubiquity could help broaden the demographic of users from patients who are restricted to their beds, to patients competent at engaging in complex locomotor tasks. Ease of setup in mobile exergames does need to be explored with Mortazavi et al. (2014) finding users had trouble integrating the wearable sensors with their clothing. With the potential limited dexterity of stroke patients, setting up the device must not be a barrier to performing home based rehabilitation.

Using exergames in the home creates an independent rehabilitative environment where the stroke patient interacts without the supervision and assistance of clinicians. Older adults' lack of familiarity with contemporary gaming systems can create barriers to interaction (Fritz et al., 2013). The touch free operation of the Microsoft Kinect is effective in engaging patients where movement restrictions prevent the use of more conventional hand held controllers (Hore, 2014 , p. 31). However, for many older adults, gestural control is found to be a foreign style of interaction, creating an uncomfortable feeling towards the exergame (Hore, 2014, p. 33). Similarly, unsupervised rehabilitation presents the opportunity for the user to perform undesirable movements to interact with an exergame. If this is not addressed there is potential for inadvertently reinforcing incorrect movements that can potentially be to the detriment of the patient's rehabilitation (Levin et al., 2015, p. 416).

\section{Criteria:}

- The design should be of a similar price to commercial gaming systems

- The design should be reliably accurate

- The design should be easy to setup and use, reducing the number of steps required for interaction

- The design should be able to be played anywhere in the home

- The design's interactions with the media should make sense to the patient 


\section{Ergonomics and Usability When Designing for Stroke Patients}

Forms of cognitive, visual and motor effects follow a stroke. In the context of exergames, Shirzad et al. (2015, p. 5), indicate that ease of use as well as ergonomics are some of the most important factors that contribute to the user's sense of control, and thus their ability to enjoy the exergame safely. This forms an interesting design challenge as there are a variety of barriers to usability that require addressing

Cognitive effects of stroke involve the loss of memory and or speech. Patients may experience unilateral neglect defined as an impairment or loss to one side of their visual field, as well as motor effects. Motor effects include paralysis or weakness to the impaired side of the patient's body (Alankus et al., 2010, p. 2114). This affects balance and causes spasticity or contractures in the upper and lower extremities. Balance is a major concern when considering the need to keep the user safe when interacting with exergames. In the development of SilverBalance, an exergame aimed at improving older adults' balance, Gerlin et al. (2010) called for interactions that can take place while either seated or standing. This can eliminate the risk of falling as users with significant impairment to their balance can still play the exergame safely.

Spasticity is the involuntary contraction or shortening of muscles. In the lower limbs this manifests itself in stiff knees, pointy feet and curled toes (American Stroke Association, 2013). Consideration of spasticity has resulted in design solutions such as providing more surface area to things that need to be gripped or held. Reducing complex motor tasks such as tying shoelaces or buttoning a shirt have been avoided by implementing alternatives such as velcro ("Unisex Stroke Shoes", 2015) or magnets ("Magnetic Closing Shirts", 2015). To further address the likelihood of a stroke patient having restricted movement in upper and lower limbs down the affected side of their body, assistive devices should be able to be used with only the unaffected limb. Alankus et al. (2010, p. 2119) even goes as far to state that in considering the exergame interactions, we should assume the stroke patient has no use of their hands.

Although stroke can happen at any age it is important when considering usability and ergonomics that stroke becomes more prevalent in those aged 65 and over (Mozaffarian et al., 2015). The World Health Organisation provides a loose definition of "older adults" in industrialised nations as anyone being older than 60-65, aligned with the average age of retirement (WHO, 2016). Older adults occupy a majority of the demographic most susceptible to stroke. Gerling et al., (2010) has called for the consideration of age-related needs of older adults in the design of exergaming systems to ensure a safe and enjoyable gaming experience.

Kroemer outlines a specific set of design goals for accommodating older adults (2006, p. 160). Designs must be "easy to use, reach and see" and avoid forcing the patient to "bend and stretch". When considering anything worn on the lower limbs, a certain amount of bending and stretching may be unavoidable. Design considerations could be made to minimise the range of motion needed to interact with the design. Kroemer (2006, p. 160) addresses the idea that usability and maintenance should also be "simple" and "conceal any complexity". 
When wearing any device close to the skin, movement will create perspiration. Materials should be considered to minimise the need to wash and clean the device. Hardware automation could also reduce the amount of controls the user needs to interact with, minimising barriers to usability. Lastly, "human dignity safety and comfort" are outlined by Kroemer as important guidelines that should inform the design process (2006).

\section{Criteria:}

- The design should be able to be interacted with using one hand

- The device should be used seated or standing

The design should...

- Be easy to use, reach and see

- Require minimal bending/ stretching from the user

- Be simple to maintain

- Have easy to use controls

- Conceal any complexity

- Consider human dignity, safety and comfort

- Use materials that consider the movement of the stroke patient

\section{Designing for the Domestic Environment}

Traditionally, design of medical, assistive and rehabilitative products have compensated for disability. Design concealed or made these devices as discrete as possible like prosthetics mimicking the form and colour of the lost limb. Pullin (2009, p. 4) argues that this helped create a stigma towards medical devices as it suggested "impairment was something to hide'. Stipe $(2009$, p.1) and Blythe et al., (2005, p. 678) argue that the pragmatism of biomedical engineering has resulted in a lack of aesthetic consideration, caught up in what the technology can do, not what it needs to do by also reflecting the user's values, needs, and self-image (Stipe, 2009 , p.1). The failure to create aesthetics that are relatable to the user in domestic and public spaces has further stigmatised these devices. This can stifle a design's intention to assist as the user may resist its use due to the simple fact that they find the product unattractive (Blythe et al., 2005, p. 677).

With exergames providing the user with increased opportunity to participate in their rehabilitation from home, the hardware developed for these systems also needs to easily synthesize and integrate into a domestic environment. Designs that transition from the clinic or hospital to the home or public spaces, tend to perpetuate the stigma. If aesthetics are not adapted for discretion and style, clinical and medical semantics can allude to the user being impaired or sick (Stipe, 2009, p. 1). "We do not want our homes to look like a clinic or a hospital" (Blythe et al., 2005, p. 678) is often expressed from those who require the assistance of medical devices in their home. By expressing an aesthetic reflective of the domestic environment, Stipe argues medical products will achieve greater market acceptance (2015, p. 1) and help break down the stigmas that create barriers to their use.

Pullin expands further on this solution by claiming that the aesthetics of these products should transcend style and discretion to celebration of their use $(2009$, p. 31). He quotes the famous athlete, actress and model Aimee Mullins whose wardrobe exists of designer clothing and prosthetic legs reflective of the most coveted designers. Mullins scoffs at the thought of wanting a prosthesis that is "discrete" and desires "glamorous" prosthetics with a range of choices to suite her array of outfits (Pullin, 
2009, p. 31). Looking to cultures traditionally separated from medical design for aesthetic inspiration could help reduce or erase the stigma.

Glasses were stigmatised as a visual crutch until the mid-twentieth century. Design of prescription eyewear and its synthesis with the culture of fashion erased the stigma of wearing glasses. They have since become widely received as a fashion accessory, and adopted by some people who don't require prescription lenses (Pullin, 2009, p. 4). Similarly, Blythe et al., (2005, p. 678) proposed medical alarms look to jewelry design as a means of encouraging older adults to wear the devices every day, thus helping them call for help if they find themself in urgent need of assistance. Akin to this example, Lauren's Hope (Medical ID Bracelets, 2016) is a service that offers medical ID bracelets to people who need important medical information to be quickly
This content is unavailable. Please consult the print version for access.

figure 1.4 - Aimee Mullin's carved wood leg designed by Alexander Mcqueen accessed in the event of an emergency. Lauren's Hope has styled these IDs into contemporary jewelry such as gold watches, silver necklaces and silicon wristbands. By reflecting the semantics and functions of something that is worn every day their use is encouraged and in the unlikely case of an emergency, can be used to diagnose the appropriate aid.

Nike also recently took up a project in collaboration with a teenager with cerebral palsy (Nike, 2015). Matthew Walzer, a high school student found Nike's range of basketball shoes to provide the best ankle support for his legs, which were affected by the disorder. A conventional lacing system proved too difficult to navigate with one hand's dexterity impaired. The solution was a zip above the shoes heel counter that opened the back of the shoe up with a simple onehanded movement. This one-handed ease of entry solution was successfully designed not to detract from the shoes aesthetic. This granted Matthew independence through being able to put on his own shoes, and pride in wearing a design that is not only fashionable, but coveted by sneaker enthusiasts. This case study provides a good

This content is unavailable. Please consult the print version for access.

figure 1.5 - Matthew Walzer's custom Nike FLYEASE shoes 
example of the importance of not just the function and ergonomics of the design, but how aesthetic forms a positive experience for the user. The designs ability to integrate indiscriminately into basketball shoe culture, avoids any stigma of it being an assistive device.

Consideration of the exergame controller's aesthetic through investigation of form, colour and materiality should be just as important as the function and usability. Using these case studies as precedence the design should take aesthetic influence from cultures that the end user identifies with or relates to. Objects within the user's everyday life should serve as influence to the game controllers semantics, to manifest aesthetics that represent the user's values, needs and self-image.

\section{Criteria:}

- The design's aesthetics should contribute to its usability

- The design's aesthetics should address the stigma towards using medical devices in the home:

- The design's aesthetic should reflect objects within the user's everyday life

- The design should reflect the domestic setting it will be used in 


\section{Summary of Background Criteria}

Functional requirements can help inform how the exergame can facilitate the key rehabilitative aspects of STT. Contextual requirements relate to the needs of the user and the ability to facilitate the use of the exergame unsupervised in the patient's home. The contextual requirements are divided into ergonomics, usability and aesthetic criteria. Criteria can be used to inform the design of an aestheticallyconsidered wearable game controller as part of a home-based exergaming system for lower limb stroke rehabilitation that facilitates strength for task training. Under clinician guidance and feedback from stroke patients, the criteria can be adapted and iterated throughout the design process.

\section{Functional Requirements}

- The design should allow strength for task training movements to act as inputs for playing an exergame

- The design should enable the user to perform priming exercises through applying load to the affected limb

- The design should provide an option of applying and increasing the weight of the lower limb during priming to make the exercises intensive

- The design should provide an option of applying and changing resistance bands to the lower limb during priming to make the exercises intensive

- The design should allow the user to perform priming and task exercises without being constrained by the game controller

- The design should enable the user to perform part and whole tasks

- The design should adapt to the patient's progress

- The design should adapt to different stages of recovery

- The design should be reliably accurate

- The design should be of a similar price to commercial gaming systems

- The design should be easy to setup and use, reducing the number of steps required for interaction

- The design should be able to be played anywhere in the home

- The design's interactions with media should make sense to the patient

- The design should be able to identify compensatory movements and encourage maintaining the correct form 


\section{Contextual Requirements}

\section{Ergonomics/Usability:}

- The design should be able to be interacted with using one hand

- The device should be used seated or standing

- The design should be easy to use, reach and see

The design should:

- be easy to use, reach and see

- require minimal bending/stretching from the user

- be simple to maintain

- have easy to use controls

- conceal any complexity

- consider human dignity, safety and comfort

- use materials that consider the movement of the stroke patient.

\section{Aesthetics:}

- The design's aesthetics should contribute to its usability

- The design's aesthetics should address the stigma towards using medical devices in the home.

- The design's aesthetic should reflect objects within the user's everyday life

- The design's aesthetic should reflect the domestic setting it will be used in 

The purpose of this thesis was to explore how the design of a game controller, as part of an exergaming system can help facilitate unsupervised STT. This research addressed

what functions the controller needed to emulate strength for task training away from the supervision of the clinic (functional requirements), ergonomic and usability concerns of designing for stroke patients as well as how to address the stigma of using medical devices in the home (contextual requirements). This formed the foundations on which a prototype exergame controller was designed to facilitate STT therapy in the home, through interactions with an aesthetically considered game controller.

\section{Biomedical engineering informed by clinical} research has created robust rehabilitative products that utilize emerging technologies. However, patients are not engaging with these products long term. Shirzad et al., (2015) believe this barrier to engagement has formed because the process of developing these technologies is "goal driven" by what contemporary technology "can" do, rather than what it "needs" to do. In contrast to this, when creating a clinical rehabilitation programme, the patient and clinician work together holistically. The clinician considers the patient's subjective needs such as their ideologies and beliefs, as well as their physical and cultural environment (clinician 1, personal communication, August 10, 2015).

A user-centered design (UCD) approach is reflective of the patients' involvement with their therapy and has been rigorously used in the development of previous exergame systems (Alankus et al., 2010, p. 2115; Billis et al., 2011, p. 1; Shirzad et al., 2015, p.362). A USD approach was subsequently used to involve the clinicians and stroke patients in the design process.
Shirzad et al. (2015, p.363) propose that the UCD approach for rehabilitative exergames should consist of three stages:

1. Understanding the contextual and functional needs;

2. Generating feasible concepts and prototypes; and

3. Development of solutions and clinical assessment.

Criteria were used to prioritise important design factors in the development of previous rehabilitative exergames with short timeframes (Flores et al., 2008; Martin et al., 2014; Moreira et al., 2010). It became essential to guiding the development and review of design concepts and prototypes to ensure the functional needs of STT and the contextual needs of the patient were met.

Background research was informed through a combination of literature and design reviews (Booth et al., 2008; Martin \& Hanington, 2012, p. 112). This developed initial design criteria and situated the project within the body of knowledge. Research began with using a combination of workshops and interviews with clinicians to acquire specialised information on lower limb stroke rehabilitation (Kuniavsky et al., 2012, p. 135). The interviews and workshops involved a neurophysiologist specialising in stroke rehabilitation (clinician 1), a physiotherapist (clinician 2), an associate professor from a school of clinical science (clinician 3), and a senior lecturer from a graduate school of nursing, midwifery and health (clinician 4). Non-directed interviews (Kuniavsky, 2003, p. 119) within the scope of lower limb stroke rehabilitation provided insight into effective contemporary clinical and home based rehabilitation practices and how they optimise patient outcomes. 
Professional insight helped expand and substantiate design criteria that was used to generate feasible concepts and prototypes (Shirzad et al., 2015, p. 363) as part of the second phase of the UCD process. Initial concepts were produced and assessed using a decision matrix model (Milton \& Rodgers, 2013, p. 146). This model involved using several potential designs assessed next to prioritised criteria. The best initial concept was used as a "datum" and other concepts were compared in a matrix against it using plus (+), minus (-) or equals (=) to the set datum. This ordered each concept by their effectiveness of fulfilling set criteria. This information was then used to re-iterate and re-compare concepts until a final design concept was formed for subsequent prototyping. UCD is an iterative and reflective process (Shirzad et al., 2015, p. 363). Prototyping was conducted following this protocol to generate feasible designs. Prototypes were reviewed by clinicians then iterated to keep them inline with the overall goal of this thesis. Subsequent prototypes were submitted to user testing with stroke patients.

This research project was conducted under approval from the Health and Disabilities Ethics Committee (see Appendix Document A, p. 149).

Recruitment for user testing began with the presentation of the project to local stroke clubs. Potential participants were then interviewed over the phone. Participants who met our inclusion/exclusion criteria were recruited for user testing (for user testing protocol see page 80 ). User testing was then carried out with stroke patients and involved participants interacting with the exergame system in their homes. Users were encouraged to use the "Think Aloud" protocol technique outlined by Martin \& Hanington (2012, p. 194) which helped fill usability heuristics (Rubin \& Chisnell, 2011, p. 19). Usability heuristics were adapted from previously developed usability criteria. Observation of participants identified any barriers to usability.
Short non-directed interviews (Kuniavsky, 2003, p. 119) with participants followed to help to gain feedback on the participants' experiences using the device. Participants were asked to fill out "Geneva Emotion Wheels" (Scherer, 2005) as an adjunct to the interview. These helped users self-report on their emotional experience, identifying and elaborating on emotions the designs' aesthetic elicited.

Feedback helped assess how the design is/ isn't meeting the contextual and functional needs of the participants. Further feedback from clinicians was also received through observation of video footage from the final user test. This helped provide professional insight into the designs' ability to address the functional requirements of STT. An iterative cycle of three tests helped expose usability deficiencies and shape the design (Rubin \& Chisnell, 2011, p. 19) aligning it with the designated requirements. Clinical assessment of the design is the third stage of the UCD process proposed by Shirzad et al. (2015, p. 363). However, clinical assessment was not possible within the scope of this research.

\section{Research Question}

How might the design of an exergame game controller facilitate unsupervised STT for lower limb stroke rehabilitation?

\section{Hypothesis}

An aesthetically-considered game controller designed as part of an intuitive exergaming system can help facilitate unsupervised strength for task training in a domestic environment. 


\section{Research Overview}

\section{Aim 1: Explore what areas of unsupervised STT can be facilitated through an exergame controller.}

\section{Objectives:}

1) Conduct literature and design reviews to establish initial criteria and situate the project within the body of knowledge.

Method: Literature and design reviews (Booth, Colomb \& Williams, 2008; Martin \& Hanington, 2012, p. 112).

2) Build on and substantiate initial criteria through the acquisition of a professional perspective to investigate how effective contemporary clinical and home-based rehabilitation practices obtain the best possible outcomes for the patient.

Method: Conduct workshops with stroke clinicians to provide specialist insight (Kuniavsky, Goodman, \& Moed. 2012, p. 135) into the treatment of stroke in the context of lower limb rehabilitation.

Method: Non-directed interviews (Kuniavsky, 2003, p. 119) within the scope of lower limb stroke rehabilitation to provide insight into effective contemporary clinical and home-based rehabilitation practices and how they optimise patient outcomes.

\section{Aim 2: Define what user requirements an exergame controller for STT should incorporate.}

\section{Objectives:}

1) Use established design criteria to generate and assess design concepts

Method: Generate and assess concepts against established criteria using a decision matrix model (Milton \& Rodgers, 2013, p. 146).

2) Use an iterative and reflective usercentered design process to generate and assess prototypes

Method: Produce and review prototypes using non-directed interviews (Kuniavsky, 2003, p. 119) with clinicians to maintain designs stay inline with the goal of the thesis.

Method: Conduct user testing with patients using the "Think Aloud" protocol (Martin \& Hanington, 2012, p. 194) to fill usability heuristics (Rubin \& Chisnell, 2011, p. 19).

Method: Assess if the design meets the users' contextual requirements using Geneva Emotion Wheels (Scherer, 2005) as part of non-directed interviews (Kuniavsky, 2003, p. 119).

Method: Review footage and non-directed interviews (Kuniavsky, 2003, p. 119) with clinicians to gain professional insight into the design ability to meet the functional requirements of STT. 



\section{DESIGN RESEARCH}

\section{"THERE ARE TOO MANY PATIENTS AND NOT ENOUGH CLINICIANS" - CLINICIAN 1}

\section{A Clinician's Perspective}

Initial workshops with clinicians were conducted at the Auckland University of Technology in their occupational therapy research facility. Presentations from three clinicians covering different areas of stroke rehabilitation were conducted. Clinician 1 and clinician 3 unpacked motor control and rehabilitation: clinician 1 focused on lower limb; and clinician 3 focused on upper limb. Clinician 2 discussed engagement, as well as the ideals a practitioner needs to facilitate in rehabilitation. These presentations were then followed by open-ended questions and discussion. We were then able to sit in on a clinical physiotherapy session. This presented the opportunity to observe the clinician/patient relationship in the context of supervised rehabilitation enabling us to experience the types of therapy our exergaming system would be facilitating. This workshop helped further establish the exergaming system in the rehabilitative context.

\section{The Reality of Clinical}

\section{Rehabilitation}

Clinical stroke rehabilitation is made up of an average of 27 minutes of training, 9 minutes of conversation and 23 minutes of resting, recovering and being inactive (clinician 1, personal communication, August 10, 2015). The clinical reality is that the dose of supervised rehabilitation is extremely low compared to the volume the literature recommends. Some literature suggests that thousands of repetitions are required to re-learn a task (Shirzad et al, 2015, p. 363) however our workshopping countered this by stating that 400 repetitions is enough to see clinical results (clinician 1, personal communication, August 10, 2015). Most patients are however practicing as little as 30 repetitions for each exercise per session (Shirzad et al, 2015, p. 363). Intensity is also hard to maintain during these sessions as much of the therapy is spent in low intensity exercises or part task training. The therapists are dealing with so many clients and variables within each therapy session that it becomes hard to increase the opportunity to practice.

With stroke becoming more and more prevalent among industrialised nations the number of clinicians is being far outnumbered by the amount of patients requiring therapy. Rehabilitative technologies have the ability to democratise availability to therapies, although it is stressed that technology should not remove the clinician from the therapeutic process, rather help maximise consultation time. Home-based technology must exist holistically with the patient and clinician to maximise beneficial outcomes for the patient. 


\section{Assessment}

A patient regaining mobility following a stroke depends on early and intensive lower limb rehabilitation. The overall objective of lower limb rehabilitation is to get patients to move their affected limb as easily as their unaffected limb (Alankus et al., 2010, p. 2113). This is achieved by having enough stimulation so the patient is able to use the neural capacity they have available. This creates new neural pathways within the brain, re-routs damaged pathways or using existing pathways that have not been fully exploited yet by the brain (clinician 1, personal communication, August 10, 2015). There is not necessarily any relationship between how early you start rehabilitation after stroke and improvement. Neural plasticity is still able to take place months and sometimes years afterwards.

Assessment is the first step in structuring the appropriate rehabilitation and assigning the right rehabilitative technologies to the patient. A broad context of the patients and where they move throughout their home and community must first be established. For example someone living in a suburban environment would be walking on the pavement, stepping up and down curbs and navigating traffic in supermarket car parks. In contrast to this, a patient living in a rural environment might be navigating uneven surfaces such as grass and gravel. Both these examples may require different therapeutic prescriptions. Following an assessment of context, the patient's walking is observed to assess their functional ability. Lesion location is also factored into this consideration and can be an accurate indicator of what problems the patient is likely to have.

Clinicians would then hypothesize the specific limitations the patient will face in terms of body structure and function. There is no binary way to accurately assess a patient to diagnose the most beneficial therapy. Clinician 1 stressed that in relation to our exergaming system, there will be no universal solution to assessment and intervention.
Focusing on a specific set of rehabilitative qualities will allow the system to be more usable. Attempting to facilitate qualities of clinical assessment is beyond the scope of this research. Instead, the focus of this project will lie in facilitating a specific intervention, unsupervised strength for task training in the home.

\section{Intervention}

Rehabilitation intervention cannot simply be prescribed off the shelf, it must be tailored to the individual. Contemporary home-based rehabilitation follows a set of criteria to ensure it offers the best outcomes for the patient. It is beyond the scope of this project to attempt to facilitate the nuances that come with the human connection provided by clinical rehabilitation. However, designing to the guidelines of how intervention is currently prescribed will help align the exergaming system with the needs of the clinician and patient.

\section{Intervention must be:}

Specific: Foremost the rehabilitation must be specific to the individual and their problems. This involves considering the patient's context alongside their physiological/cognitive impairments and comorbidities. Our exergaming system facilitates STT. The task-based portions of the STT exercises are specific to the environments the patient will have to navigate. An example of this is the fifth STT exercise (see p. 11) which uses a stepping board to replicate the action of going up and down stairs (Signal, 2015, p. 48).

Salient/Transfer: The rehabilitation must be personal and meaningful to the patient. Creating therapies that involve the user making task-based movements that transfer to movements they make in their everyday life help the rehabilitation become more tangible (Flores et al., 2008). The strength and task training components of STT directly transfer to the user's everyday life through promoting and refining locomotion. There 
is room to speculate that the hardware's aesthetic could also be salient. The form of the game controller could be considered in a way that reflects and promotes the goal of STT to improve locomotion and help the user regain mobility.

Repetitious: High repetitions of movement (volume of dose) provide better rehabilitative outcomes for the patient (Shirzad et al., 2015; Alankus et al., 2010). An exergame prescribed for clinical intervention must encourage repetition to make it clinically useful (Shirzad et al. 2015 p. 364). In a clinical setting 15 intensive repetitions is effective for the strength portion. In the task portion of STT the number of repetitions is decided by how many intensive movements the patient can perform in the given timeframe. Under further discussion with clinician 1, it was made clear that the exergame would not have to be as strict as the clinical programme (clinician 1, personal communication, March 16, 2016). With this in mind, the quantity of task movements were also set at 15 repetitions. Both strength and task exercises were then set at 15 repetitions. These sets of repetitions were later translated into input movements for the exergame.

Intensive: The intensity of the exercises completed during rehabilitation has been suggested to be the most important factor for patient improvement (clinician 1, personal communication, August 10, 2015). Intensity is defined by complexity of the task/rate of work. During supervised clinical rehabilitation the therapist is able to encourage intensity. However, when rehabilitating unsupervised, the intensity exerted has been observed as adequate enough to benefit the patient (clinician 1, personal communication, April 6, 2016). Strength for task training uses progress across nine parameters for progression to maintain intensity (see p. 11). The exergame system should maintain intensity by changing the nine parameters. Both the media and hardware have the opportunity to facilitate these parameters. The hardware will focus on facilitating intensity through the ability to perform part and whole tasks, and by changing the load applied to the affected limb during the priming component.

\section{Criteria:}

- The device's form should promote and reflect the patient's mobility

- 15 repetitions of movements specific to either the priming or task exercises of STT should be used as input for the exergame

- The design should provide an option of applying and increasing the weight of the lower limb during priming to make the exercises intensive

- The design should provide an option of applying and changing resistance bands to the lower limb during priming to make the exercises intensive

\section{Personas}

Designing for large population groups can dilute a design by not delivering specific and personal outputs. By creating design personas from aggregated information derived from real life stroke patients, profiles of fictitious users were created (Martin \& Hanington, 2012, p. 132). These archetypes helped inform the design process before user testing with real patients.

Design personas were developed (see Appendix B, p. 170) through information obtained from observation of stroke patients partaking in clinical rehabilitation. Clinical observation, with narration from stroke clinicians provided insight into the subtleties of guided rehabilitation (Zeisel, 1993, p. 113). 
A non-directed interview (Kuniavsky, 2003, p.

119 ) with a nurse (nurse 1) (see Appendix A, p.

168), a nurse who specializes in the assisted

care and rehabilitation of stroke patients, was

used to gain information about different

stroke patients' day to day experiences.

Data obtained from the both clinical

observation and interview was used to

generate three design personas. The goal of these personas were to represent patients recovering from stroke across a spectrum of physical and cognitive abilities, comorbidities, ideologies, and living environments. These personas (see Appendix A, p. 169) helped inform design decisions and assumptions about the functional and contextual needs of the end users. 


\section{term}

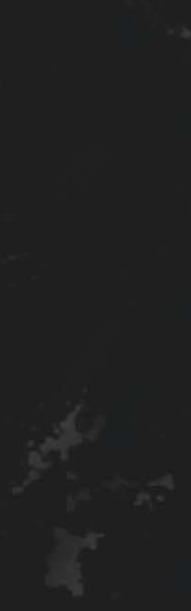

$$
\begin{aligned}
& \sin x
\end{aligned}
$$

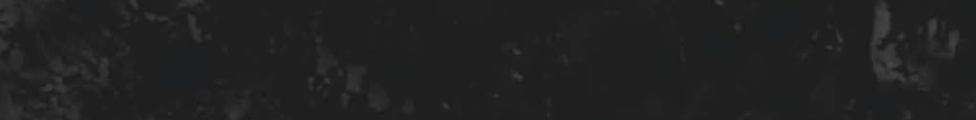

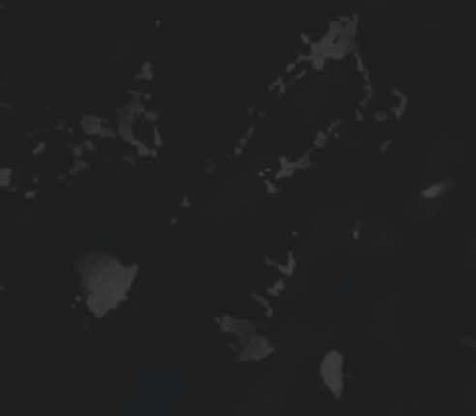

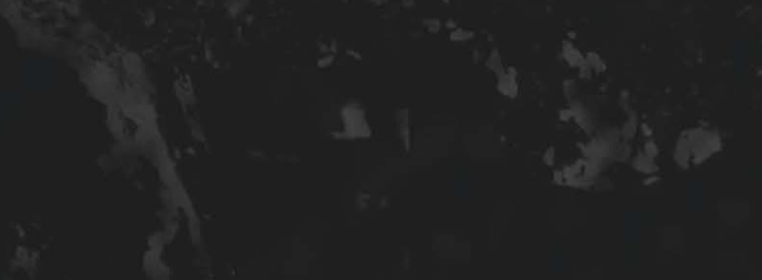

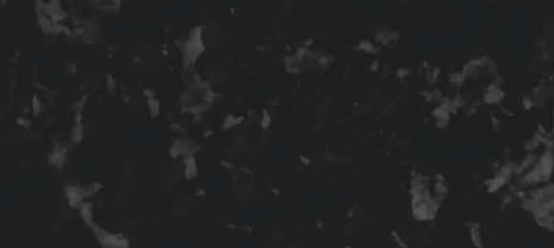$$
\text { ? } \quad k
$$

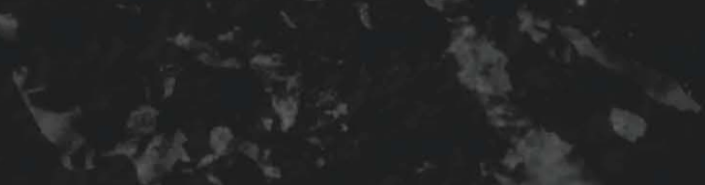$$
\text { the }
$$

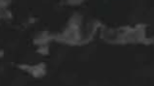

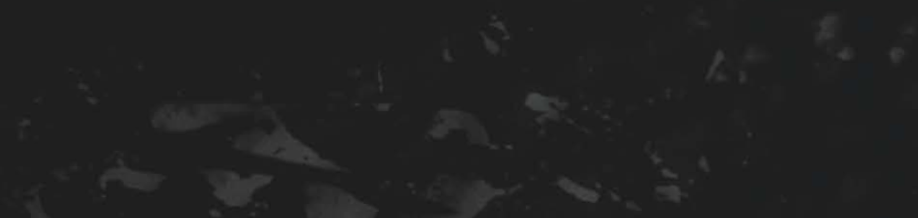

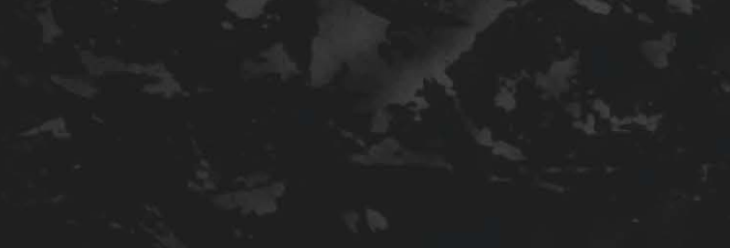

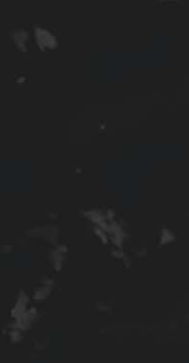

$+7$

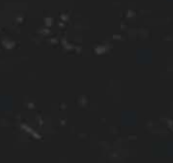

y
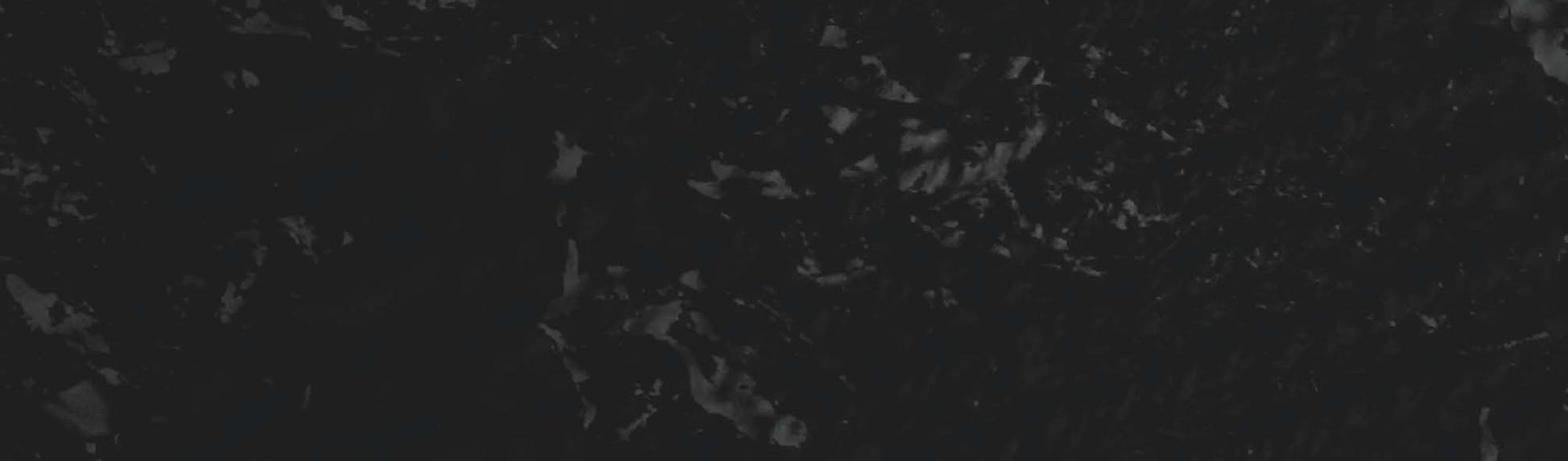

$-x^{2} x^{2}+8$ $s=-d x$ 


\section{FINAL DESIGN CRITERIA}

Using information generated and substantiated through background research and interviews with clinicians, a broad set of design criteria was created. This criteria represented the outcome of the first aim of this research to explore what areas of unsupervised STT can be facilitated by an exergame controller. The criteria provided insight into how, by addressing functional requirements, certain contextual requirements must also be met. The hardware must attempt to facilitate the key features of STT. However, because the exergame system will be used unsupervised, in the home, and by stroke patients of different ability levels, there remains a significant amount of contextual requirements the design must attempt to address. Functional and contextual requirements were broken down into subheadings of Function, Ergonomics \& Usability and Aesthetics.

\section{Function}

Facilitate Strength for Task Training: The game controller should create media inputs based on the user completing STT exercises. The technology implemented in the controller must be able to quantify the dynamic motions of STT in 3D space and translate them into ingame interactions. This must take into account the hardware's ability to facilitate intensive priming by applying load to the lower limb using adaptable weights and/ or resistance bands. The design must then allow the user to promptly remove the load and transition to the task training component. The design should facilitate and promote the increasing complexity of task training movements the part/whole task progression demands. The hardware should also not restrict the user's lower limb movement in any way.
The design should allow strength for task training movements to act as inputs for playing an exergame

- Priming movements must be directly followed by the counterpart task-based movements

- 15 repetitions of movements specific to either the priming or task exercises of STT should be used as inputs for the exergame

The design should enable the user to perform priming exercises through quickly applying and removing load to/from the affected limb

- The design should provide an option of applying and increasing the weight of the lower limb during priming to make the exercises intensive

- The design should provide an option of applying and changing resistance bands to the lower limb during priming to maintain intensity

The design should enable the user to perform part and whole tasks

The design should allow the user to perform priming and task exercises without being constrained by the game controller

Adaptable: The exergaming hardware must adapt to encourage use by patients at all ability levels and at different stages of recovery. Load applied to the lower limb must also be tailored to the user's ability levels and adapted as they progress in their rehabilitation. 
The design should adapt to different stages of recovery

The design should adapt to the patient's progress

Affordable: A big appeal of home- based rehabilitation is that there is a significant difference in cost to clinical rehabilitation. With an increasing amount of stroke survivors there are not enough clinicians to cater to the growing population of patients' needs. This can help justify the one off cost of buying a home-based rehabilitation system compared with the ongoing cost of additional guided clinical therapy. Off the shelf consoles that accommodate exergame systems can range anywhere from $\$ 400$ to $\$ 1000$ NZD. Mass production of consoles keeps the cost down. Hardware that is singularly produced for lower limb rehabilitation should attempt to fall within a similar price bracket.

The design should be of a similar price to commercial gaming systems

Accurate: The technology used for the design must be able to accurately and reliably track the affected limb. Inaccuracies and inconsistencies can risk frustrating the patient or habituate incorrect movements.

\section{The design should be reliably accurate}

User Friendly: With the majority of stroke patients being older adults the hardware must be as intuitive as possible. There is reason to suggest that older adults are able and willing to adopt console gaming (Gerling et al., 2010, p. 66), however, the number of steps required to set up and use the exergame system should be minimal. Interaction required with the game controller should be reflective of the user's intuition.

The design should be easy to setup and use, reducing the number of steps required for interaction

Portable: Exergames that are popular in home-based rehabilitation are able to be set up and used in a domestic environment.
Once setup, console systems are hard to move and restrict the area of play. In contrast, a wireless controller that interacts with another wireless screen such as an iPad has a significant advantage as it can be used anywhere in the home. This also makes the system increasingly more adaptable to the patient's changing needs, promoting mobile use as the patient's mobility increases.

The design should be able to be played anywhere in the home

\section{Ergonomics/Usability}

\section{Consider the Cognitive, Visual and Motor} Effects Following Stroke and Keep the User Safe: Impairments to the patient's balance, vision as well as spasticity in the affected limbs should not be a barrier to using the device. Complex motor tasks should be avoided and interactions should be able to be made using one hand or hands free to consider spasticity in the upper and lower limbs. Falling is the greatest risk to a stroke patient during rehabilitation as their balance can become severely impaired following stroke. Patients may also lose awareness of their mid-line further contributing to fall risk. Interaction from seated or standing positions should be considered to address this.

The design should be able to be interacted with using one hand

The device should be used seated or standing

\section{Consider the Comfort and Movement of} Older Adults: With a device that could be worn most days, maintenance of the hardware may be unavoidable. Being worn close to the skin the device should be washable. Material considerations should be made for this and to reduce the amount of bacteria and moisture that can build up. When charging the device this process must not require fine motor skills or good eyesight as this can lapse in older adults and specifically stroke patients. With the demographic for the design being significantly older adults, Kroemer's (2006, p. 160) design guidelines should be followed. 
The design should ...

- Be easy to use, reach and see

- Require minimal bending/ stretching from the user

- Be simple to maintain Have easy to use controls

- Conceal any complexity

- Consider human dignity, safety and comfort

- Use materials that consider the movement of the stroke patient

\section{Aesthetics}

Aesthetics Should Inform Interaction: How the user should interact and uses the device should be informed through clear visual cues.

The design's aesthetics should contribute to its usability

\section{Address The Stigmas Associated with} Medical Products: Patients do not want their homes looking like hospitals. Hardware that blends itself into a domestic environment will help reduce this stigma. Rehabilitative and medical products can also be seen by the users or the general public as a crutch or indicative of disability. The hardware should elicit pride and avoid embarrassment in its use. By considering the hardware's aesthetics the user could be able to wear the device without stigma.

The design's aesthetics should address the stigma towards using medical devices in the home

- The design's aesthetic should reflect objects within the user's everyday life

- The design's aesthetic should reflect the domestic setting it will
- The design should elicit pride and avoid embarrassment

Rehabilitation must be personal and meaningful to the patient. The hardware's form should attempt to be salient to the user by reflecting STT's goal to promote locomotion.

- The device's form should promote and reflect the patient's mobility

These criterion helped inform the generation of concepts and prototypes. This allowed the rapid generation of concepts and prototypes prior to accessing feedback from stroke patients. Further iteration of the criteria was informed by the subsequent design experiments and further reviews from clinicians. This ensured the criteria was specific to design concepts and prototypes, while still accurately representing the initial macro functional and contextual requirements. 



\section{DESIGN RESEARCH}

\section{Selected Technology}

A variety of contemporary technologies were considered for implementation in our exergame system. Console based technologies have been adapted by previous exergame systems due to their ease of use and affordability. However, Microsoft Kinect faces accuracy problems when light levels are inconsistent and all console use is restricted to where they are set up. A combination of wireless inertial measurement units (imu) and an iPad would facilitate mobile use anywhere in the home and mitigate accuracy issues of motion capture controllers such as the Kinect. Console systems are harder to tailor to the specific functional requirements of strength for task training. The compact size of imu sensors and the ubiquity of an iPad could provide a better solution for addressing these requirements.

\section{Relevant Criteria:}

A. The design should allow strength for task training movements to act as inputs for playing an exergame

B. The design should allow the user to perform priming and task exercises uninhibited by the game controller

C. The design should be reliably accurate

D. The design should be of a similar price to commercial gaming systems

E. The design should be easy to setup and use, reducing the number of steps required for interaction

F. The design should be able to be played anywhere in the home

G. The design should have easy to use controls

Figure 5.1 - Technology Selection Matrix

$\begin{array}{cccc}\text { Microsoft } & \text { Wii Balance } & \text { Wii } & \text { IMU \& } \\ \text { Kinect } & \text { Board } & \text { Remote } & \text { iPad }\end{array}$

\begin{tabular}{|c|c|c|c|c|}
\hline$A$ & $\checkmark$ & $X$ & $\checkmark$ & $\checkmark$ \\
\hline$B$ & $\checkmark$ & $X$ & $X$ & $\checkmark$ \\
\hline C & $X$ & $\checkmark$ & $\checkmark$ & $\checkmark$ \\
\hline$D$ & $\checkmark$ & $\checkmark$ & $\checkmark$ & $X$ \\
\hline$E$ & $\checkmark$ & $\checkmark$ & $\checkmark$ & $\checkmark$ \\
\hline$F$ & $X$ & $X$ & $X$ & $\checkmark$ \\
\hline$G$ & $\checkmark$ & $\checkmark$ & $\checkmark$ & $\checkmark$ \\
\hline
\end{tabular}


An inertial measurement unit (imu) is a low cost and energy conservative sensor that can be used to track movements noninvasively. Imu sensors use a combination of accelerometers, gyroscopes and magnetometers to provide live feedback on their respective acceleration, angular positioning and orientation in $3 d$ space (Ding et al., 2013, p. 269). I Measure U (IMU) have combined imu sensors with low energy bluetooth technology to wirelessly stream sensor data to a mobile device in real time (IMeasureU, 2016). Custom firmware for IMU allows data to be streamed accurately and with very low latency to a low energy bluetooth device such as a smartphone or tablet.

The IMU's hardware is enclosed within a small plastic housing measuring $39 \times 29 \times 15 \mathrm{~mm}$. Low energy bluetooth means the sensor can be used for several hours at a time before it needs to be charged via USB. The compact and wireless design of the IMU means it can be integrated into wearables to track movements performed during STT exercises. The mobile device we chose to interpret the IMU data through, and host the gaming media, was an iPad. IMUs are not reliant on cameras to track movement, therefore the lighting concerns relating to the Microsoft Kinect's inaccuracies (Xu Xu, 2015; Hore, 2014) could be avoided. iPads are also portable and unlike console-based exergaming systems (Hore, 2014; Fritz et al., 2013) iPads can facilitate use in most environments. Seamless communication between the iPad and IMU sensors can also help address usability concerns (Mortazavi et al., 2014) with setting up the exergame, requiring only instruction on how to turn on/ off and charge the sensors.

If the length of the lower limb is known, placing sensors above the ankle and midfoot, would allows the knee and ankle to be tracked in $3 d$ space. Sensor data could then be translated into motion data by the iPad when the user performs STT exercises. This would subsequently create inputs for the exergame.

\section{Defining the Intervention}

The exergame media designed by fellow masters student Scott Brebner consisted of a digital domino game that patients could play against a computer player, friends and family or other stroke patients (figure 5.2). The framework of how STT exercises translate into gameplay was outlined by both Brebner and myself to ensure cohesion between the hardware and media. The gameplay was structured around the patient performing priming movements followed by task-based movements to interact with the game.

Opposite page: Figure 5.3 - Brebner's exergaming media with subsequent priming movements

Below: Figure 5.2 - (12 - 12) Digital dominoes game for STT
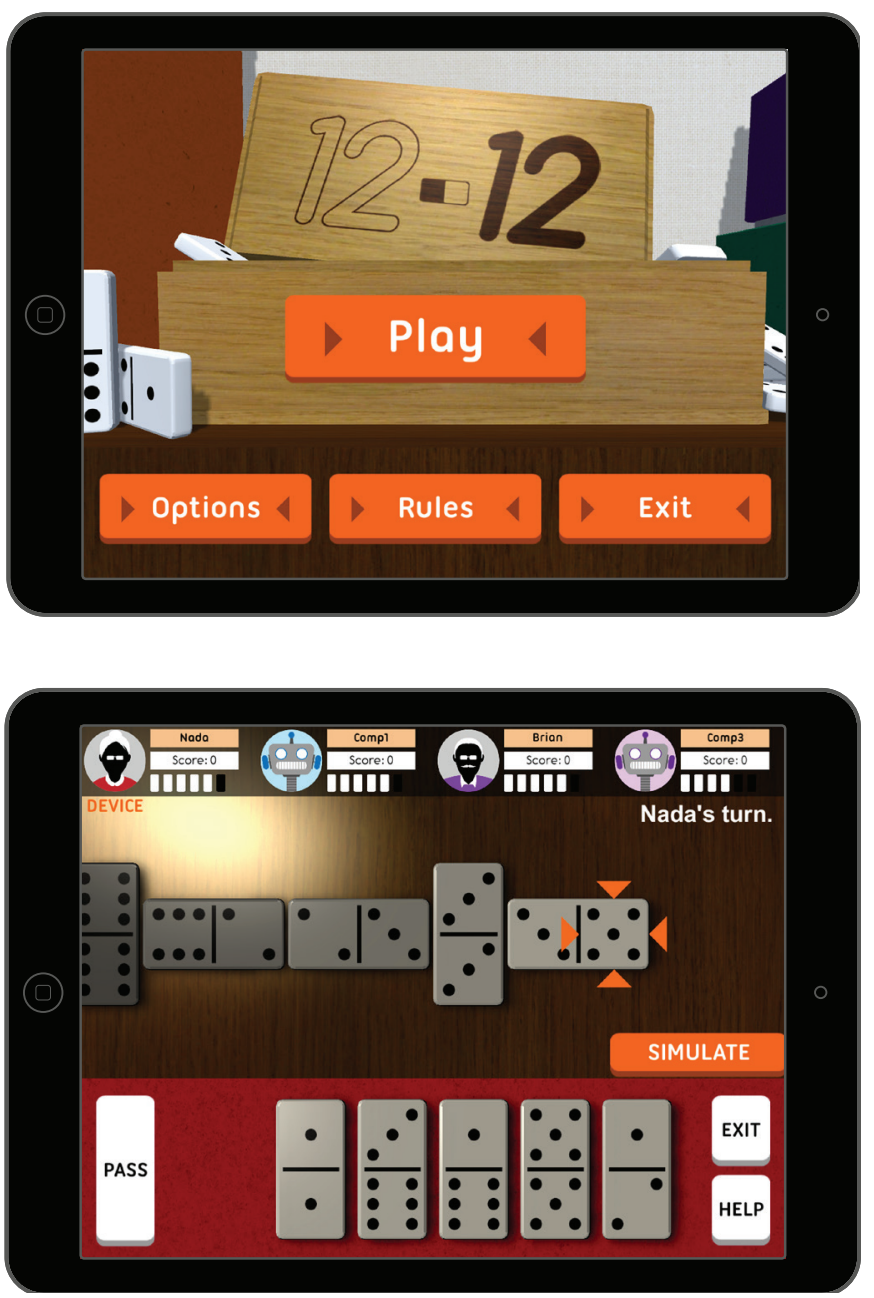
Two STT exercises were chosen based on their feasibility of being emulated in an unsupervised environment as inputs for the game. Quadriceps, plantar flexors and Hip Flexors were exercises that we discounted due to their requirements of a leg press machine and Rotary Hip Machine that feature high load thresholds. Ankle dorsiflexors and hip flexors feature tasktraining components that demand navigation of a range of obstacles. This narrowed the selection down to two STT exercises 3 (Hip Abduction \& Sideways walking) and 6 (Hamstrings \& Backwards walking).

The priming component was introduced to gameplay through shuffling a virtual box of dominoes before the players' hands were dealt. This required the patient (the primary player) to attach a specific amount of weight to their affected limb and complete the relevant priming component. The onscreen display required the user to complete 15 repetitions of the priming exercise. After the
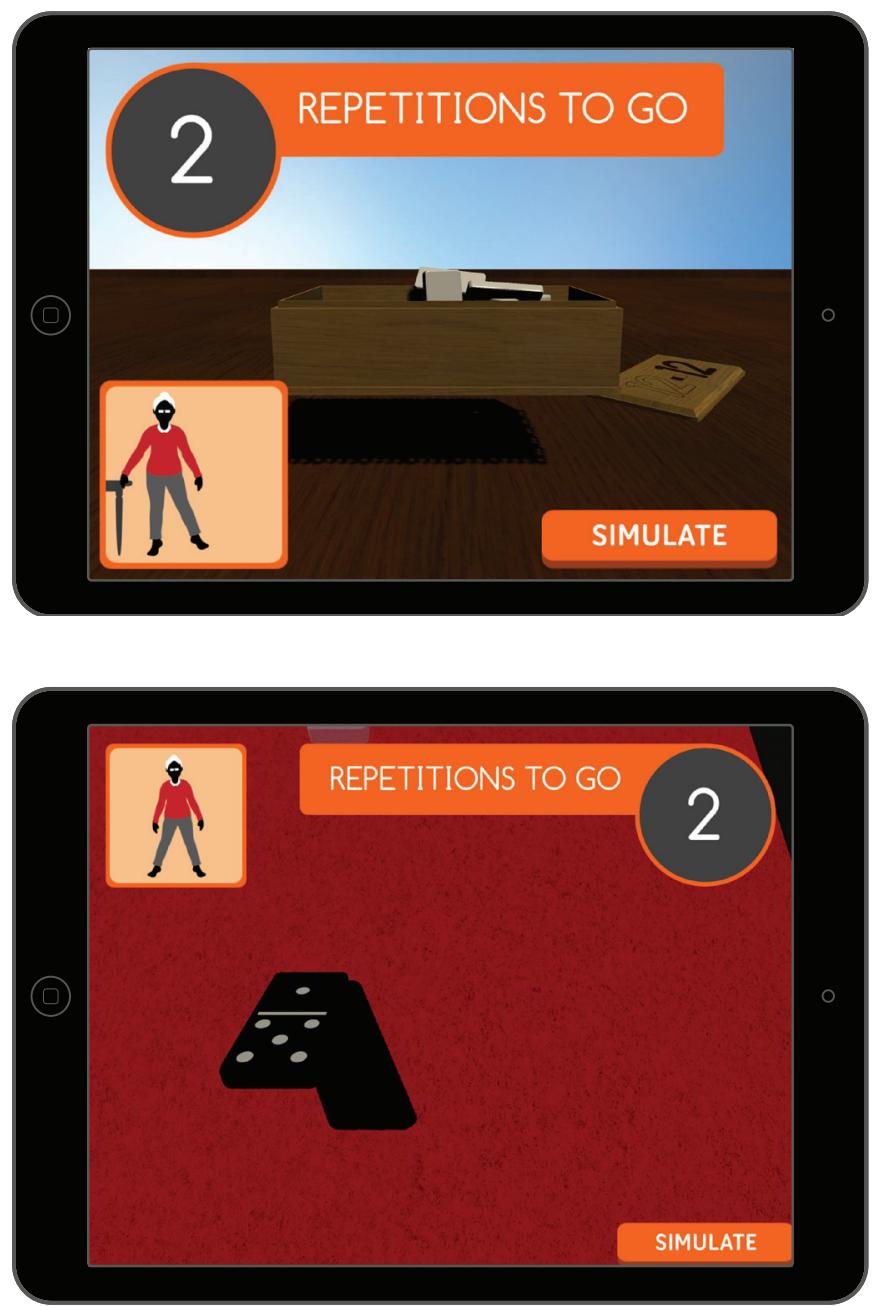

primary player had completed one repetition an animation on screen moved the box tossing the dominoes in the air. After the repetitions were completed the primary player was prompted to remove the load from their feet and was dealt a hand of dominoes. The task component was then introduced when the player decided to play a selected domino. This required the primary player to complete 15 repetitions of the relevant task-training component to push the domino into play. After each repetition an animation was displayed of their selected domino moving from their hand onto the table. The other players would then complete their turns and the task training component would repeat until the primary player ran out of dominoes resulting in victory, or another player ran out first in which case the primary player would have lost that round. The relevant priming and task training components were changed from round to round to simulate how STT exercises are completed in a circuit in a clinical environment.

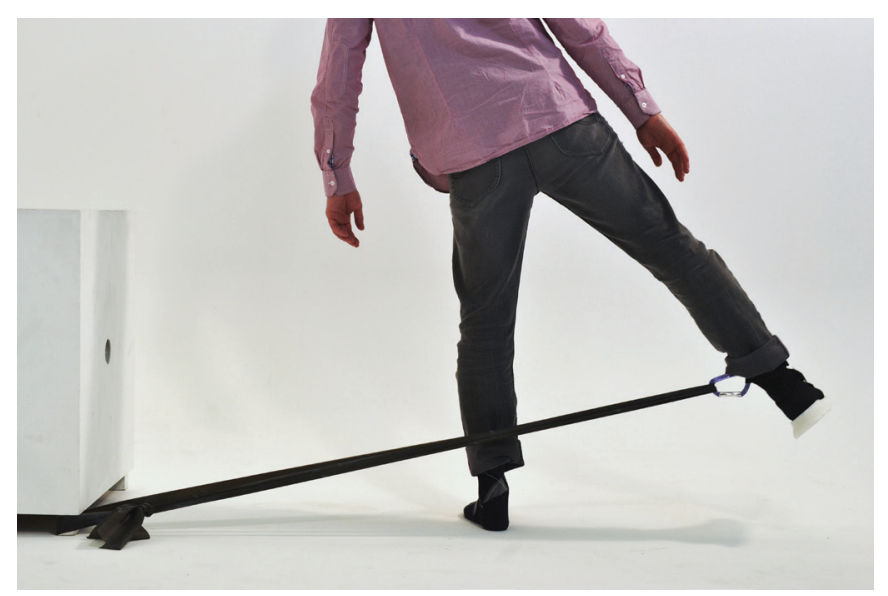


Criteria Addressed:

The design should allow strength for task training movements to act as inputs for playing an exergame

- Priming movements must be directly followed by their counterpart task-based movements

- 15 repetitions of movements specific to either the priming or task exercises of STT should be used as input for the exergame

\section{Initial Design Concepts}

Initial design concepts were generated in response to the design criteria. Each design attempted to address functional, aesthetic and ergonomic requirements outlined in the previous chapter. Initial design concepts were assessed using Pugh's method, forming qualitative information about which design was most successful at meeting set criteria. Pugh's method uses a matrix evaluation to gain qualitative data about the strengths and weaknesses of designs. The personas constructed (see Appendix 8, p. 170) were used to help assess the strengths and weaknesses of the design from the point of view of the patient. Designs were compared against a datum to establish if concepts were greater than $(+)$, equal to $(=)$, or worse $(-)$ at fulfilling the designated criteria.

Opposite page: Figure 5.4 - Initial design 1 \& 2
Concept 1: The first concept (figure 5.4) generated a weighted band that is attached to the user's foot. The user would purchase differently weighted bands recommended for their ability level by therapists. Sensors can then be attached/removed easily using velcro dots. The form of the band reflects the physiology of the user, forming comfortably around the midfoot. This concept provides a low cost solution to generating a lower limb game controller. Being the most basic design solution, this concept was selected to be used as the datum for matrix evaluation of all five concepts.

Concept 2: The second concept (figure 5.4) was a foot wrap with embedded sensors. The design can be rolled out flat and wraps around the ankles and feet, making it easy for people with spasticity in their foot to put the device on. Attachments for the resistance band are added to below the midfoot and above the heel. This allows the user to complete resistance exercises with the forces being equally dispersed around the foot.

Concept 3: The third concept (figure 5.5) was a slipper with modular soles of different weights that could be easily interchanged without the use of the hands. The ambiguity of using the archetype of a slipper aesthetic helps the device blend into the domestic environment. Sensors can be attached using magnets to the upper of the slipper to track movement.

Concept 4: The fourth concept (figure 5.5) was based on the form of a shin guard used in football. Sensors can be attached to the ankle brace and the weighted guard easily clips off to change the weight. The user can wear this under their shoes and pants maintaining the design's low profile.

Concept 5: The final concept (figure 5.6) were compression tights with embedded sensors. The tights can be worn underneath the user's clothes and have high levels of resistance around the knees and ankles to increase the intensity needed during therapy. 


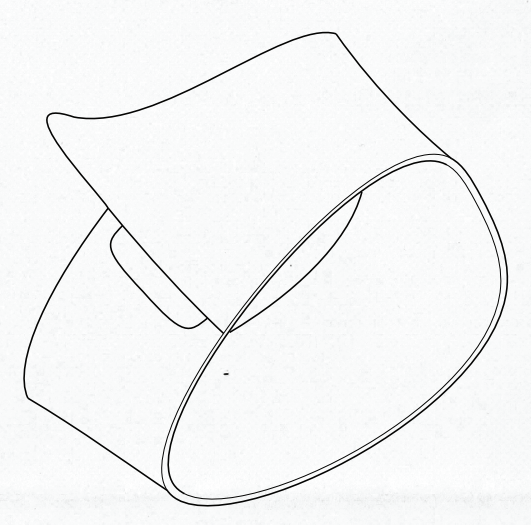

Concept: 1
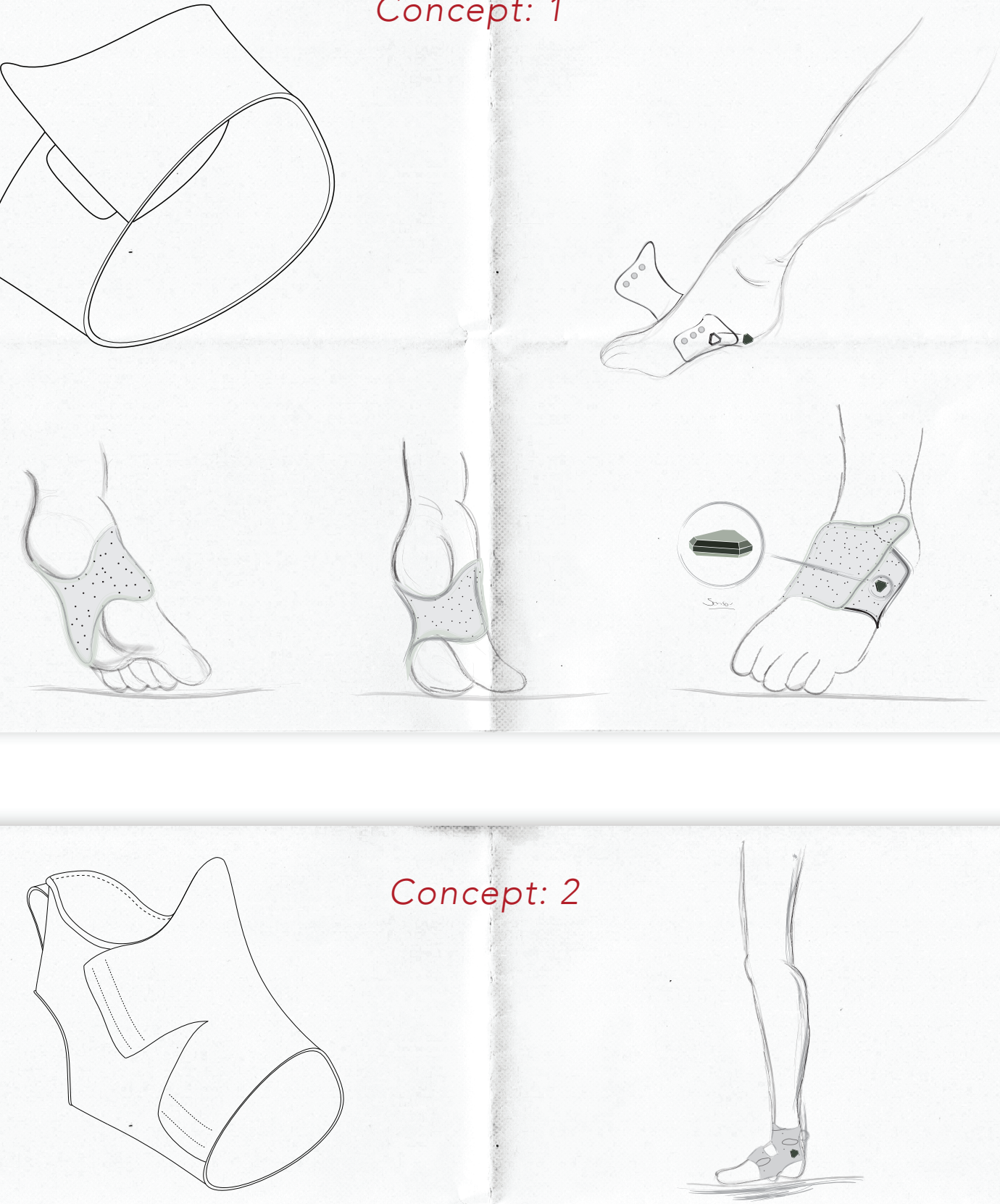

Concept: 2
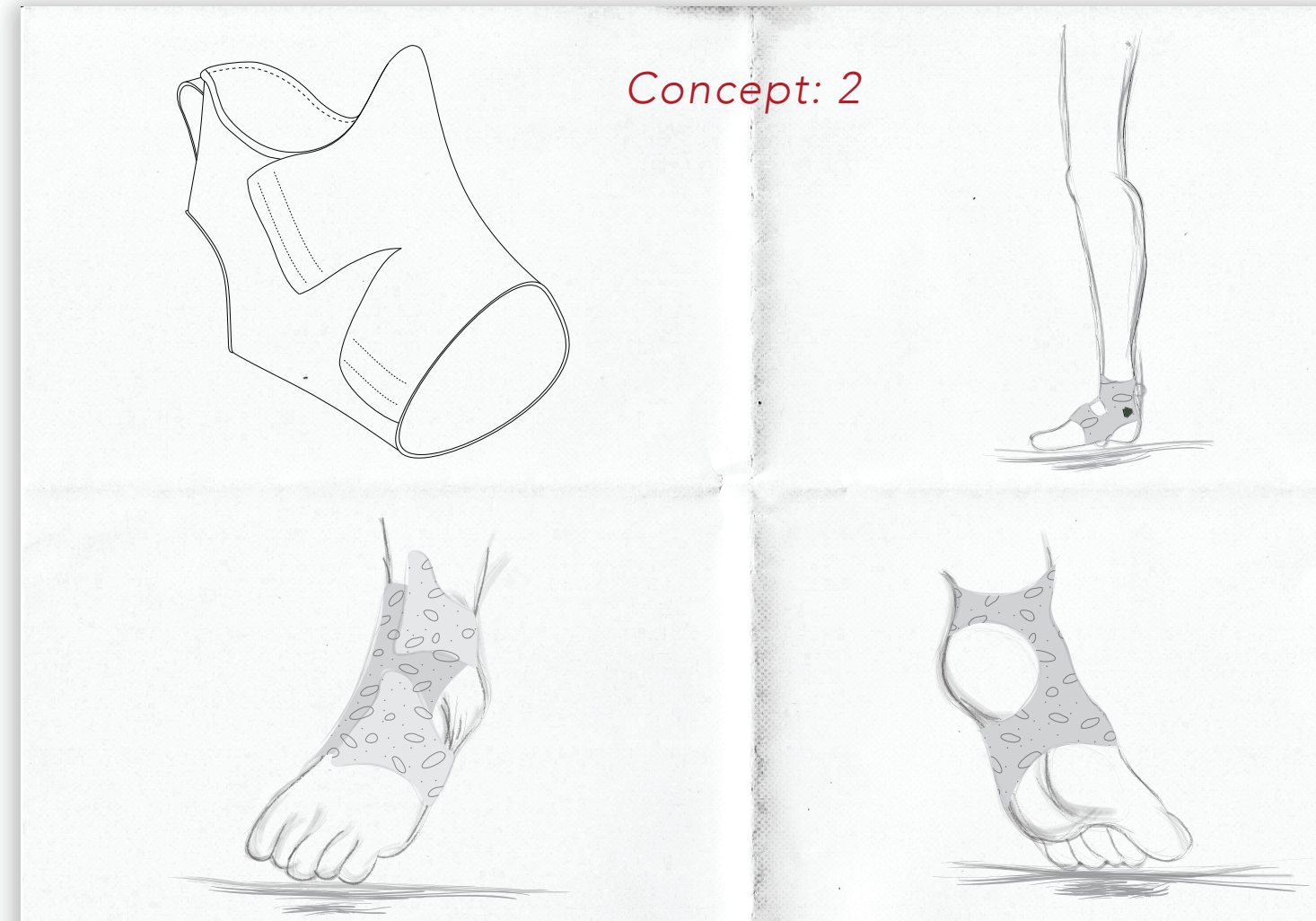


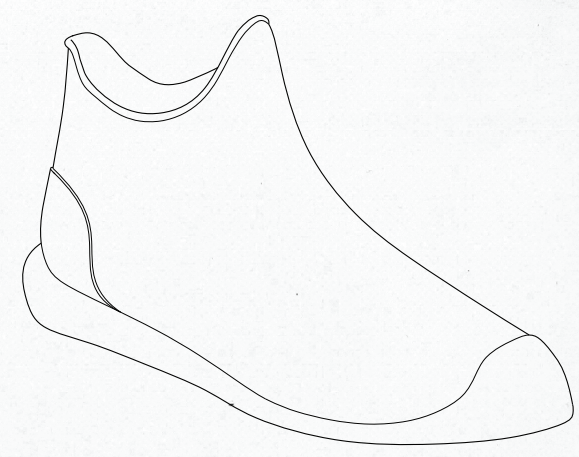

Concept: 3
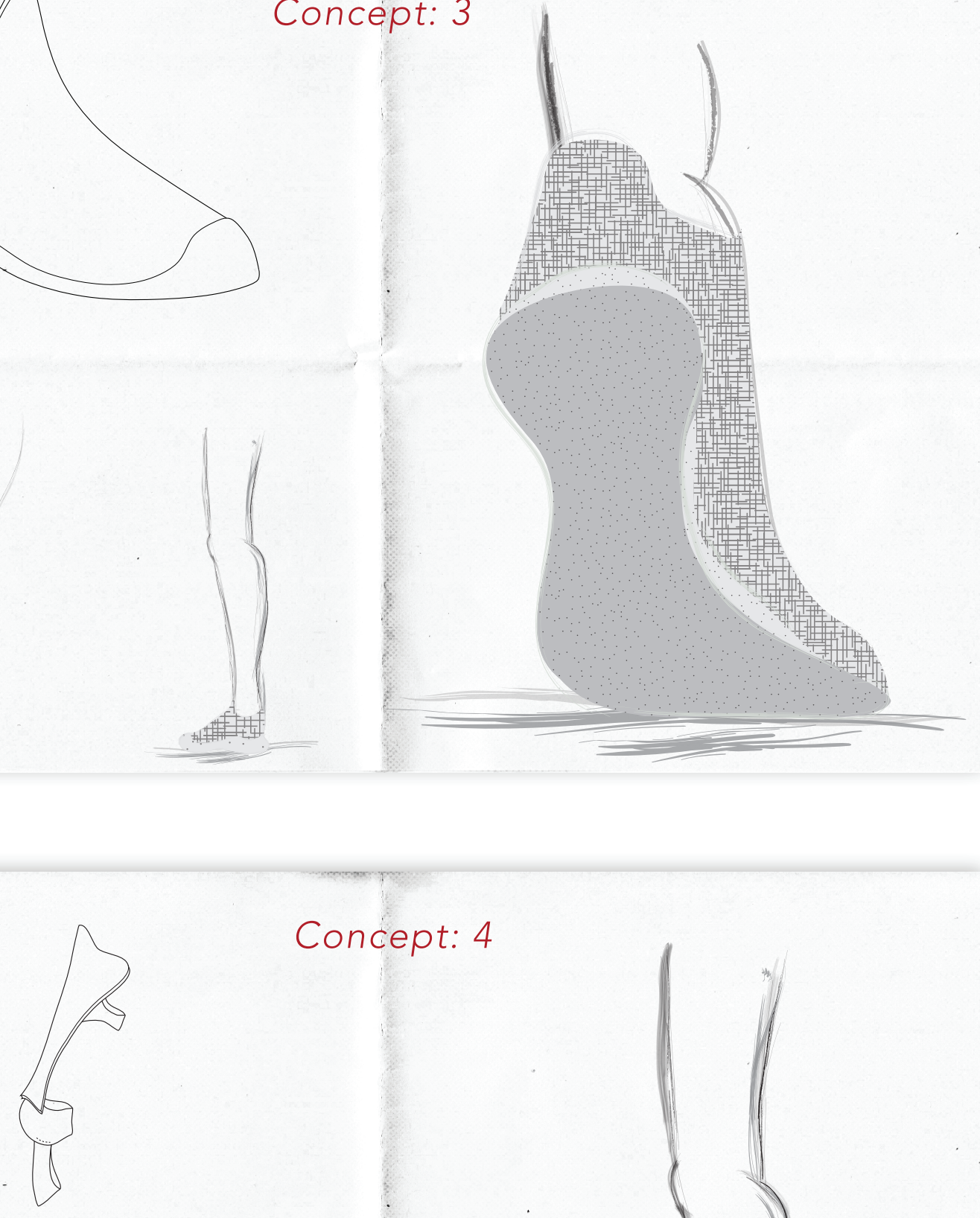

Concept: 4

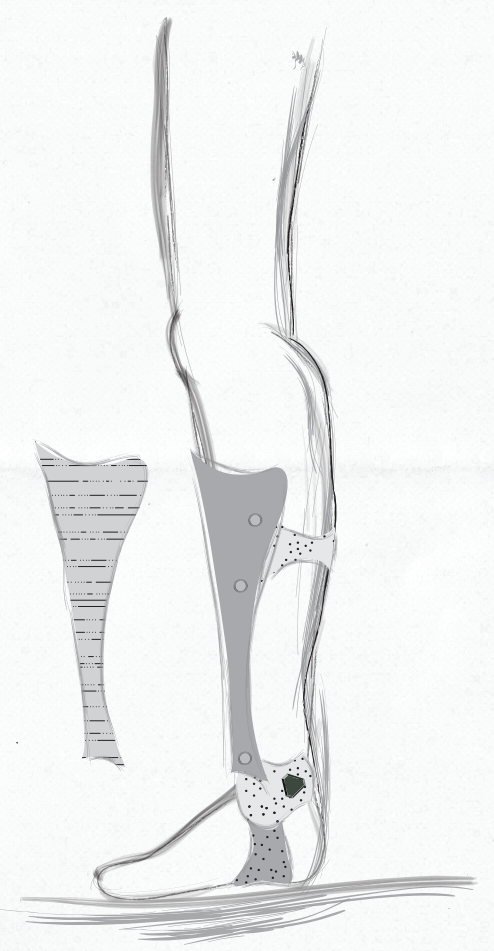




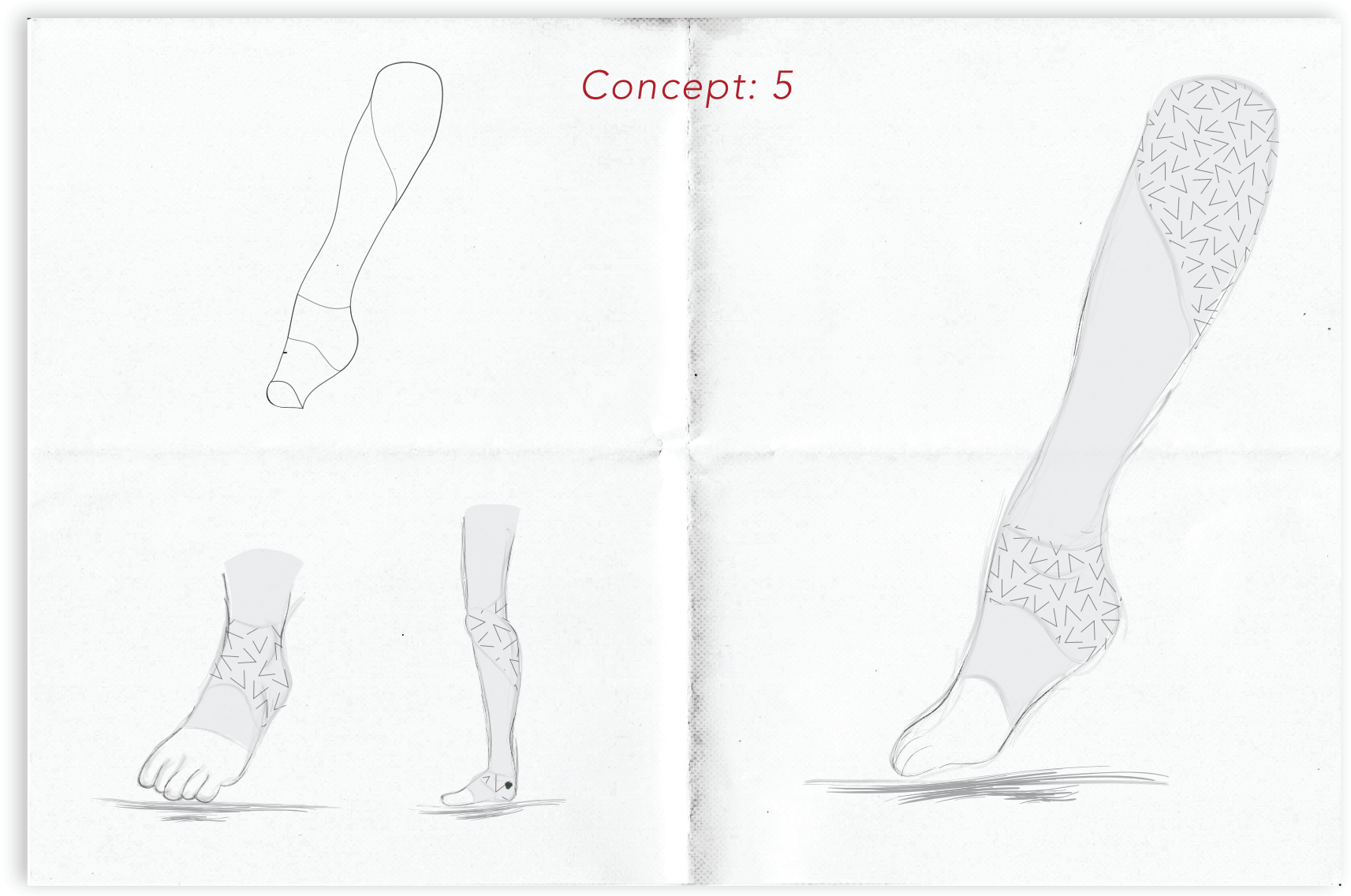

Above: Figure 5.6 - Initial design 5

Opposite Page: Figure 5.5 - Initial Designs 3 \& 4 


\begin{tabular}{|c|c|c|c|c|c|}
\hline \multicolumn{6}{|l|}{ Function } \\
\hline$A$ & D & - & $=$ & $=$ & - \\
\hline$B$ & $A$ & + & $=$ & $=$ & - \\
\hline C & $T$ & $=$ & $=$ & $=$ & $=$ \\
\hline$D$ & $U$ & $=$ & $=$ & $=$ & $=$ \\
\hline$E$ & M & $=$ & $=$ & $=$ & $=$ \\
\hline$F$ & & $=$ & + & $=$ & $=$ \\
\hline G & & $=$ & + & $=$ & - \\
\hline \multicolumn{6}{|c|}{ Ergonomics/Usability } \\
\hline$H$ & & $=$ & $=$ & - & - \\
\hline 1 & & $=$ & $=$ & $=$ & $=$ \\
\hline$J$ & & $=$ & $=$ & $=$ & $=$ \\
\hline$K$ & & $=$ & + & $=$ & $=$ \\
\hline$L$ & & $=$ & $=$ & $=$ & - \\
\hline$M$ & & $=$ & $=$ & $=$ & $=$ \\
\hline$N$ & & $=$ & + & $=$ & - \\
\hline O & & + & + & - & $=$ \\
\hline$P$ & & $=$ & $=$ & $=$ & $=$ \\
\hline \multicolumn{6}{|c|}{ Aesthetics } \\
\hline Q & & $=$ & + & $=$ & + \\
\hline$R$ & & $=$ & + & $=$ & + \\
\hline$S$ & & $=$ & + & $=$ & + \\
\hline$T$ & & $=$ & + & $=$ & + \\
\hline+ & & 2 & 9 & 0 & 4 \\
\hline- & & 1 & 0 & 2 & 7 \\
\hline Totals: & & 1 & 9 & -2 & -3 \\
\hline
\end{tabular}


A. The design should provide an option of applying and increasing the weight of the lower limb during priming to make the exercises intensive

B. The design should provide an option of applying and changing resistance bands to the lower limb during priming to make the exercises intensive

C. The design should allow the user to perform priming and task exercises without being constrained by the game controller

D. The design should enable the user to perform part and whole tasks

E. The design should adapt to the patient's progress

F. The design should adapt to different stages of recovery

G. The design should be easy to setup and use, reducing the number of steps required for interaction

H. The design should be able to be interacted with using one hand

I. The design should be used seated or standing

J. The design should be easy to use, reach and see

K. The design should require minimal bending/stretching from the user

L. The design should be simple to maintain

M. The design should have easy to use controls

N. The design should conceal any complexity

O. The design should consider human dignity, safety and comfort

P. The design should use materials that consider the movement of the stroke patient

Q. The designs aesthetics should contribute to its usability

$R$. The designs aesthetic should reflect objects within the user's everyday life and reflect the domestic setting it will be used in

S. The design should elicit pride and avoid embarrassment

T. The design's form should promote and reflect the patient's mobility
Digital sketches and renders of initial concepts were presented to peers and research supervisors to obtain feedback over a period of two weeks. Peers consisted of three postgraduate students enrolled in the Masters of Design Innovation in Industrial and Media Design; and two PhD students in Design. Research supervisors included the Associate Professor and Programme Director of Industrial Design with experience designing medical devices for stroke rehabilitation and 12 years of industry experience, a Senior Lecturer Graduate School of Nursing, Midwifery and Health and a Senior Lecturer in Media Design. This feedback (see Appendix B, p. 173), alongside the design personas previously created helped inform the first decision matrix (figure 5.7).

Feedback indicated concept three was the most effective at addressing the design criteria followed by concepts two and one. The three most successful designs allowed noninvasive ways for the user to complete priming and task based exercises. They also adapted to the patient's ability and maintained intensity through changing the load on the lower limb. Concepts one and two allowed the load to be changed by providing attachment points for resistance bands and concept three used removable soles to change the load through adding a weighted sole. An important design feature would be for the device to facilitate both resistance band attachments and the addition of a weight. From a usability perspective concepts one, two and three had the potential to be put on one-handed in contrast to concepts four and five which required finer motor control and two hands. Because concepts Three and Five replicated the form and function of a traditional item of clothing, it was speculated that the user would not need any instruction as to how to take them on or off. These key findings were used to iterate the most successful three designs and submit them to a further decision matrix. 


\section{Revised Design Concepts}

Concept 1: The revised first concept was two bands that attach to the foot and ankle providing points to fix removable sensors and resistance bands. Small sleeves around the exterior of the bands can be filled with sand to increase/decrease the weight of the device (figure 5.8). The austerity of this design could provide a comfortable and good looking alternative to neoprene bands.

Concept 2: The iteration of the footwrap (figure 5.9) attempts to semantically replicate the upper of a shoe. It was speculated that this would help create a tangible interaction of how to put on/take off the device.

Resistance bands can be attached at the back of the device and disperse pressure evenly around the ankle and foot. Rigid bodies woven into the fabric and a velcro strap help the device easily fold around the foot and laces can be added and adjusted for the perfect fit. Pockets around the exterior could allow for small steel weights to be added, facilitating load.

Concept 3: Concept three (figure 5.9) builds on the idea of a slipper with a modular sole system. A sleeve around the ankle was added for resistance band attachment and the upper folds across the foot for ease of access. The form reflecting a shoe or slipper could not only reduce the perceived complexity of using the technology, but also allow the device to fit seamlessly in the home environment.

Opposite Page: Figure 5.9 - Revised concepts 2 \& 3

Below: Figure 5.8 - Revised concept 1

Concept: 1
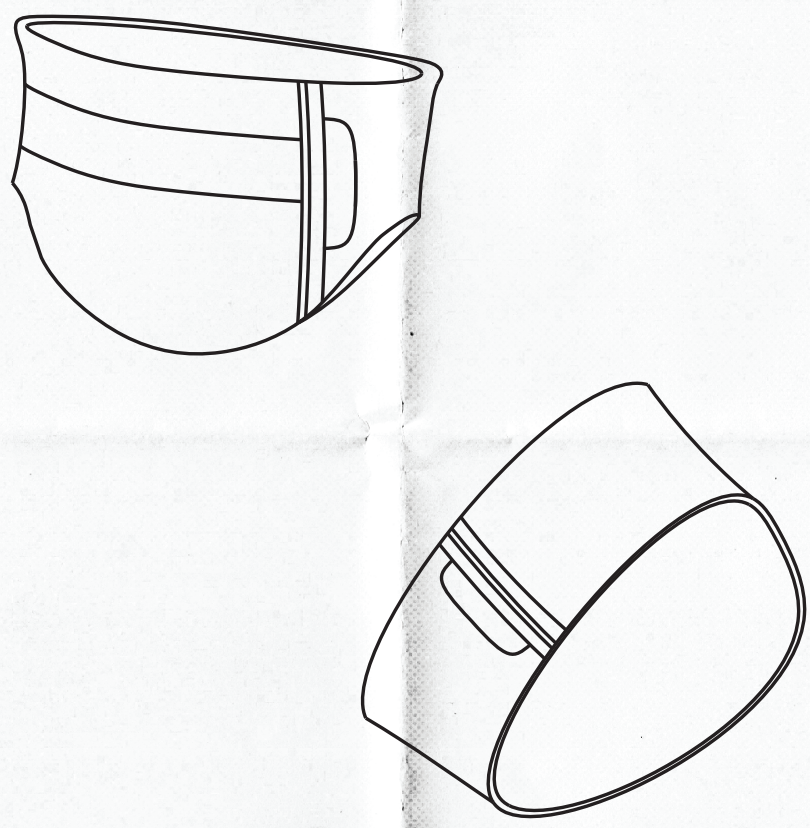
Concept: 2

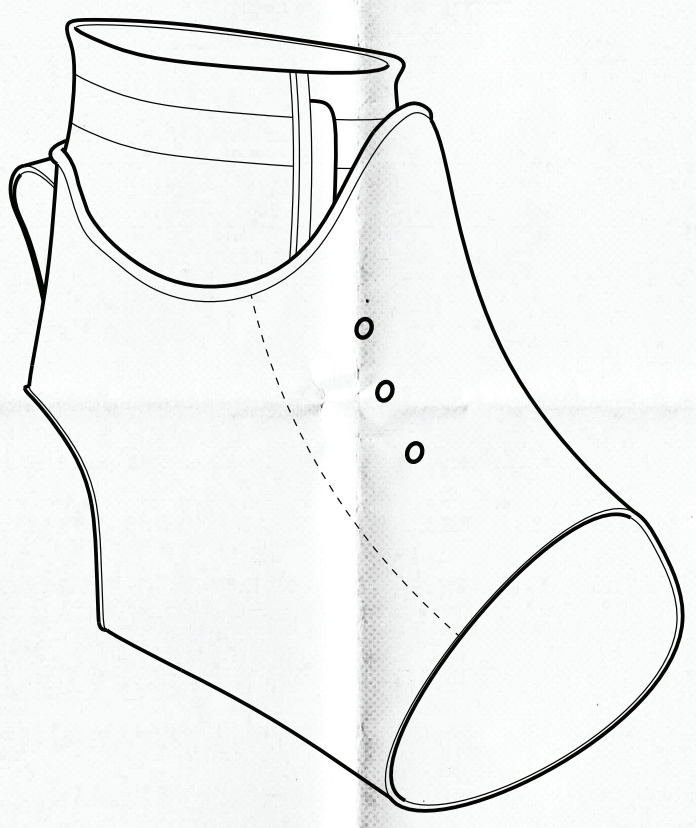

Concept: 3

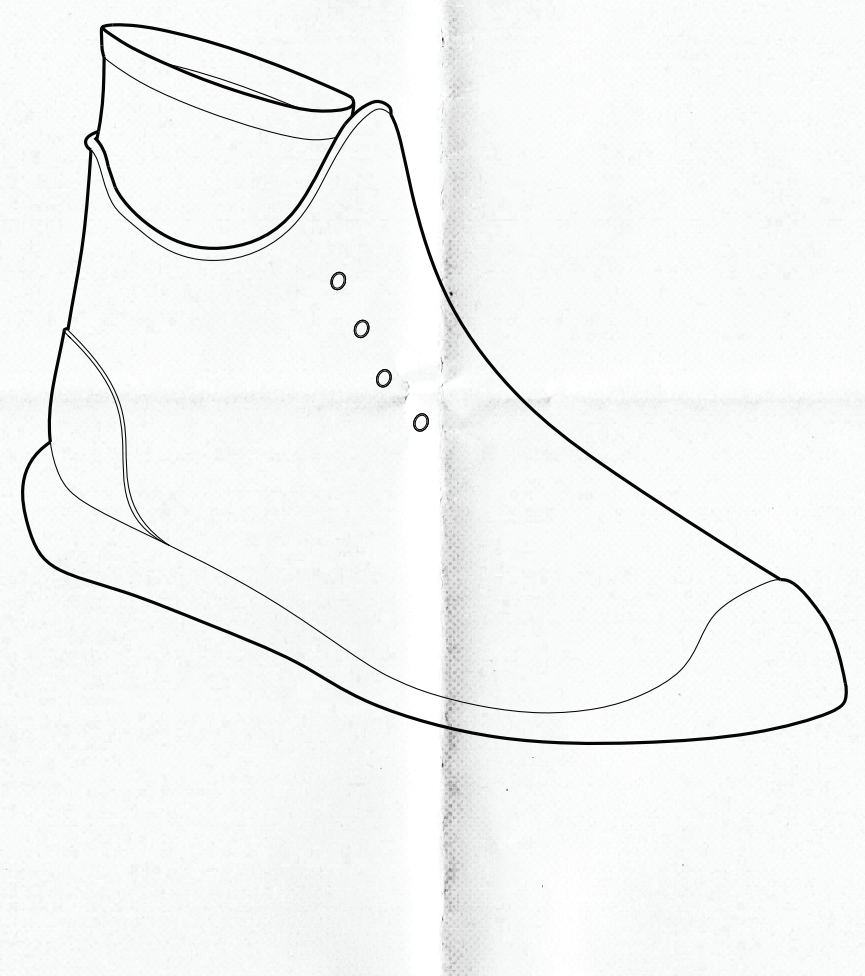


$\nabla$

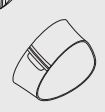

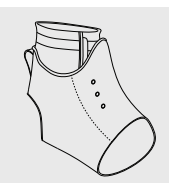

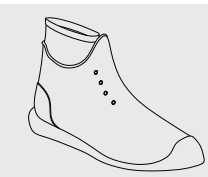

Function

\begin{tabular}{|c|c|c|c|}
\hline$A$ & $=$ & $=$ & $D$ \\
\hline$B$ & $=$ & $=$ & $A$ \\
\hline$C$ & $=$ & $=$ & $T$ \\
\hline$D$ & $=$ & $=$ & $U$ \\
\hline$E$ & $=$ & $=$ & $M$ \\
\hline$F$ & $=$ & $=$ & \\
\hline$G$ & - & - & \\
\hline
\end{tabular}

Ergonomics/Usability

\begin{tabular}{|c|c|c|}
\hline$H$ & - & $=$ \\
\hline 1 & $=$ & $=$ \\
\hline$J$ & - & $=$ \\
\hline$K$ & - & - \\
\hline$L$ & + & + \\
\hline$M$ & $=$ & $=$ \\
\hline$N$ & $=$ & $=$ \\
\hline 0 & $=$ & $=$ \\
\hline$P$ & $=$ & $=$ \\
\hline \multicolumn{3}{|c|}{ Aesthetics } \\
\hline Q & - & $=$ \\
\hline$R$ & - & $=$ \\
\hline$S$ & - & - \\
\hline$T$ & - & - \\
\hline+ & 1 & 1 \\
\hline- & 8 & 4 \\
\hline Totals: & -7 & -3 \\
\hline
\end{tabular}


Relevant Criteria Criteria Coding for Matrix Evaluation

A. The design should provide an option of applying and increasing the weight of the lower limb during priming to make the exercises intensive

B. The design should provide an option of applying and changing resistance bands to the lower limb during priming to make the exercises intensive

C. The design should allow the user to perform priming and task exercises without being constrained by the game controller

D. The design should enable the user to perform part and whole tasks

E. The design should adapt to the patient's progress

F. The design should adapt to different stages of recovery

G. The design should be easy to setup and use, reducing the number of steps required for interaction

H. The design should be able to be interacted with using one hand

I. The design should be used seated or standing

J. The design should be easy to use, reach and see

K. The design should require minimal bending/stretching from the user

L. The design should be simple to maintain

M. The design should have easy to use controls

N. The design should conceal any complexity

O. The design should consider human dignity, safety and comfort

P. The design should use materials that consider the movement of the stroke patient

Q. The design's aesthetics should contribute to its usability

$R$. The design's aesthetic should reflect objects within the user's everyday life and reflect the domestic setting it will be used in

S. The design should elicit pride and avoid embarrassment

T. The design's form should promote and reflect the patient's mobility

\section{Matrix Evaluation 2}

The Datum was changed to the most successful design in the last matrix evaluation.

The second decision matrix (figure 5.10) was informed by feedback from peers and research supervisors as well as a Neurophysiologist expert in stroke rehabilitation and an Associate Professor (School of Clinical Sciences) (see Appendix B p. 173) The datum concept remained to be the strongest concept out of the three iterations. An important consideration that was brought up on review of these concepts was that they must "consider the patients' skin integrity, especially when adding resistance using resistance bands" (clinician 1, personal communication, October 14, 2015). Co-morbidities (diseases or disorders co-occurring with the stroke) are also common with older adult stroke patients. Comorbidities often include hypertension, osteoarthritis and shoulder pain (Karatepe, Gunaydin, Kaya \& Turkmen, 2008). These are important considerations as the environment can severely affect these comorbidities. A good example is peripheral vascular disease, a common comorbidity of older adult stroke patients that can compromise the skin integrity of the patient (clinician 1, personal communication, October 14, 2015). Pressure from clothing, bed linen, pillows and even certain mattresses can cause pressure sores and tearing of the skin. This is a factor when considering the ergonomics of anything a patient could be using for extended amounts of time. Concept three was submitted as the most viable concept and developed through low fidelity prototyping.

\section{Additional Criteria:}

- The design should consider the stroke patient's skin integrity

Opposite Page: Figure 5.10 - Matrix Evaluation 2 


\section{Initial Design Assumptions}

The proposed design was a wearable game controller, intended to replicate the aesthetics of a shoe or slipper. The proposed concept had attachment points for IMU sensors to track lower limb movement. Motion data from the sensor would be interpreted by the gaming media on the iPad and the sensor would be easy to remove for re-charging. Detachable modular soles of different weights, and resistance band attachment points change the load applied to the foot to facilitate intensity during the priming component. The design was intended to be adaptable enough to facilitate small or large amounts of load, catering to patients at different stages of recovery. The design also needed to be stable and secure enough to allow the user to perform the part/whole tasks of stepping up and down off raised surfaces during the task-based component safely and without losing balance.
The design was intended to be intuitive and easy to use. The shoe would need to be easy to put on and take off as well as providing an easy and quick way of adding and removing load from the foot. Because of the limited motor control patients may have in their affected arms and legs, it was hypothesised that putting on/taking off the shoe and adding/removing weight would need to be carried out using one (the unaffected) hand. Due to load being applied to the foot, the design would also need to distribute pressure over as much surface area as possible for comfort and considering the skin integrity of the patient.

By designing footwear that functions as a game controller, it was speculated that the familiarity of a shoe form would help contribute to how it should be intuitively put on and taken off. By replicating the aesthetics of contemporary footwear, it was assumed that the design could blend into the domestic environment and avoid any embarrassment or stigma towards using an assistive device. With the design also being an object that is
1. Upper

2. Heel Counter

3. Mid Sole

4. Vamp

5. Modular Sole (Outer Sole)

Opposite Page: Figure 5.12 - Initial upper prototypes \& sketches
(1)

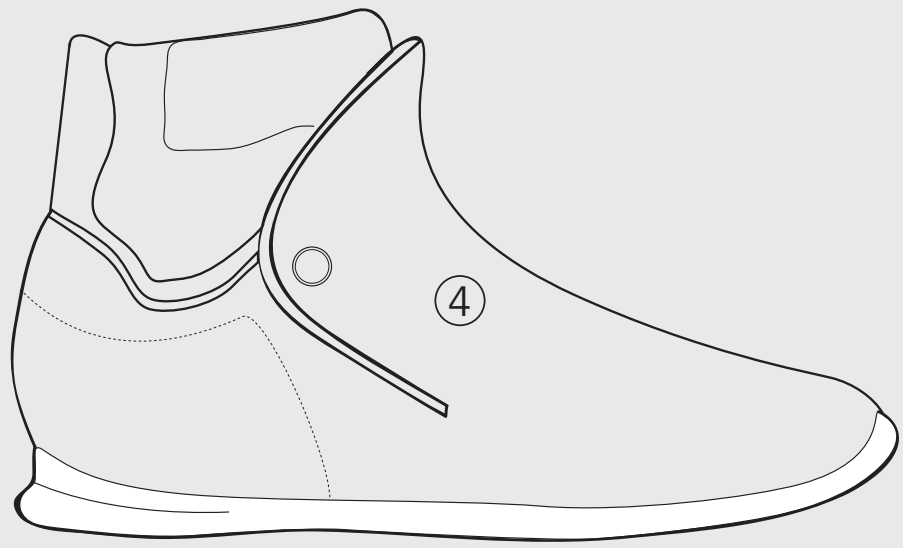

(5)

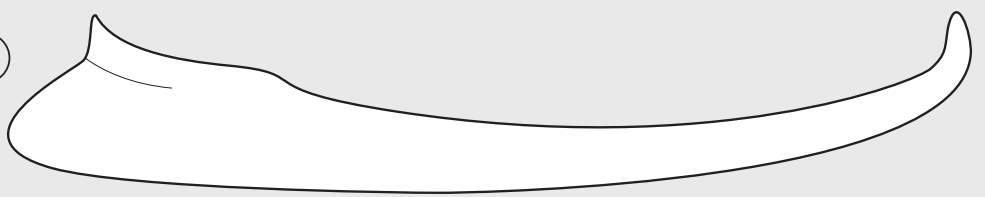

Figure 5.11 - Footwear Anatomy 
synonymous with movement it was intended that the design's aesthetic could help reflect and promote the patient's mobility.

The criteria were then revised to become more specific to the proposed design. This criteria were also iterated alongside the design during the prototyping and testing phases.

\section{Revised Criteria:}

- The shoe upper must have an attachment point for the IMU sensor

- Modular soles must provide a selection of different weights that can easily, intuitively and quickly be changed/removed

- Resistance bands must be able to be easily, intuitively and quickly attached/removed from the shoe

- The shoe must be easy and intuitive to put on/take off with one hand

- The shoe must be comfortable and secure

- The shoe's form should dictate how it is to be put on and taken off

- The shoe should replicate the aesthetics of contemporary footwear

\section{Low Fidelity Prototyping}

The proposed design followed structural conventions of contemporary footwear (figure 5.11). The upper is the soft body of the shoe that incorporates rigid bodies such as a heel counter for structure and support. The upper of the proposed design had to facilitate an easy way for stroke patients to put on and take off the shoe intuitively. The upper also had to remain comfortable while retaining the structural integrity needed to prime using attached resistance bands and weighted soles.
The modular sole system of the proposed design had to provide an easy and intuitive way of, changing soles of different weights whilst fixing the modular sole securely to the upper. This would ensure the sole didn't come loose or fall off whilst performing STT. The design also had to mediate the application of load with the practicalities of a conventional shoe sole by providing comfort, flexibility and traction.
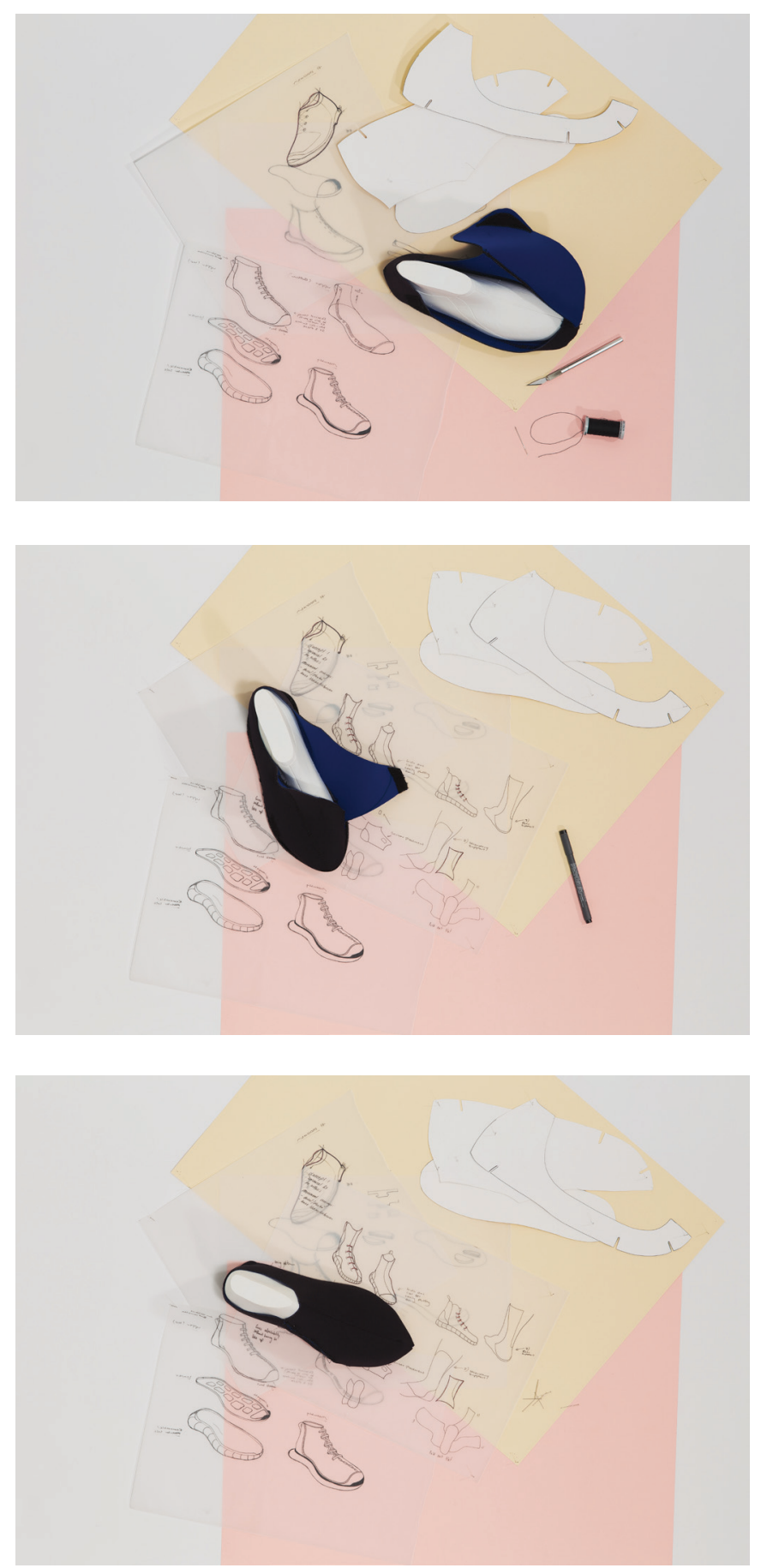

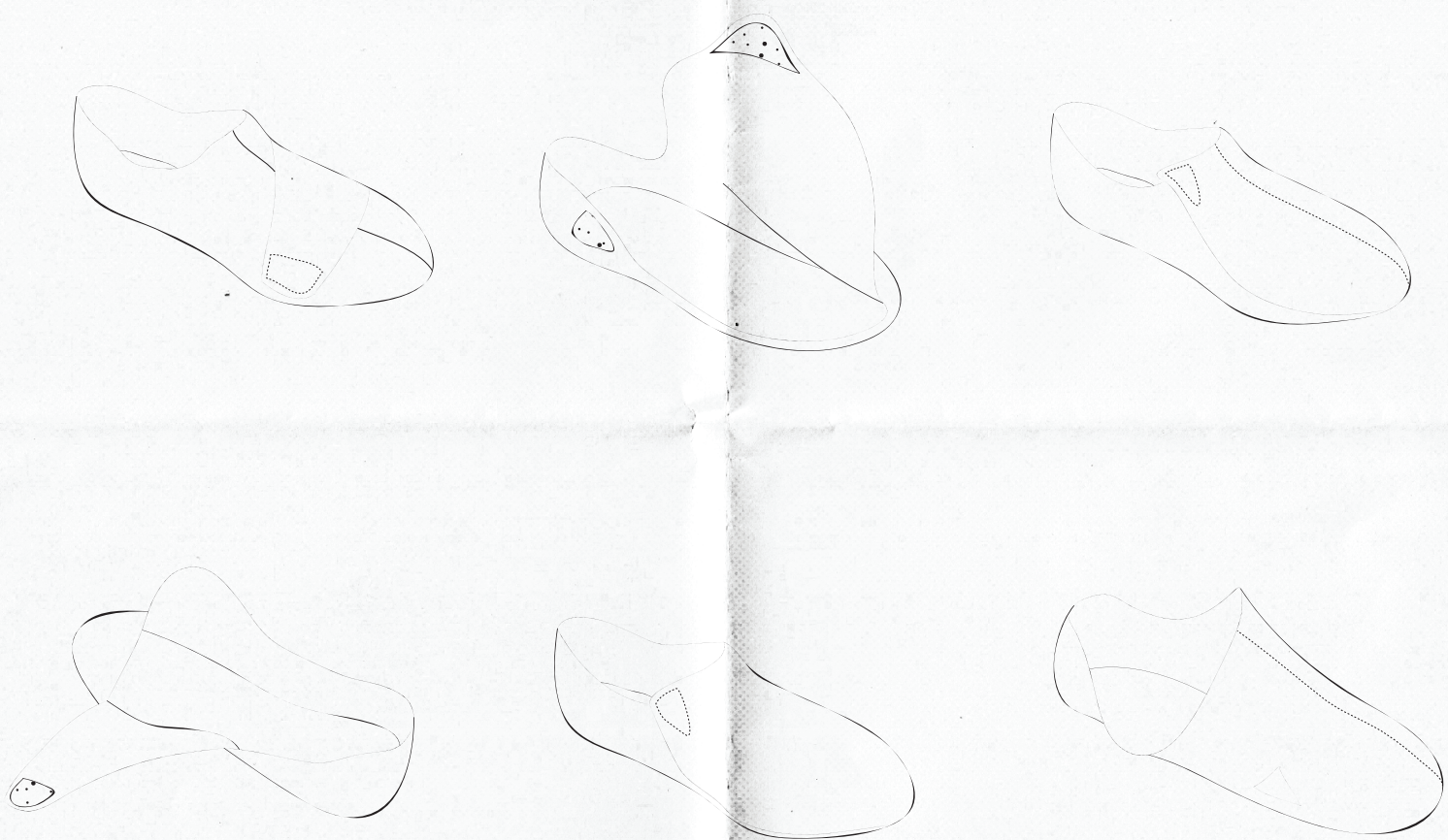

Figure 5.13 - Concept sketches of uppers
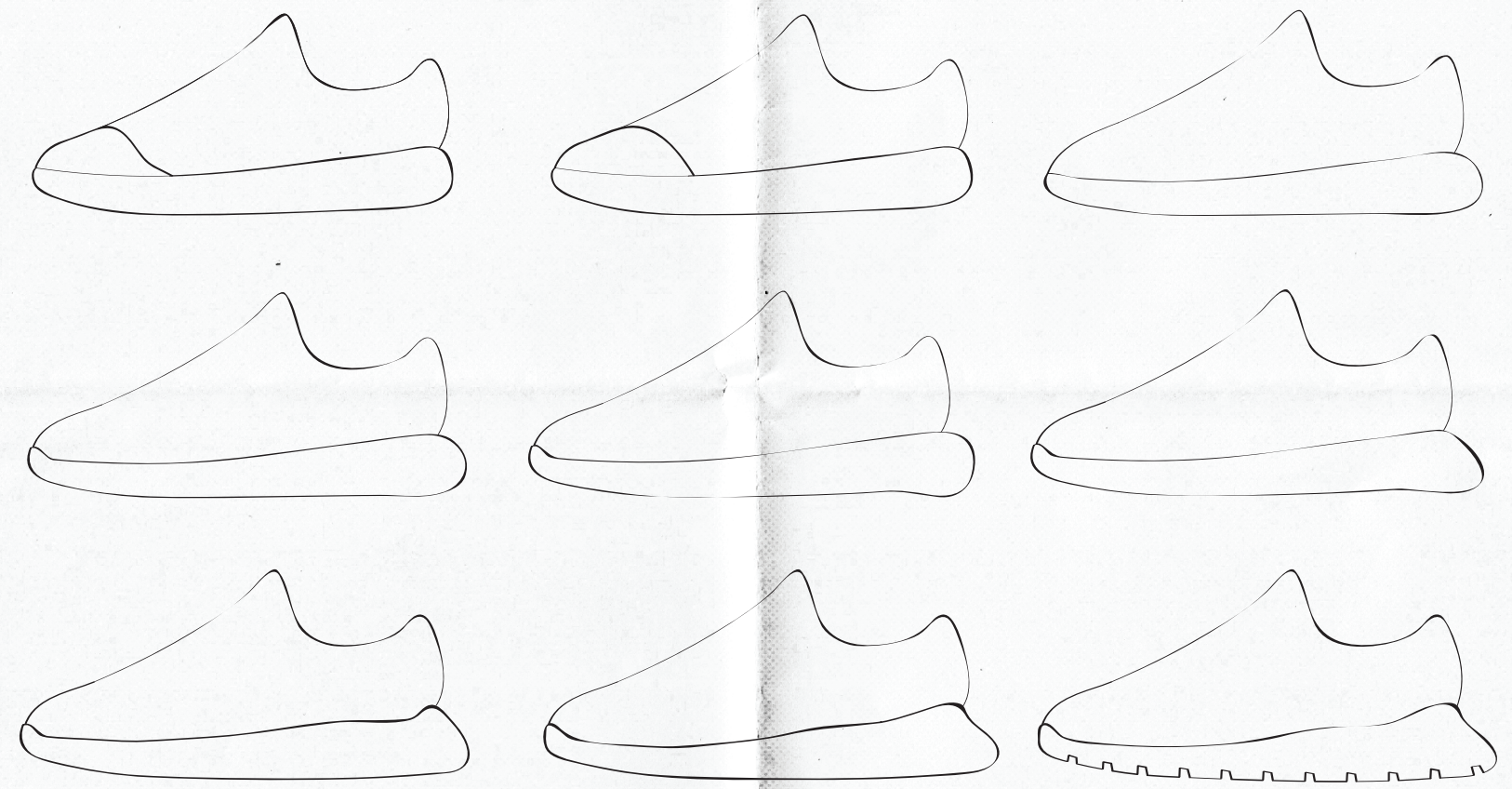

Figure 5.14 - Form exploration of modsole 

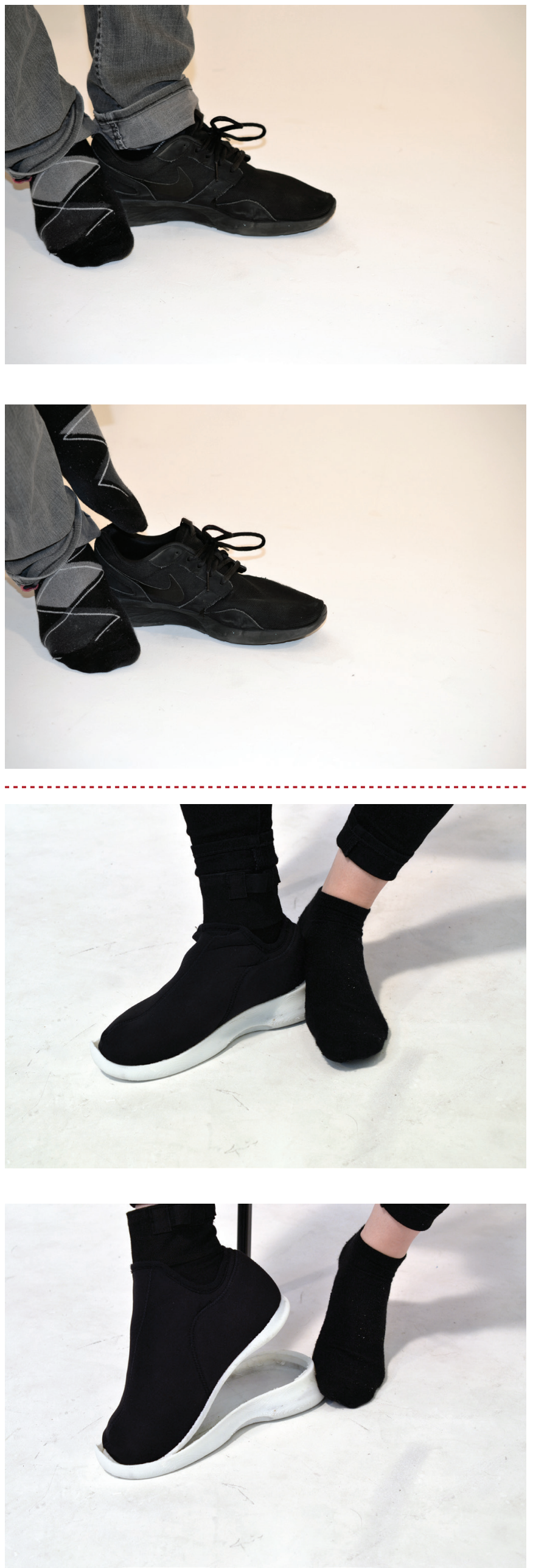

\section{Development of the Upper}

Initial neoprene prototypes of the upper (figure 5.12) where focused on providing design solutions that would enable stroke patients to put on the shoe easily. Tasks that require fine motor skills where minimised or replaced altogether. Laces were substituted with magnets or velcro to adhere to the upper. Providing large surface areas where grasping is needed was also found to be essential for considering spasticity in the user's affected arm or hand. Twisting of the affected lower limb due to spasticity was considered through increasing the size of the opening or allowing the upper to fold out flat.

\section{Development of the Modular}

\section{Sole System}

Load is applied differently to the foot according to the STT exercise. The priming component for Hip abduction requires load to be applied to the foot using a resistance band. The priming component for Hamstrings requires weight to be attached to the foot through the use of a Westminster Pulley. Modular soles of different weights were proposed to facilitate similar load to what is applied through the use of the Westminster Pulley.

Interaction with the modular sole's was considered to represent intuitive movements of putting on and taking off a shoe (figure 5.15). This involved clipping the toes in followed by the heel. The sole could then be removed in a reverse manner by placing pressure on the heel (figure 5.16).

Top: Figure 5.15- Shoe being taken off

Bottom: Figure 5.16 - Modsole being taken off 
Load was added by filling the sole's hollow internals with sand (figure 5.18). To facilitate the adaptability of load, the infill material was changed to garnet and steel grit. The difference in density of these materials produced three duplicate soles, but of different weights. Silicon Sand (500g), Garnet $(1,000 \mathrm{~g})$ and Steel Grit $(1,300 \mathrm{~g})$.

The intention was that the user would be provided with three different soles to provide a progression of load. Triple Seven adhesive (commonly used by cobblers) was used to bond the upper to the midsole. Initial tests of the system found the bond between the upper and midsole sufficient to facilitate the difference in weight provided by the three soles. Stitching between the upper and midsole was used as a contingency to mitigate the extra force applied during the removal of the modular sole.

Resistance band attachments were created by raising the upper around the ankle and fixing an internal sleeve. This sleeve used robust fabric and velcro to provide secure attachment points for the resistance bands (figure 5.17). The resistance band attachment points were fixed at the back and inside of the ankle. These were originally static but on iteration were placed inside a sleeve where they could be pulled out/hidden as needed. This also provided different attachment points for the resistance bands around the ankle.

The aesthetic of different shoes were explored to inform the design. Characteristics and semantics of traditional and contemporary footwear helped derive three design archetypes. Alongside the set criteria and design development of both the upper and modular sole system, aesthetic exploration helped produce the initial design that could be submitted to high fidelity prototyping.

\section{High Fidelity Prototyping and Development}

\section{Iterative Prototyping}

The rapid process of iterating prototypes to narrow down the requirements of the final design was facilitated using a specific set of tools and materials.

Shoe lasts, which are used to create the pattern for a shoe's upper were digitally modeled then 3D printed and iterated (figure 5.20). This process allowed experimentation with different last shapes that represent the dynamic foot types of stroke patients due to spasticity.

The upper was also created digitally, then projected onto the digital last before it was printed (figure 5.19). This helped streamline the process of pattern making by creating precise cutting guides on the printed last. The last was then wrapped with tape and pattern pieces could then be cut off using the cutting guides. The 2D patterns were then nested onto neoprene, cut and sewn together to form the prototype uppers (figure 5. 21; 5,22). Neoprene was used for the initial prototypes as it was an easy to use and forgiving material. Because of the neoprenes stretch, parts of the upper that required minimal stretch where reinforced with a more robust denim fabric.

The soles were 3D printed using a Thermoplastic polyurethane (TPU) filament. TPU is a robust but flexible material that emulates the properties of conventional sole materials such as Ethylene-vinyl acetate (EVA). This facilitated rapid development and experimentation with the sole's form and function. 


\section{Initial High Fidelity Prototypes}

A major design discovery during high fidelity prototyping was the opportunity to create a self-closing upper (figure 5.27). The assumption was that a shoe upper that opened when the shoe is not being worn (disengaged) and was able to securely close over the foot (engaged) when put on handsfree it would reduce any strain caused by bending over.

\section{Revised Criteria:}

- The upper should minimise the amount of upper limb interaction needed to put on and take off the shoe

Top Right: Figure 5.17 - Resistance band attachements

Right: Figure 5.18 - Modsole filled with garnet

Bottom: Figure 5.19 - Upper curves projected onto the digital last
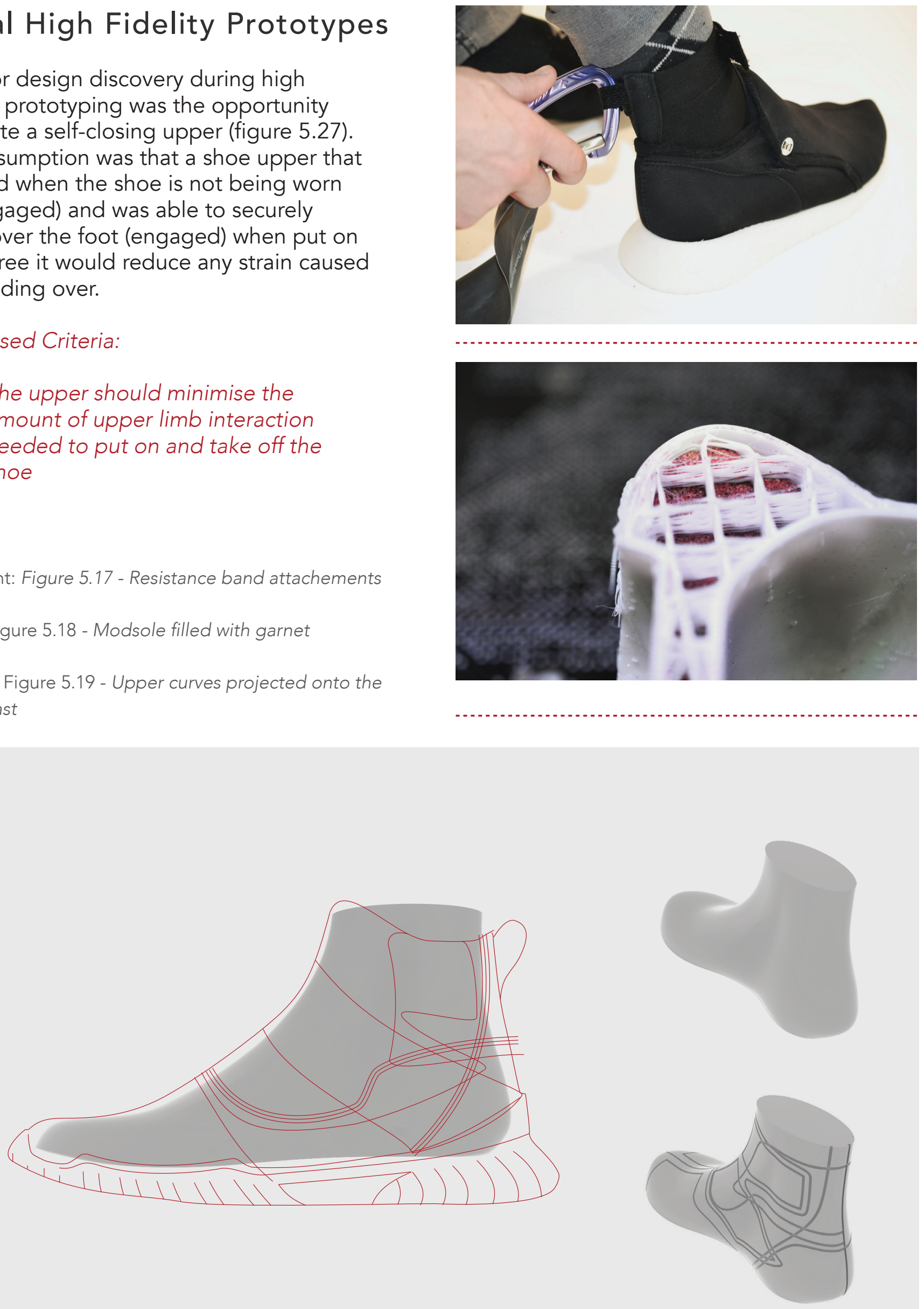


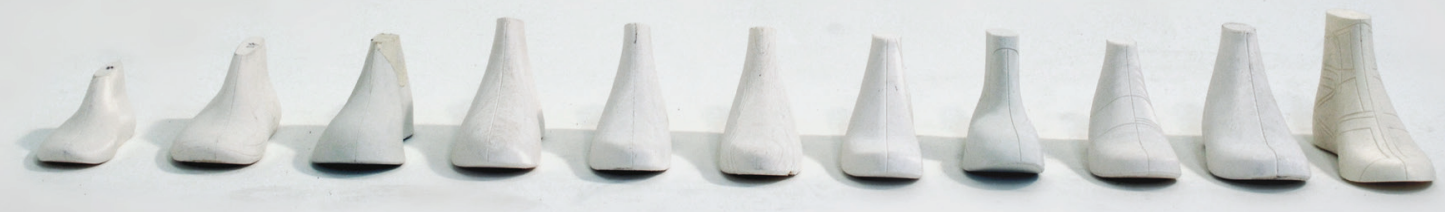

Figure 5.20 - 3d printed last iterations

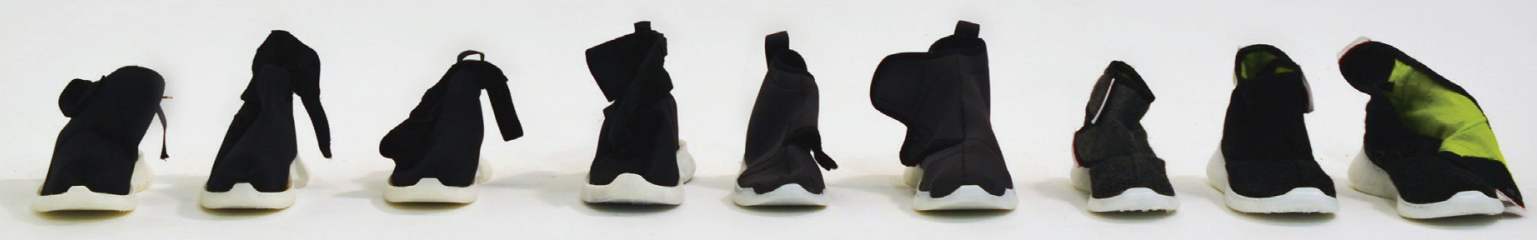

Opposite page: Figure 5.22 - Shoe making process

Figure 5.21 - Shoe prototype iterations 

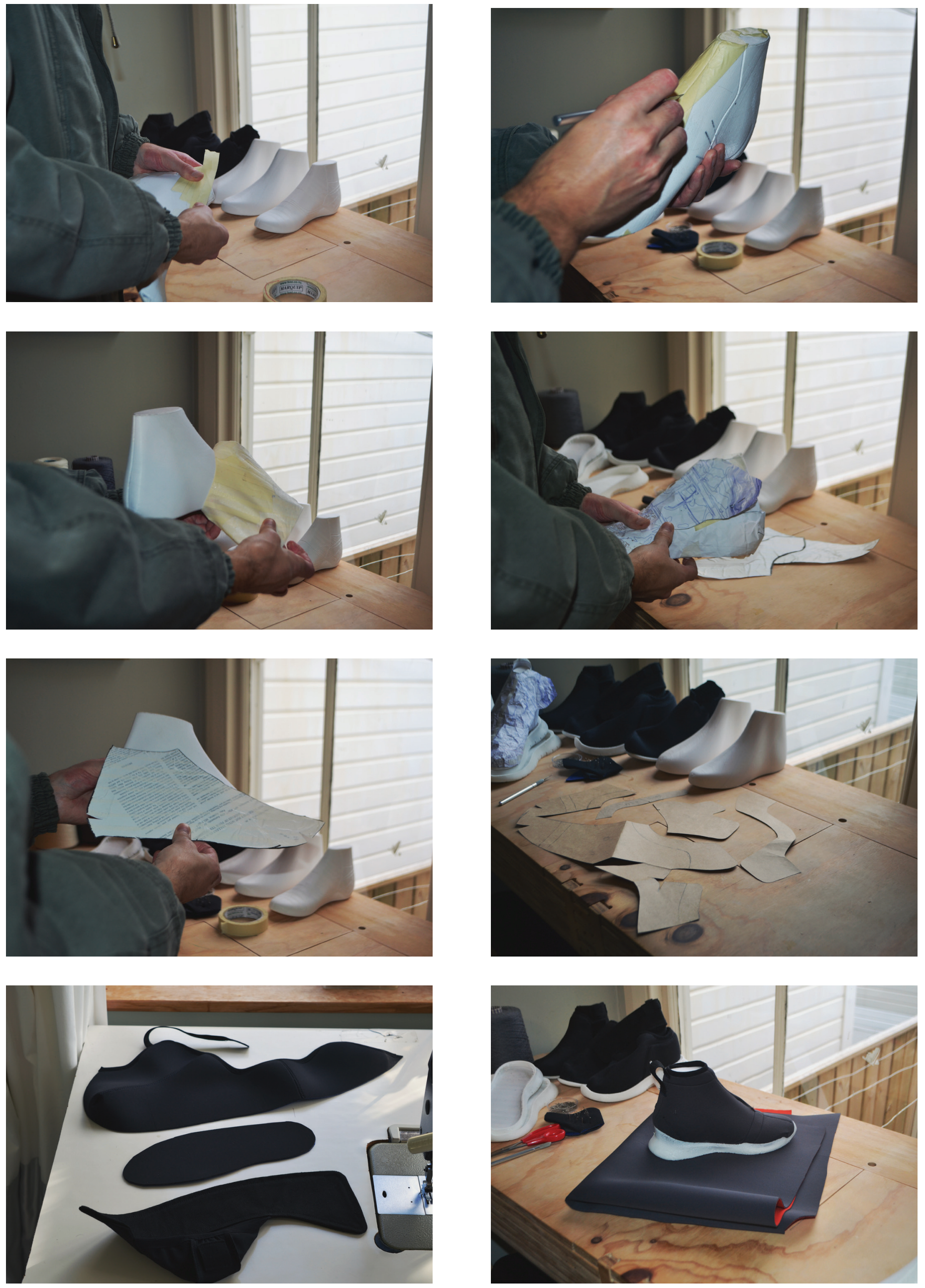
The design for the self-closing upper used a non-invasive sleeve around the heel that raised when disengaged. An elastic band was attached to the inside of the TPU heel counter and run through a fabric channel underneath the heel sleeve. This was then attached to the top of the upper. When the foot is placed into the shoe, the motion of the heel dropping towards the sole pulls the sleeve and band downwards. This motion subsequently pulled the upper over the foot like a sock. A magnetic buckle was then placed accordingly to secure the shoe in place.

The self-closing mechanism relied on the upper, by default, to remain open when not in use. This helped the foot enter and engage without any fabric folding over itself. A rigid spine was sewn between the top of the ankle brace to the bottom of the heel. This rigid body was flexible enough not to compromise the comfort of the upper, but firm enough to hold the ankle brace and upper open to allow ease of access for the foot.
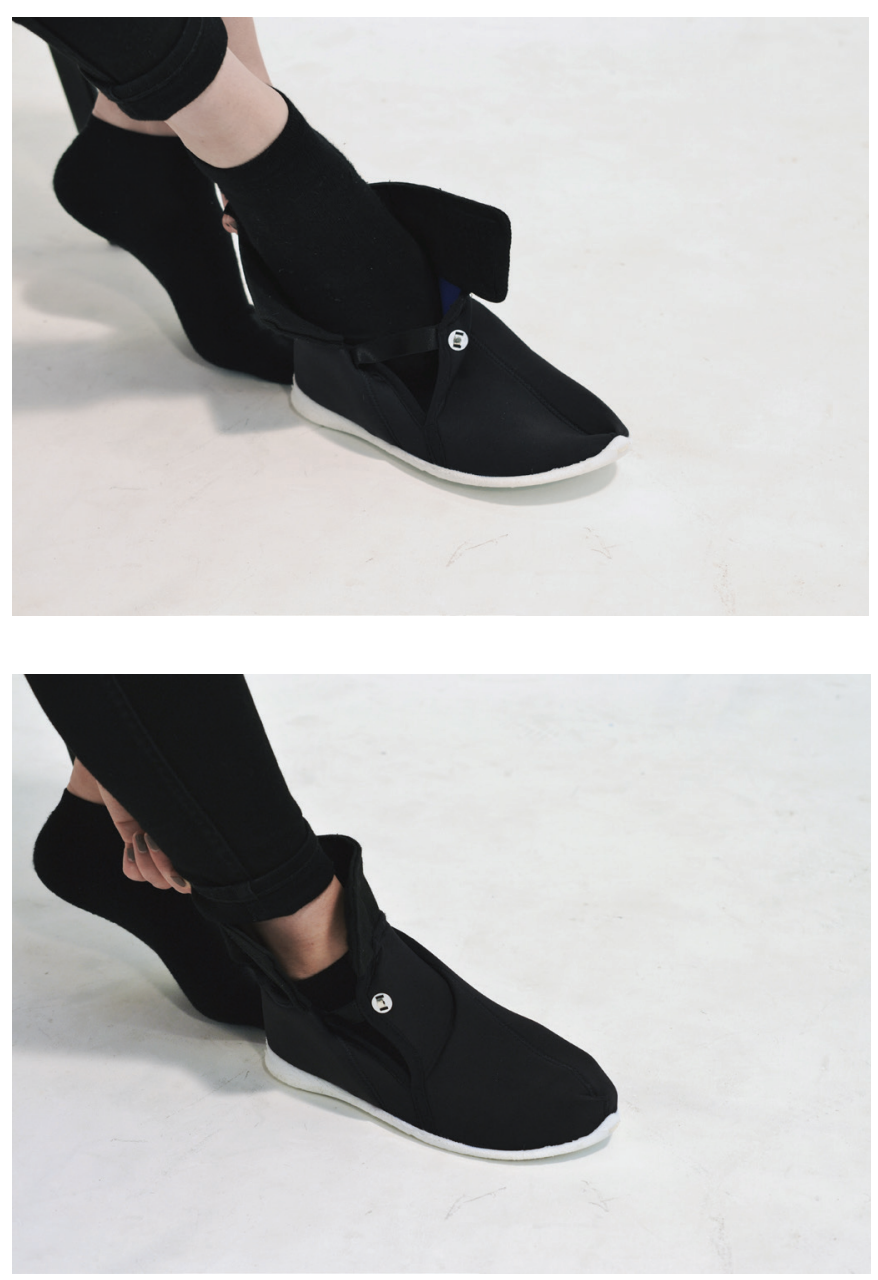

Further testing found the self-closing upper still required the use of one hand to hold the shoe in place (figure 5.23). Even with a TPU heel counter and spine the fabric still tended to fold into itself. The amount the upper opened up automatically was minimal. It was assumed this would create further issues with users who have limited motor control over their affected leg.

On review of the prototypes with clinicians, it was suggested that the ankle brace might not distribute force equally enough to be comfortable for the patient (clinician 1, personal communication, March 16, 2016). Resistance bands are used in stroke rehabilitation in part, due to their ability to distribute force across the limb (figure 5.28). The shoe's ankle brace only distributed the force of the resistance band across the width of $2 \mathrm{~cm}$. It was speculated this could be uncomfortable and compromise the skin integrity of the patient. The ankle band was then adapted (figure 5.29) to provide more width subsequently distributing force across a larger area, creating less pressure on the skin.

A follow up interview with clinician 1 revealed concerns about the unsupervised use of resistance bands during lower limb rehabilitation (clinician 1, personal communication, April 6, 2016). Resistance bands are considered a fall risk as they must be fixed to the user's lower limb as well as an anchor point. In most domestic

\section{Above: Figure 5.24 - First prototype}

\section{Left: Figure 5.23 - Self closing upper}

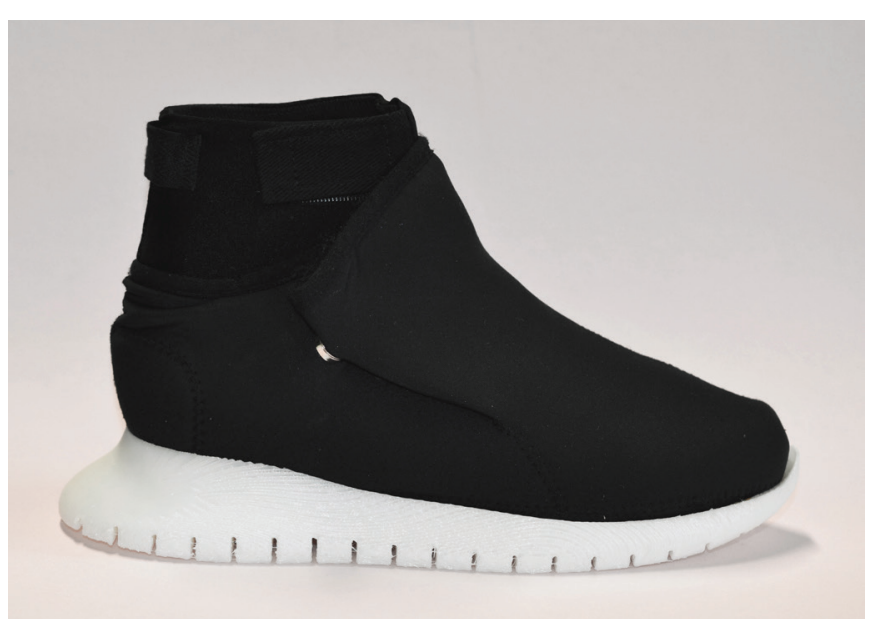



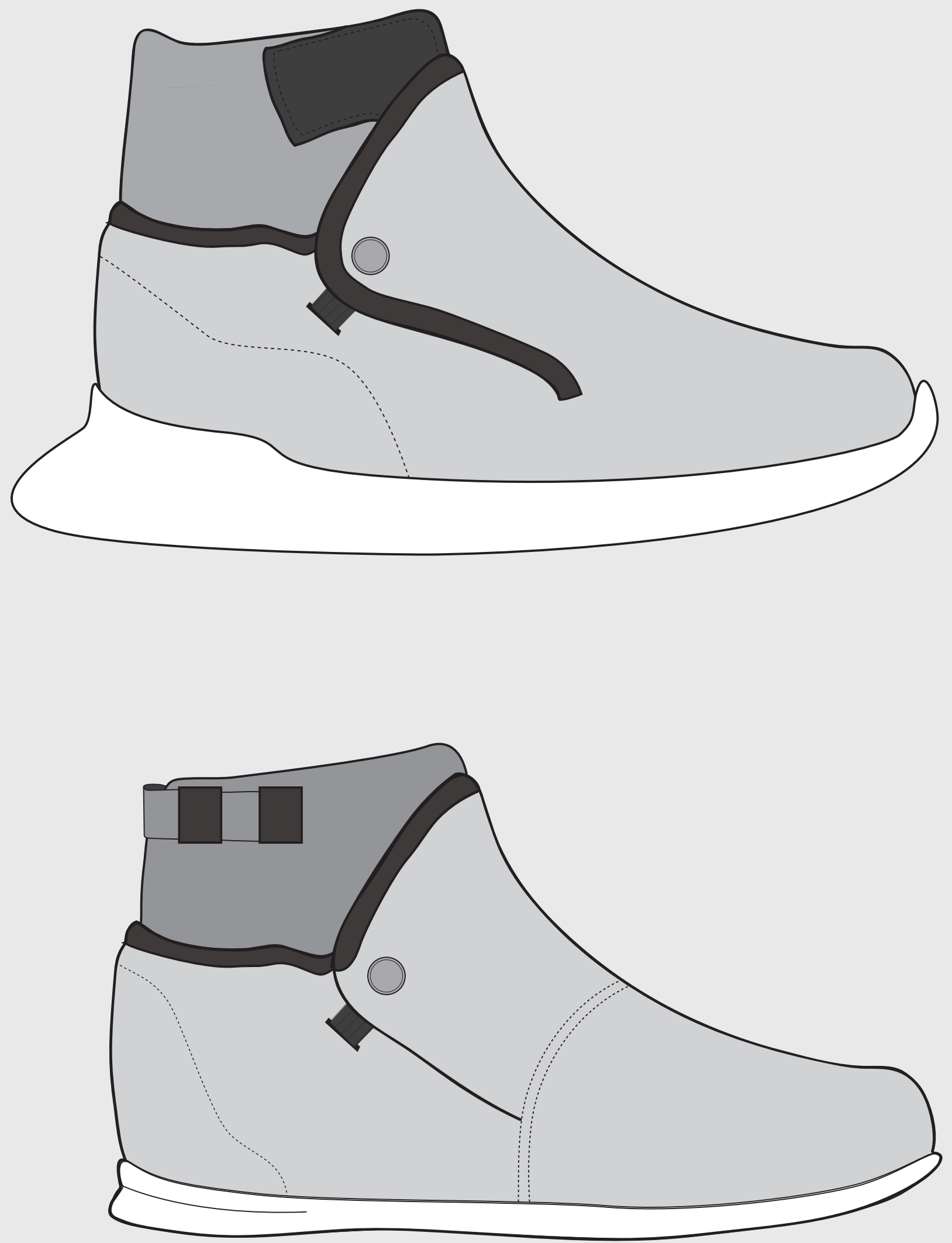

Figure 5.25 - Diigital sketch of the first prototype 
environments the resistance band is anchored to a heavy object such as a bed frame or table. These environmental restrictions and safety concerns lead to patients not using the resistance bands in a way that makes the strength training intensive.

In priming for hip abduction, clinician 1 indicated that the weighted soles might provide enough load to facilitate priming for hip abduction without the need to use a resistance band. Hip extension, uses a Westminster Pulley where large amounts of weight can be used to add load. Clinician 1 raised her concern that the weight of the modular soles may not facilitate the same load as a westminster pulley. Due to the amount of load needed to facilitate intensive priming being relative to the patient, clinician 1 was unable to provide a specific amount of weight the soles should attempt to facilitate.

Although the discovery of the unsuccessful use of resistance bands in the domestic setting disrupted the proposed criteria, it
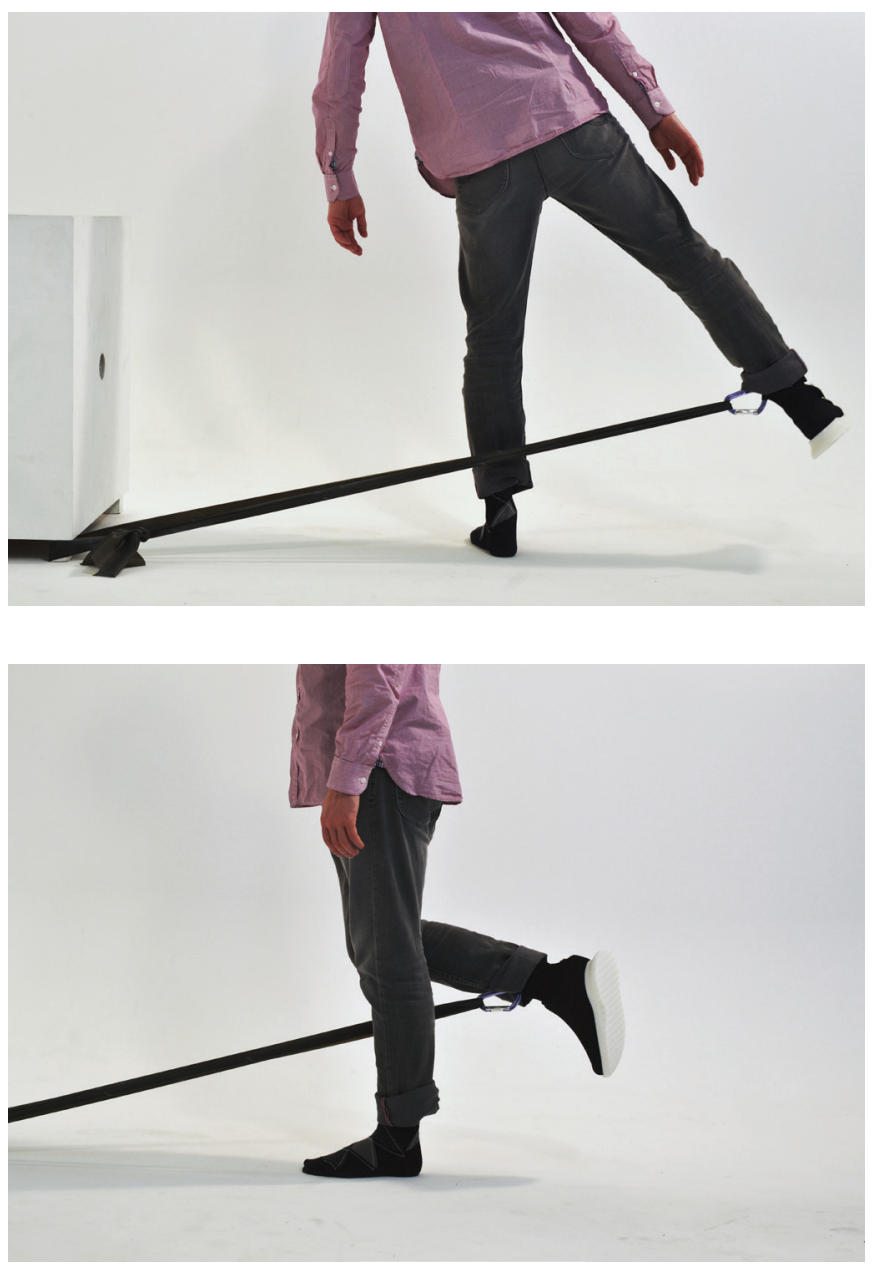

formed an interesting design opportunity. By facilitating sufficient load required for hip abduction and extension without having to be anchored to something such as a resistance band or weight training machine, design could provide a safe and effective way to strength train in the home.

\section{Refined Criteria:}

- Modular soles must providea setection of different weights that ean easily, intuitively and quickly beehanged/removed-

- Resistance bands must be able to

Opposite page: Figure 5.27 - Diagram of self closing upper

Below: Figure 5.26 - Testing first prototype using STT priming and task training movements
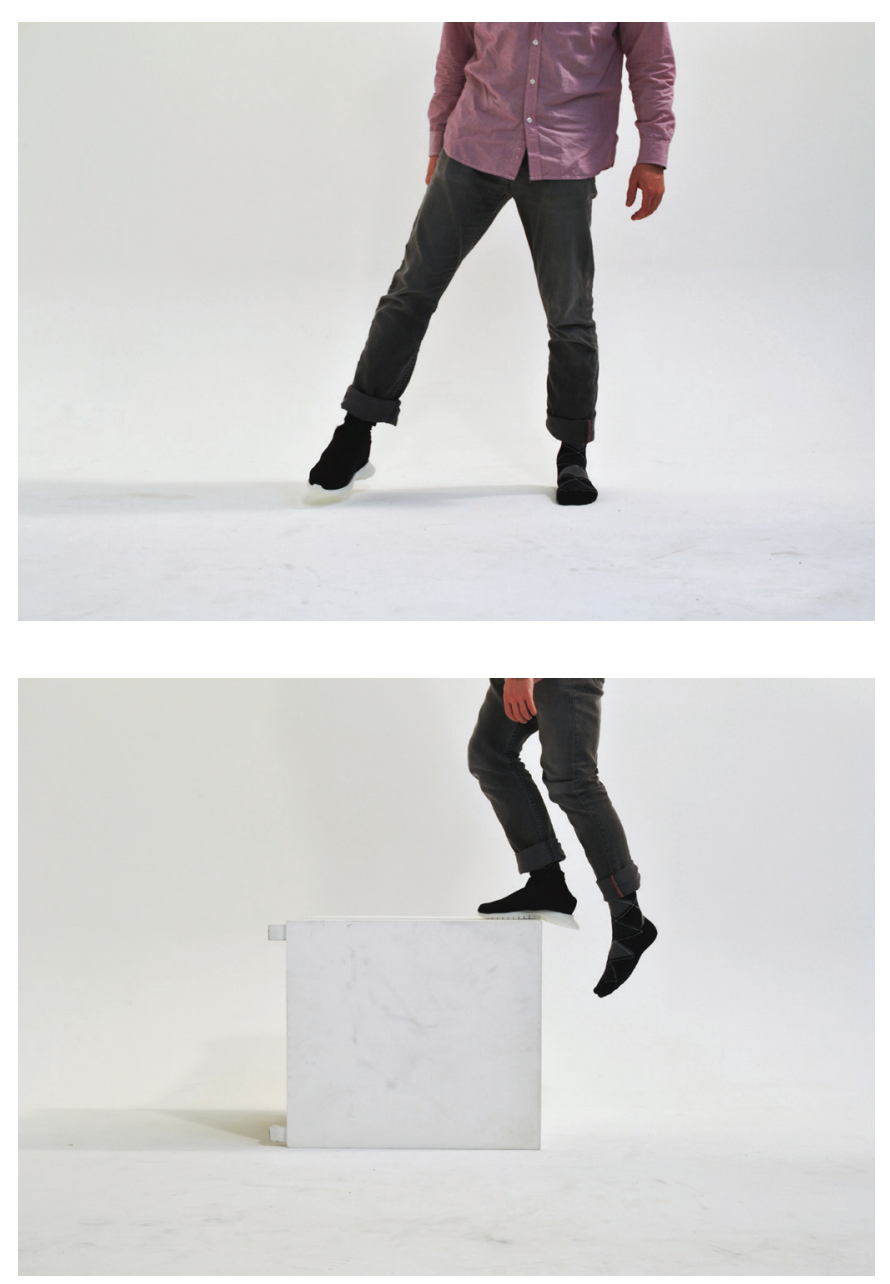

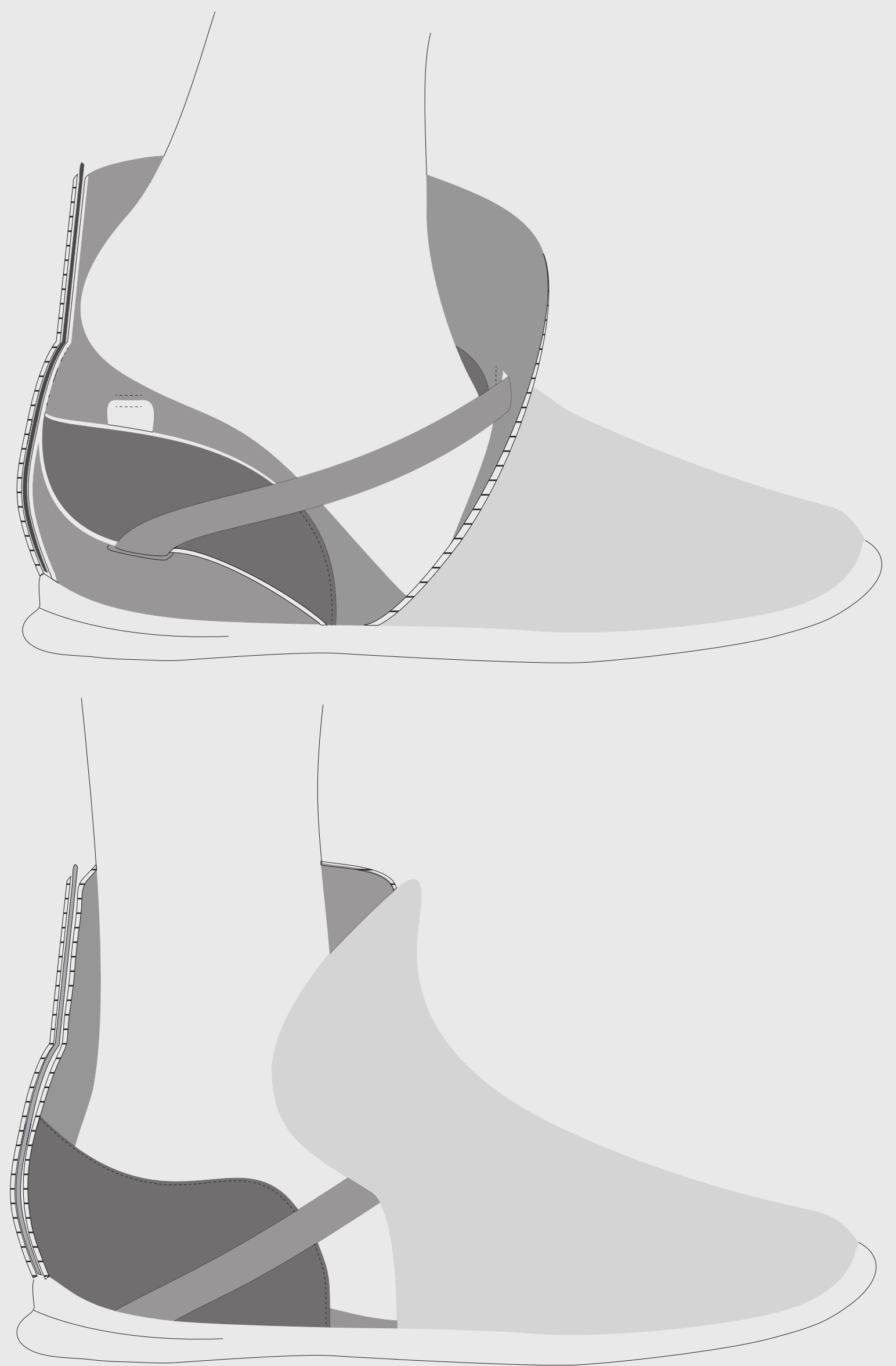
be easily attached/removed from the shoe

- The design should provide sufficient and adaptable load for hip abduction and extension

- The design should allow for load to be removed quickly and easily to facilitate priming

- The design should allow for load to be added/removed hands free

- The design should maximise patient safety by avoiding fixing patient's legs to anchor points

\section{Pivotal Design Decisions}

The modular sole system was revised in order to facilitate a higher load threshold. When filled with the densest material (Steel Grit) a max weight of $1,300 \mathrm{~g}$ could be achieved. To facilitate a higher weight the sole would have needed to be enlarged, potentially affecting the user's balance. Pivotal design decisions were made in an attempt to facilitate more weight.

The revised design proposed a weighted sole (figure 5.34) made of Acrylonitrile butadiene styrene (ABS), a robust plastic. This would facilitate a higher weight threshold of $2,500 \mathrm{~g}$ The midsole of the shoe would clip into the weight module using the same interaction as the previous modular sole (figure 5.32). During strength training the patient moves only the affected limb in one direction.

Opposite page, top left: Figure 5.30 - Repositioned opening of upper

Opposite page top right: Figure 5.31 - Self closing mechinisim

Opposite page Bottom Right: Figure 5.33 - Prototype 3 in use

Opposite page bottom left: Figure 5.32 - Weighted sole in use
Because no locomotion is required during strength training the module would not need to be walked on. Load was applied to the weighted sole using steel, cut to follow the ergonomic profile of the module. This provided weight that could be changed at standardised increments (figure 5.34).

Further iterations of the design's upper created to maximise the opening of the upper (figure 5.33). A small non-invasive mechanism was used in place of the previous self-closing sleeve. The new mechanism pushed the sides of the shoe out when "disengaged" and pulled them in towards the sides of the foot when the user's heel entered (figure 5.31). The patient would then use one hand to fold the back of the shoe around the side of the foot, then fold the top of the upper over the foot, securing the shoe (figure 5.39).

\section{Below: Figure 5.28 - Correct use of resistance band}

Bottom: Figure 5.29 - Second prototype with greater surface area around the ankle
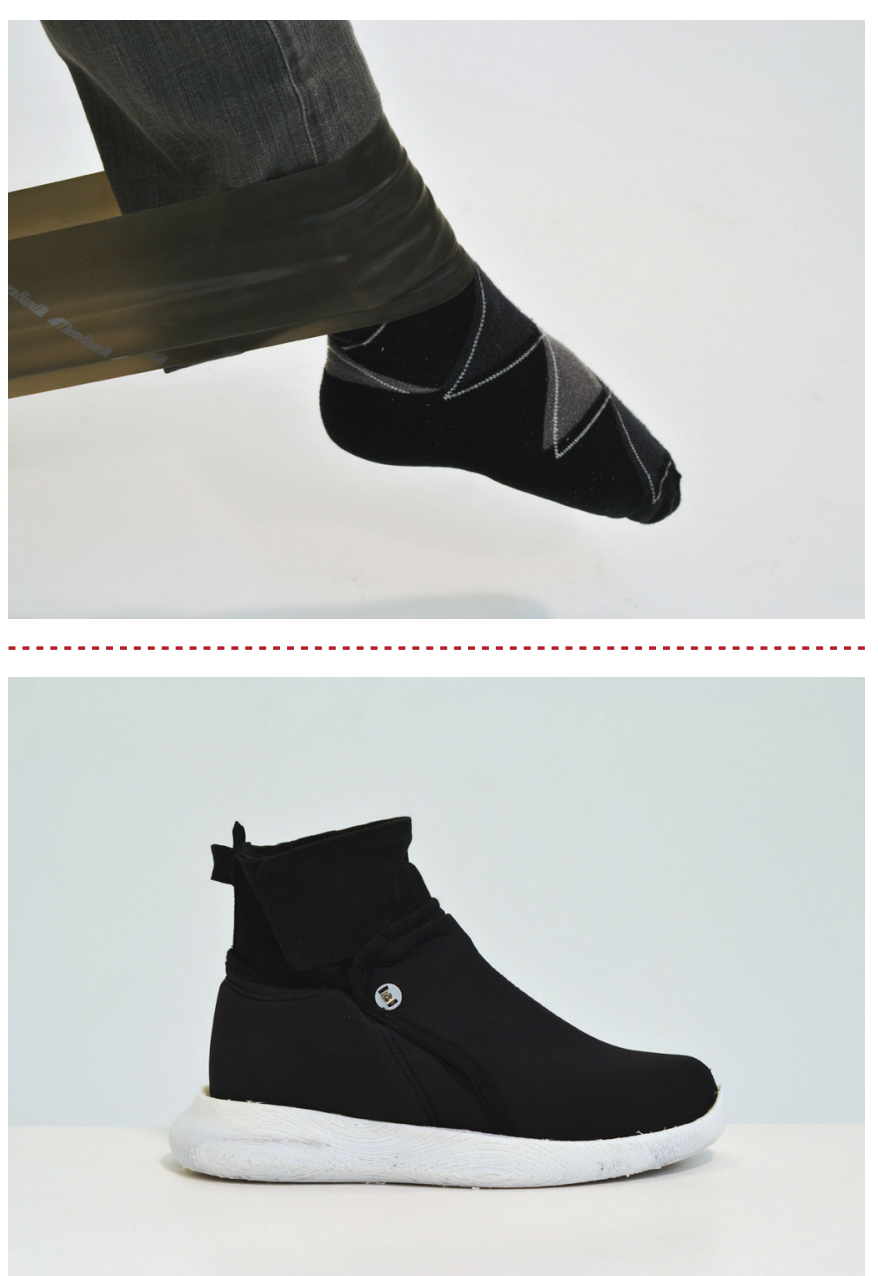

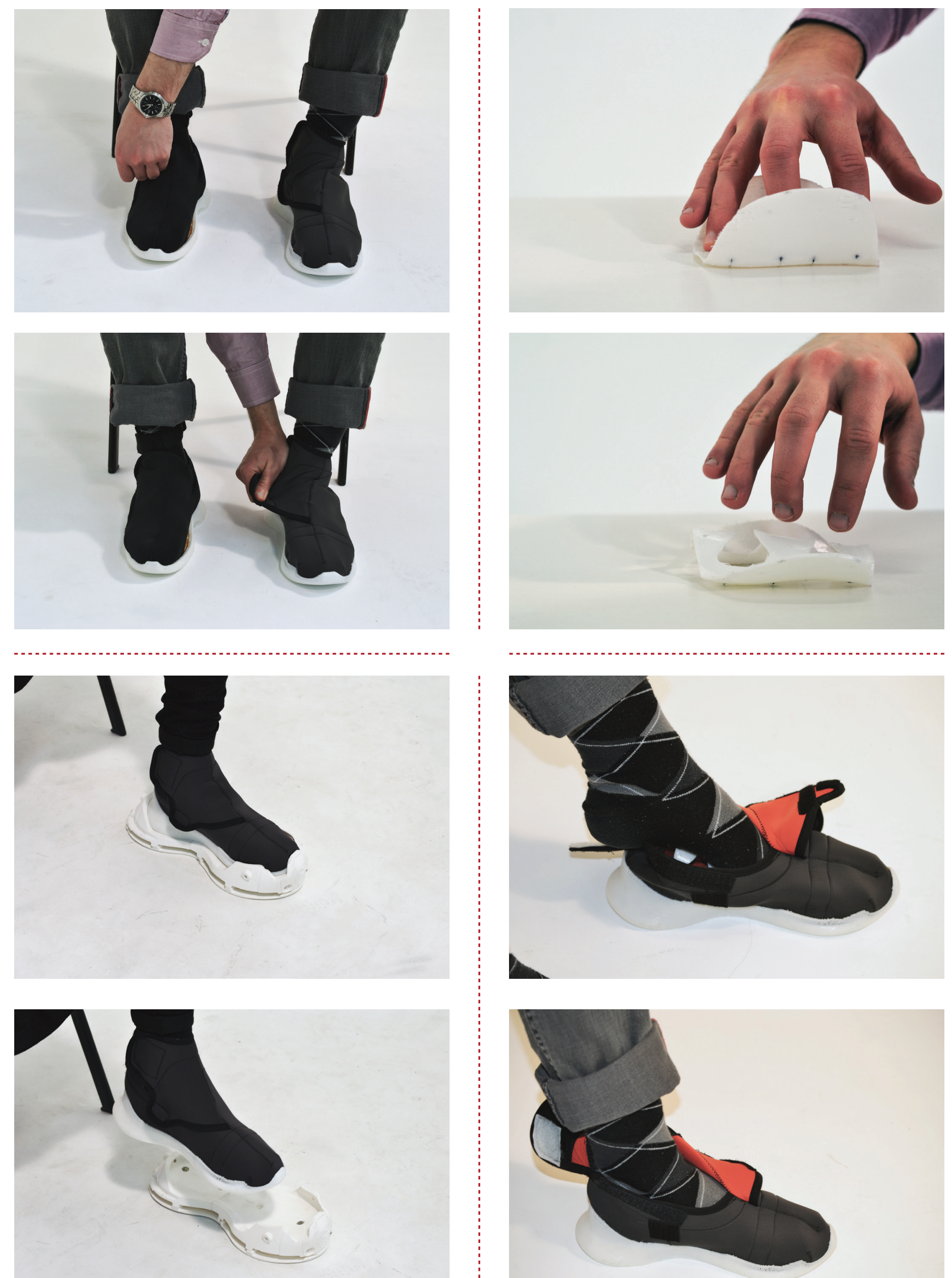
Through self-testing, it was also discovered that affixing the straps required the user to reach across their affected limb with their unaffected hand. To minimise the amount of reaching and stretching required, the position of the velcro and magnets were moved to the inside of the foot (figure 5.30).

The form of the sole was designed to slide and clip into the modular weighted sole for priming, then easily and quickly unclip by applying pressure to the heel using their unaffected foot (figure 5.40). Variations to the structure of the upper disperse the weight evenly across the foot and kept the shoe from moving too much during the priming phase.

\section{Colour Considerations}

Colour was used to help address the usability concerns of putting on the shoe. When considering colour for an older audience, there were several factors that informed the selection. During the aging process the human eye undergoes physiological changes. These changes result in a loss of spectral perception around the age of 60 . In combination with the cognitive impairments stroke patients may suffer, changes to sight affect an older adult's perception of their environment. Consequently, these

\section{Areas of Renforced Rigid Fabric}

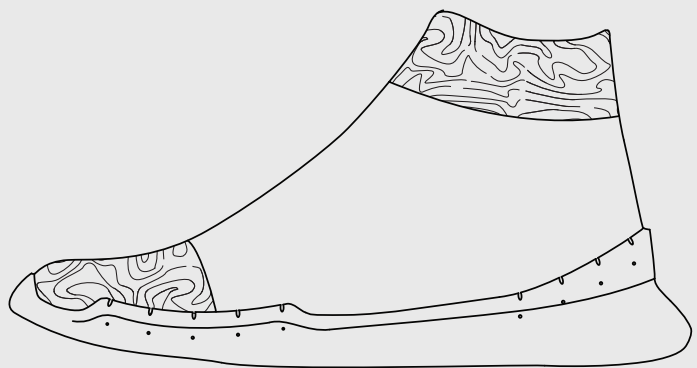

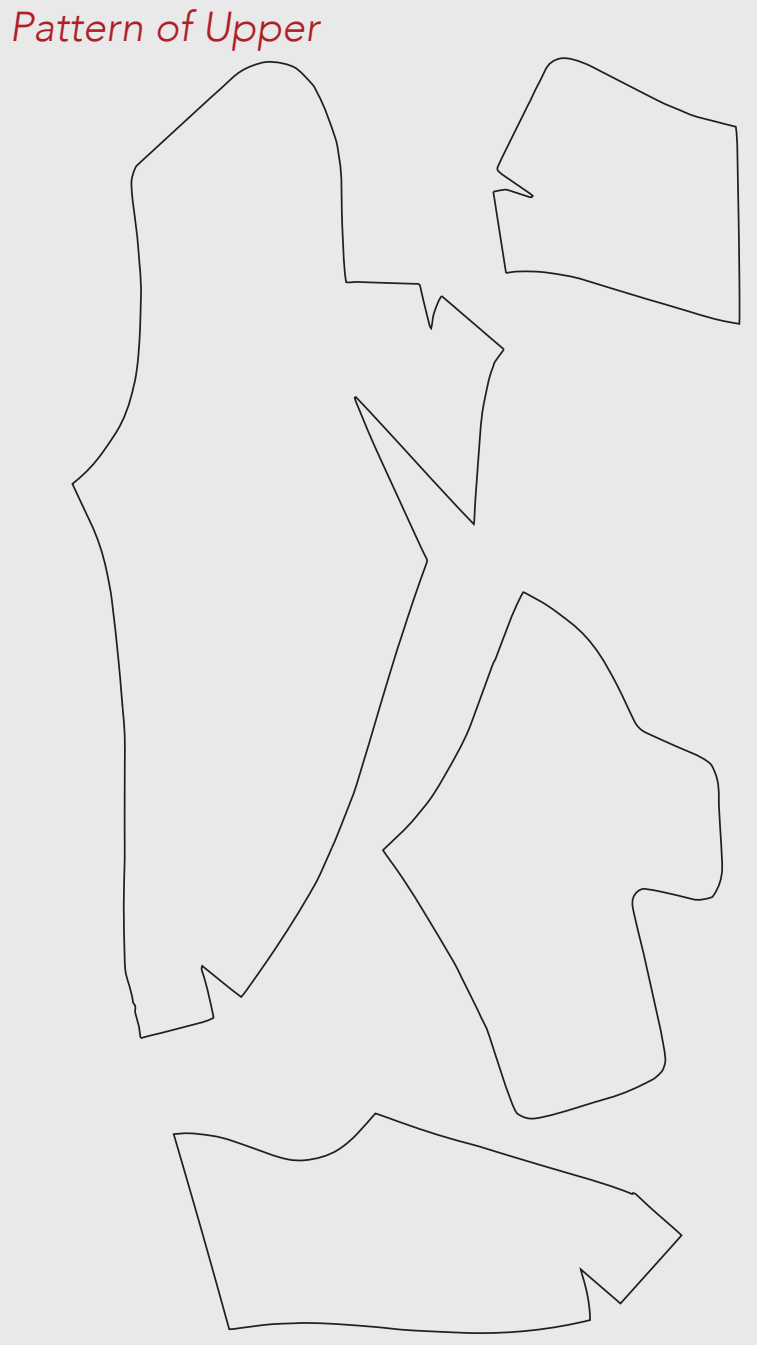

\section{Closed Upper}

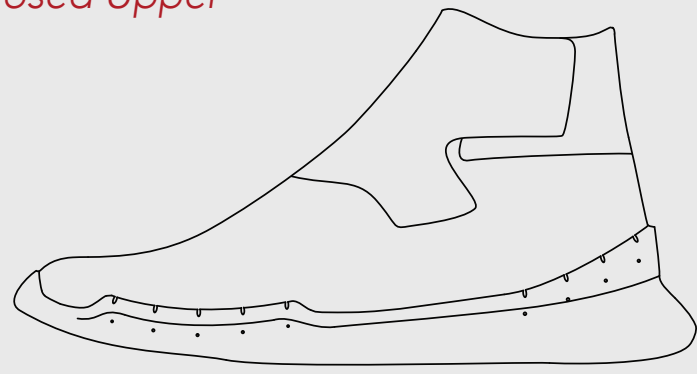

Open Upper

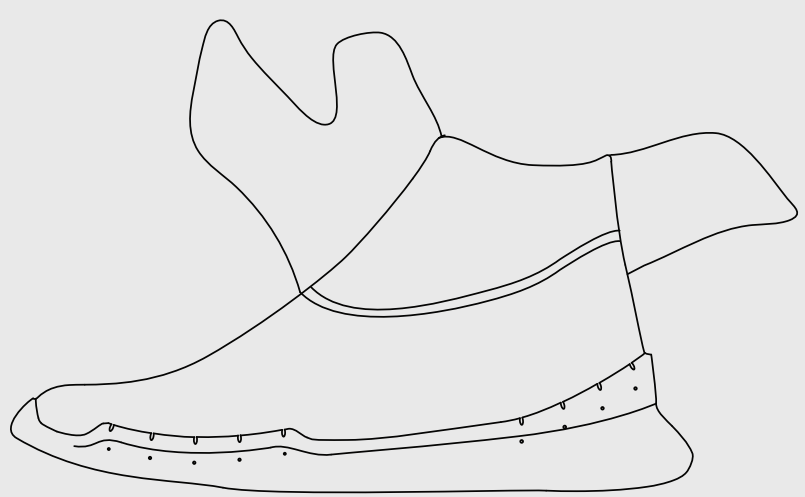

Figure 5.34 - Prototype 3 specifics 


\section{Prototype 3}

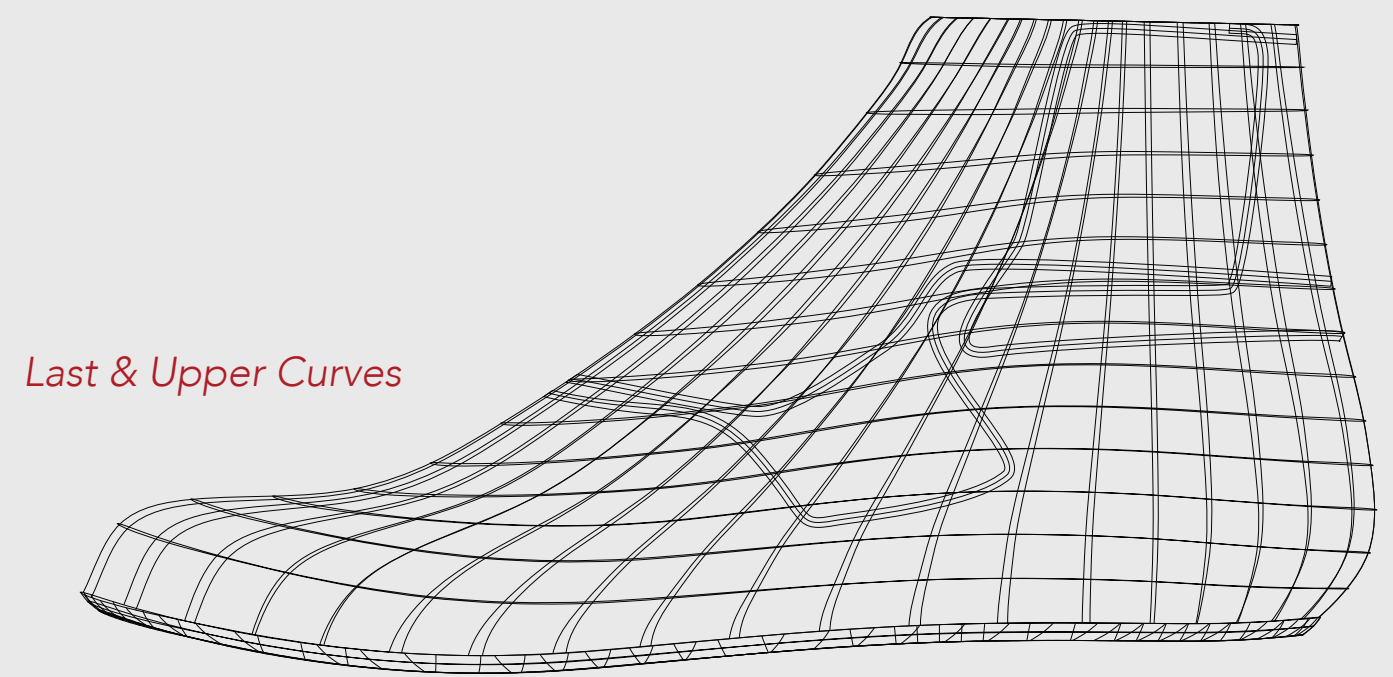

Mid Sole Wireframe

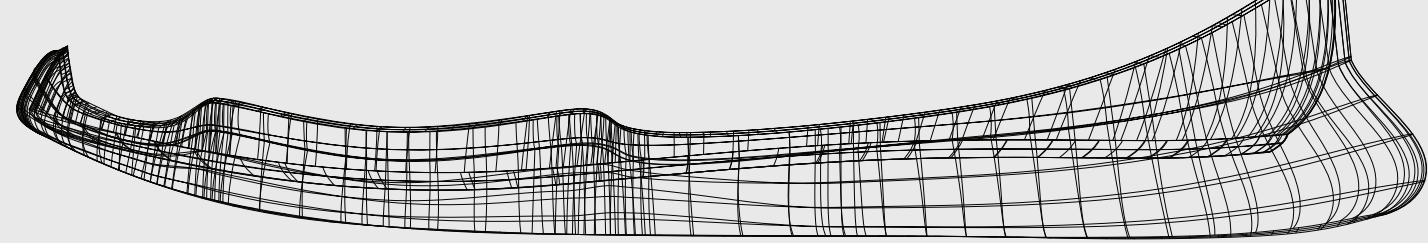

Modular Sole Wireframe

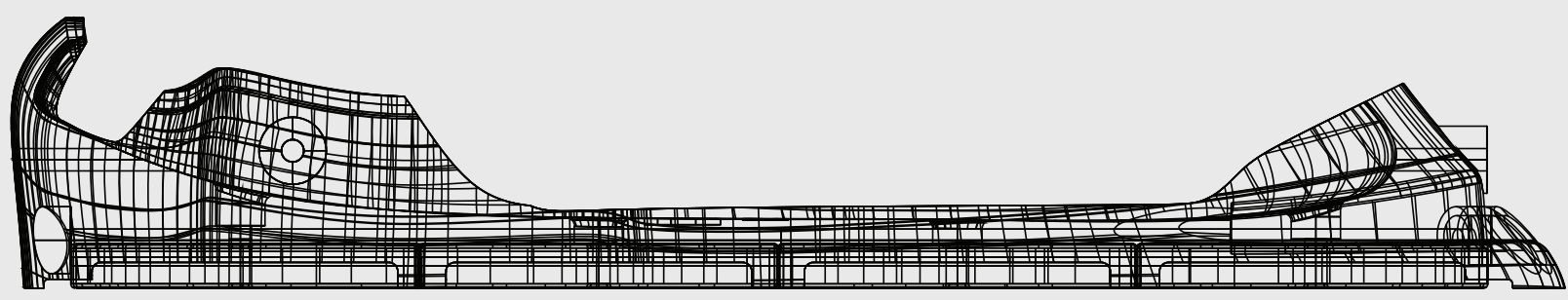

Interchangable Steel Weights

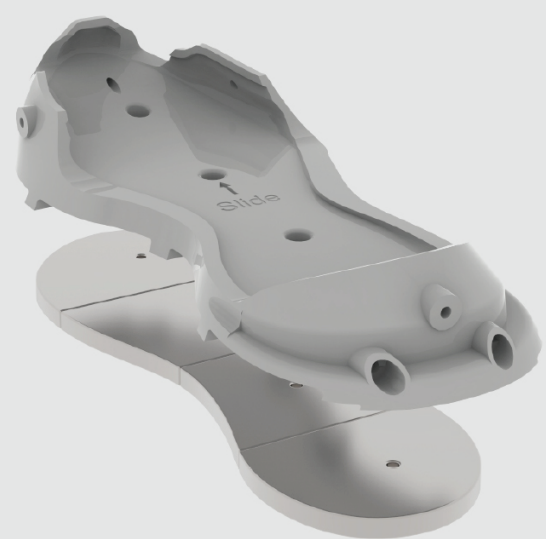

Modular Sole

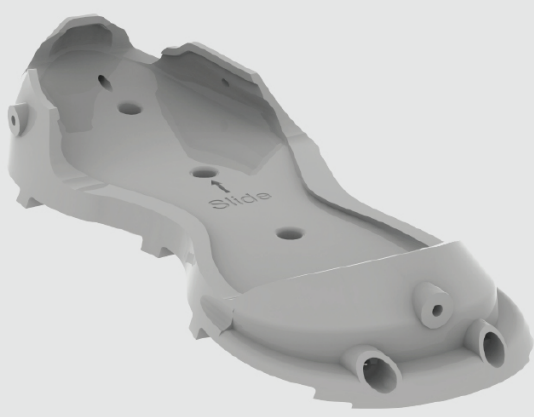




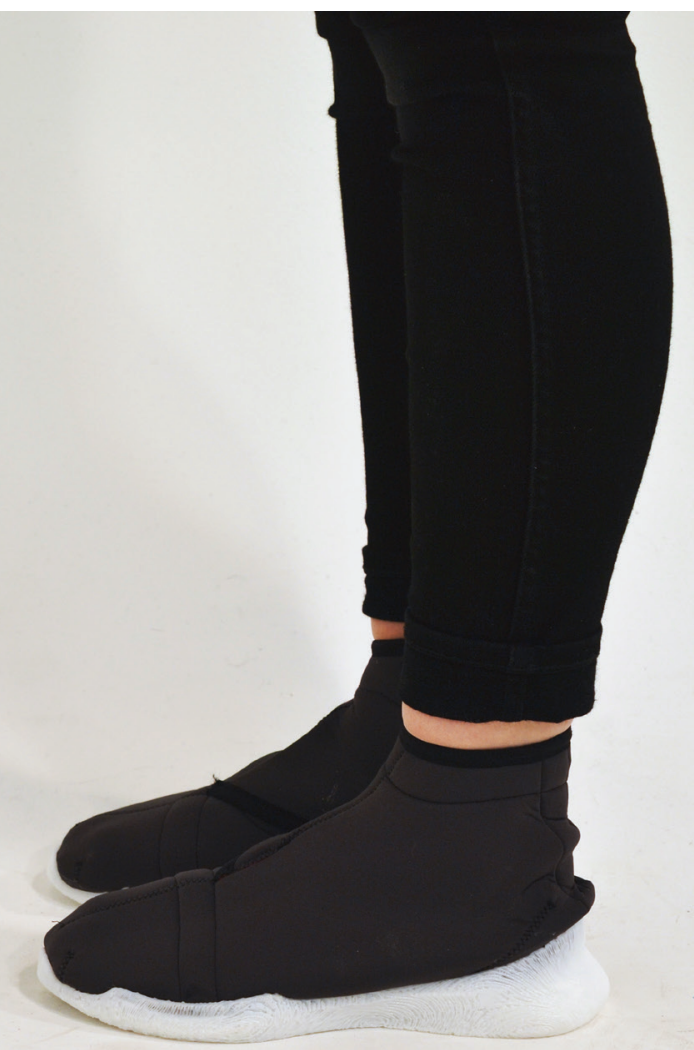

Figure 5.35 - Prototype 3 on feet

Figure 5.36 - Demonstrating flex of TPU midsole 
changes result in loss of depth perception, loss of peripheral vision and increased depth of field. This reduces visual acuity, sensitivity to contrast and the ability to differentiate between colours (Kopacz, 2003, p. 212).

Exaggerating contrast was used to help build a more accurate perception of a 3D object or environment. In considering the colours of shoes, contrasting the inside of the upper with the outside (figure 5.38) could help with visual accessibility, aiding the user in putting the shoe on easily and correctly. Contrasting points of interaction (any part of the shoe that is gripped or held) could also aid with distinguishing points of interaction. Colours such as dark red, red-orange and red-violet should be considered in these areas of the design as they are most easily recognised by older adults. (Kopacz, 2003, p. 218). This idea was implemented by contrasting the black outer of the prototype with a bright red inner.

This iteration was then reviewed by clinicians who validated the design direction of the
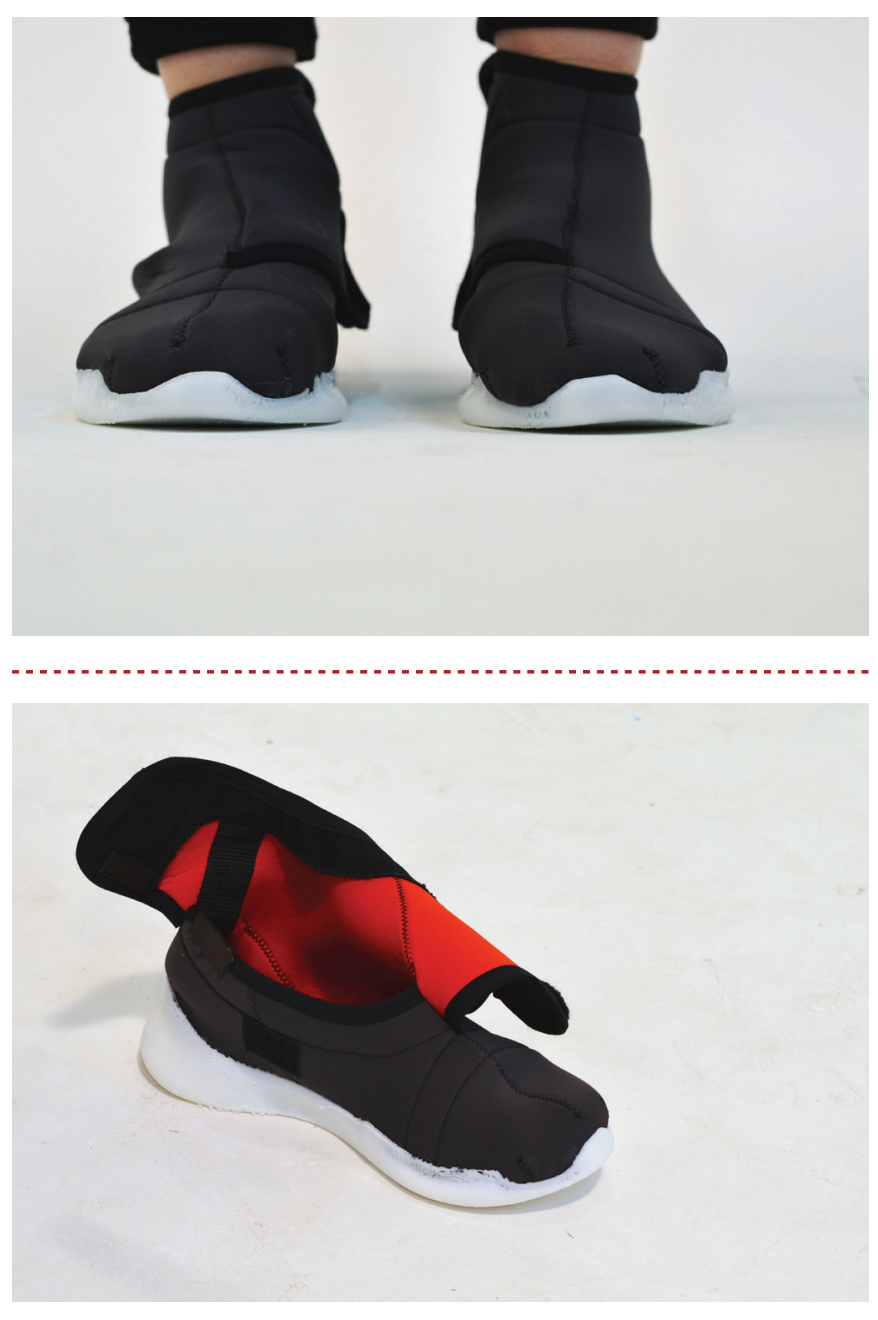

presented prototype. The ability to apply significantly more load than previous iterations indicated that it may be able to provide sufficient load for priming and that any way of replacing resistance bands use in the home would be a beneficial design discovery (clinician 1, personal communication, May 3, 2016). Dr Signal also suggested that the shoe must be intuitive enough for the user to be able to put on without needing written instructions. Patient's affected by a left hemiplegia often have memory issues which could be a barrier to usability. This prompted a refinement of criteria.

\section{Refined Criteria:}

- The shoe's aesthetic should inform usability

- The shoe and weighted sole should be able to be put on without written instruction

- Areas of high contrast should help distinguish between the shoe's inner and outer

- Areas of high contrast should help distinguish key points of interaction

\section{Final Design Assumptions}

The final design was made up of two components: the shoe and the weighted sole. The assumption was that through the weighted sole's ability to facilitate up to $2,500 \mathrm{~g}$ of weight, intensive priming could be achieved. It was also assumed that if the fit of the shoe was comfortable and remained stable on the foot, the user would be able to perform the task-training component intensively.

Top: Figure 5.37 - Prototype 3

Bottom: Figure 5.38 - Demonstrating high contrast inner 

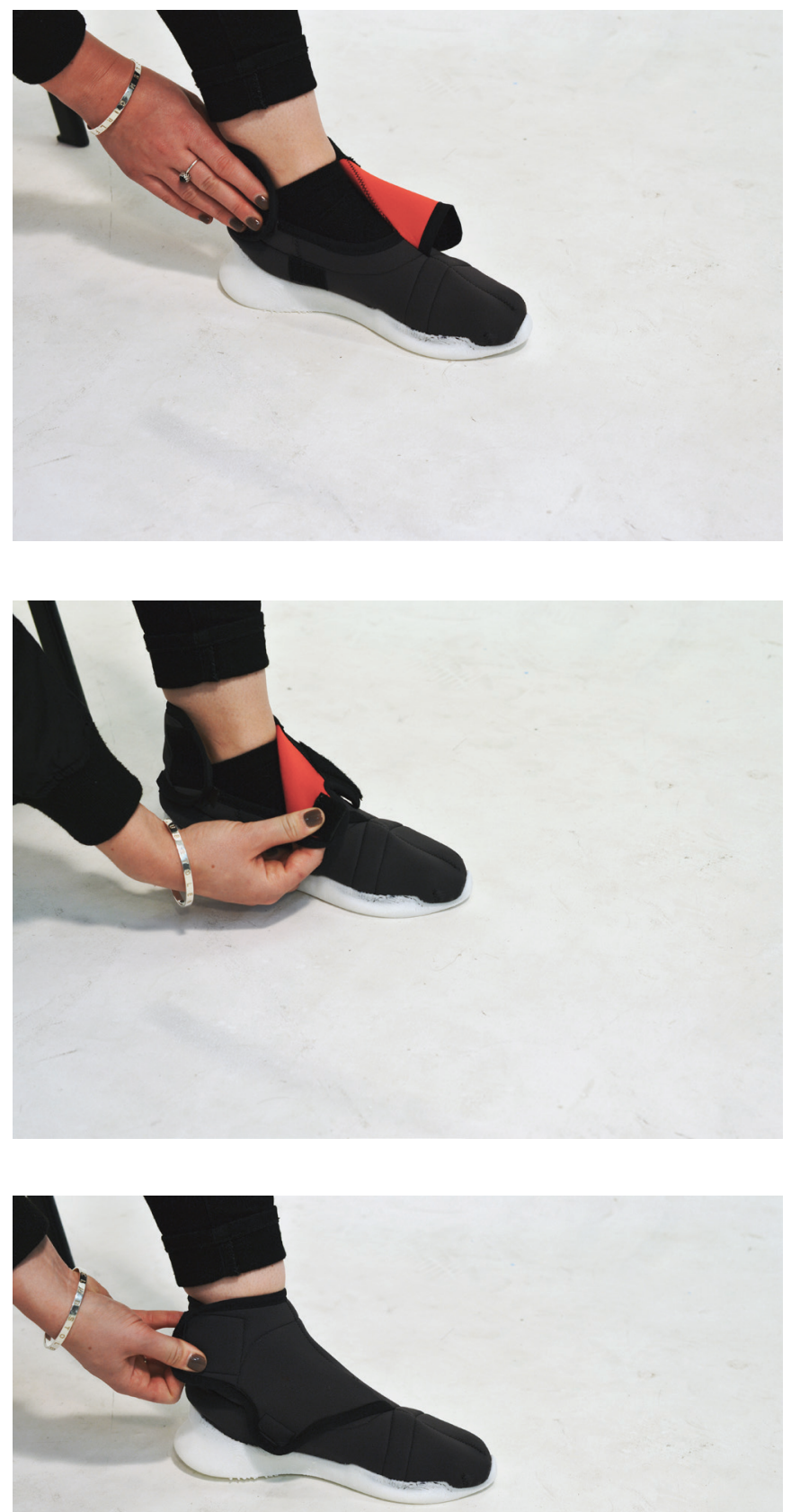

Figure 5.39 - Doing up the upper
It was assumed that the user would have the shoe on the ground and the internal mechanism would hold the sides of the shoe open. This would keep the upper open wide enough for the user to slide their foot inside without collapsing the fabric around it. The pressure of their heel would compress the mechanism and fix the sides of the shoe to the user's foot. The user would then simply fold the top of the shoe over their foot and affix it with velcro using their unaffected hand.

The movement required to put on the weighted sole reflected how the shoe was to be put on. It was assumed that the most relatable movement was to slide the front of the shoe into the toe brace then stand up to clip the heel in. The weighted sole could then be removed similar to how someone would naturally remove their shoes without their hands. This process would involve using the unaffected foot to apply pressure to the heel of the weighted sole and unclip their affected foot at the heel. The user would then simply slide their toes out of the toe braces to remove the weighted sole completely. This process would need to take place in a short amount of time to minimise time between priming and task training.

The outer of the shoe was contrasted with red to provide a distinct difference between when the upper is open or closed. The overall aesthetic was considered to reflect the form of a contemporary sneaker or boot. It was assumed that this familiar form would disrupt any stigmas of using a medical device and elicit feelings of pride, encourage the user

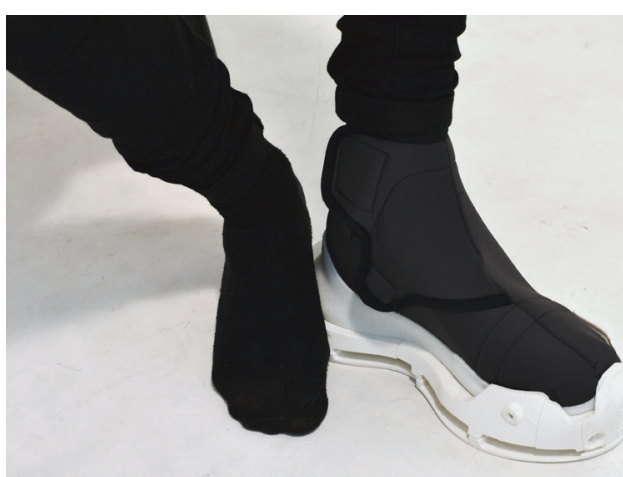

Figure 5.40 - Removing weighted sole
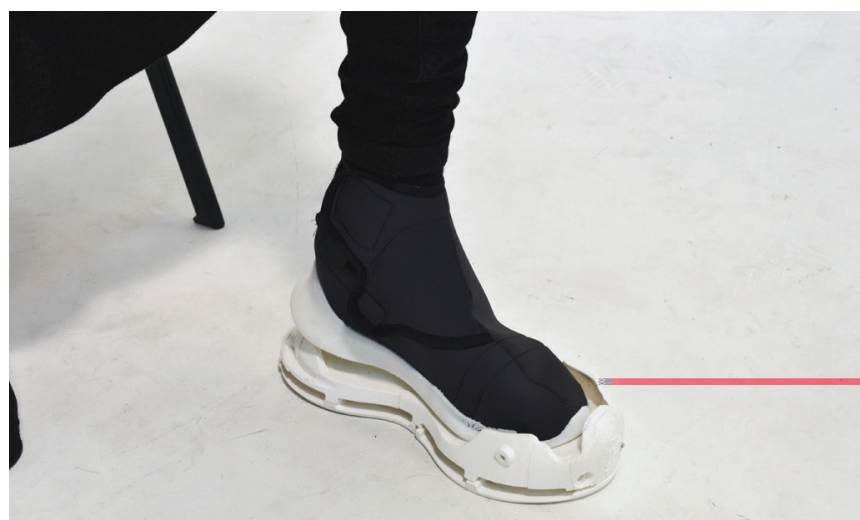
to wear and subsequently use the device frequently. A further intention of the aesthetic was to help remove any feelings of the device being complicated, encouraging the user that this piece of technology would be easy to use.

This prototype was then submitted to testing where these assumptions could be tested. Feedback from the users who had themselves suffered strokes was key to validating or discrediting these assumptions. The design was then iterated further with feedback from its key demographic, presenting new design discoveries and limitations.

\section{Function:}

- The design should provide sufficient load for intensive hip abduction and extension during the priming component

- The design should enable the user to perform part and whole tasks to maintain intensity during the task training component

\section{Ergonomics \& Usability:}

- The shoe should be able to be put on and taken off using one hand

- The design should allow for load to be removed quickly and easily to facilitate priming

- The design should allow for load to be added/removed handsfree

- The shoe and weighted sole should be able to be put on and taken off without written instruction

- The design should be easy to setup and use, reducing the number of steps required for interaction

- The design should use materials that consider the movement of the stroke patient

- The design should be comfortable

- The design should be usable for patients at different stages of recovery

\section{Aesthetics:}

- Areas of high contrast should help distinguish between the shoe's inner and outer

- Areas of high contrast should help distinguish key points of interaction

- The designs aesthetic should reflect contemporary footwear

- The user should not feel embarrassed wearing and using the design 



\section{TESTING \& \\ ASSESSMENT}

Testing of the exergame system involved the smart shoe and weighted sole as well as Brebner's gaming media. Three tests of the system were completed at two-week intervals with the findings influencing iterations to the design between each session. As explained by clinician 3 (personal communication, August 10, 2015) three months of supervised training is required to make any noticeable difference in the user's locomotion. User testing of the design pursued feedback on the usability of the design and the design's aesthetic.

Wellington stroke clubs (Northern Suburbs and Kapiti Coast) were contacted and the project was presented to gain interest from potential participants. Brief phone calls were made to establish if the potential participant could meet our inclusion/exclusion criteria. A follow-up interview over the phone was then conducted to build user profiles to inform our selection.

(For interview questions, see Appendix Document C1)

\section{Inclusion Criteria:}

- Aged $>18$

- Had experienced a disabling stroke

- Has or has experienced hemiplegia or hemiparesis following their stroke

- Can walk without standby assistance

\section{Exclusion Criteria:}

- Significant cognitive deficit

- Unable to follow a 1-step verbal command
- Unable to give informed consent

- Medically unsuitable in the opinion of the screening physiotherapist, GP or medical specialist

- Experiences excessive joint pain

- Suffering other conditions that could impact results (eg. substance abuse, significant mental illness such as major depression)

User profiles gave us insight into the participants' experiences with stroke as well as ensuring we recruited a user base of different physiological and cognitive abilities. The system was designed with the intention of being used for home-based rehabilitation. It was therefore important that participants could interact with the system safely and without clinical supervision. Finally due to the feedback we required, user profiles also ensured we selected participants that could communicate their opinions on the system.

Three participants were recruited for user testing of the exergame system. Participants were given aliases for anonymity.

\section{User Profiles}

'Ned' had the most limited motor control of our three participants. Ned had multiple sclerosis, a premorbidity that worsened the effects of his stroke. Following his stroke, Ned suffered left hemiplegia, paralysing the left side of his body completely. During his early stages of rehabilitation he was confined to his bed but recovered some of his prior mobility over time. Ned has little to no use of 
his left arm due to contractures and no fine motor control over his left leg. He can walk independently, however shuffles at a slow walking speed. Ned lives with his partner who is able to offer assistance when needed.

Eve's cerebellar stroke affected the right side of her body and initially confined her mobility to a wheelchair. Her determination to regain independence resulted in her regaining the ability to walk unassisted. Her balance does still remain affected and she will occasionally require a walking stick. Eve lives independently and maintains an active lifestyle when possible.

'Nancy' has survived two strokes in the past decade. However, she was the most mobile and able of our three participants. She had right hemiparesis and lives independently, even regaining her ability to drive. Nancy still has minor issues with her balance, however has the longest stride length and fastest walking speed of our participants. Her shortterm memory is still affected following her stroke. This has affected her relationship with technology as she often forgets how to use it.

Three final prototypes were created, each individual to the participant's shoe size. These were then submitted to the first set of user testing. This would help assess the usability of the design and how it's aesthetic would be received.

\section{Testing Protocol}

With consent from participants, testing took place in their homes. User testing took 2530 minutes and involved usability testing followed by a short semi-structured interview.

User testing involved the user putting on the smart shoe and beginning to play one round of the Brebner's Dominoes game on the iPad. The game then prompted them to put on, use and remove the weighted sole for the priming component. Following this the participant would perform various repetitions of the STT's task-based component to complete the round. The participant would then remove the smart shoe to complete the usability test. Ethics restricted the user testing timeframe to 30 minutes. This only allowed for one round of the game to be played. As only one set of priming and task-based components were used per round, the testing was limited to observation of hip abduction and sideways walking. Participants were required to complete 15 leg raises (Hip Abduction) for the priming component then 5 side steps for each task component. Users were prompted to complete each task component every time they wished to play a domino from their virtual hand. The number of side steps the player would complete was dictated by how many dominoes they played. This resulted in the player completing between 20 to 30

\section{Below: Figure 6.1 - Nancy putting on the shoe}

Directly below: Figure 6.2 - Screenshot from '12 - 12' prompting the user to put on thier weighted sole for the priming component
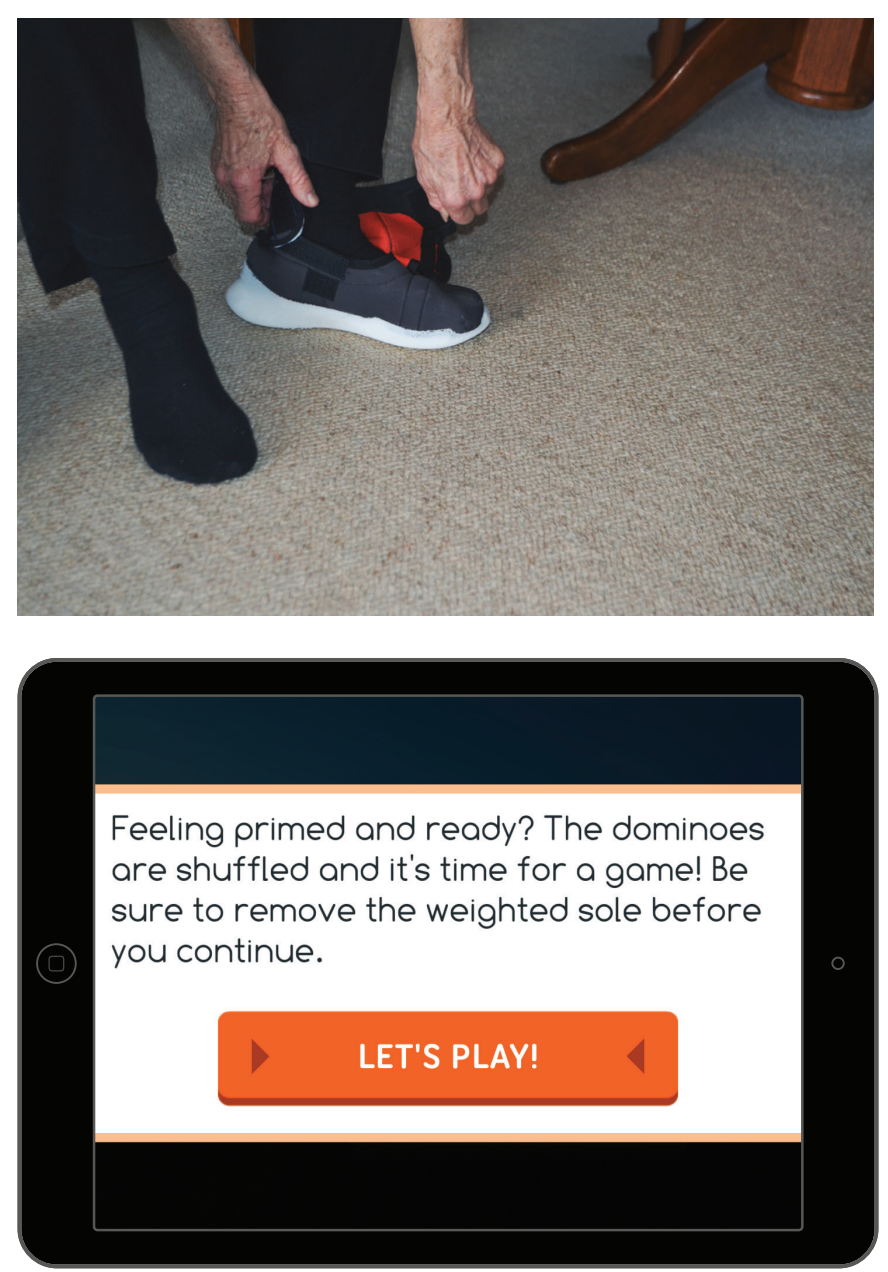
repetitions of the task-based component. The pace of each game was dictated by the player so each round would take anywhere between 15-30 minutes. The think aloud protocol was used to assist our observation in order to fill usability heuristics. When a participant became confused or stuck for longer than 30 seconds we provided prompts and/or assistance. Handwritten notes were taken alongside a non-identifying video for review purposes.

At the stage of testing, interpretation of the IMU's tracking data did not provide consistent enough results to accurately represent the player's motions. This was addressed during user testing through the implementation of the "Oz Paradigm" (Kelley, 1984). The Oz Paradigm allows the researcher to act as the connection between the participant and the technology. This gives participants the illusion of interacting with a fully functional exergame system, granting authentic feedback. To facilitate this connection a wireless application was created on a smartphone. When the participant completed a motion the gaming media required of them, the researcher could use the app to send a signal to the iPad.

This signal confirmed the user had correctly performed the movement, thus emulating the sensor's functionality.

Duration and number of movements for each interaction was recorded. This allowed a comparison between each iteration. More importantly, it gave an indication of how much time was taken between the priming and task components. Reducing this timeframe was one of the main focuses of increasing usability to facilitate the beneficial effects of priming.

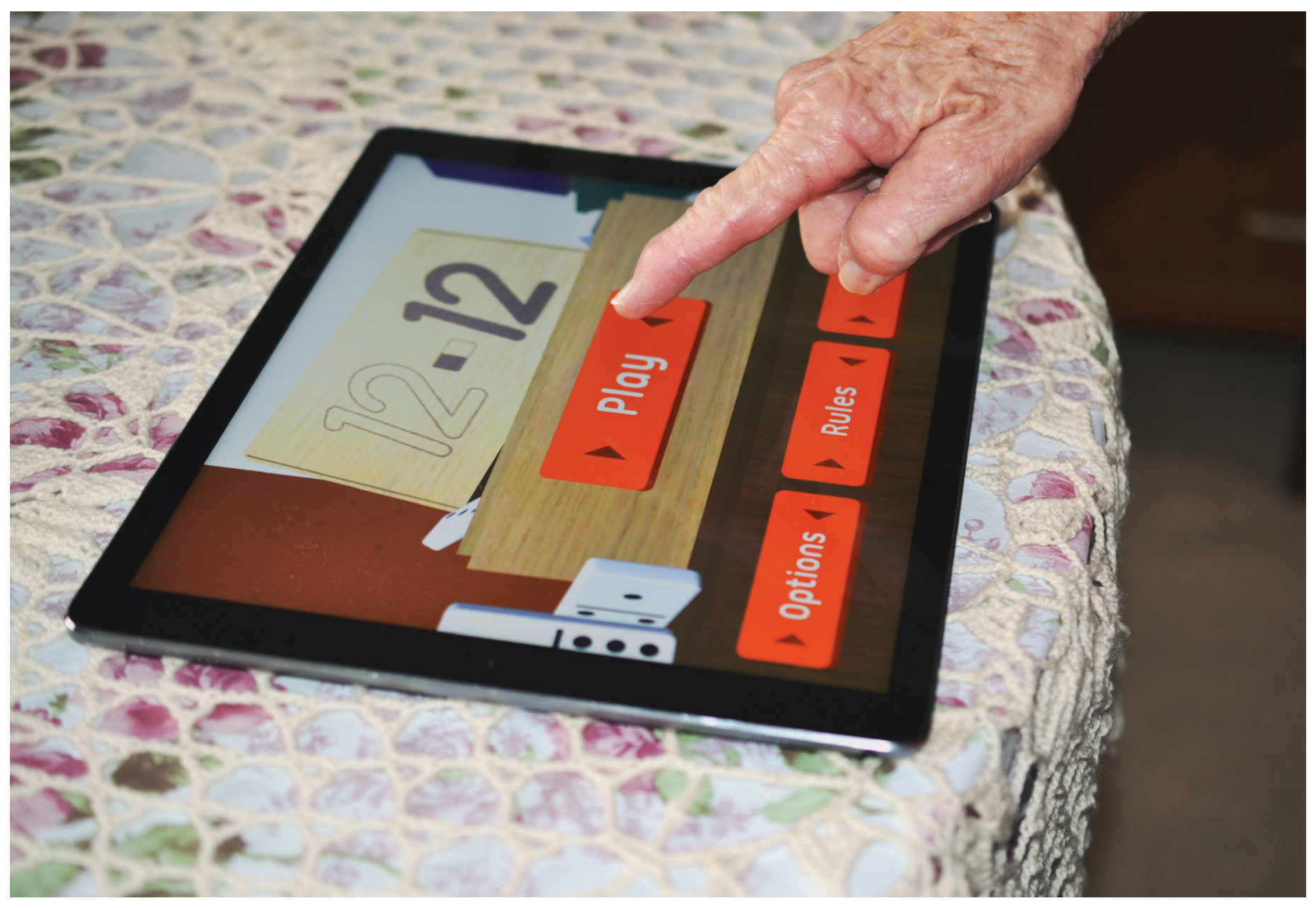


Usability heuristics were created based on the relevant criteria that informed the ergonomic and usability requirements of the design.

Ergonomic \& Usability Requirements:

- The shoe should be able to be put on/taken off using one hand

- The design should allow for the load to be removed quickly and easily to facilitate priming

- The design should allow for load to be added/removed hands free

- The shoe and weighted sole should be able to be put on/taken off without written instruction

- The design should be easy to set up and use, reducing the number of steps required for interaction

- The design should use materials that consider the movement of the stroke patient

- The design should be comfortable

- The design should be usable by patients at different stages of recovery

\section{Usability Heuristics:}

1. Does the user seem confused by any interaction with the design?

2. Are they using one hand?

3. Are they struggling at any point?

4. How long did it take them to put on/take off?

5. How many movements did it require?

6. Did the shoe change shape or not fit correctly?

7. Did they use their hands to remove the modular weights?

8. Did they lose balance or seem unsafe at any point?

9. Were they uncomfortable at any point?

Brief open-ended interviews were conducted with participants following each usability test. Guided by simple questions to avoid primed responses, the interview allowed the participants to expand on any thoughts they had during testing (see Appendix Document c2). This also presented the opportunity for the participant to comment on the design's aesthetic. During the final user test, participants were also invited to fill out two "Geneva Emotion Wheels"(see Appendix Document c4). These allow participants to self-report on their emotional experience (Scherer, 2005) with the smart shoe and weighted sole. The participants were then asked to elaborate on the selected emotions to gain feedback on the design's aesthetics. Audio was recorded to avoid participants becoming camera shy ensuring they could communicate cohesively and in detail.

(For expanded interview notes, see Appendix C) 


\section{User Testing Session: 1}

User testing took place at the participants' homes according to the protocol outlined above. Adequate space was cleared and the iPad was placed on a table or surface of similar height. A chair was kept within arm's reach of the participant and did not obstruct their exercise movements. The amount of weight initially added to each of the participants' weighted soles was $500 \mathrm{~g}$. This was the minimum weight of the device with no steel plates attached. Load is usually prescribed and modified by the clinician (clinician 1, personal communication, May $3,2016)$ to ensure priming is intensive. As the exergaming system was not intended to facilitate clinical reasoning, we had no way to accurately assess how much load each participant required. Usability testing did not require feedback about how intensive each participant found it. However, applying load to the foot could change the way the user interacts with the design. Load was then increased or reduced depending on feedback from the participant.

\section{Feedback}

Several interaction assumptions were quickly invalidated during the first usability session. It was assumed that the participant would place the shoe on the ground, then slide their foot into the shoe. This was accurate in Nancy's case, however both Ned and Eve brought their affected foot up towards their midline to put the shoe on (figure $6.5 ; 6.6$ ). Both Eve and Ned commented that their balance would become compromised if they bent over for more than a brief moment. This rendered the internal self-closing mechanism useless as it required the body's downward force to engage it.

The length of the ankle straps proved to be an issue with how the fit of the shoe adapted from person to person. Although each shoe was designed to the shoe size of each participant, the length of the ankle straps did not account for different ankle
Top: Figure 6.5 - Ankle fit issues with Eve's shoe

Middle: Figure 6.5 - Ned bringing the shoe up towards his midline

Bottom: Figure 6.6 - Eve bringing the shoe up towards her midline
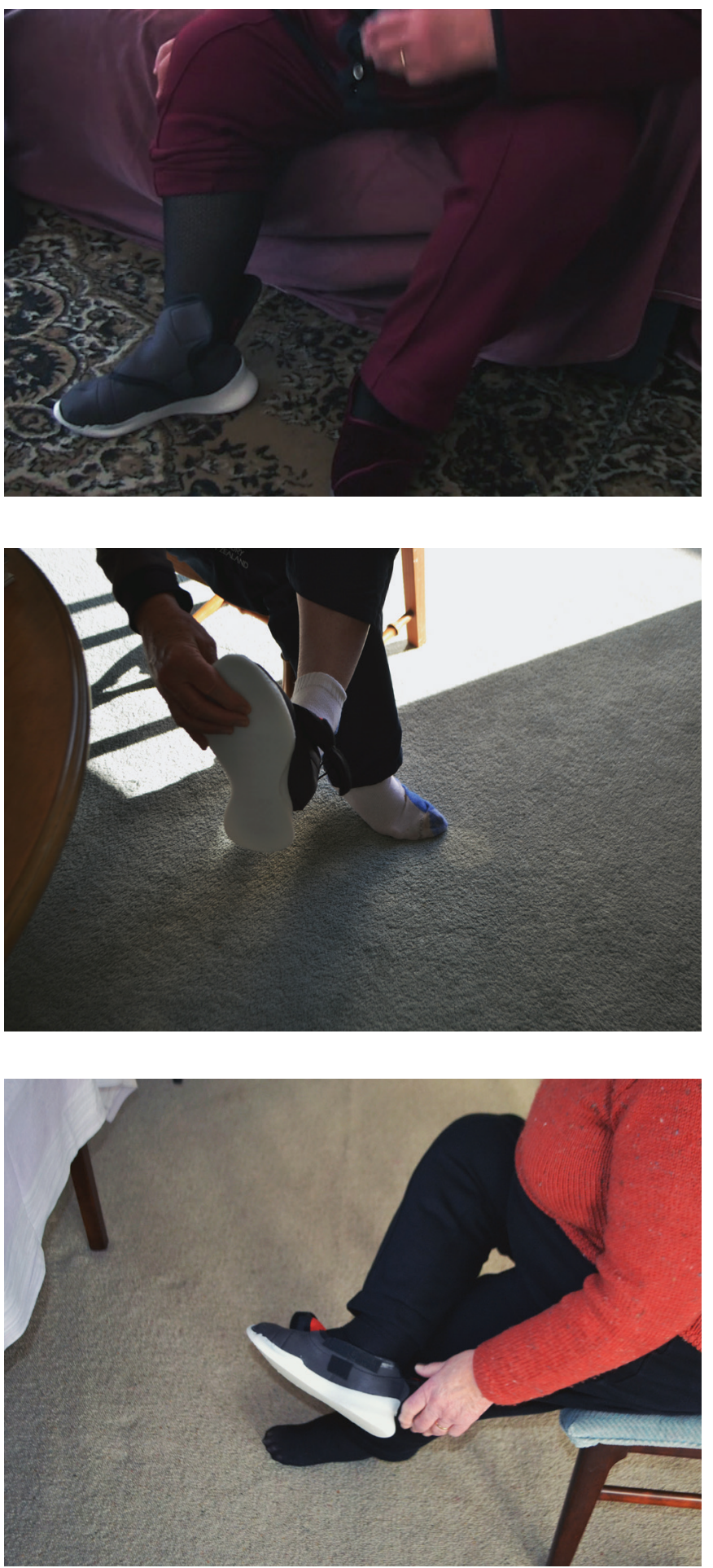
sizes. This resulted in fit issues as the velcro did not adhere properly. In Eve's case, the ankle straps would not do up at all (figure 6.5). It was later identified by clinicians during the video review of the third test that Eve has peripheral oedema, resulting in swelling of her ankles and feet (clinician 1, personal communication, July 27, 2016). Further fit issues were presented as the heel collapsed when all three participants put the shoes on. This was in part caused by velcro adhering to the user's socks and the heel counter not being robust enough. The magnets used with the intent of keeping one strap in place while the other strap is pulled over also had adherence issues. All three participants became confused with the purpose of the rear ankle strap, this required us to step in to show them how it worked. Negotiating these problems resulted in Nancy and Eve needing to use two hands to put on the shoe.

Assumptions on the most intuitive way to put on the modular sole also proved incorrect. It was assumed the users would want to slide their toes into the front then clip their heel into the back. This was Eve's first intuition however both Nancy and Ned attempted

Below: Figure 6.7 - Eve getting assistance with putting on the weighted sole to put their heels into the device first, then clip their toes in with downward force. Once prompted Nancy was able to slide her toes into the weighted sole, however Ned did not have enough fine motor control to perform that task. All participants required help with putting on the weighted sole as they could not generate enough downward force to clip their heels in (figure 6.7). None of the participants were able to independently remove the weighted sole and required our assistance once again. Due to the limited adherence of the velcro, the upper of Eve's shoe came loose in attempting to remove the weighted sole. Both Ned and Nancy were able to remove their shoes easily. Ned brought his foot up towards his midline whilst Nancy reached down. Eve had further issues with velcro adhering to her feet during removal and requiring us to give assistance.

No pain or major discomfort was reported from any of the users during the first session. Ned found some back pain was associated with bending over to interact with the iPad however this was easily corrected by stacking three books underneath. Both Nancy and Ned found the shoe secure during both the priming and task component however with the fit issues associated with Eve's shoe, the upper began to come loose when the load

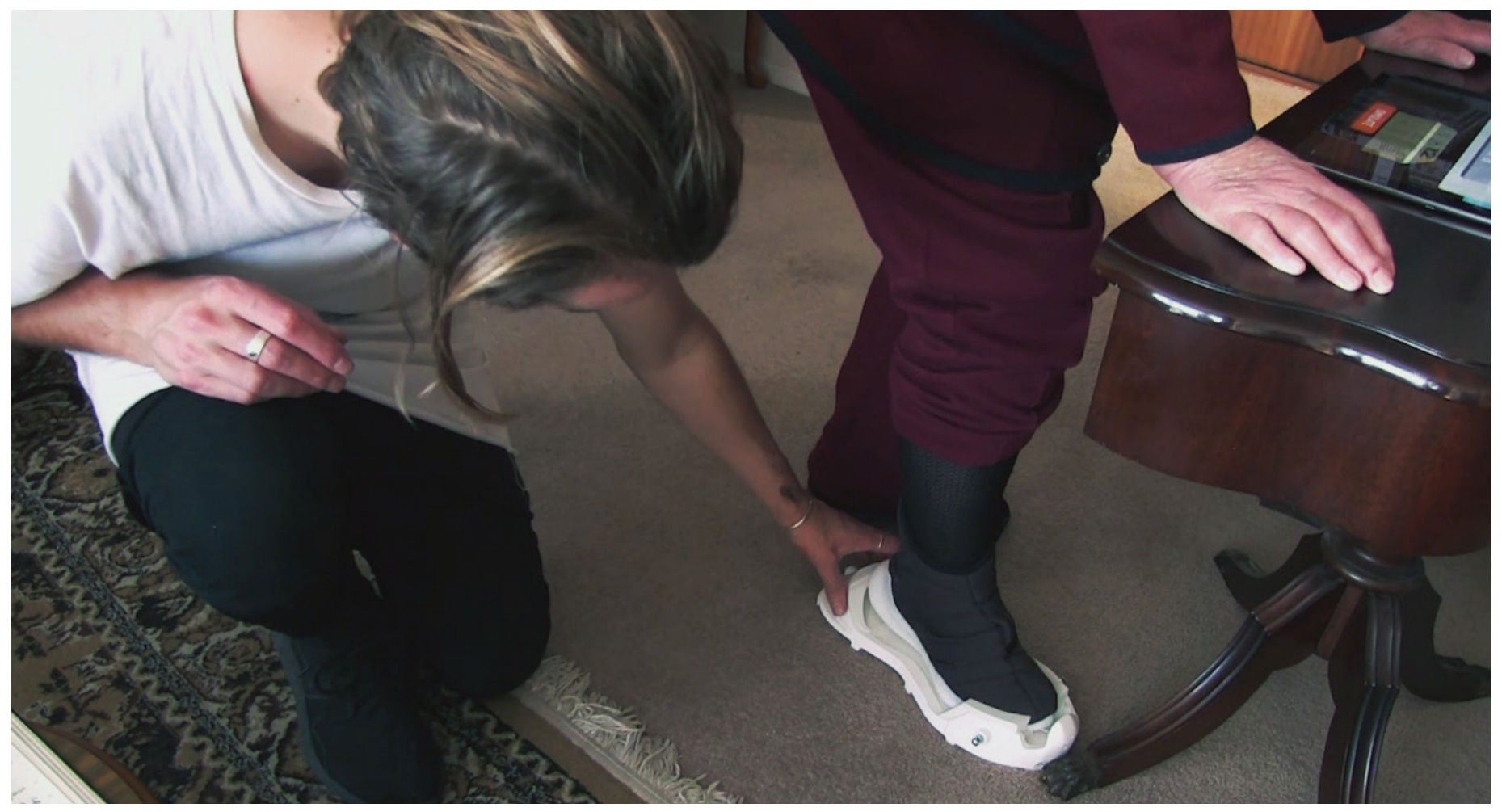


was applied.

Issues with participants' balance became apparent during the priming phase.

When lifting the leg with load attached all participants became unstable. This was corrected during the session by encouraging participants to place both hands on the table in front of them for stability. Nancy also reported feeling unstable during the task component due to the fact that she was only wearing a shoe on the affected foot. Participants were then presented with a pair of shoes each for the following session.

Early feedback on the look of the device provided some insight into how the initial form was received. Eve mentioned she would be happy to wear the shoe in public and Nancy provided similar remarks stating that to her "it's fashionable. Nowadays everyone wants to wear boots and I have one on". 


\section{Changes to the Design}

\section{Shoe}

The internal self-closing mechanism was removed and the ankle straps were lengthened for a more adaptable fit. A heel tab was added to the heel to help with picking up the shoe and to help stop the heel collapsing when put on. The heel counter was swapped for a more robust substitute and the magnets were replaced for velcro dots. The placement of the velcro was reconsidered to avoid adherence to the participants' socks.

\section{Weighted sole}

The toe and heel clips were redesigned to sit on spring-loaded rails. This would allow the user to either slide or clip their heels and toes into the weighted sole. Allowing a certain amount of movement of the clips was hypothesised to make the sole easier to take off. The design of the weighted sole was also adapted to fit both the left and right feet and different shoe sizes. This avoided the need to create one weighted sole for each participant.

Areas of Renforced Rigid Fabric

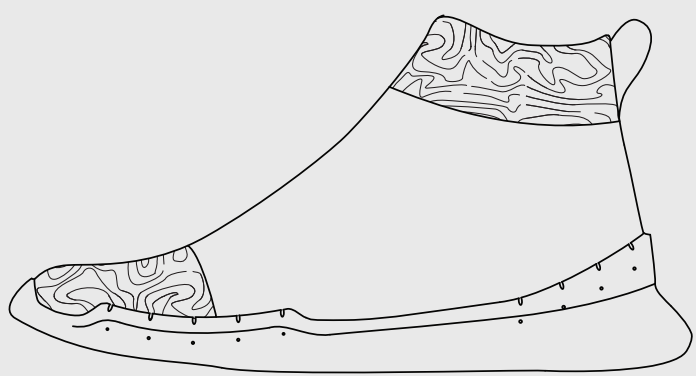

Figure 6.8 - Prototype 4 specifics
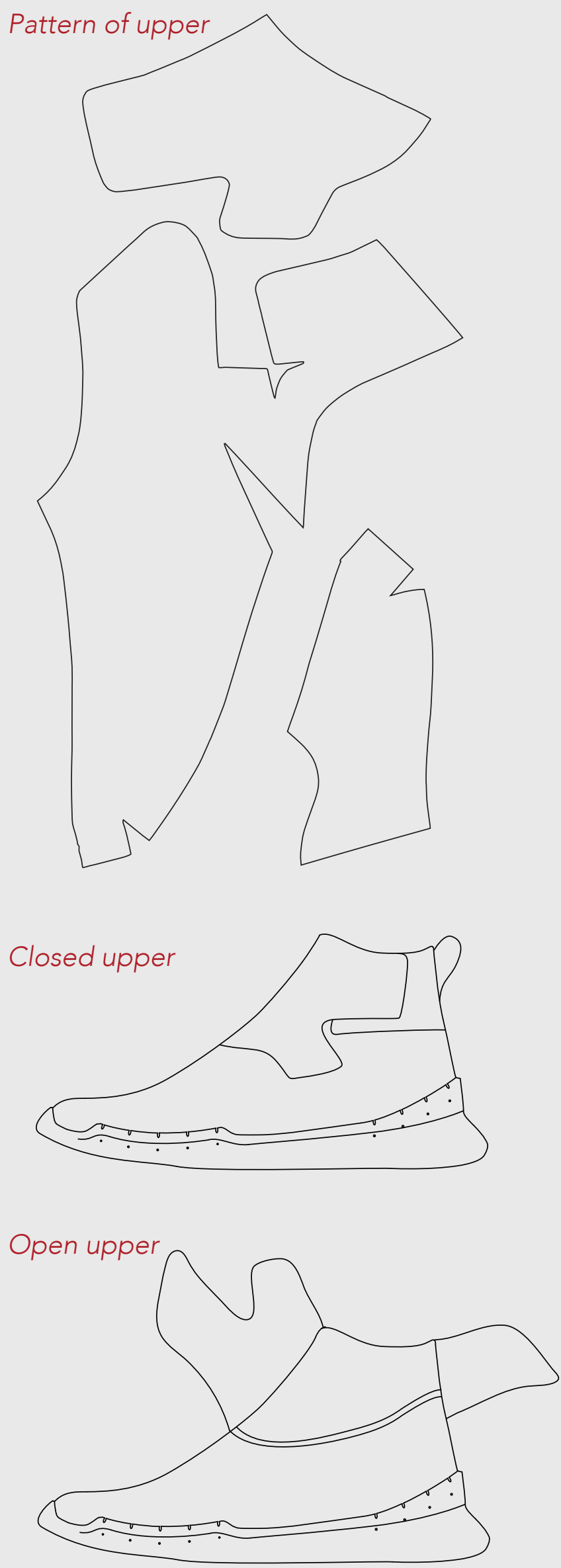


\section{Prototype 4}

Last \& Upper Curves

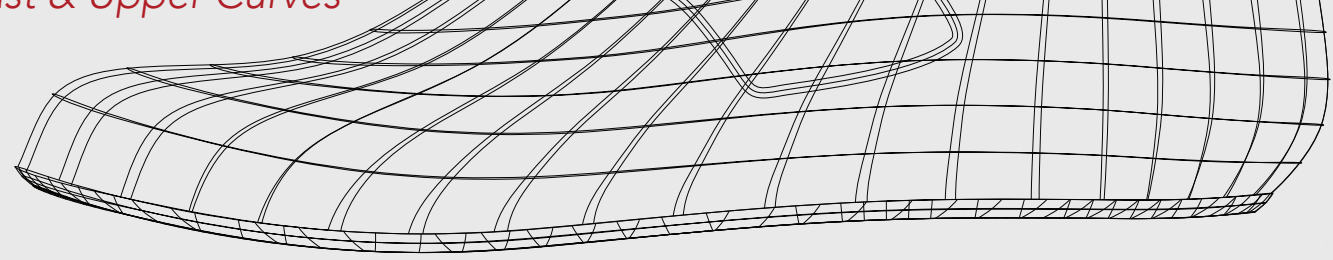

Mid Sole Wireframe

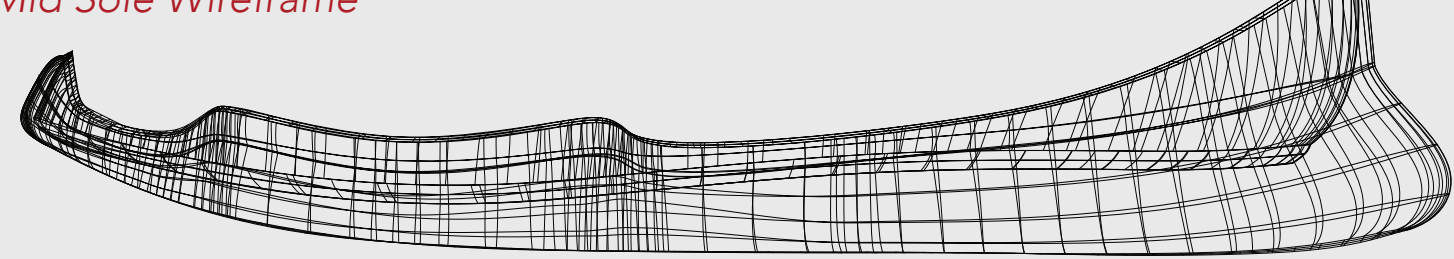

Weighted Sole Wireframe

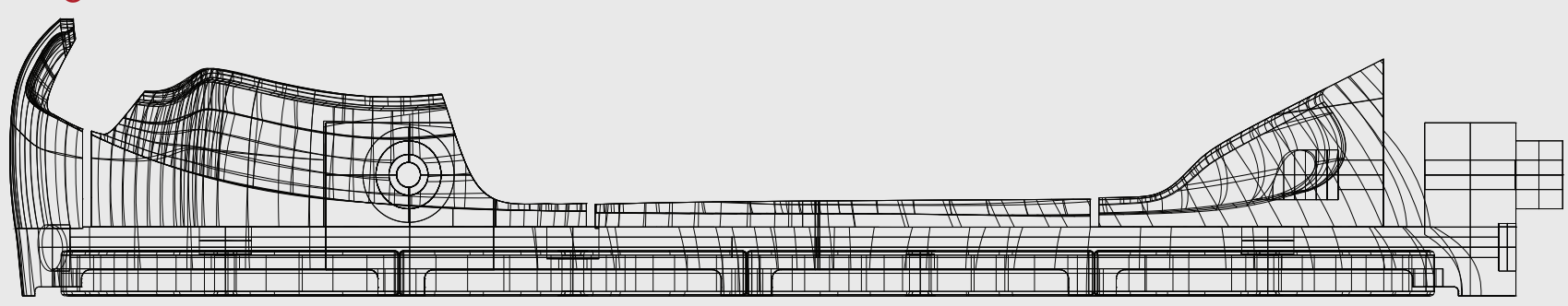

Interchangable Steel Weights

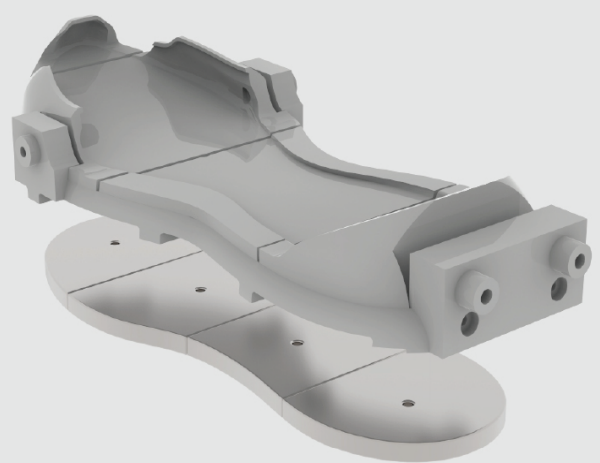

Modular Sole with Spring Loaded Clips 


\section{User Testing Session: 2}

The second session took place according to the same conditions as the previous. Before the test the iPad was elevated to a height that would minimise the user bending over during interaction. Users were also given a pair of shoes to address the balance concerns of only wearing one.

\section{Feedback}

Lengthening the ankle strap solved the fit issues Eve had previously experienced. With the addition of a robust counter and heel tab, there was minimal shape change to the upper when the shoe was put on. The heel tab also made the shoe easier to be picked up off the ground as Ned and Eve still preferred to put on the shoe at their midline.

There still remained some confusion as to how to do up the shoe's straps. Rather than bringing the back strap around first, all three participants' intuition was to bring the top strap over, then proceeded to get confused when the back strap wouldn't adhere properly (figure 6.9). Nancy was able to quickly reasses and reorder the interaction to successfully do up the upper, however Eve required prompting and Ned required assistance.

Eve also complained of discomfort around the toes of her affected foot. Due to contractures in her right foot it supinates irregularly off to the right. This was causing her toes to extend over the side of the shoe's sole. When asked to compare to her other foot she reported that the discomfort was unilateral, and that the unaffected foot fit comfortably.

Putting on the weighted sole proved to be significantly easier than the previous session for Eve and Nancy (figure 6.10). Both participants cliped their heels then toes into the weighted sole. Ned managed to align his heel with the weighted sole but could not generate enough force to clip in his toes requiring us to step in and assist. Ned also had problems with the weighted sole sliding as he tried to put it on. All users reported the shoe felt secure on their feet during priming and there was minimal change in the shape of the shoe's upper.

Opposite Page: Figure 6.10 - Eve using the weighted sole

Below: Figure 6.9 - Users' inuitive way of putting on the upper
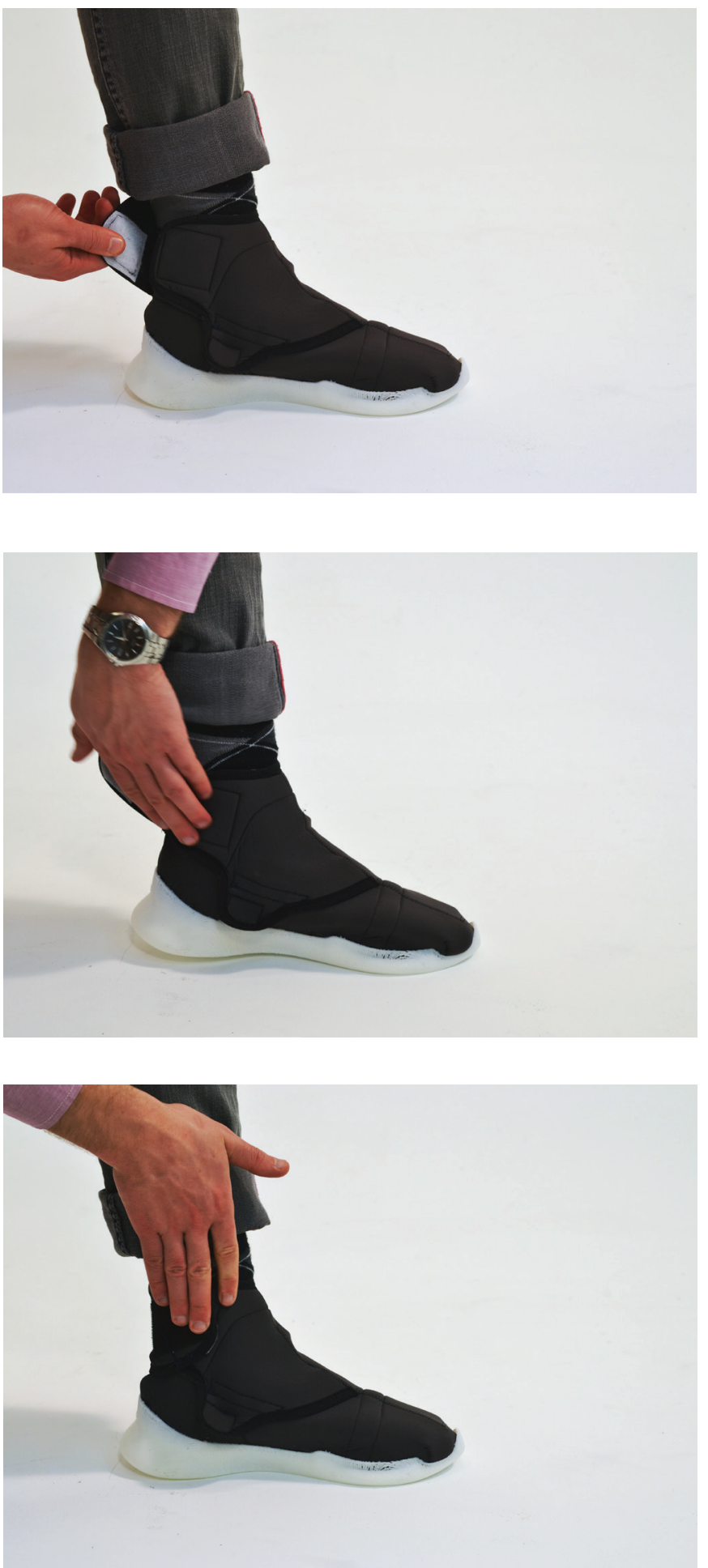
Removal of the weighted sole still provided some difficulty. All participants required prompting on how they should attempt to remove the weighted sole. No participants could generate enough downward force on the heel of the weighted sole to remove it. Both Eve and Ned needed assistance for removal. Nancy was able to persist and find her own method for removal by pulling the heel clip back with her hands and sliding her toes out.
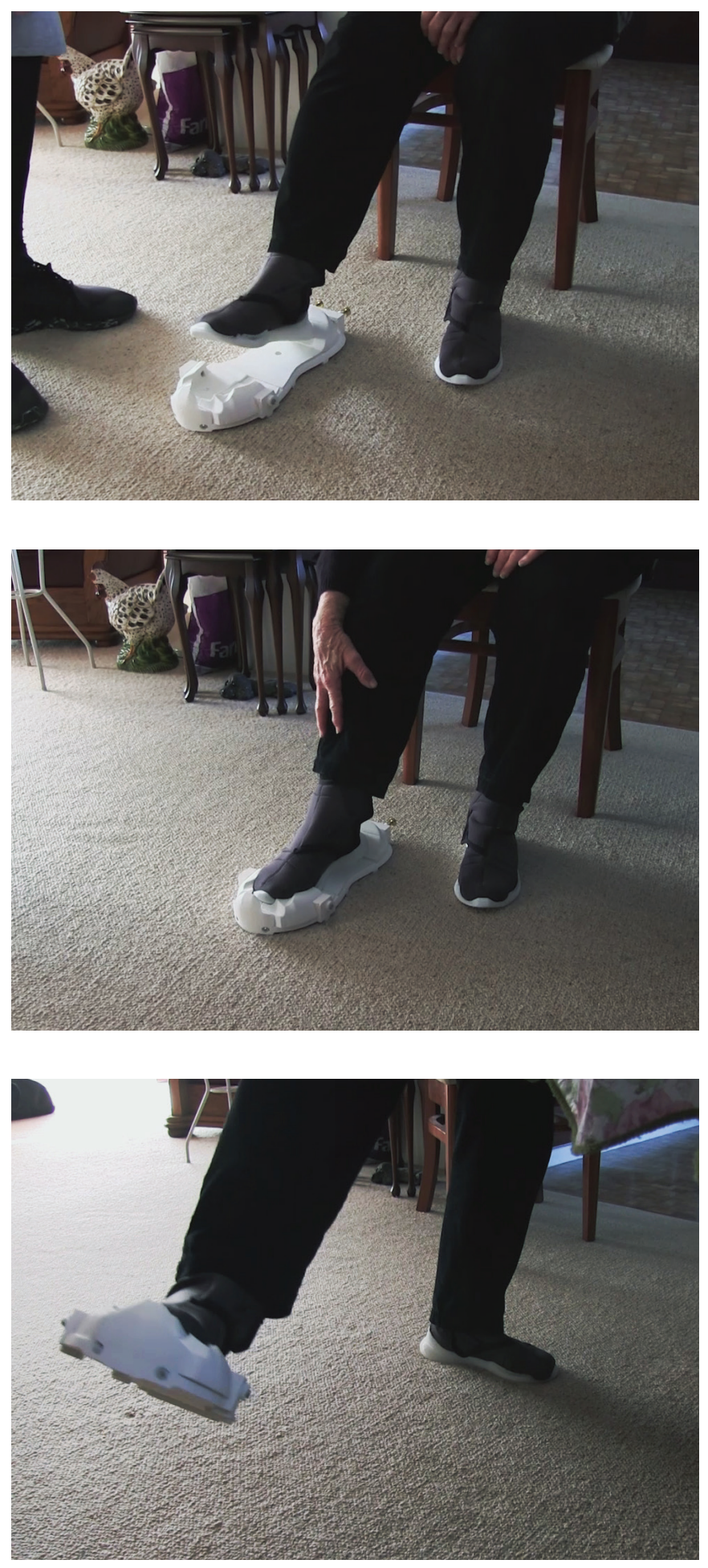

Nancy raised a problem with the material of the shoe. She complained that her feet were cold during the test and this was common with her footwear. She explained that medication prescribed following stroke leads to poor circulation in her feet. To counter this she wears knitted merino "booties" around her home. 


\section{Changes to the Design}

\section{Shoe}

The structure of the straps was changed to help create a more intuitive interaction of how the shoe upper was done up (figure 6.12). The hierarchy of the straps was changed so the user would fold the top strap over their foot then wrap and adhere the ankle strap. The sole of the shoe was altered to consider abnormal foot shapes due to spasticity.

The material of the shoe was changed to a felted wool outer and ultra fine merino wool inner. The intention of this material choice was to ensure users with circulation issues were kept warm. Merino wool also regulates heat keeping the user's feet from overheating. Wool also has antibacterial properties and keeps moisture away from the skin. This helps with perspiration caused during intensive training, minimising odour and the need to clean the upper. A canvas skeleton sewn in between the wool layers stopped the shoe stretching under the weight of the midsole. Canvas was used strategically across the top of the foot and around the ankles to provide stretch in nonstructural areas of the upper.

\section{Areas of Renforced Rigid Fabric}

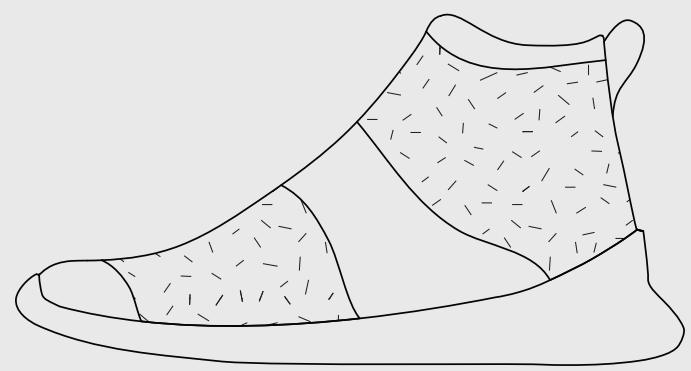

\section{Pattern of Upper}
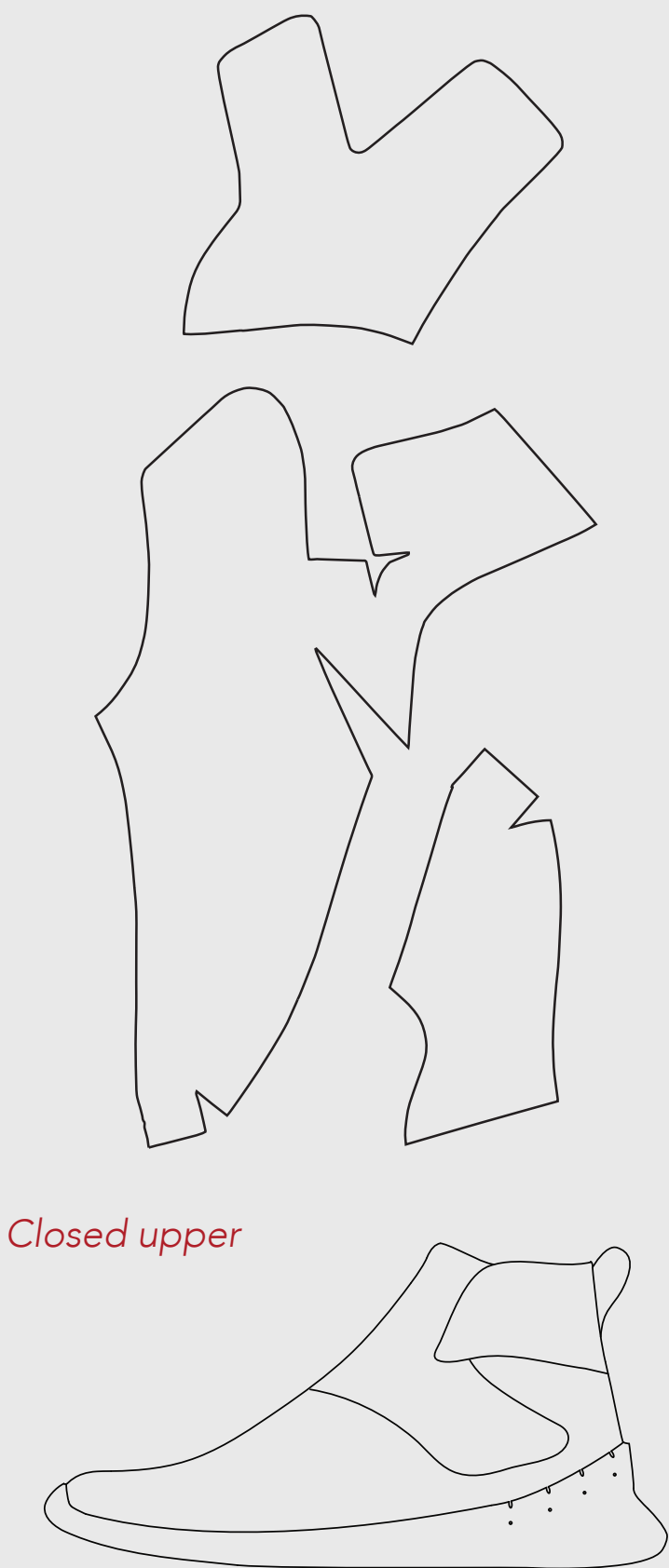

Open upper

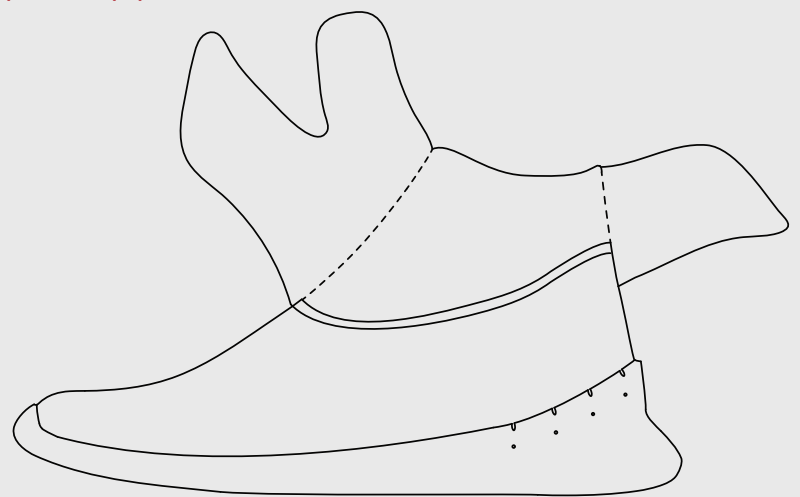

Figure 6.11 - Prototype 5 specifics 


\section{Prototype 5}

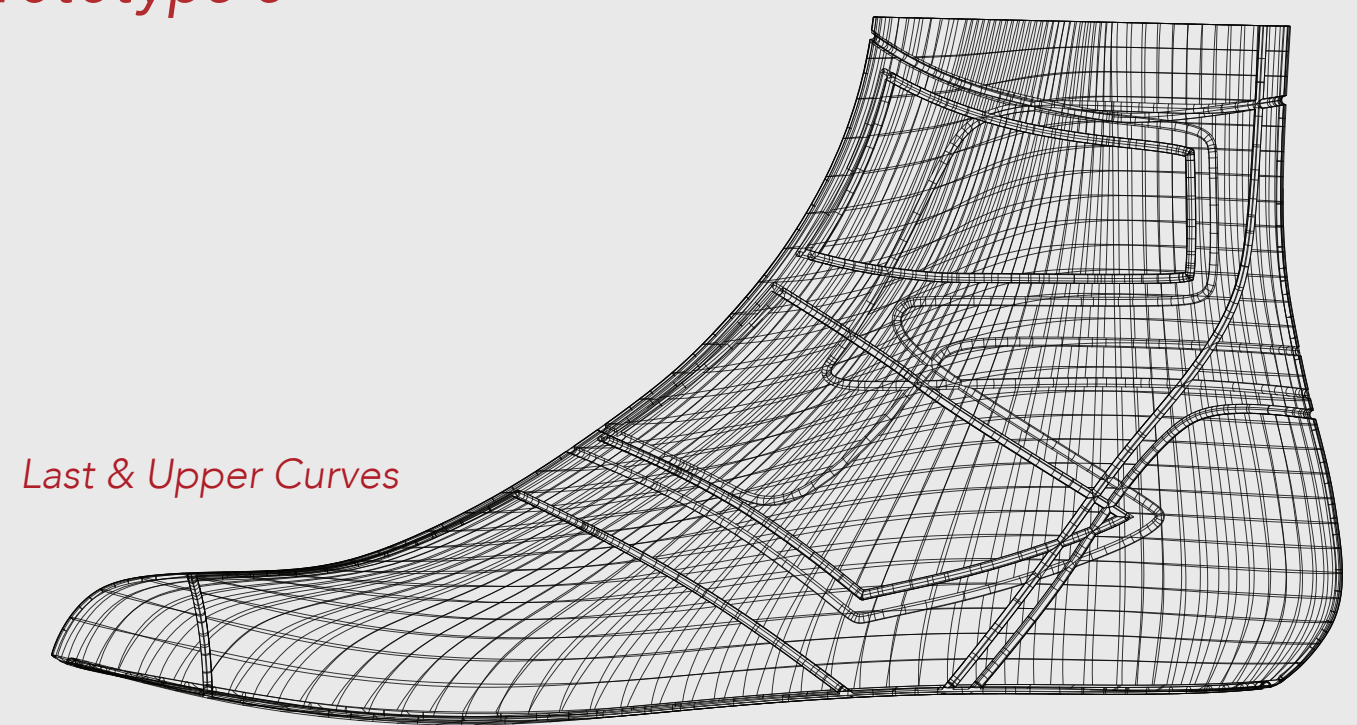

Mid Sole Wireframe

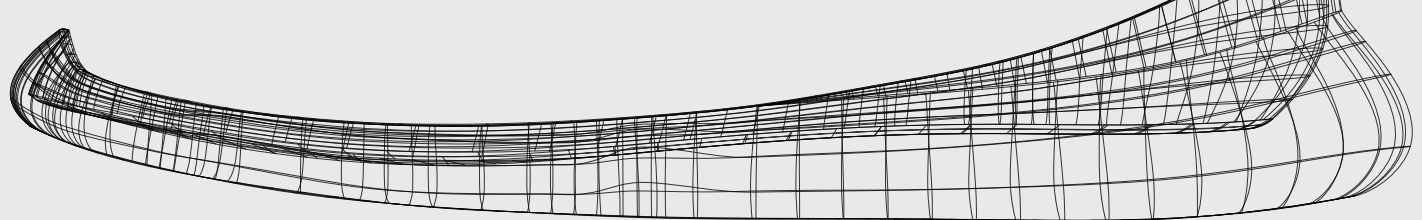

Modular Sole Wireframe

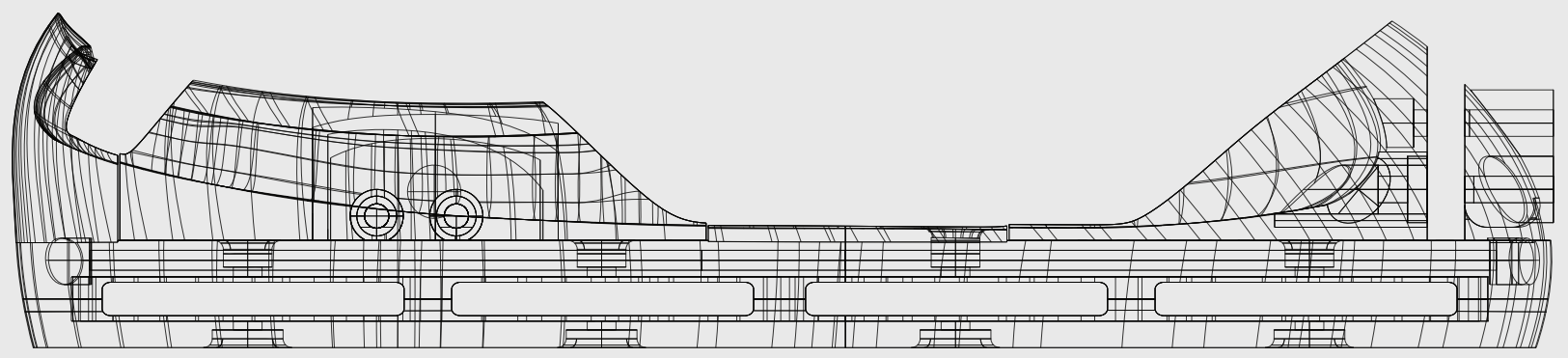

Interchangable Steel Weights

Modular Sole with Heel Pull-Tab
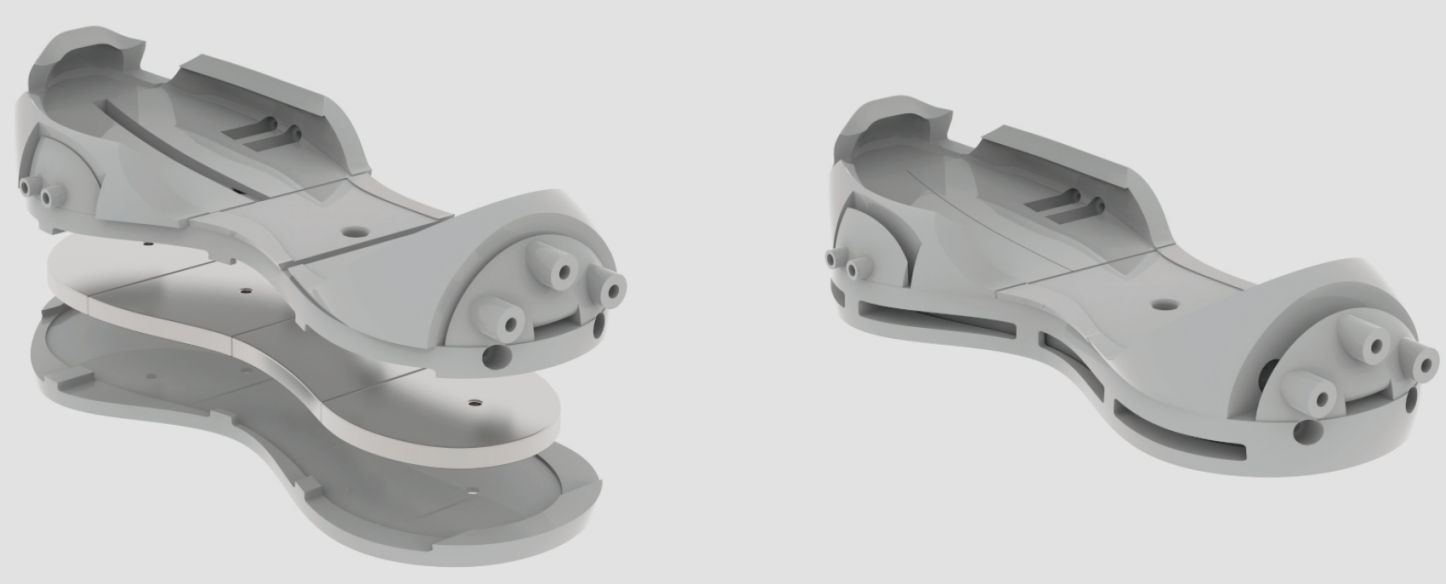
The colour of the upper was created in two colours, grey and black. Areas of interaction were contrasted with white and red to assist with usability. White fabric tabs and red stitching were added to the ends of the straps indicating where the user should grasp and provided more surface area to hold on to. The inner was neon green to contrast the black exterior, with the intention of indicating when the shoe was open or closed. The high contrast inner was also intended to help with the user's depth perception when inserting their foot into the upper. It also gave a visual indication to when the design was put on securely as no green would be visible. If the straps and velcro were not aligned the user would see the green inner contrasted against the black outer.

\section{Weighted Sole}

A fabric tab was added to the back of the weighted sole. This would allow the user to pull the heel clip back and remove their feet if they did not have the motor control or strength to remove it with their unaffected foot (figure 6.13). A TPU grip was also added to the bottom to prevent any movement from the weighted sole when the user was putting it on. The base of the modular sole was also adapted to facilitate a further $2,000 \mathrm{~g}$ of weight. This provided a higher threshold of $4,500 \mathrm{~g}$ (figure 6.17) that could be changed at $500 \mathrm{~g}$ increments.

Opposite page right: Figure 6.13 - Demonstration of taking off the weighted sole

Opposite page left: Figure 6.14 - Demonstration of putting on the weighted sole

Right: Figure 6.12 - Demonstration of new strapping order
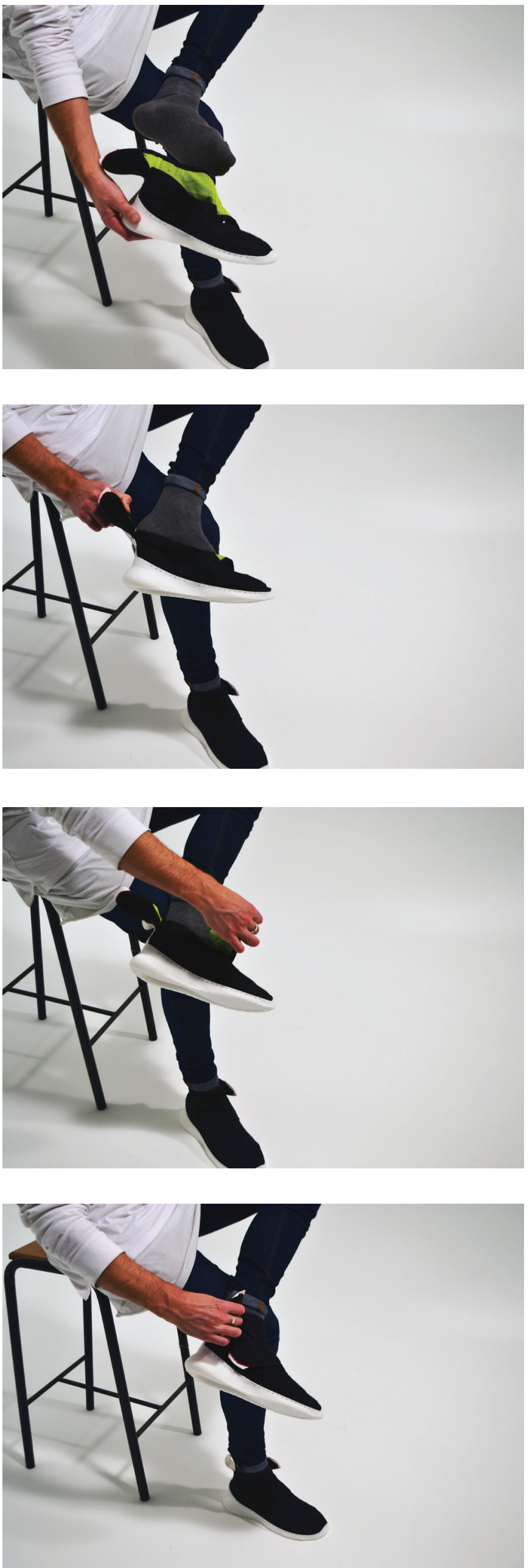

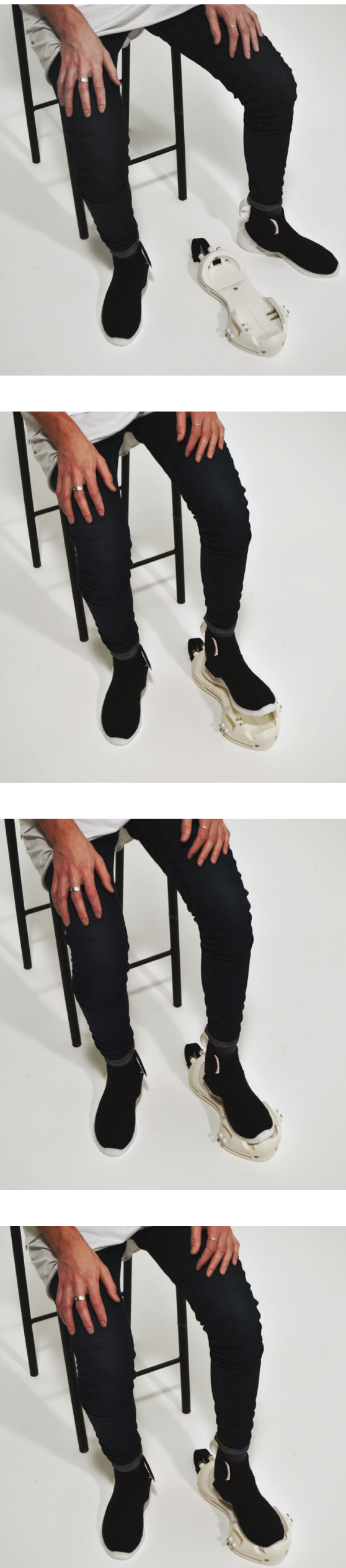
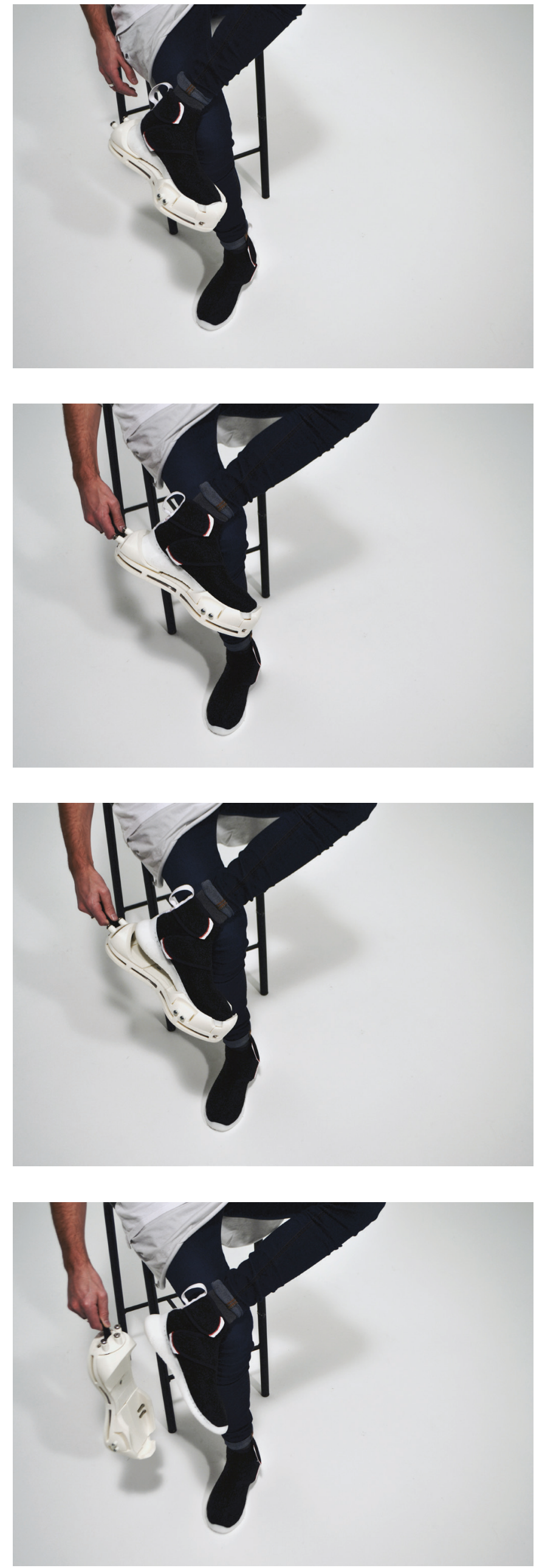

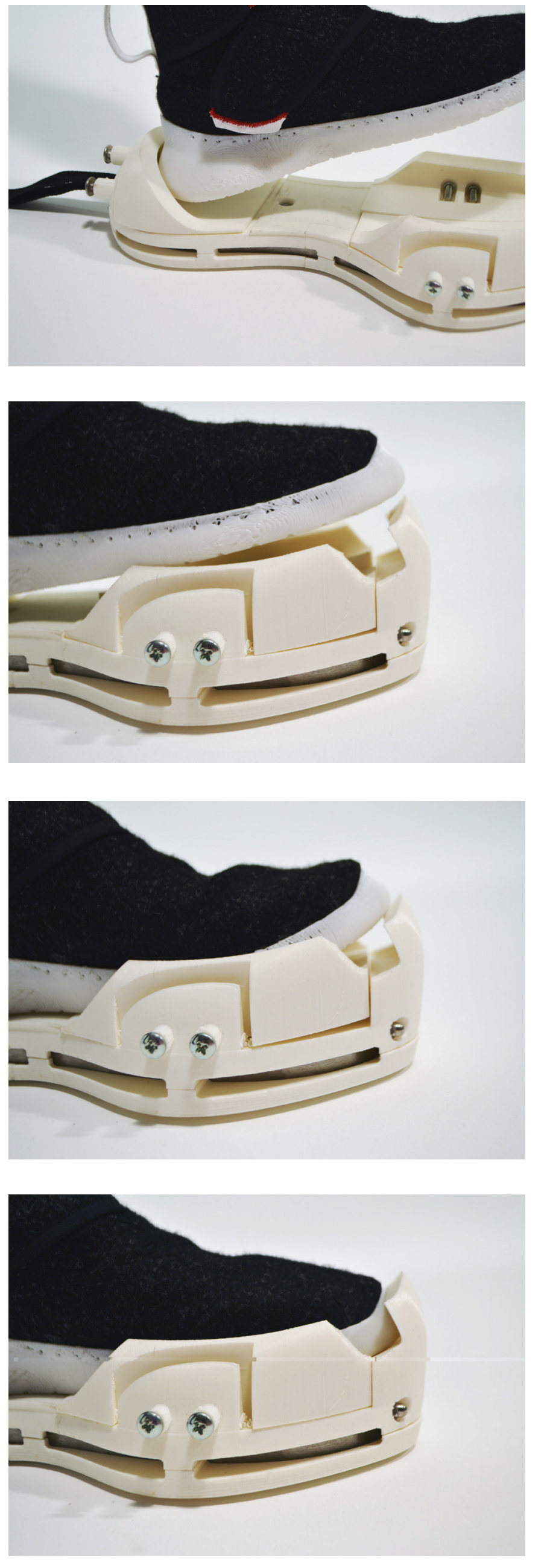

Opposite page top: Figure 6.17 - Weighted sole with 4,500g attached

Opposite page: Figure 6.18 - Hamstrings priming using weighted sole with $4,500 \mathrm{~g}$ of load

Left: Figure 6.15 - Weighted sole being put on

Above: Figure 6.16 - Hip abduction priming using weighted sole with $2,250 \mathrm{~g}$ of load 

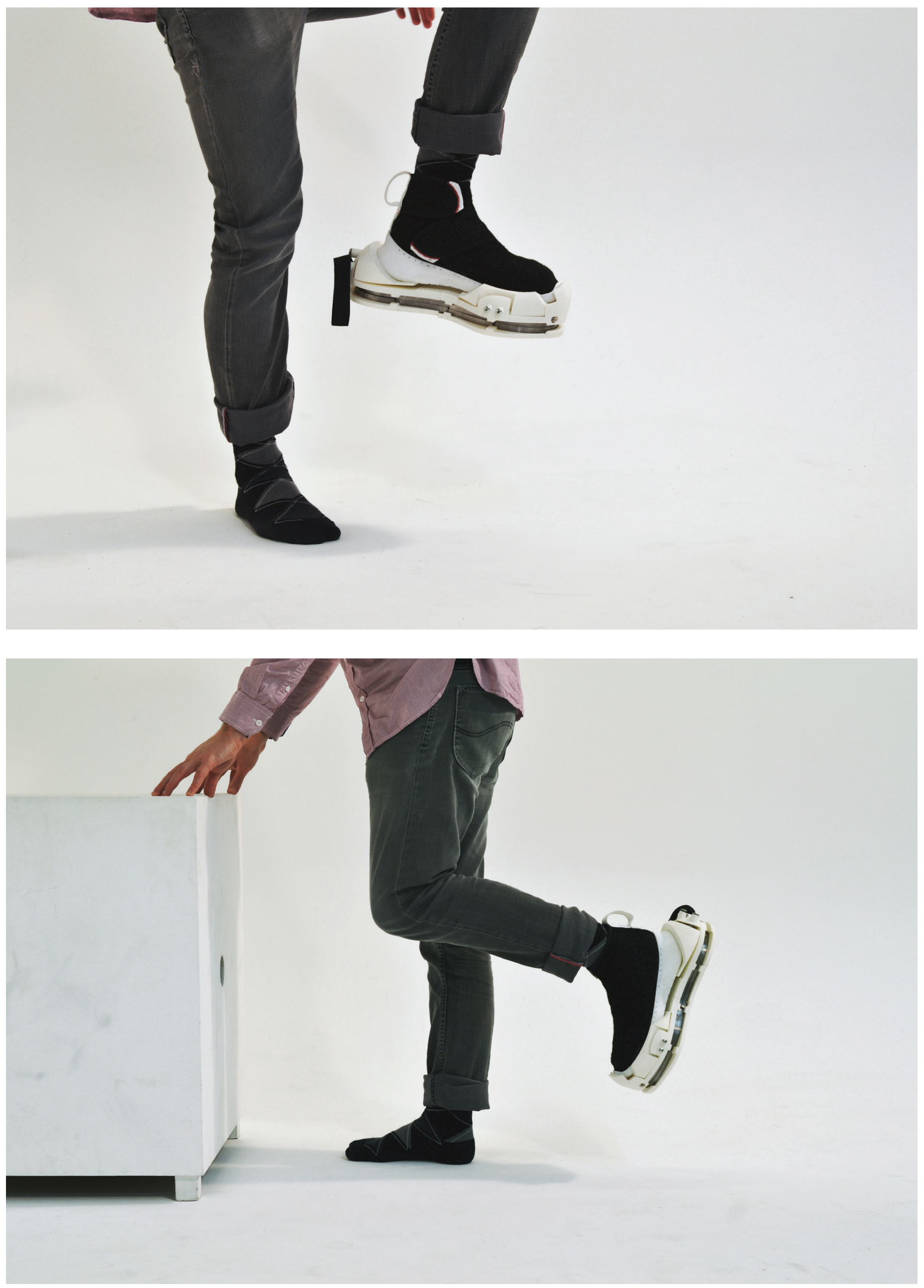


$$
\frac{\pi}{11}
$$




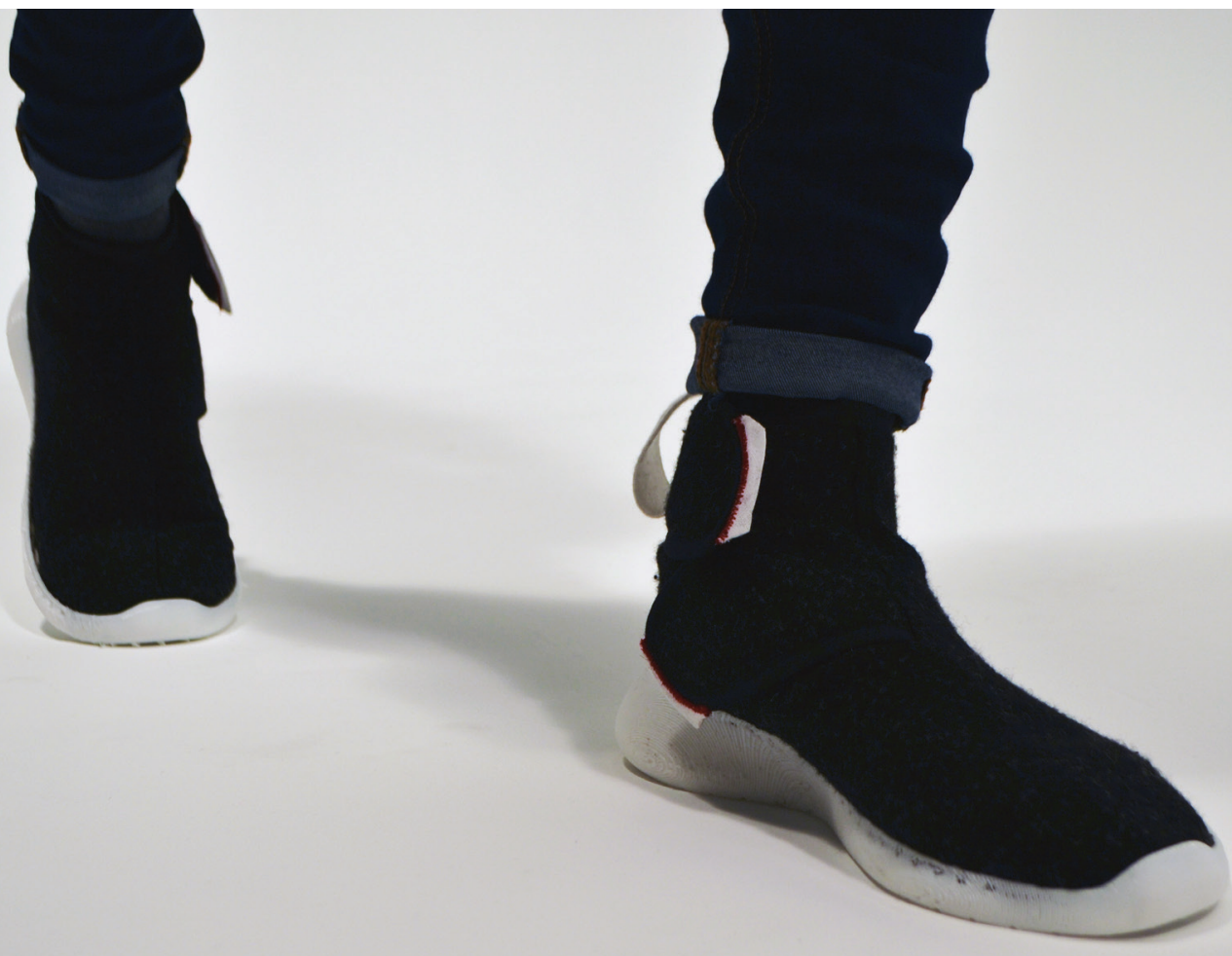

\section{User Testing} Session: 3

The third and final test involved the addition of $1,500 \mathrm{~g}$ of weight to the mod sole. The open-ended interview following the usability test involved the participants filling out two Geneva Emotion Wheels to help them selfreport on their emotional experience with the device. This data helped form feedback about the aesthetic of both the shoe and weighted sole. A final review with clinicians was also conducted following the test. The clinicians were shown footage of the user testing session and gave feedback on the hardware's ability to meet the functional requirements of STT.

\section{Feedback}

Participants found the revised order of strapping a lot more intuitive and easy to use. The wool had less stretch than the previous neoprene iteration, which led to Eve and Ned having trouble with getting the vamp over the top of their feet. The average amount of movements taken to put on the shoe decreased from the previous session suggesting the revised interaction was more intuitive. The time taken to put the shoe on did increase from previous tests slightly across all three participants (see figure 7.1).

Once on the feet all participants reported the shoes were a lot more comfortable and secure than the previous design. Eve also found that the revised form of the sole meant her toes did not protrude over the edges making it a lot more enjoyable to wear. Eve and Nancy were able to easily use both hands to put on and take off the shoe. Ned who has little function of his left hand was able 
to put on/take off the shoe from his affected foot using only his unaffected hand, but had trouble with getting the vamp over the top of his affected foot.

Both Nancy and Eve were able to quickly attach the weighted sole to their affected foot, however Nancy had to be reminded which foot to use. Ned again required assistance in engaging the weighted sole. His foot is twisted due to contractures and he was unable to get the sole of his foot flat to effectively clip his toes in.

All participants were able to quickly remove the weighted sole after priming. Anne's intuition was to again use both hands to pull back the heel clip whilst both Ned and Eve lifted the shoe up towards the midline and used the fabric tab to unclip their heels and slide their toes out. Participants reported the weight feeling secure on their feet during priming, however Eve felt the weight was too heavy. After reducing the weight she found the load much more manageable and enjoyed the ability to adapt it to her requirements. One concern that was observed was the fabric tab on the back of the weighted sole. This could present a fall risk during priming as some of the users were close to standing on it during testing.

The material choice was well received with both Nancy and Eve commenting on the strength and softness contributing to their experience of comfort. Nancy went on to add that the extra warmth the merino would give her feet would encourage her to wear them around the home.

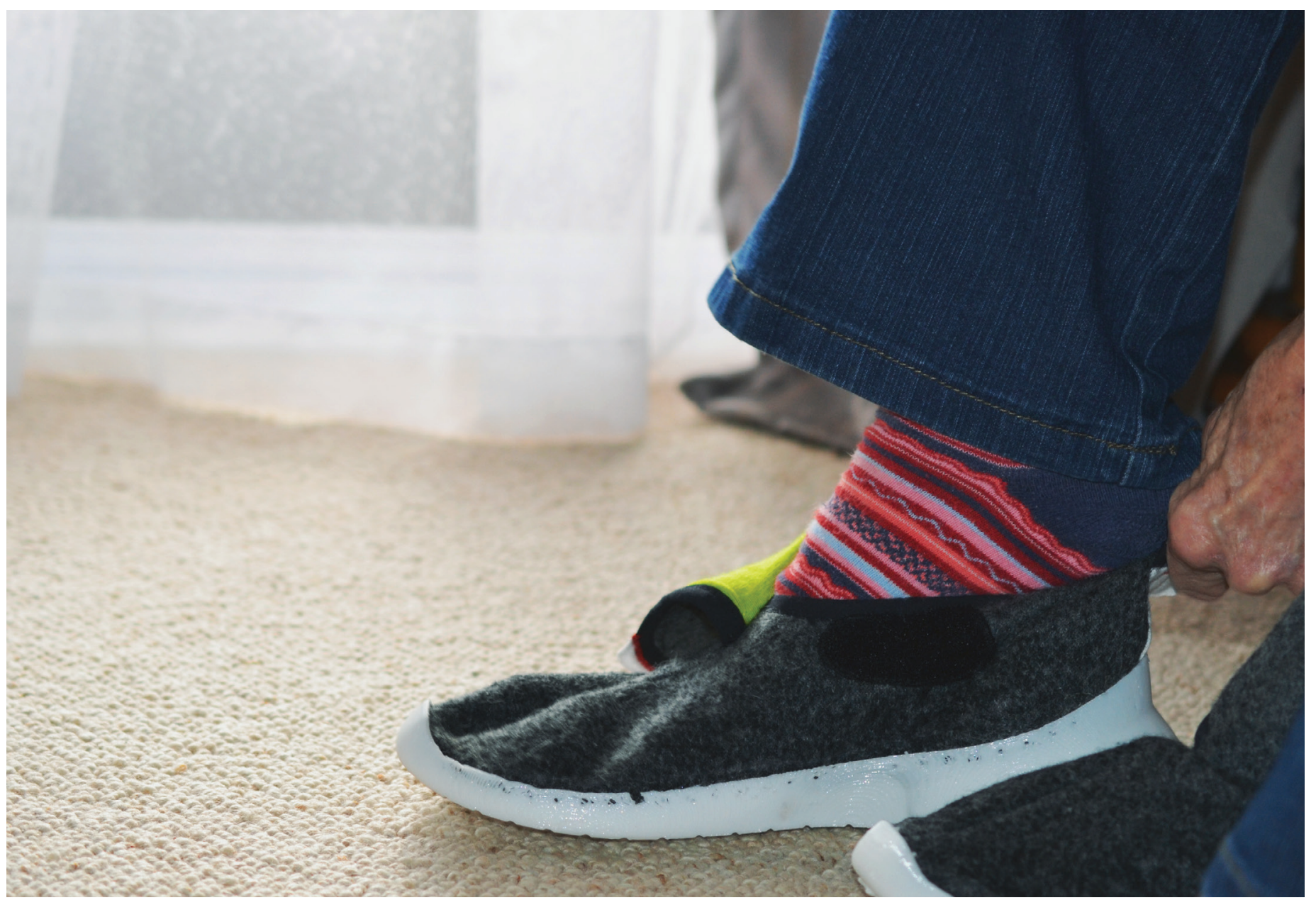




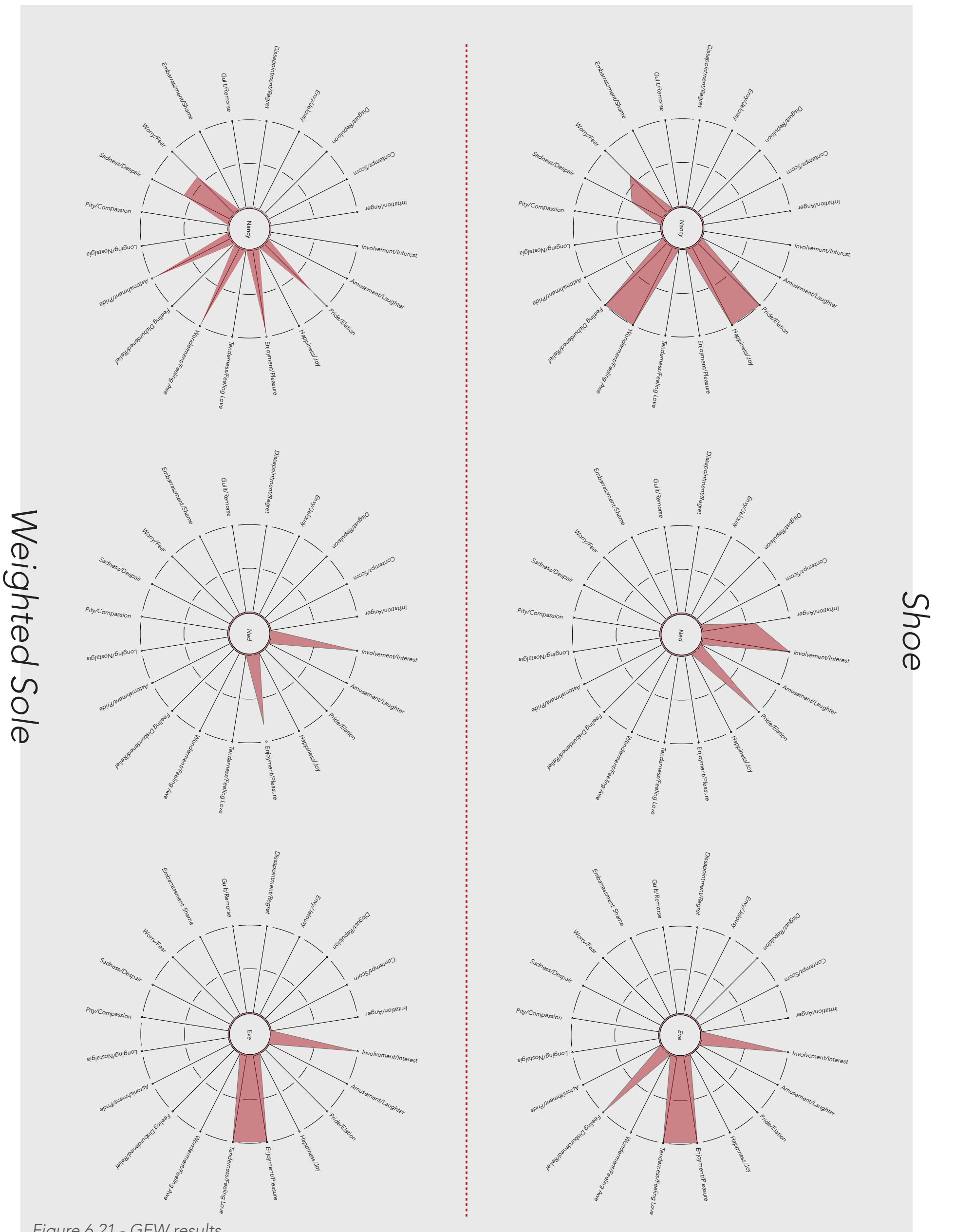

Figure 6.21 - GEW results 


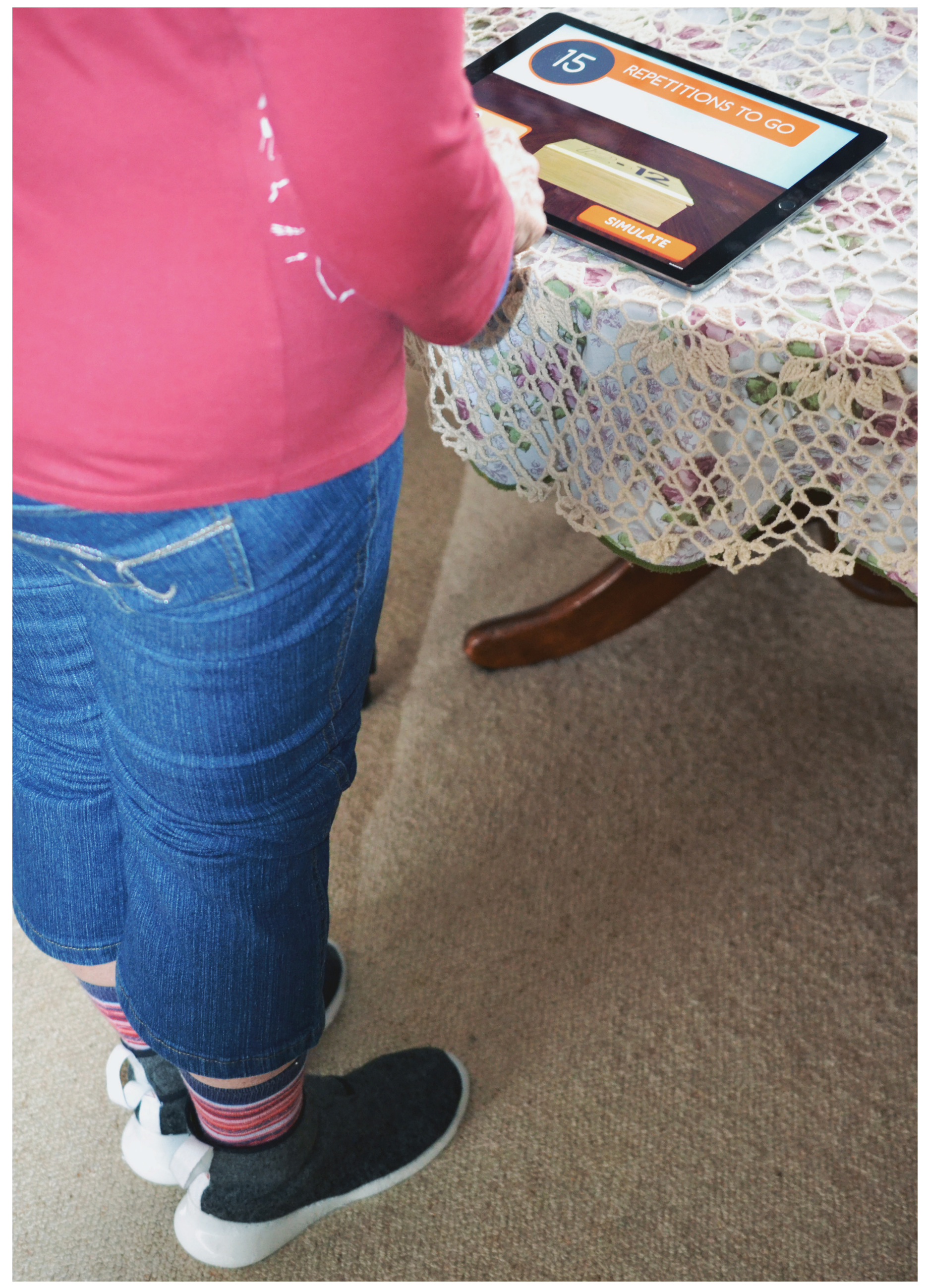


No participant reported feelings of embarrassment towards wearing the shoes (figure 6.21). Both Nancy and Ned commented that they would be proud to wear the shoes in their homes. Ned expanded on this saying he enjoyed that he was wearing something that was "useful (to his rehabilitation) and fashionable".

Eve and Nancy both related their feelings of enjoyment and relief towards the hardware as it symbolised their steps towards making progress in regaining their independence. Eve went on to discuss how the design of the shoe made her feel like her position as a stroke survivor was being considered.
Nancy admitted that on first viewing the weighted sole that she was fearful that she would not be able to work them. She found the appearance complicated and foreign however this feeling quickly changed to pride when she discovered she was capable of using it independently. Ned explained that he found the aesthetic to be bulky. Eve also did not like the components that protruded outwards from the device.
Opposite page: Figure 6.22 - Nancy playing 12 - 12 with the shoes on her feet

Below: Figure 6.23 - Nancy taking off the weighted sole

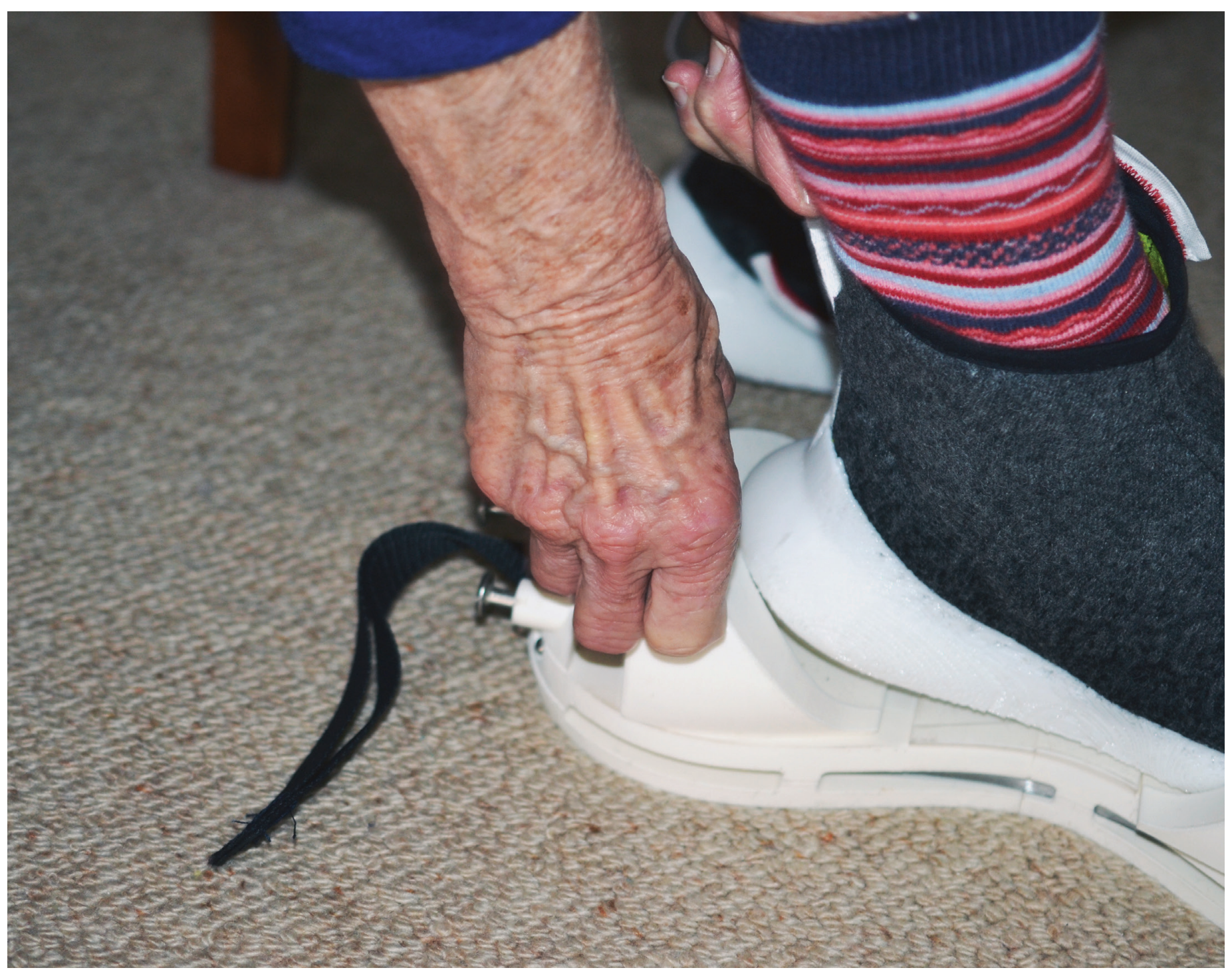


$\sin 2 x^{\circ}$
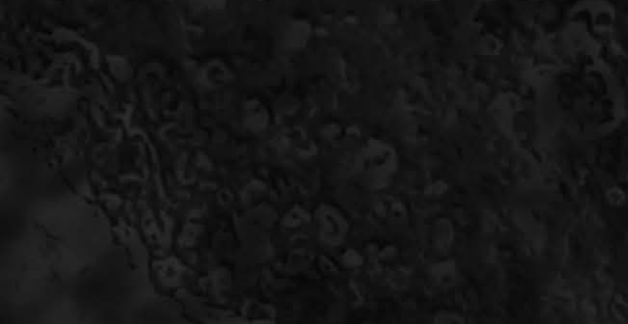

$-5 x^{5}-1=2$ 


\section{ANALYSIS OF RESULTS}

\section{"WE ARE NOT A FORGOTTEN CAUSE. YOU'RE STILL A PERSON AND SHOULD BE TREATED LIKE A PERSON."}

\section{- NANCY}

The shoe and weighted sole remained stable and secure on the user's foot during the priming component with load applied. Kroemer's (2006, p. 160) design requirement of maximising patient safety and comfort were applied through addressing the safety concerns raised by clinician 1 (personal communication, May 3, 2016) of using resistance bands unsupervised. The review of the third user test with clinician 1 indicated that the weighted sole has "mitigated" the need to use resistance bands for hip abduction strength training and was a "valid outcome" of the design (clinician 1, personal communication, July 27, 2016).

Concern was also raised about rough or protruding parts hitting the unaffected leg. With enough force, rough surfaces or protruding components have the potential to tear the skin of users, especially those with skin integrity issues, which can lead to an infection. Although smooth surfaces still have the ability to bruise the user "streamlining the design" and removing as much "bulk" as possible should be prioritised to minimise these safety concerns (clinician 1, personal communication, July 27, 2016). As addressed by Levin et al., (2015) adapting the difficulty to the needs of the patient makes exergames motivating, engaging and enjoyable. Priming required load specific to the individual to maintain intensive strength training (Signal, 2014, p 53). The hardware's ability to adapt the weight was demonstrated through Nancy's request to subtract load during the third user testing session.

Increasing the intensity of the task-training component through part task and full task requires dynamic movements from the participant (Signal, 2014, p. 55). The shoe itself was praised by participants for its comfort and stability. This suggests that the shoe could facilitate and even promote the user's ability to perform task-based movements of increasing complexity.

Although user testing did not measure the level of intensity exerted by patients, feedback suggests the system does allow a sufficient level of intensity, with Ned reporting he was "starting to break out a sweat" by the end of the second user testing session.

Usability of the hardware was essential to not only address the specific requirements of stroke patients, but to facilitate STT's intent to maximise gains in locomotion (Signal, 2014 , p. 46). As the increase in corticomotor excitability begins to breakdown following strength training, Signal $(2014$, p. 47) stresses a prompt transition time between priming and task training. Results from the testing indicate that time taken to remove the weighted sole decreased across the three testing sessions. In the third test all three participants were able to independently remove the weighted sole in under thirty seconds (figure 7.1). This would suggest the hardware has the ability to facilitate the prompt transition time required between strength and task components. 
Clinician feedback did however raise concerns about how the weighted sole was taken off. Nancy was able to bend down to remove the weighted sole, however $\mathrm{Ned}$ and Nancy were not. Ned and Nancy were able to remove the weighted sole by lifting their affected leg up onto their opposite knee. Clinician 1 (personal communication, July 27,2016$)$ mentioned that this movement would not be able to be performed by all patients. Clinician 1 recommended that the release mechanism should facilitate another interaction for removal that can be conducted from an upright-seated position.

Aside from Ned requiring assistance putting the weighted sole on, the third user test demonstrated that each user could use the device independently and without prompting. As mentioned by Alankus et al., (2010, p.

\section{Below: Figure 7.1 - Duration (minutes: seconds) and} number of movements required from each participant during user testing
2119), exergames should promote use by patients at different stages of recovery. Ned's ability to use the hardware without the use of his affected hand helped substantiate the hardware's use among patients of different ability levels.

Participant's Intuition of how to perform tasks of putting on the shoe and midsole were paramount to informing the usability of the design. Initial assumptions on how the shoe and weighted sole were put on lead to the users becoming confused and using the hardware incorrectly. Adapting the order in which the straps were done and adding contrasting colour to inform points of interaction reduced the average number of movements required when compared to the previous test. This not only helped the participants overcome any usability barriers due to stroke, but in Nancy's words, she was "proud that [she] could do it". Changing the movement of sliding the toes to clipping the toes into the weighted sole was also informed

\begin{tabular}{|c|c|c|c|c|c|c|c|c|c|}
\hline & & \multicolumn{2}{|c|}{ Putting ON Shoe } & \multicolumn{2}{|c|}{$\begin{array}{c}\text { Putting ON } \\
\text { Weighted Sole }\end{array}$} & \multicolumn{2}{|c|}{$\begin{array}{c}\text { Taking OFF } \\
\text { Weighted Sole }\end{array}$} & \multicolumn{2}{|c|}{ Taking OFF Shoe } \\
\hline & & Duration & $\begin{array}{l}\text { Move- } \\
\text { ments }\end{array}$ & Duration & $\begin{array}{l}\text { Move- } \\
\text { ments }\end{array}$ & Duration & $\begin{array}{l}\text { Move- } \\
\text { ments }\end{array}$ & Duration & $\begin{array}{l}\text { Move- } \\
\text { ments }\end{array}$ \\
\hline \multirow{3}{*}{1} & Ned & $00: 53$ & 8 & $N / A$ & N/A & $N / A$ & $N / A$ & $00: 15$ & 4 \\
\hline & Eve & $01: 25$ & 10 & $N / A$ & $N / A$ & $N / A$ & $N / A$ & $N / A$ & $N / A$ \\
\hline & Nancy & $00: 37$ & 10 & $N / A$ & $N / A$ & $N / A$ & $N / A$ & $00: 17$ & 2 \\
\hline \multirow{3}{*}{2} & Ned & 01:01 & 9 & N/A & $N / A$ & $N / A$ & $N / A$ & $00: 17$ & 5 \\
\hline & Eve & $00: 27$ & 6 & 00:04 & 1 & N/A & N/A & $00: 17$ & 3 \\
\hline & Nancy & $00: 16$ & 5 & $00: 12$ & 3 & $00: 16$ & 6 & $00: 12$ & 3 \\
\hline \multirow{3}{*}{3} & Ned & $00: 45$ & 7 & $N / A$ & $N / A$ & $00: 28$ & 4 & $00: 10$ & 3 \\
\hline & Eve & $00: 40$ & 5 & 00:04 & 1 & $00: 15$ & 3 & $00: 12$ & 3 \\
\hline & Nancy & $00: 20$ & 5 & $00: 11$ & 2 & 00:06 & 2 & $00: 12$ & 3 \\
\hline
\end{tabular}


by the intuition of the users. This provided a way of putting on and taking off the weighted sole that made sense to the user and required no instructions. It was also interesting to note that the subjective nature of intuition led to users interacting with the device in different yet successful ways.

Testing the system in the homes of the participants demonstrated the minimal requirements needed to play the exergame. Participants were able to easily position the iPad on a flat surface and keep a chair handy for putting on and taking off the shoe and weighted sole. As preferenced by Gerling et al, (2010) the wireless nature of the system was able to minimise the steps required for use and subsequent cognitive load on the user. Being free of the environmental constraints console-based systems demand (Hore, 2014, p. 32; Fritz et al., 2013, p. 222), the ability to be easily set up anywhere within a user's home promoted the ubiquity of the system.

The aesthetic of the hardware was ultimately well received by participants. None of the users felt embarrassed wearing the shoes or using the weighted sole. Nancy and Ned also went on to state that they found the shoes to be fashionable, with Nancy claiming she would "quite happily wear them around [her] home". This feedback resonates with Stipe (2015, p. 1) and Pullins' (2009, p. 4) idea that aesthetic consideration can break down the stigma of using medical devices. Feedback from participants indicated there was still a strong stigma towards stroke as Nancy explained "until you're comfortable telling people about your stroke you tend to avoid it".

The shoes being identified by participants as a fashionable item of clothing, rather than a medical device is reflective of the synthesis of eyeglasses into fashion culture (Pullin, 2009 , p. 4) or Blythe et al., (2005, p. 678) proposition of medical alarms as jewellery. As also addressed by Stipe (2009, p. 1) and Blythe et al., (2005, p. 678), medical design semantics can make the home feel like a hospital and allude to the user's impairment.
Identifying with the hardware as a fashionable item could also help the hardware blend anonymously into a domestic environment. The aesthetic of the weighted sole did however raise concerns. Nancy admitted the apparent complexity of the device elicited a fear that she would not be able to use it. "The appearance makes it feel complicated. It's different to anything I have ever seen". This validates Kromer's (2006, p. 160) goal to conceal complexity when designing for older adults.

Nancy and Eve commented on how the aesthetic elicited emotions about the positive progress they had made/were making in their rehabilitation. This drew parallels to Pullin's (2009, p. 31) idea that the aesthetic of medical products should celebrate their positive intervention in their users' lives. Eve commented that when she puts it on she is glad that she "has something that's going to help [her] improve and get independent. [She] feels, one step closer' to [her] independence". 


\section{Changes and The Proposed Final Design}

Final changes to the design addressed small aesthetic and usability concerns brought up in the final user test. The vamp was given slightly more stretch to help with the upper stretching over the foot to reduce time taken to put the shoe on. A small magnet was added to both the back of the heel clip and the fabric loop to minimise risks of tripping. The form of the weighted sole was changed to minimise the look of complexity and bulkiness reported by participants. All mechanisms were internalised concealing any complexity. The form was also streamlined to take away any protruding componentry. The size of steel plates added to increase load was also changed. Small uniform profiles allow the weight to be changed at smaller increments and distributed evenly across the weighted sole.
The final design was called the "Indee Rehabilitation System". The system features; smart footware, a weighted sole, removable imu sensor and a charging dock. The following images propose how the exergame system would be set up and used.

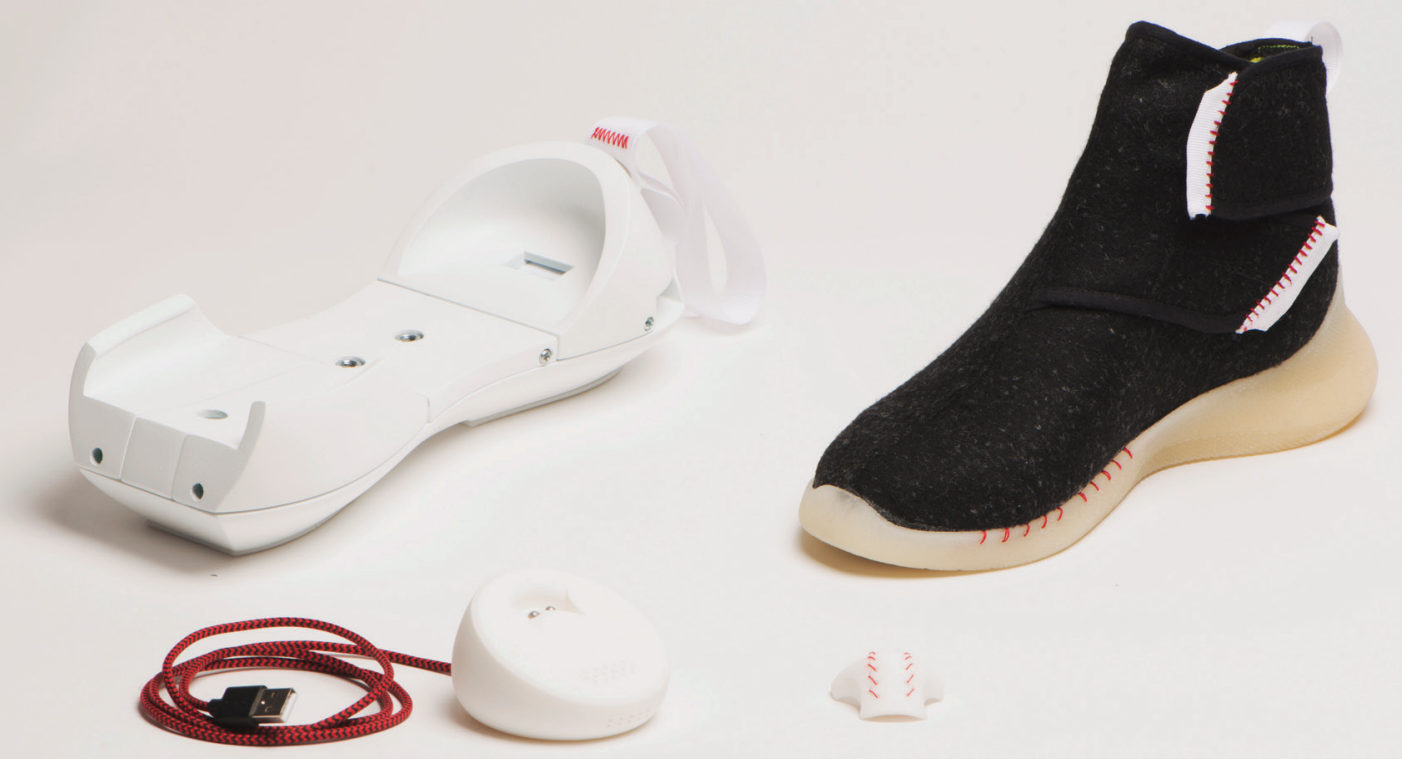

Figure 7.2 - Proposed system 

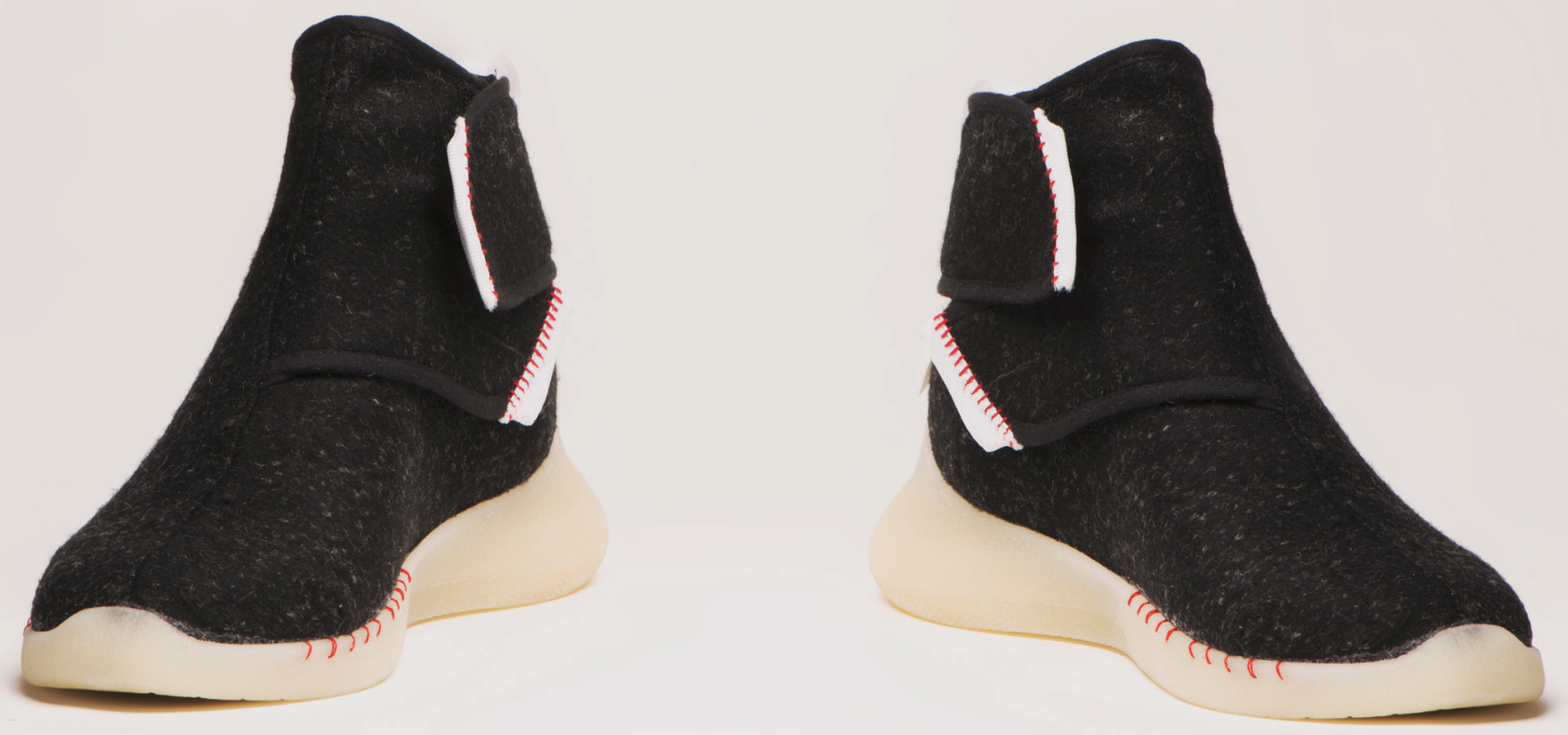

Figure 7.3 - "Indee" shoes
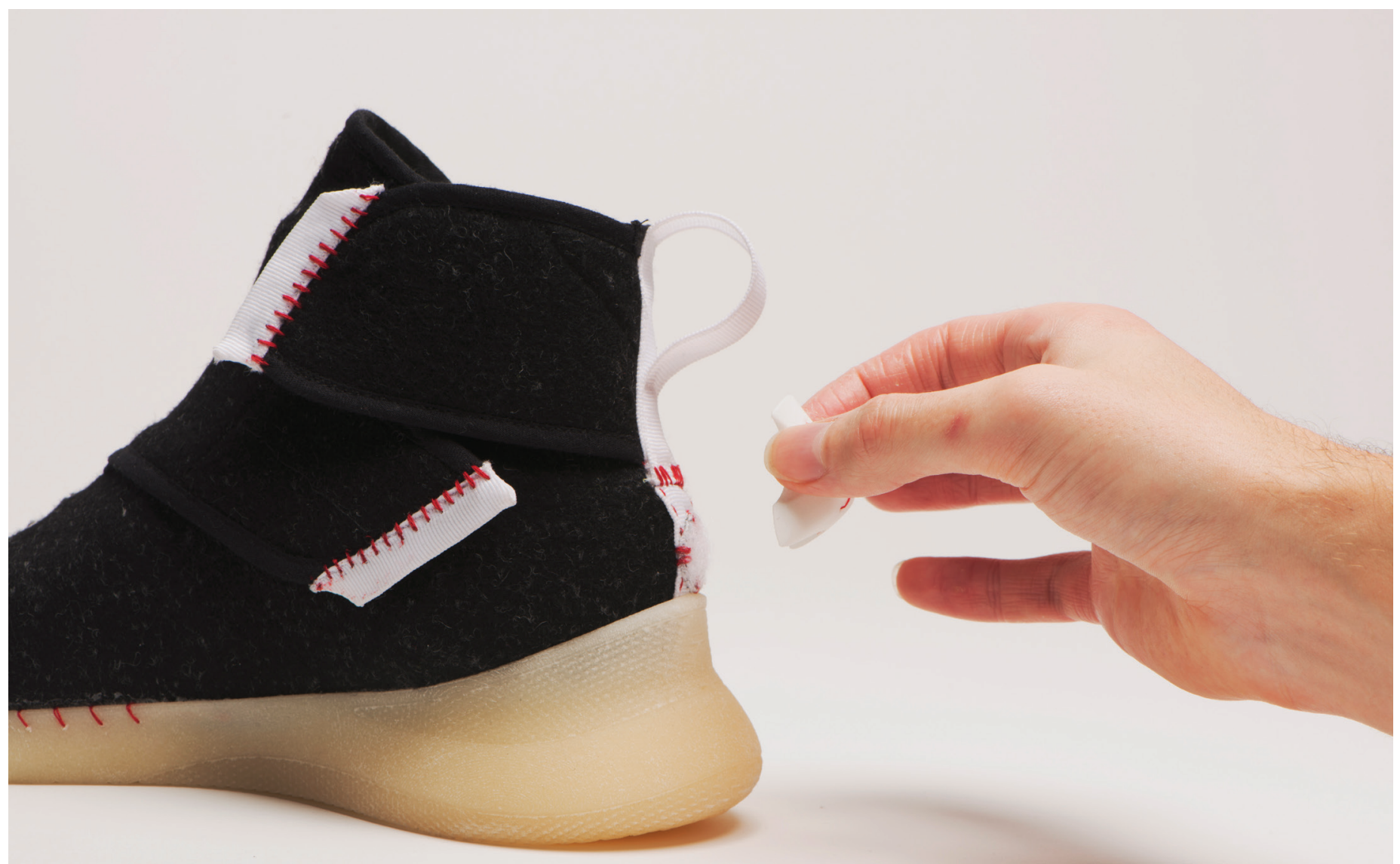

Figure 7.4 - Sensor Placement 


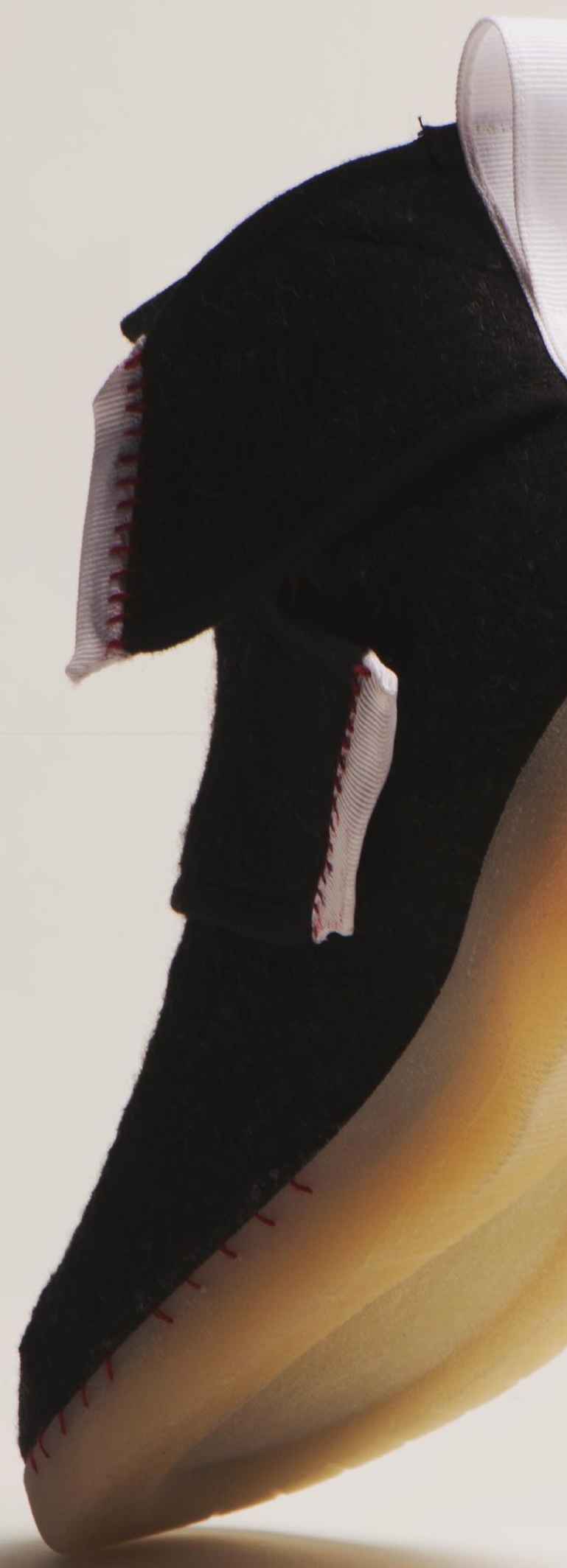

Figure 7.5 - TPU sole detail 
$1 / 1)$

restind 


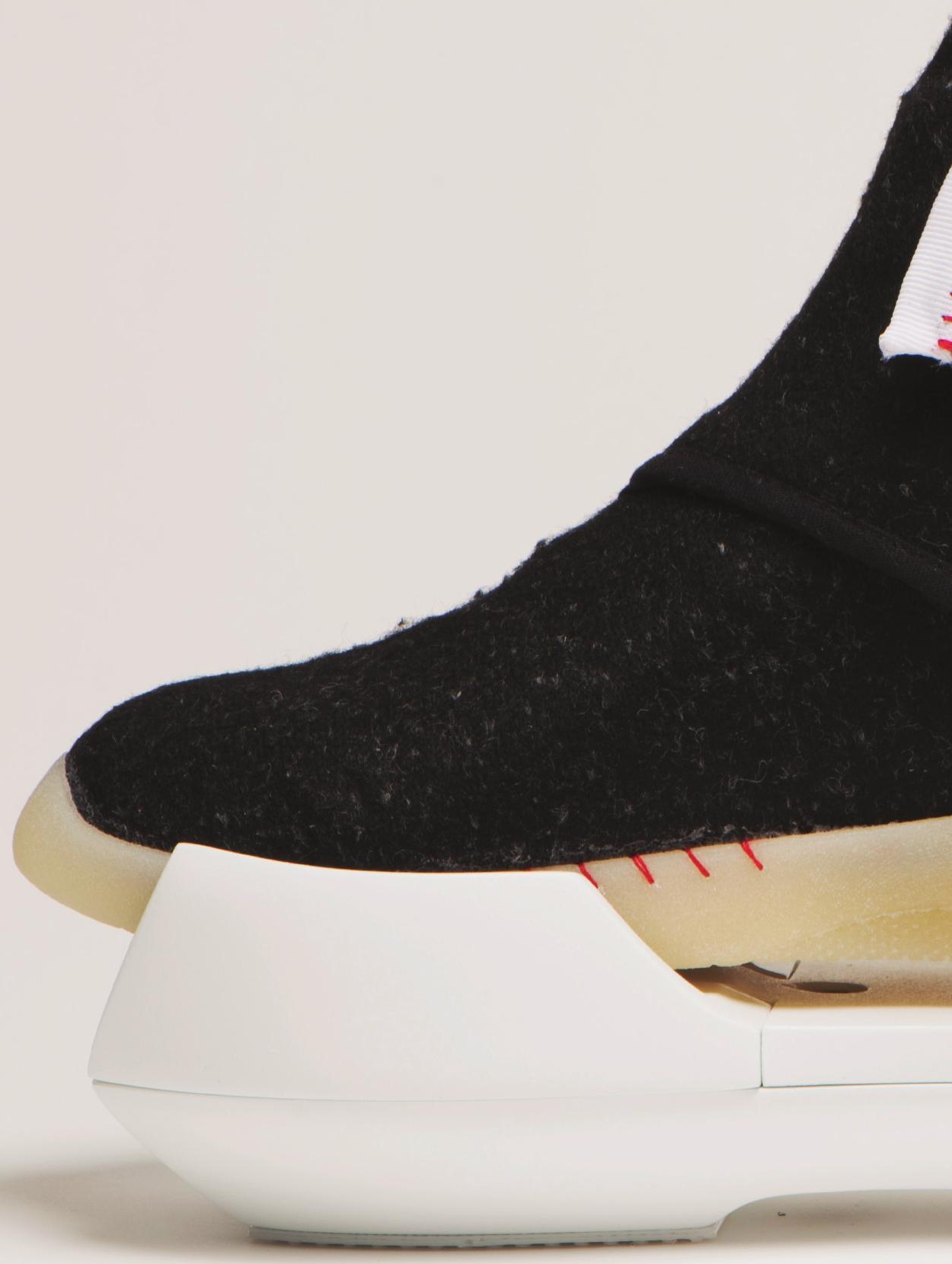

Figure 7.6 - Shoe and weighted sole 



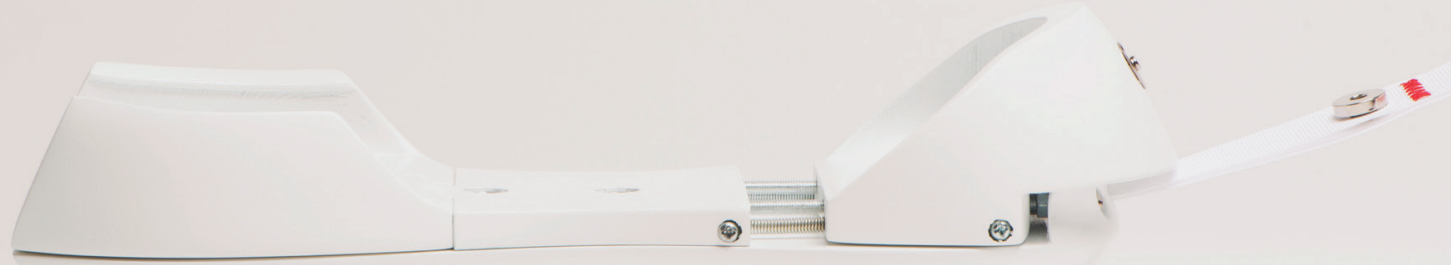

Figure 7.7 - Demonstration of weighted sole's function

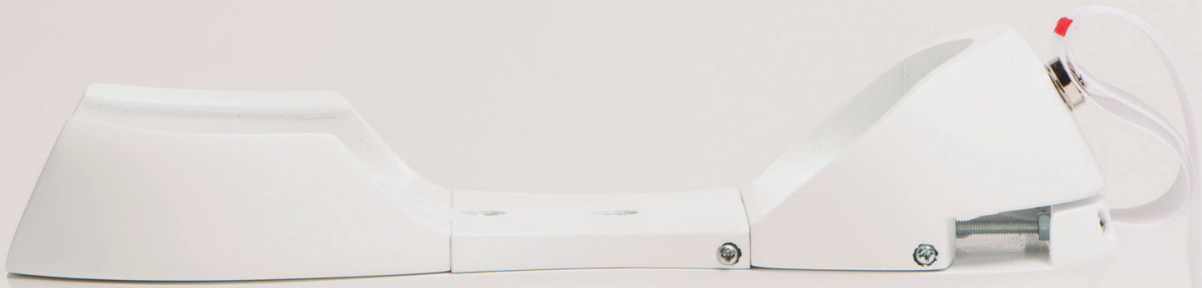

Figure 7.8 - Weighted sole 


\section{mun}

Figure 7.10 - Weighted sole detail 

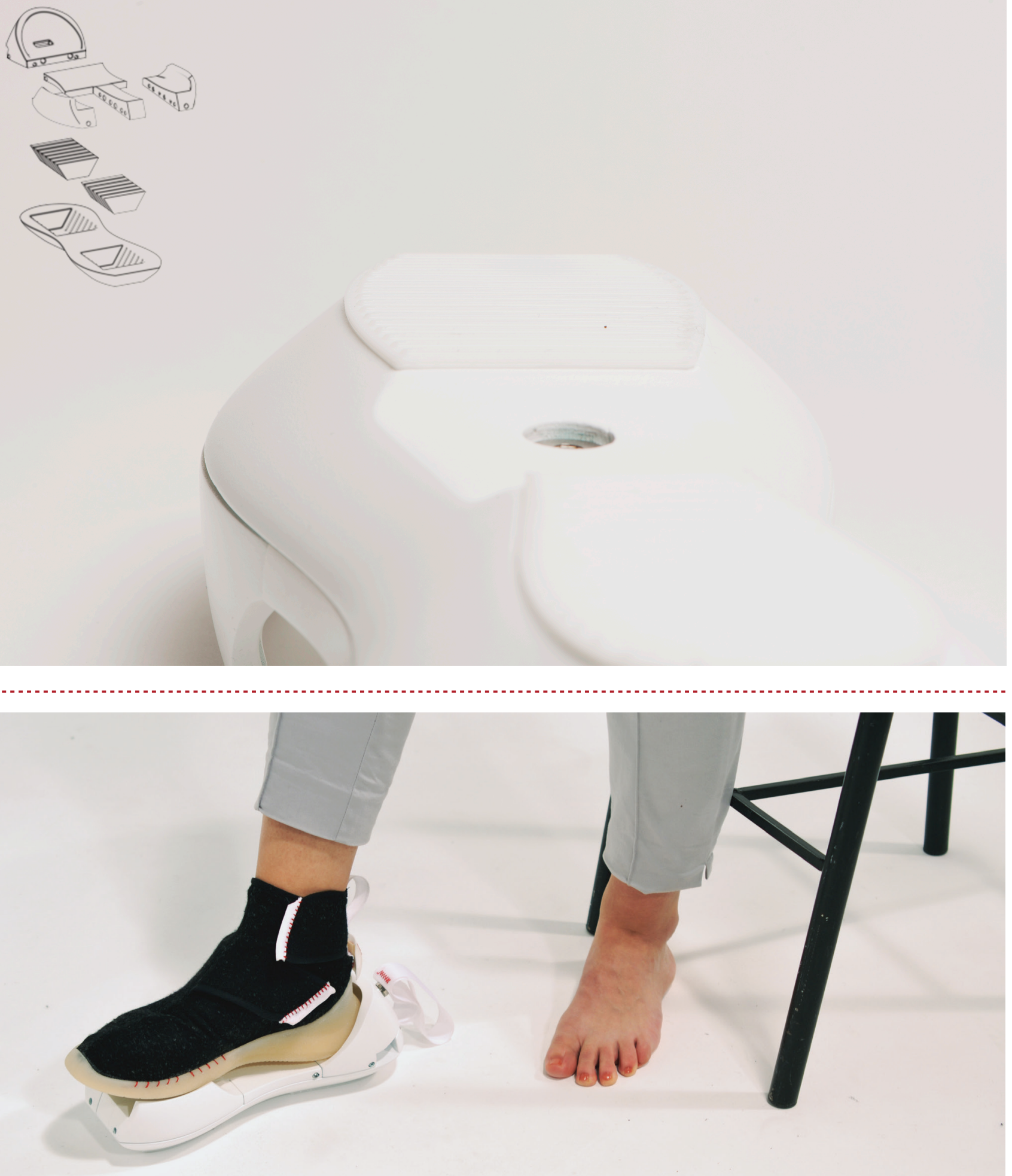

Above: Figure 7.12 - Weighted sole in use 1

Figure 7.11 - Weighted sole detail and exploded diagram 


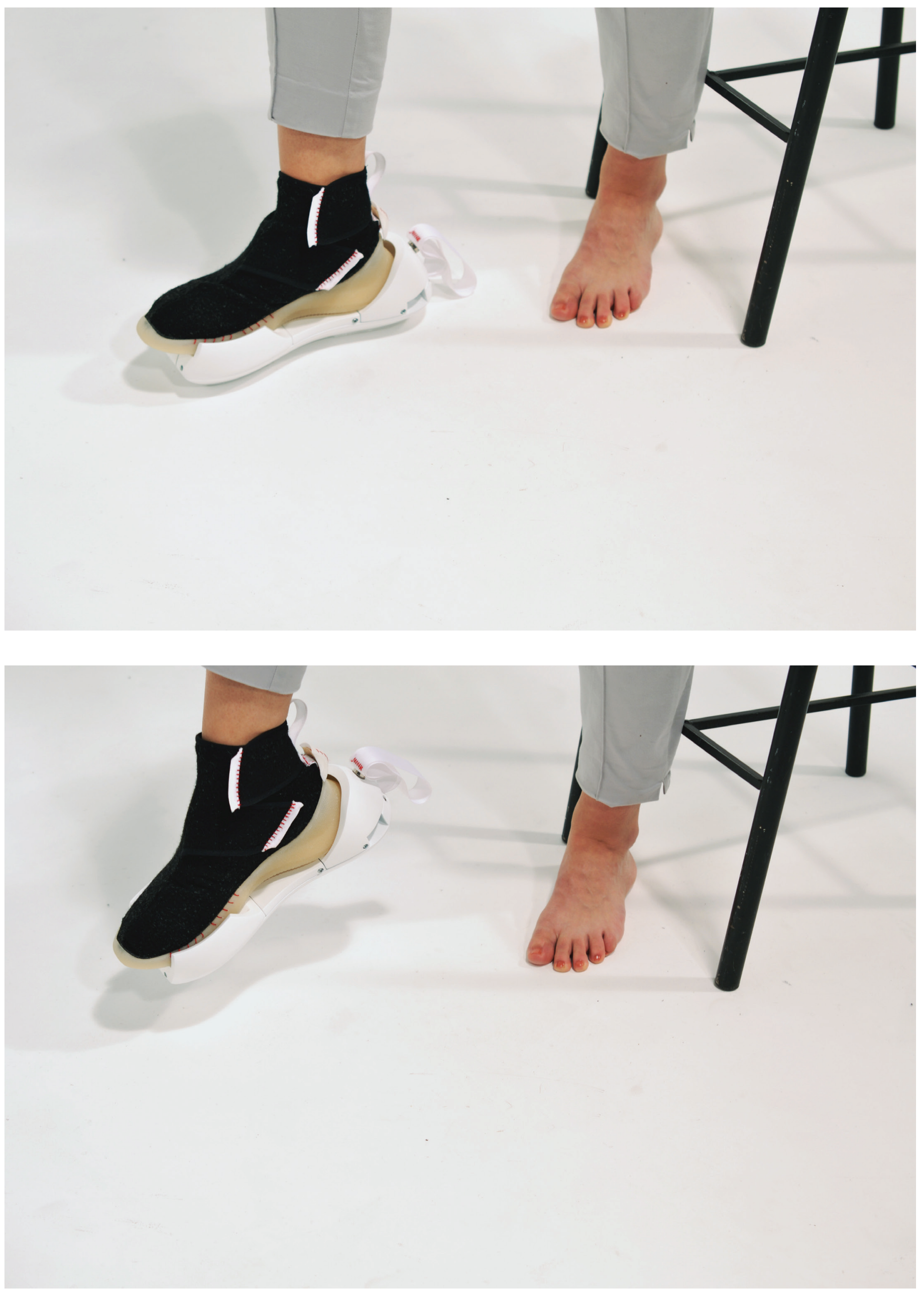



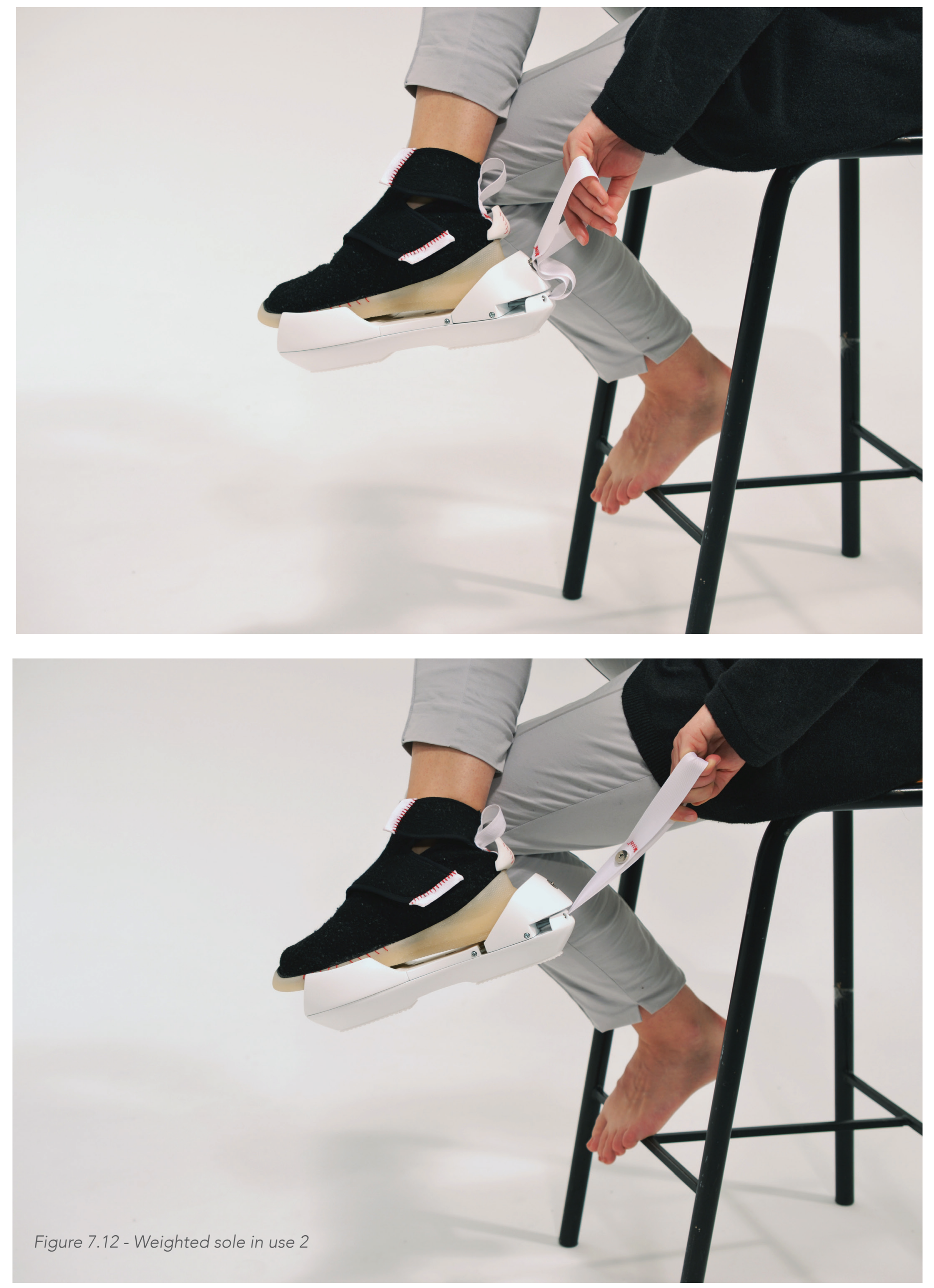

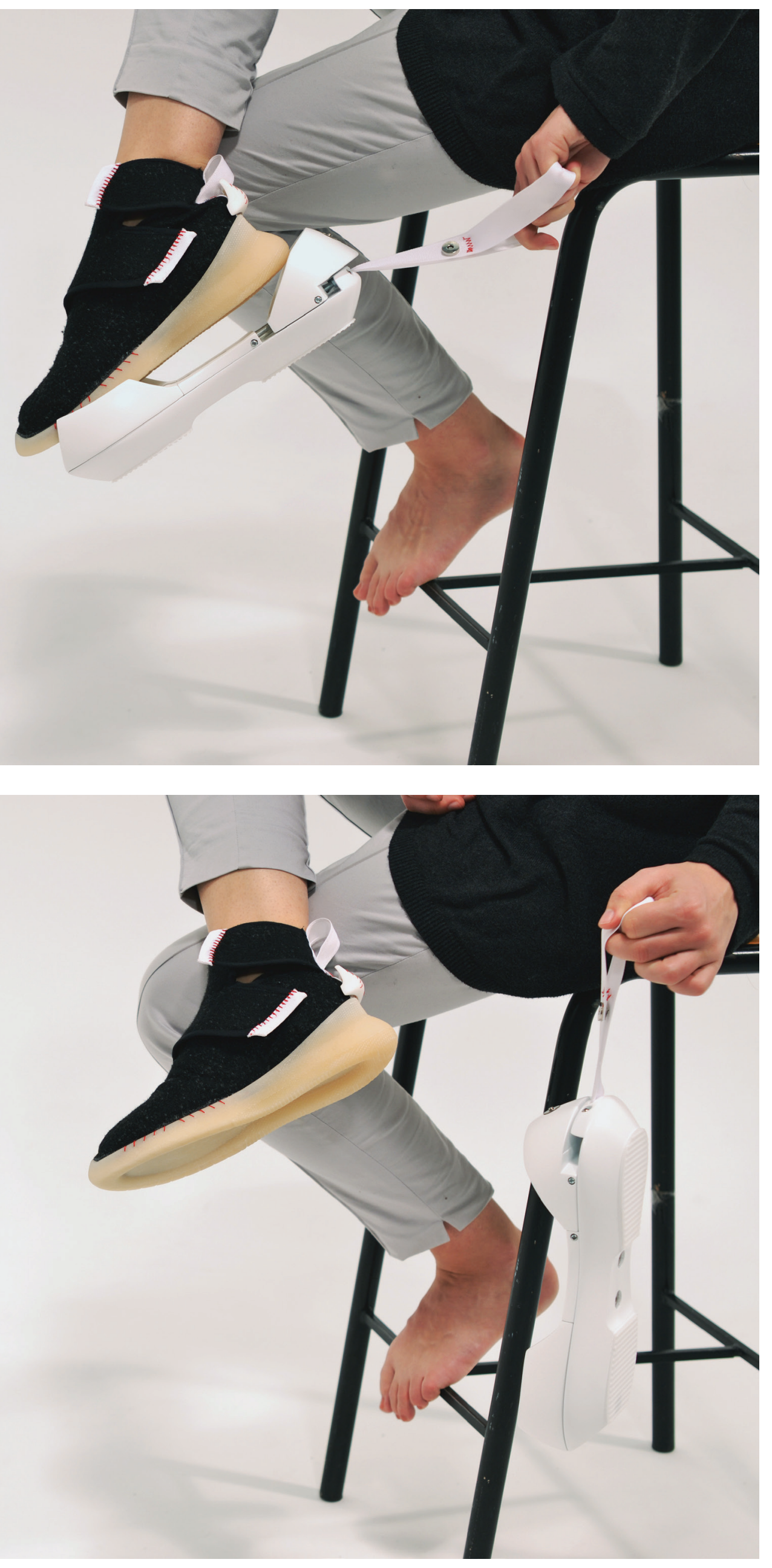


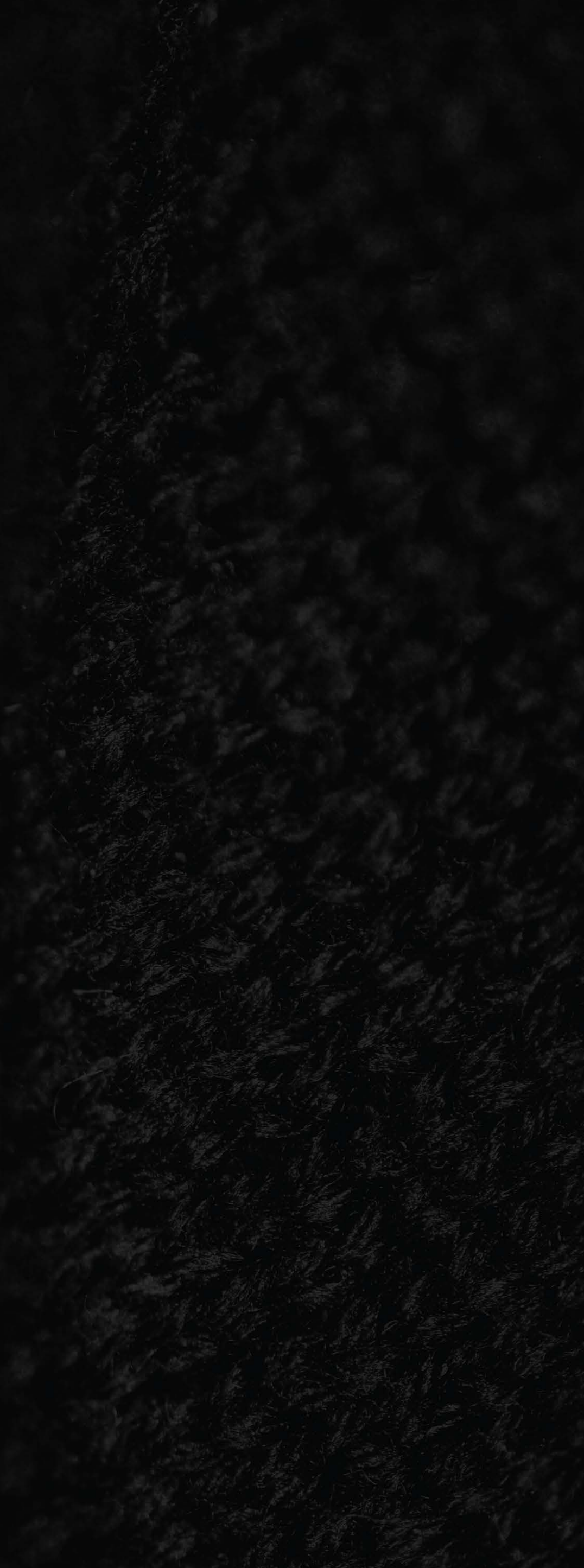


Findings from the user testing of the system suggest the hardware can facilitate aspects of STT in an unsupervised environment. Currently, STT is only conducted in a clinical environment. Facilitating STT through the medium of an exergame could provide an engaging way to motivate the user to perform this lower limb therapy intensively and consistently in their home. This not only could reduce the load on the public health system but also help maximise patients' locomotive gains, helping them retain their mobility and subsequently their independence.

The design requirements of the hardware proved to be diverse and complex. Defining the functional criteria of the hardware was heavily influenced by the requirements of STT. Ergonomic and usability requirements aimed to minimise barriers to using the exergame in an unsupervised environment. Addressing the diverse cognitive and physiological abilities of stroke survivors was paramount to overcoming these obstacles. Aesthetic requirements attempted to avoid the stigma attached to medical products creating hardware that is cohesive with the domestic environment, thereby encouraging its use.

\section{Evaluation Through Design Criteria}

\section{Functional requirements:}

Priming and task training components of STT can be used as a means of interaction with gaming media. A gaming controller in the form of a smart shoe could be used to track movement of the lower limb noninvasively.

Initial user tests indicate intensive hip abduction priming can be facilitated by securely and comfortably fixing load in the form of external weight to the smart shoe.
Load must also be specific to the user's capabilities through adapting the weight of the sole. Avoiding resistance bands during unsupervised rehabilitation also circumvents fall risks and their observed erroneous use outside of a clinical context. By mitigating the use of resistance bands unsupervised this ensures the priming component is intensive yet safe and manageable, keeping the user motivated to continue using the exergaming system. The clinician's review of the weighted sole also indicated that beyond STT, any unsupervised rehabilitative strength training could benefit from the design's ability to mitigate the use of resistance bands (clinician 1 , personal communication, July 27, 2016).

Maintaining intensity during the task-training component requires increasing the complexity of the task. Complexity is increased across nine components, part and whole tasks being one element where the patient must complete more dynamic movements as they progress. Testing indicates that creating footwear that provides a comfortable and stable base of support can allow the user to perform movements of increased complexity as the progression demands.

An initial limitation was that measuring the intensity of STT components was beyond the scope of the research. Reviews with clinicians indicate that the weighted sole could facilitate enough load to make priming intensive. However, surveying intensity requires a clinician to first diagnose an appropriate starting weight; then for the patient to self-report on the level of intensity; followed by the clinician adapting the load over multiple sessions. The restricted timeframe and limited access to clinicians over the duration of the testing sessions made it difficult to gauge if the participants were exercising intensively. However, reviews of the user test with clinicians indicate that the weight threshold of the hardware 
would likely facilitate intensive priming components of both hip abduction and hamstring contraction (clinician 1, personal communication, July 27,2016$)$. Anecdotal feedback from participants was also positive, indicating both STT components were physically demanding.

Clinician 1 (personal communication, July $27,2016)$ went on to explain that the more you can individualise the rehabilitation, the more effective it is likely to be. Embedding an algorithm to prescribe the weight and repetitions the user should perform during priming should be the next progression of the system.

A further limitation was the functionality of the IMU sensors. Use of the "Oz Paradigm" (Kelly, 1984) allowed us to simulate the sensors' desired functionality, but this is limited to the controlled environment of user testing. As addressed by Levin et al., (2015, p. 422) accurate tracking of movement is critical to ensuring the user is maintaining correct form during rehabilitation. This was validated through feedback from clinicians identifying that Eve was not performing the priming exercise correctly, including undesired external rotation of the foot during the abduction of the hip (clinician 1, personal communication, July 27,2016$)$. Solving the functionality of the sensors is beyond the scope of this thesis in Design. However, the functionality of the sensors is currently being solved by the engineers at I Measure $U$. I Measure $U$ is an industry partner of this research within the MedTech CoRE and should have fully functioning sensors by the end of 2016.

\section{Contextual Requirements}

\section{Ergonomics and Usability:}

The dynamic range of abilities survivors of strokes possess, must be addressed to ensure the patient can use lower limb exergame hardware independently and intuitively. To consider the physiological effects of hemiparesis, one-handed interaction was necessary to complete all tasks. Observation of tests indicated that, apart from Ned needing assistance to put on the weighted sole, participants were able to put on and take off the shoe and weighted sole independently. It's critical that hardware promotes its use across all ability levels.

Reducing time between strength and task training components was crucial to facilitating priming. User observation illustrated that the design of the weighted sole enabled the user to remove load and promptly begin task training. This suggests the hardware can maximise corticomotor excitability during strength training to subsequently enhance neural plasticity during the task component. Effective priming maximises the patient's gains in locomotive ability helping them regain independence.

An unanticipated but important outcome was the feeling of pride participants felt after figuring out how to complete certain interactions with the exergame system. We speculate that reducing cognitive/physical challenges rather than removing them completely could create a more beneficial experience for the user.

\section{Aesthetics:}

Feedback suggests that aesthetic consideration of exergame hardware can remove any medical semantics and address the stigma towards using medical devices. By designing a game controller that was considered a "fashionable" piece of footwear, the user avoided the feeling of embarrassment wearing and using the smart shoes. Counter to the praise of the footwear's aesthetic, the weighted sole receive critique on its perceived complexity. This was shown to elicit feelings of fear towards using the device, worrying that the user wouldn't be able to work it properly. This suggests that the exergame hardware's aesthetic could lead to its perceived complexity, subsequently becoming a barrier to use.

Beyond "fashionable" semantics, the aesthetic seemed to resonate on a deep emotional level with participants. The design 
elicited emotions that relate to positive progress that the patient was making in their recovery. Moreover participants seemed to find that wearing shoes does not just make rehabilitation novel and motivating, it can also act as a tool to help them regain their independence. Furthermore just knowing that there was something designed specifically for them made the user feel valued as a person. Based on these results we speculate that the aesthetics of an exergame controller could transcend the stigma towards medical devices and help create a meaningful object that represents the stroke survivor's journey back to independence.

\section{Research Limitations}

Similar to Alankus et al. (2010, p. 2121); Shirzad et al. (2015, p. 3); and Flores et al. (2008, p. 383); our chosen methodology required the collection of qualitative data and produced findings that are subjective. Recruitment had to be sought outside of the Wellington District Health Board. This involved contacting and presenting to stroke clubs around the greater Wellington region. Seven potential participants indicated their interest in participating however through conducting over the phone interviews, only three meet our inclusion/exclusion criteria. Our sample size of participants may not be accurately representative of the broad demographic of stroke patients.

Although the early research process was guided by stroke professionals within the medical community, access to stroke clinicians during the testing phase was limited.

Clinician involvement was needed to correctly prescribe load to the user during priming.

The time constraints under which testing took place also meant that the intensity of STT could not be assessed. Clinician-guided testing over an extended period of time would provide a better indication of whether the exergaming system promotes intensive STT.

Finally the functionality issues of the IMU sensors were a limitation to interpreting motion data from the participants' movements. Multiple meetings were conducted with the IMU engineers and a filtering issue with the data was apparent. The IMU sensors use a Madgwick filter to process excess data that creates orientation issues with the sensor. The Madgwick algorithm did not translate across to unity, the gaming engine used to build the exergame media. This filter will have to be rebuilt in order to interpret the IMU motion data accurately.

\section{Final Evaluation}

\section{"How might the design of an exergame game controller facilitate unsupervised Strength for Task Training for lower limb stroke rehabilitation?"}

An exergame controller must fulfill not only the functional requirements of STT but consider the dynamic abilities and subjective contextual requirements of stroke patients.

An exergame controller for unsupervised STT should use strength training and task training components as a means of interaction with gaming media. The hardware must allow external load to be easily and promptly applied/removed from the user's lower limb to facilitate priming. Load must also be tailored to the user's ability level, facilitating intensive strength training. To maintain intensive task training, the exergame controller should provide stability and security. This can enable the user to complete increasingly complex task-based movements, facilitating part task/whole task progressions. A smart shoe with embedded IMU sensors with an attachable sole featuring adaptable weights could facilitate these functional requirements.

\section{Exergaming hardware for STT training} must consider the specific ergonomic and usability needs of stroke patients. Hardware should also be intuitive and require simple interactions, promoting its use across different levels of ability. Common cognitive deficits such as short-term memory loss can be mitigated by structuring means of 
interaction that make sense to the user.

Physiological impairments such as symptoms of hemiparesis can be addressed through facilitating one-handed interactions. By designing a smart shoe with an upper that is structured to allow the user to put on and take it off using one hand, barriers to use can be minimised. The design of a weighted sole for strength training that can be put on hands free and removed one handedly could also promote usability whilst minimising discomfort.

Unsupervised STT takes place predominantly in the user's home. The aesthetic consideration can be an important factor in breaking down the stigma towards medical devices in the home, and creating meaningful exergame hardware. Exergame controllers that emulate the forms of objects in the user's everyday environment can help disassociate the hardware from a medical context. Designing a game controller in the form of a smart shoe that the user consider "fashionable" can attempt to break down stigmas of wearing a medical device in the home. 



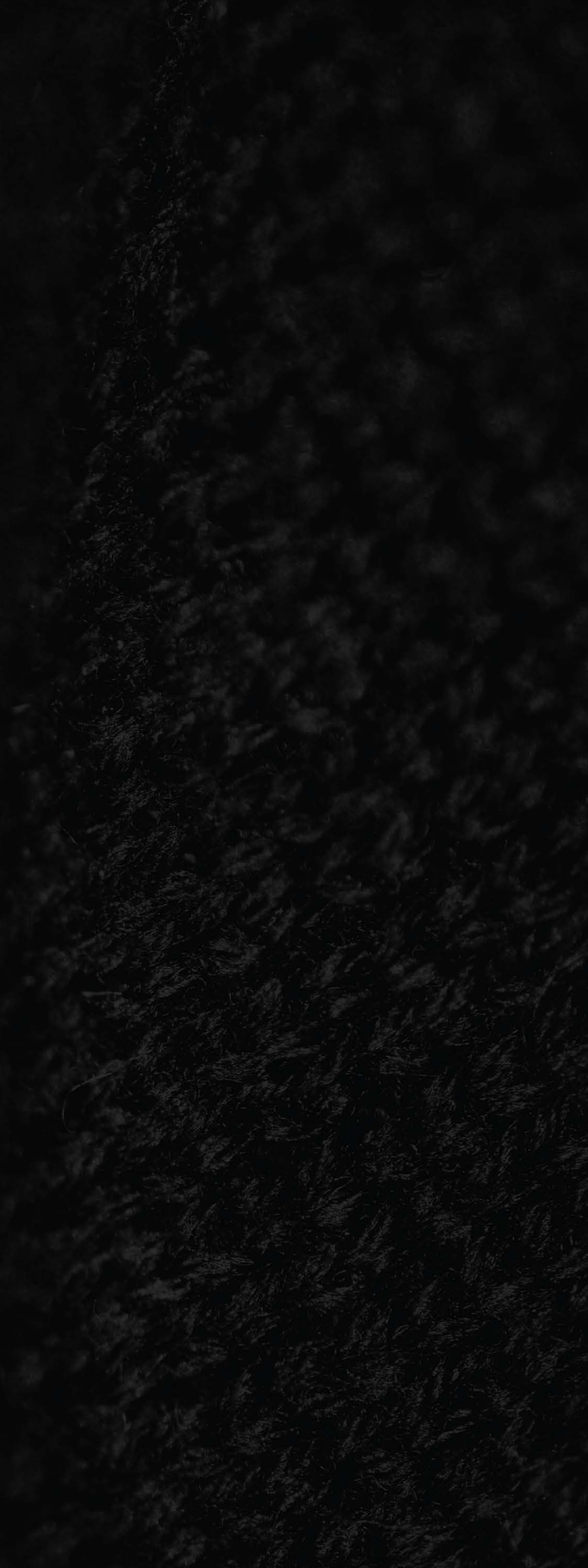




\section{CONCLUSION}

\section{Future work}

Some further developments need to be made to the system before it can be submitted to clinical trials. How the gaming engine interprets sensor data from the IMU needs to be explored to ensure accuracy. Accurate sensor data should be used to mitigate incorrect motions and promote proper form. Integration of an algorithm that diagnoses and progresses load and repetitions should also be investigated to keep Strength for Task Training (STT) intensive.

This research addressed one progression for increasing the intensity of the task component, (sideways stepping) by facilitating part/whole task modifications. Further design exploration in conjunction with the exergaming media should explore how the system can facilitate the other eight modifications in an unsupervised environment.

It is also important to remember STT relies on seven different exercises, each addressing the strengthening of different muscle groups and repeating task movements relevant to different areas of locomotion. Priming components hip flexion, hip extensors and quadriceps often require more load than the hip abduction and hamstrings. Further testing would help indicate if the load threshold of the design could also facilitate intensity of these exercises (clinician 1, personal communication, July 27, 2016). Further clinician involvement will also be needed to suitably adapt STT exercises for unsupervised environments. Further exploration of the hardware's functional requirements will then be required, in an attempt to facilitate a spectrum of locomotive exercises.

Expert opinions should be sought to gain insight into what other areas of rehabilitation the hardware could apply to. The application of a smart shoe that tracks lower limb movement, and a simple and safe way to strength train could benefit people recovering from traumatic brain injuries or conditions that impair locomotion such as cerebral palsy or muscular dystrophy.

As outlined by Shirzad et al., $(2015$, p. 3$)$ the final stage of their UCD process involves clinical testing with further functional modifications based on the results. Before clinical testing takes place, clinician-guided user testing should be conducted with a large user base consisting of individuals with a range of ability levels.

As discussed with clinician 1 (personal communication, July 27, 2016), clinical trials should look at how the user is instructed to set up and use the system against how they actually adhere to these instructions. The user base should extend to include participants with comorbidities that lead to poor circulation such as diabetes. This would help give a more accurate assessment of any skin integrity concerns that interaction with the hardware may create.

\section{Conclusion}

Stroke is a leading cause of disability in developing nations leading to impairments affecting patients' locomotion and limiting their independence. Research into exergames for rehabilitation is an emerging field, however the benefits they present make further exploration a necessity. STT is a novel intervention for lower-limb stroke rehabilitation that aims to promote gains in locomotion, however currently only practiced in a clinical environment. This research has contributed to the greater field of exergame rehabilitation tools by investigating how the design of an exergame controller could facilitate unsupervised STT as part of an exergaming system for lower limb stroke rehabilitation.

The functional and contextual requirements 
of an exergame controller were explored through background research and interviews with stroke clinicians. These initial requirements informed the design and prototyping of exergame hardware as part of an exergaming system for unsupervised STT.

Smart footwear that interacts with an adaptable strength training weighted sole was prototyped and tested. Functional requirements of the device promoted a way to strength train safely and comfortably through applying load to the lower limb. The weighted sole that provided load was removed to promptly begin task training in order to facilitate the merits of priming. The interactions with the system needed be intuitive and facilitate a one-handed interaction. Aesthetic consideration of the hardware indicated the device could disrupt the stigma of using medical devices in the home and become a meaningful object in the user's life.

Reviews with clinicians and feedback from user testing with stroke patients helped substantiate and build on the functional and contextual requirements, helping to better understand how exergaming hardware can facilitate clinical interventions like STT.

Although the findings were subjective, the involvement of clinicians and stroke survivors from the early stage of the design process helped minimise biases and assumptions. The growing population of stroke patients represent a diverse and complex demographic target group. The scope of this research allowed for a small user base, not fully representative of the needs of the wider stroke community. The final design could benefit from further testing with a wider user base of patients over longer periods of time.

There is a growing amount of research in the field of exergaming media design, however, little research furthering the design of purpose built game controllers has been done. There is undiscovered potential through a design approach to exergaming hardware. More case studies into these processes could help foster an abundance of novel and innovative design discoveries, broadening the abilities of home-based rehabilitation systems .

A complete exergaming system has been presented with meaningful hardware that is user friendly and provides a safe way to participate in home-based stroke rehabilitation. This research has proposed a way to enhance the lives of survivors of stroke, and potentially the wider population of people living with muscular disabilities such as multiple sclerosis and cerebral palsy. Further research into similar systems can benefit the ageing population and assist those seeking to reclaim their independence. 



\section{REFERENCES}


Alankus, G., Lazar, A., May, M., \& Kelleher, C. (2010). Towards customizable games for stroke rehabilitation. Proceedings of the 28th international conference on human factors in computing systems - $\mathrm{CHI}$ ' 10 . doi:10.1145/1753326.1753649

American Stroke Association. (2013, March 18). Spasticity. Retrieved from: http:// www.strokeassociation.org/STROKEORG/ LifeAfterStroke/Regaininglndependence/ PhysicalChallenges/Spasticity_ UCM_309770_Article.jsp

Bainbridge, E., Bevans, S., Keeley, B., \& Oriel, K. (2011). The effects of the Nintendo Wii Fit on community dwelling older adults with perceived balance deficits: A pilot study. physical \& occupational therapy in geriatrics, 29(2), 126-135.

Billis, A. S., Konstantinidis, E. I., Ladas, A. I., Tsolaki, M. N., Pappas, C., \& Bamidis, P. D. (2011). Evaluating affective usability experiences of an exergaming platform for seniors. 2011 10th International Workshop on Biomedical Engineering. doi:10.1109/ iwbe.2011.6079048

Blythe, M. A., Monk, A. F., \& Doughty, K. (2005). Socially dependable design: The challenge of ageing populations for $\mathrm{HCl}$. Interacting with Computers. doi:10.1016/j. intcom.2005.09.005

Booth, W. C., Colomb, G. \& Williams, J. M. (2008). The Craft of Research. Chicago: University of Chicago Press.

Bright, F. A. S., Kayes, N. M., Worrall, L., \& McPherson, K. M. (2014). A conceptual review of engagement in healthcare and rehabilitation. Disability and Rehabilitation, 37(8), 643-654.

Brunner, I., Skouen, J., Hofstad, H., Strand, L., Becker, F., Sanders, A., ... Pallesen, H. (2014). Virtual reality training for upper extremity in subacute stroke (VIRTUES): Study protocol for a randomized controlled multicenter trial. BMC Neurology, 14(186), 2-5. Retrieved from http://www. biomedcentral.com/content/pdf/s12883014-0186-z.pdf

Burke, J. W., McNeill, M. D. J., Charles, D. K., Morrow, P. J., Crosbie, J. H., \& McDonough, S. M. (2009). Optimising engagement for stroke rehabilitation using serious games. The Visual Computer 25$12,1085-1099$.

Crouch, C., \& Pearce, J. (2012). Doing research in design. 72-73. Oxford: Berg. Link: http://cypress.library.ubc.ca/ handle/2429/53099

Ding, Z., Luo, Z., Causo, A., Chen, I., Yue, K., Yeo, S., \& Ling, K. (2013). Inertia sensorbased guidance system for upper limb posture correction. Medical Engineering \& Physics, 35(2), 269-276. doi:10.1016/j. medengphy.2011.09.002

Duncan, P. W., Zorowitz, R., Bates, B., Choi, J. Y., Glasberg, J. J., Graham, G., Reker, D. (2005). Management of adult stroke rehabilitation care. Stroke, 36(9), 100-143.

Eng, K., Siekierka, E., Pyk, P., Chevrier, E., Hauser, Y., Cameirao, M., ... Kiper, D. (2007). Interactive visuo-motor therapy system for stroke rehabilitation. Medical \& Biological Engineering \& Computing. doi:10.1007/s11517-007-0239-1

Flores, E., Tobon, G., Cavallaro, E., Cavallaro, F. I., Perry, J. C., \& Keller, T. (2008). Improving patient motivation in game development for motor deficit rehabilitation. Proceedings of the 2008 International Conference in Advances on Computer Entertainment Technology ACE ‘08. doi:10.1145/1501750.1501839

Fritz, S. Peters, D. Merlo, A \& Donley, J. (2013) Active video-gaming effects on balance and mobility in individuals with chronic stroke: a randomized controlled trial, Topics in Stroke Rehabilitation, 20(3), 
Gerling, K. M., Schild, J., \& Masuch, M. (2010). Exergame design for elderly users: The case study of Silver Balance. In Proceedings of the 7th International Conference on Advances in Computer Entertainment Technology, 66-69.

Gil-Gómez, J., Lloréns, R., Alcañiz, M., \& Colomer, C. (2011). Effectiveness of a Wii balance board-based system (eBaViR) for balance rehabilitation: A pilot randomized clinical trial in patients with acquired brain injury. Journal of NeuroEngineering and Rehabilitation, 8(1), 30. doi:10.1186/17430003-8-30

Goodman, R. N., Rietschel, J. C., Roy, A., Jung, B. C., Diaz, J., Macko, R. F. \& Forrester, L. W. (2014). Increased reward in ankle robotics training enhances motor control and cortical efficiency in stroke. Journal of Rehabilitation Research and Development, 51(2), 213-228. doi:10.1682/ jrrd.2013.02.0050

Görgü, L., Campbell, A. G., McCusker, K., Dragone, M., O'Grady, M. J., O'Connor, N. E. \& O'Hare, G. M. (2012).

Freegaming: Mobile, collaborative, adaptive and augmented exergaming. Mobile Information Systems, 8(4), 287-301.

doi:10.1155/2012/549173

Hijmans, J. M., Hale, L. A., Satherley, J. A., McMillan, N. J., \& King, M. J. (2011). Bilateral upper limb rehabilitation after stroke using a movement based game controller. The Journal of Rehabilitation Research and Development, 48(8), 1005.

Hore, N. S. (2014). A motion-detection biology-based learning game for children. Potentials, IEEE, 33(6), 31-36. Retrieved fromhttp://ieeexplore.ieee.org/xpls/abs_ all.jsp?arnumber $=6954598 \& \mathrm{tag}=1$

IMeasureU. (2016). Retrieved from http:// imeasureu.com/

Karatepe, A., Gunaydin, R., Kaya, T., \&
Turkmen, G. (2008). Comorbidity in patients after stroke: Impact on functional outcome. J Rehabil Med, 40(10), 831-835. doi:10.2340/16501977-0269

Kelley, J. F. (1984). An iterative design methodology for user-friendly natural language office information applications. ACM Transactions on Information Systems, 2(1), 26-41. http://doi. org/10.1145/357417.357420

Kleim, J. A. (2011). Neural plasticity and neurorehabilitation: Teaching the new brain old tricks. Journal of Communication Disorders, 44(5), 521-528. doi:10.1016/j. jcomdis.2011.04.006

Kopacz, J. (2003). Residential applications. In Color in Three-Dimensional Design (pp. 212 - 218). New York, NY: McGraw-Hill.

Kroemer, K. H. (2006). "Extra-ordinary" ergonomics: How to accommodate small and big persons, the disabled and elderly, expectant mothers and children. Boca Raton, FL: Taylor \& Francis.

Kuniavsky, M. (2003). Observing the User Experience. Burlington, US: Morgan Kaufmann. Retrieved from http://www. ebrary.com

Kuniavsky, M., Goodman, E., \& Moed, A. (2012). Observing the user experience: A practitioner's guide to user research (2nd ed). Amsterdam, Boston: Morgan Kaufmann.

Levin, M. F., Weiss, P. L., \& Keshner, E. A. (2015). Emergence of virtual reality as a tool for upper limb rehabilitation: Incorporation of motor control and motor learning principles. Innovative Technologies Special Series, 95(3), 415425. Retrieved from http://ptjournal.apta. org/content/ptjournal/95/3/415.full.pdf

Luque-Moreno, C., Ferragut-Garcías, A., Rodríguez-Blanco, C., Heredia-Rizo, A., Oliva-Pascual-Vaca, J., Kiper, P. \& Oliva-Pascual-Vaca, A. (2015). A decade of progress using 
virtual reality for poststroke lower extremity rehabilitation: Systematic review of the intervention methods. BioMed Research International, 1-5. Retrieved from http:// www.hindawi.com/journals/bmri/ aa/342529/

Magnetic Closing Shirts With Shirt Magnet Buttons. (2015). Retrieved from http://www. silverts.com/show.php/product/40100magnetic-buttons-mens-short-sleeve-shirtarthritis-parkinsons-mens-magnetic-closingshirts-with-shirt-magnet-buttons

Martin, A. L., Götz, U., Müller, C., \& Bauer, R. (2014). "Gabarello v.1.0" and "Gabarello v.2.0": Development of motivating rehabilitation games for robot-assisted locomotion therapy in childhood. Games for Health 2014, 101-104. doi:10.1007/9783-658-07141-7_13

Martin, B., \& Hanington, B. M. (2012). Universal methods of design: 100 ways to research complex problems, develop innovative ideas, and design effective solutions. Beverly, MA: Rockport Publishers.

Medical ID Bracelets. (2016). Retrieved from https://www.laurenshope.com/

McDonagh, D. \& Thomas, J. (2010). Disability + relevant design: Empathetic design strategies supporting more effective new product design outcomes. The Design Journal, 13(2), 180-198

Milton, A., \& Rodgers, P. (2013). Research methods for product design. London: Laurence King.

Mortazavi, B., Nyamathi, S., Lee, S. I., Wilkerson, T., Ghasemzadeh, H., \& Sarrafzadeh, M. (2014). Near-realistic mobile exergames with wireless wearable sensors. IEEE Journal of Biomedical and Health Informatics, 18(2), 449-456. doi:10.1109/jbhi.2013.2293674

Mozaffarian, D., Benjamin, E. J., Go, A. S., Arnett, D. K., Blaha, M. J., Cushman,
Turner, M. B. (2015). Heart disease and stroke statistics. A Report From the American Heart Association. Circulation, 131(4), e29-e322.

Nahid Norouzi-Gheidari, M. F., \& Levin, J. F. (2014). Interactive virtual reality gamebased rehabilitation for stroke patients. Archambault School of Physical and Occupational Therapy, 1. Retrieved from http://ieeexplore.ieee.org/stamp/stamp. jsp?tp $=$ \&arnumber $=6662126$

Nike. (2015, July 13). Nike News - The FLYEASE Journey. Retrieved from http:// news.nike.com/news/the-flyease-journey

Perry, J., Garrett, M., Gronley, J. K., \& Mulroy, S. J. (1995). Classification of walking handicap in the stroke population. Stroke, 26(6), 982-989. doi:10.1161/01.str.26.6.982

Pullin, G. (2009). Design meets disability. Cambridge, MA: MIT Press.

Rubin, J., \& Chisnell, D. (2011). Handbook of usability testing: How to plan, design, and conduct effective tests. Indianapolis, IN: Wiley.

Scherer, K. R. (2005). What are emotions? And how can they be measured? Social Science Information, 44(4), 695-729. doi:10.1177/0539018405058216

Shaughnessy, M., Resnick, B. M., \& Macko, R. F. (2006). Testing a model of post-stroke exercise behavior. Rehabilitation Nursing,31(1), 15-21. doi:10.1002/j.2048-7940.2006.tb00005.x

Shirzad, N., Valdes, B., Hung, C.-T., Law, M., Hay, J., \& Van der Loos, M. (2015). FEATHERS, A bimanual upper limb rehabilitation platform: A case study of user-centred approach in rehabilitation device design. In Design for Life (pp. 361-370). Milan, Italy: University of British Columbia.

Signal, N. (2014) Strength for Task Training: A novel intervention to improve locomotor 
ability following stroke (Unpublished Doctoral Thesis). Auckland University of Technology, Auckland, New Zealand.

Sinclair, J., Hingston, P., \& Masek, M. (2007). Considerations for the design of exergames. Proceedings of the 5th International Conference on Computer Graphics and Interactive Techniques in Australia and Southeast Asia - GRAPHITE '07. doi:10.1145/1321261.1321313

Stipe, D. (2015, May 1). Incorporating Aesthetic design into medical products. Nasa Tech Briefs: Medical Design Briefs. Retrieved from http://www. medicaldesignbriefs.com/component/ content/article/mdb/features/22067 Unisex Stroke Shoes - Silvert's Adaptive Clothing \& Footwear. (2015). Retrieved from http://www.silverts.com/show.php/ list/unisex/shoes/stroke-clothing

Unity - Game Engine. (n.d.). Retrieved from https://unity3d.com/

WHO. (2002). Innovative care for chronic conditions: Building blocks for action. Noncommunicable Diseases and Mental Health, 0108.

WHO (n.d.). The Atlas of Heart Disease and Stroke. Retrieved March 23, 2015, from http://www.who.int/cardiovascular_ diseases/resources/atlas/en/

WHO (2016) Definition of an older or elderly person. Retrieved from http://www.who.int/ healthinfo/survey/ageingdefnolder/en/

Whitehead, A., Johnston, H., Fox, K., Crampton, N., \& Tuen, J. (2011). Homogeneous accelerometer-based sensor networks for game interaction. Computers in Entertainment (CIE), 9(1), 1-18. doi:10.1145/1953005.1953006

YouRehab - Interactive Rehabilitation Systems. (2015). Retrieved fromhttp://yourehab.com
Xu Xu, R. W. (2015). Accuracy of the Microsoft KinectTM for measuring gait parameters during treadmill walking. Gait \& Posture, 42(2), 145-151. Retrieved from http:// ac.els-cdn.com/S0966636215004622/1s2.0-S0966636215004622-main.pdf? tid =d2915e92-40a1-11e5-865f-00000aacb 361\&acdnat $=1439350127 \_2547 d b 46 c 327 a$ 869d4ff9804a3017b70

Zeisel, J. (1993). Inquiry by design: Tools for environment-behaviour research (reprint). Cambridge: Cambridge University Press. 

FIGURE LIST 
Figure 1.2 - Jintroix in Use

Jintronix (2015) Kinect Rehabilitation Software. Retrived from http://www. jintronix.com/

Figure 1.3 - Wii Balance Board in Use

Pittman, G (2008) Doctor's Orders: Play Video Games. Retrived from http://scienceline. org/2008/12/tech-pittman-wii-video-gametherapy/

Figure 1.4 - Aimee Mullin's wooden leg designed by Alexander Mcqueen

McQueen, A (2010) Ensemble, No. 13, spring/summer 1999. Retrived from http:// blog.metmuseum.org/alexandermcqueen/ tag/no-13/

Figure 1.5 - Matthew Walzer's custom Nike FLYEASE shoes

Nike. (2015). The FLYEASE Journey. Retrieved from http://news.nike.com/news/theflyease-journey

Figures $5.2,5.3 \& 6.2$

Figures courtesy of fellow researcher Scott Brebner

Figures 1.1, $2.1-5.1,5.4-6.1 \& 6.3-7.12$

All images, tables and figures made by author. 
APPENDIX 


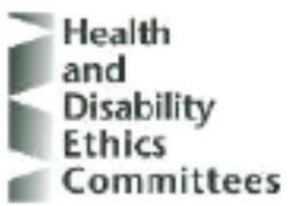

Health and Disability ethics Committe

$$
\begin{array}{r}
\text { Mnis ty of Hed } \\
\text { Freyberg Build } \\
20 \text { Aitken Ste } \\
\text { PO Box } 501 \\
\text { Welingt: } \\
601 \\
08004 \text { ETHIC } \\
\text { hdecodmohgont }
\end{array}
$$

10 February 2016

Dr Brian Robinson

Graduate School of Nursing, Midwifery \& Health

PO Box 7625

Newtown 6242

Dear Dr Robinson

\begin{tabular}{lll}
\hline$R e:$ & Ethics ref: & $16 / C E N / 5$ \\
& Study ftle: & $\begin{array}{l}\text { Developing Interactive Devices and Games for Physical Therapies } \\
\text { in Stroke Recovery }\end{array}$ \\
&
\end{tabular}

This application was reviewed by the Central Health and Disability Ethics Committee and provisionally approved pending receipt of further information. This decision was made through the HDEC-Full Review pathway.

\section{Summary of Study}

This study is a joint collaboraf on between the Victoria University of Wellington School of Design and the Victoria Universily Graduate School of Nursing. Midwifery and Health and senior physiothera pists at AUT University in Auckland. It is a 'usa bility' study which will aim to test two things: software and computer controllers in stroke patients as potentially useful rehablitation aids.

The research team is seeking ethical approval for $4-5$ design projects ewery 3 year for 3 years so for 12-15 projects and around 100 participants. There is not one particular piece of software but students will build on previous students' workso the software and physical controllers may vary over the three years.

The researchers intend to test in the participant's home. A design student will explain the device and watch the participant use the device and record the partidipant using the device with a sensor and photograph/videos and secondy interview the participant and record data.

\section{Summary of etrical issues (resolved)}

The main ethical issues considered by the Committee and were addressed by the Researcher are as follows.

- The committee asked what 3-4 projects are lined up for this year. Dr Robinson explained that one project involved students developing games guiding an astronaut around a screen that would inform other projects. The overall aim is to create a blanket application to cover these students. Dr Robinson expl ained that the same game will always be used but a dfferent style of mouse will be tested. The games will be made progressively more dificult to help enhance movement This game "level $1^{\text {P }}$ will be tested to see whether stroke patients an us the device. The idea is to use upper limb movement to stimulate neural plasticity and students will create a portlolio of games with these devices. 
The committee queried whether the design students might need support. Dr Robinson advised that the students will be in their 208 . The students do not have a health background and a physiotherapist will support them in dealing with health issues ethically. Structure set up where both students and people in the community have protocols in place. Focussing purely on upper limb.

[ The commi ttee asked whether the participants in this study will have a degree of cognifive impairment and if so how will the research team assess this.

Robinson advised that they are anticipafing that pafients who are unimpaired are the ones who will make contact with the researchers. There is currently no formal screening process and the researchers were not intending to recruit through dinicians.

0. The committee asked to see the wording that will be used for the recruitment tyers.

[ The committee noted the answer stated at question $p .4 .3$ on page 22 of the application form that consultation with Mar on is not required. The committee reminded the researchers that formal consultation is required $\mathrm{MC}$ formal consultation with Malori is required for all research in New Zealand that involves Marori. Dr Robinson thought that the answer may have been stated in error and noted for the committee that they had consulted with Professor Rawina Tumaki, Head of the School of Marori studies regarding the cultural issues of this research programme who had offered useful feedback for the research team. Please provide the name and contact details of a Masoni support person who parficipants can contact. The committeen oted that 'Whakama' is a cultural issue for some Mar on and that protocols for behaving in people's homes need to be observed.

0. The committee noted that it is dffcult for them to give a blanket approval for the ongoing updates to the software and controllers when they don't know what they will be. With this in mind the committee agreed to approve the cur rent study protocol but requested that the research team submit each update as a substantial amendment via Online Forms for this committee to consider. Please include updated participant information shee ts with each amendment and indude updated version numbers and dates on the updated documen 18 .

\section{The committee requested the following changes to the participant information sheet and} consent forms:

0 Page 2, What will my participation in the study involve?': The committee noted the statement that the session should take no more than 30 minutes and was concerned that this might set the expectaton that partcipants would have to make this fime. In parfipan ts who have experienced a severe stroke 30 minutes may be too long to concentrate.

0 Page 2, What are the possible benefits and risks of this study?: the committee noted that the informafon provided here appeared to be a contradictory and could be confusing for partcipants. On the one hand it stated that people should do rehabilitation for several hours a day and on the other hand the researchers intend to take the devices away after the session. Dr Robinson confirmed that they are not wanting to use the device as a therapeuf c device at this stage but to find out whether it might be useable as a therapeutic device. Please make this dear to participants.

0. The committee noted that the research team intend to take and use images but this is not clearly spelt out in the participant information sheet and consent forms. The committee advised that if the researchers are going to use images then they need to tell people clearly and they need to seek consent for that as well.

0 The committee asked how the researchers intend to make sure that any photos taken are unidenffiable. Dr Robinson explained that they will use a standard technique of blurring facial images and images of participant's houses will notbe used. Please make this clear to participants. 
D. The committee asked what kind of device the researchers intend to use to record the images and noted that there are issues of confidentiality associated with recording. Dr Robinson advised that Victoria University of Wellington School of Design cameras will be used and the images taken will be deleted from the cameras. The committee asked that this information be induded in the participant cameras. The comm

0. Please submit the wording that will be used for the recruitment fyers.

- Please provide the name and contact details of a Misori support person who partidipants can contact

- Please make dear to partid pants what will happen in this study - for example. that that studen's will come to their home and please make dear arrangements for the safety of students. For example that they don't travel to the house alone and that they take cell phones with them.

0 Consent form please only include yes/no boxes for statements that are truly optional (i.ethat a person could still participate if they an swer ' $n o$ ')

[ Please provide a 24 hour contact number for the lead inwestigator and for the supervisor for this study. While you are not studying participants with acute problems, students will be going to participants' homes in the evening and the requirements are that there is a 24 hour contact number.

\section{Further information requested}

The further informafion requested in order for the Central Health and Disability Ethics Committee to make a final decision is as follows.

0 Please amend the information sheet and consent forms, taking in to account the suggestons made by the Committee (Ehical Guidelines for interventian Studies para 6.22).

Iimeline for providing further information, and for giving a final opinion

You have 90 days to provide this further information. Your appli cation will be considered to have been withdrawn if this information is not received on or before 10 May 2016. A new application would be required in this case.

The 35-day clock within which a final decision must be made on this study is suspended as of the date of this letter. This clock on which 16 days remain, will restart on the date on which all of the further information requested above is received by the Central Health and Disability Etrics Committee.

Please remember to track changes made to new versions of documentation. 
searchers intend to use to record infidentiality associated with versity of Wellington School of ien will be deleted from the tion be induded in the participant

- The committee asked what kind of device the res Macrultment fyers.
the images and noted that there are issues of col the images and noted that there are issues of $c 0$ recording. Dr Robinson advised that Victoria Un
Design camen in this study - for example, camer as. The committee asked that this informa information sheet.

n't travel to the house alone

Q Please submit the wording that will be used for

- Please provide the name jand contact details of partidipants can contact

for statements that are truly

(ey answer 'no')

- Please make dear to partic pants what will happ lead inwestigator and for the that that studen's will come to their home and piling participants with acute for the safety of students. For example that they do number. and that they fake cell phones with them.

- Consent form please only include yes/no boxes. optional (i.eth at a person could still participate if thi

D Please provide a 24 hour contact number for the 1 Health and Disability Ethics supervisor for this study. While you are not stud problems, students will be going to participants' ho requirements are that there is a 24 hour contact

\section{Further information requested}

int forms, taking in to account the uidelines for intervention Studies

The further informafion requested in order for the Centra Committee to make a final decision is as follows.

- Please amend the informafion sheet and cons ur application will be considered suggestons made by thil 10 May 2016. A para 6.22).

Timeline for

iade on this study is suspended
remain, will restart on the date

You have 90 days to provide this further information. $\mathrm{Yc}^{\mathrm{s}}$ 3 received by the Central Health to have been withdrawn if this "information is not receiver new application would be required in this case.

The 35-day clock within which a.final decision must be on is of documentation. as of the date of this letter. This clock, on which 16 daye on which all of the further information requested above and Disability Ethics Committee,

Please remember to track changes made to new versio: 


\section{How to respond to a Provisional Approval}

You will need to submit your new or amended documents through Online Forms.

New versions of existing documents :

Steps

Screenshots

1. Go to the Documents Tab to upload the revised documentation requested by the secretariat

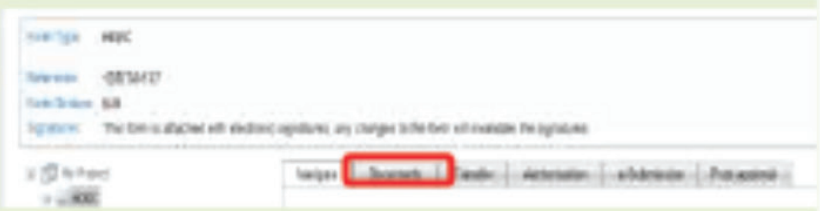

2. To update versions of documents, go to the List tab. Select View/Man age to upload a newer version of the document.

1 For example you can upload new versions of the PISICF

0 Remember to track changes.

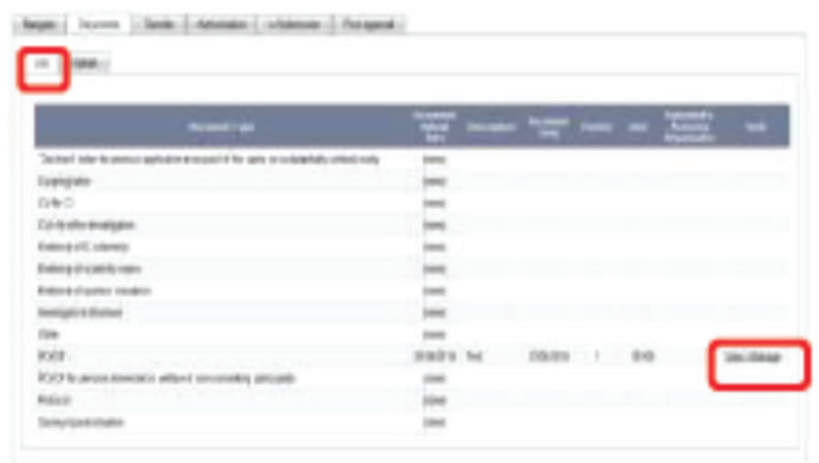

3. When you click ViewManage for a particular document it will take you to the upload tab for that document.

U Update the version number and document date.

D Browse to find the new version of the flle.

Q Click Upload New Version'

a Once the upload is complete the history will populate with the new version.

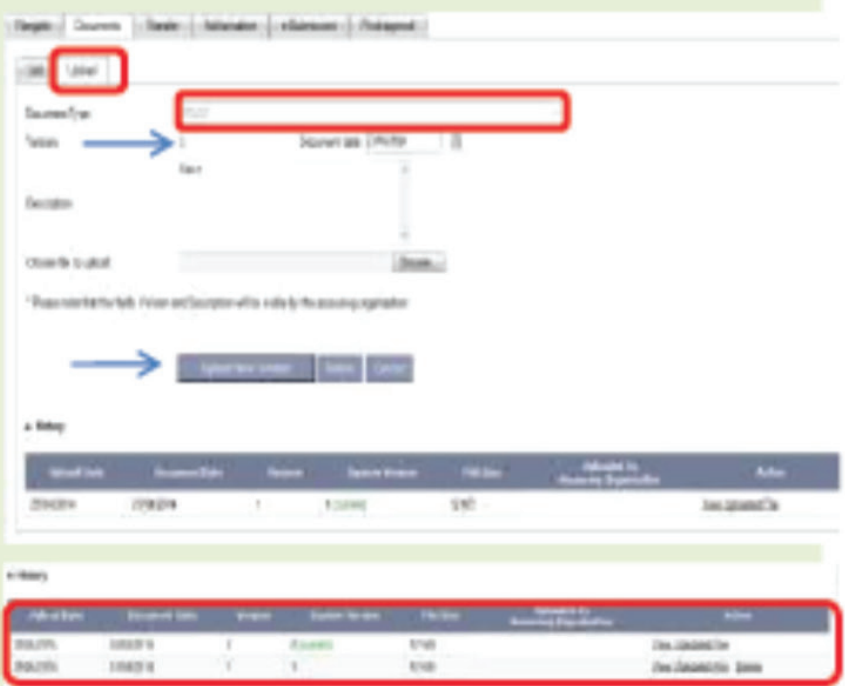


New documents:

Steps

Screenshots

4. For New documents, go to the upload tab.

¿ For example you can upload a word document responding to questions raised by the Committee.

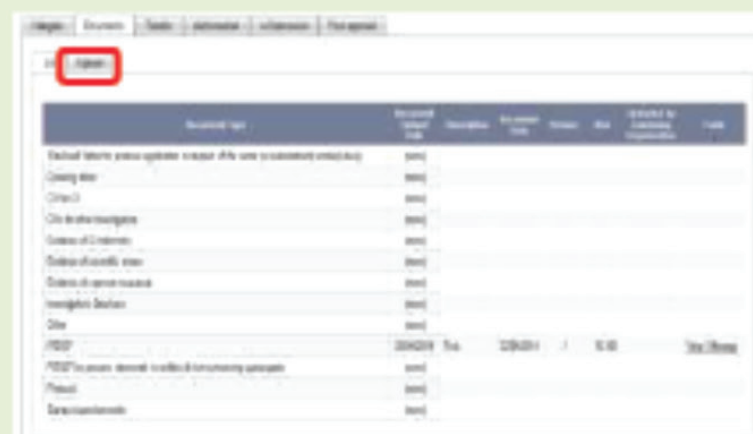

5. Select the document type. Add a version number, document date and add a description if required.

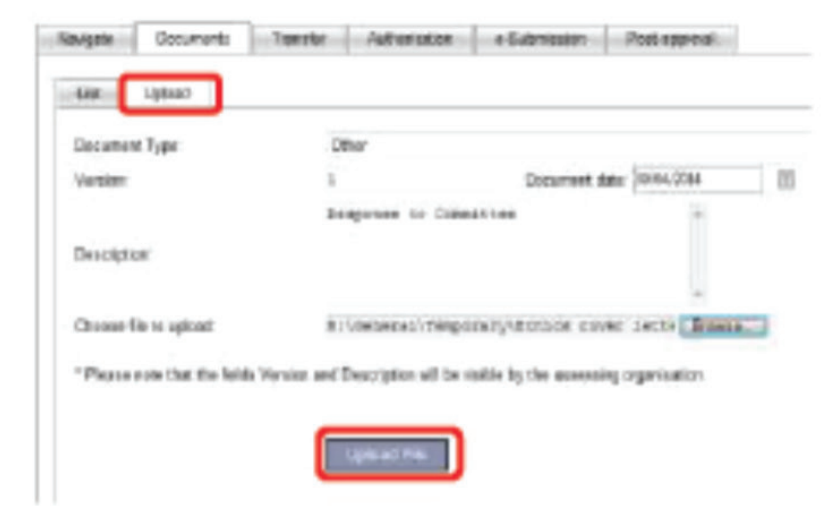

Browse your computer to find the new file and select Upload File.

6. The new document will now be uploaded and visible on the List Tab.

-in-in-ine

Before submitting check to see all your documents are on the List tab and are displaying the correct vers ion and document date.

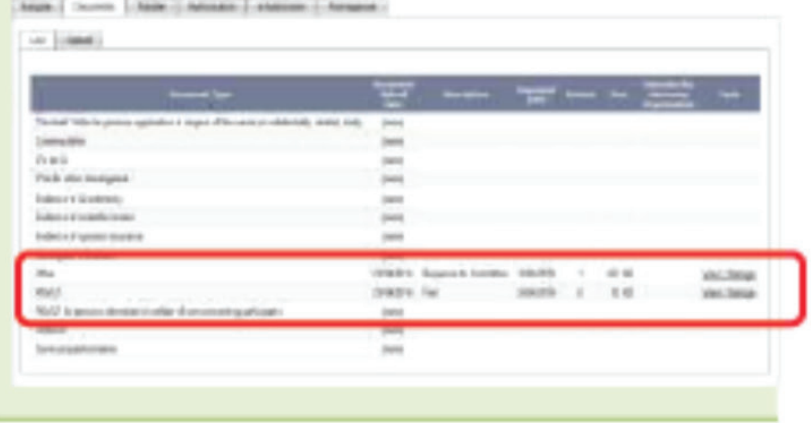


To submit:

7. Once you have uploaded all new documents of updated all exising documen's click the E-Submissions tab.

8. Scroll down until you see 'Provisional Approval Response'.

This button will only be able to be used when you have received a 'Provisional A pproval' letter.

Please note: only click submit once.

Please don't hesitate to contact the HDEC secretariat if you have any queries. We look forward to receivingyour response.

Yours sincer ely.

Mrs Helen Walker

Chairperson

Central Health and Disability Ethics Committee

Enct: appendx $\mathrm{A}$ : documents submitted

appendx B: statement of compliance and list of members 
Appendix A

Documents submitted

\begin{tabular}{|l|l|l|}
\hline Document & Version & Date \\
\hline Covering Lefter: Covering Letter & 1 & 11 December 2015 \\
\hline CV for Cl: Cl CV & 1 & 11 December 2015 \\
\hline Evidence of scientific review. Peer Review & 1 & 11 December 2015 \\
\hline Protocol: Protocol for Research & 1 & 11 December 2015 \\
\hline $\begin{array}{l}\text { Survey/questionnaire: Demographic questions and examples of } \\
\text { quesfions for semi-structured interviews }\end{array}$ & 1 & 11 December 2015 \\
\hline PIS/CF: Participant Information and Consent Form & 1 & 11 December 2015 \\
\hline Application & & \\
\hline
\end{tabular}




\section{Appendix B}

Statement of compliance and list of members

\section{Statement of compliance}

The Central Health and Disability Etrics Committee:

0. is constituted in accordance with is Terms of Reference

0 operates in accordance with the Standard Operating Procedures for Health and Disabiwty Ethics Committees, and with the principles of intemational good dinical practice (GCP)

0 is approved by the Health Research Coundil of New Zealand's Ethics Committee for the purposes of section 25(1)(c) of the Health Research Council Act 1990

0 is registered (number 00008712) with the US Department of Health and Human Services' Office for Human Research Protect ion (OHRP).

Ust of members

\begin{tabular}{|l|l|l|l|l|l|}
\hline Name & Category & Appainted & $\begin{array}{l}\text { Term } \\
\text { Expires }\end{array}$ & $\begin{array}{l}\text { Present an } \\
28 / 01 / 2016 ?\end{array}$ & $\begin{array}{l}\text { Declaration } \\
\text { of interest? }\end{array}$ \\
\hline $\begin{array}{l}\text { Mrs Helen } \\
\text { Walker }\end{array}$ & $\begin{array}{l}\text { Lay } \\
\text { (consumer/community } \\
\text { perspectives) }\end{array}$ & $01 / 07 / 2012$ & $01 / 07 / 2015$ & Yes & No \\
\hline $\begin{array}{l}\text { Dr Angela } \\
\text { Ballantyne }\end{array}$ & $\begin{array}{l}\text { Lay (ethical/mor al } \\
\text { reasoning) }\end{array}$ & $01 / 07 / 2015$ & $01 / 07 / 2018$ & No & No \\
\hline $\begin{array}{l}\text { Dr Melissa } \\
\text { Cragg }\end{array}$ & $\begin{array}{l}\text { Non-lay (observational } \\
\text { studes) }\end{array}$ & $01 / 07 / 2015$ & $01 / 07 / 2018$ & No & No \\
\hline $\begin{array}{l}\text { Dr Peter } \\
\text { Gallagher }\end{array}$ & $\begin{array}{l}\text { Non-lay } \\
\text { (health/disability } \\
\text { service provision) }\end{array}$ & $01 / 07 / 2015$ & $01 / 07 / 2018$ & Yes & No \\
\hline $\begin{array}{l}\text { Mrs Sandy } \\
\text { Gill }\end{array}$ & $\begin{array}{l}\text { Lay } \\
\text { (consumer/community } \\
\text { perspecfives) }\end{array}$ & $30 / 07 / 2015$ & $30 / 07 / 2018$ & Yes & No \\
\hline $\begin{array}{l}\text { Dr Patries } \\
\text { Herst }\end{array}$ & $\begin{array}{l}\text { Non-lay (intervention } \\
\text { studes) }\end{array}$ & $27 / 10 / 2015$ & $27 / 10 / 2019$ & No & No \\
\hline $\begin{array}{l}\text { Dr Dean } \\
\text { Quinn }\end{array}$ & $\begin{array}{l}\text { Non-lay (intervention } \\
\text { studies) }\end{array}$ & $27 / 10 / 2015$ & $27 / 10 / 2021$ & Yes & No \\
\hline $\begin{array}{l}\text { Dr } \\
\text { Cordelia } \\
\text { Thomas }\end{array}$ & $\begin{array}{l}\text { Lay (ethical/moral } \\
\text { reasoning) }\end{array}$ & $19 / 05 / 2014$ & $19 / 05 / 2017$ & Yes & No \\
\hline
\end{tabular}

Unless members resign, vacate or are removed from their office, every member of HDEC shall confinue in office until their successor comes into office (HDEC Terms of Reference)

\section{http: Hwww.ethics.health govt.nz}




\section{Participant Information Sheet}

Study title:

Locality:

Lead investigator:
Interactive Devices and Games for Stroke Recovery

Wellington Ethics committee ref.:

Brian Robinson
VICTORIA

UNIVERSITY OF WELLINGTON TE WHARE WĀNANGA
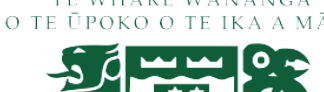

You are invited to take part in a study on $[x]$. Whether or not you take part is your choice. If you don't want to take part, you don't have to give a reason, and it won't affect the care you receive. If you do want to take part now, but change your mind later, you can pull out of the study at any time.

This Participant Information Sheet will help you decide if you'd like to take part. It sets out why we are doing the study, what your participation would involve, what the benefits and risks to you might be, and what would happen after the study ends. We will go through this information with you and answer any questions you may have. You do not have to decide today whether or not you will participate in this study. Before you decide you may want to talk about the study with other people, such as family, whānau, friends, or healthcare providers. Feel free to do this.

If you agree to take part in this study, you will be asked to sign the Consent Form on the last page of this document. You will be given a copy of both the Participant Information Sheet and the Consent Form to keep.

This document is 6 pages long, including the Consent Form. Please make sure you have read and understood all the pages.

\section{WHAT IS THE PURPOSE OF THE STUDY?}

This study is to develop computer controllers and computer games that can be used by people who are recovering from stroke. This is for rehabilitation that they can carry out by themselves at home.

We are wanting to know how you find using the computer, the controller and the game. Our aim is that these will easy to use and understand as well as challenging and rewarding. It is also important that the movements made when using the games will help with stroke rehabilitation.

These devices and games are developed by students as a requirement for their Masters degree. This research is funded by the School of Design at Victoria University of Wellington. Any other questions you have can be answered by Dr. Brian Robinson (463 6155) This research has been approved by the Health and Disability Ethics Committee. 
We asked you to take part in this research because you have had a stroke in the past 12 months and may have limited use of one of your legs or arms.

We will ask some questions about you such as how old you are, your ethnic background, how long ago you had the stroke and how the stroke affects you now.

We will show you a computer, a computer controller and a game

You will be asked to use the computer and the control device to play a computer game.

You can play this game for as long as you like and can tell us when you want to stop.

We will take a video and photographs of you using this computer controller and game. This is to make sure that using the controls and the game in ways that will be useful for stroke recovery and not cause harm. Stroke rehabilitation physiotherapists will review these recordings.

We will ask you for your thoughts on using the computer control and game. We will record what you say.

This should take no more than 30 minutes. You may be invited to take part again if you would like to help us test changes.

\section{WHAT ARE THE POSSIBLE BENEFITS AND RISKS OF THIS STUDY?}

We know that people who have had stroke cannot access stroke rehabilitation therapy regularly. They have to travel to clinics or hospital. We also know that rehabilitation is more effective when it is carried out for several hours throughout day, every day.

This study is to support people who have had a stroke to provide stroke rehabilitation therapy in their home. This can be by themselves or with the help of carer support or family members.

This does not replace any other therapy you may be receiving.

While you are using the computer and playing the game you will be sitting in a chair. We will want you to stay sitting.

\section{WHO PAYS FOR THE STUDY?}

This study is funded by Victoria University of Wellington and the School of Design through medical technology research grants from the Ministry of Business, Innovation and Employment.

You will not incur any costs by taking part and we will travel to you.

\section{WHAT IF SOMETHING GOES WRONG?}

If you were injured in this study, which is unlikely, you would be eligible for compensation from ACC just as you would be if you were injured in an accident at work or at home. You will have to lodge a claim with ACC, which may take some time to assess. If your claim is accepted, you will receive funding to assist in your recovery. 


\section{WHAT ARE MY RIGHTS?}

You are volunteering to take part. You do not have to take part in this study and you can withdraw at anytime.

We can show you the video recording and photographs of you we have collected. We can also give you a copy of what we have recorded you saying to us about using the computer device and game.

It is unlikely that participating will affect your health but if it does, we will contact you immediately.

We will not identify you in any of the students work or presentations of the work.

\section{WHAT HAPPENS AFTER THE STUDY OR IF I CHANGE MY MIND?}

After you have taken part and change your mind about being involved, please contact the researcher (the design student) or the lead investigator (Brian Robinson) and any data, information and images associated with your participation will be destroyed.

We will securely store the information and data you have provided for five (5) years and it will then be destroyed.

We can present the findings of this study at stroke clubs within a year of conducting the study.

We can also send you a summary of the student's thesis describing the outcome of the study.

We may also present this study with other similar studies we are conducting at conferences or in books or journals.

\section{WHO DO I CONTACT FOR MORE INFORMATION OR IF I HAVE CONCERNS?}

If you have any questions, concerns or complaints about the study at any stage, you can contact:

Dr Brian Robinson, Senior Lecturer, Graduate School of Nursing, Midwifery \& Health, Victoria University of Wellington.

(04) 9349321

brian.robinson@vuw.ac.nz 
If you want to talk to someone who isn't involved with the study, you can contact an independent health and disability advocate on:

\begin{tabular}{|c|c|}
\hline Phone: & 0800555050 \\
\hline Fax: & 08002 SUPPORT (0800 2787 7678) \\
\hline Email: & advocacy@hdc.org.nz \\
\hline
\end{tabular}

For Maori health support please contact your health provider and they will refer you to the representative Maori health support group.

You can also contact the health and disability ethics committee (HDEC) that approved this study on:

Phone: $\quad 08004$ ETHICS

Email: hdecs@moh.govt.nz 


\section{Consent Form}

If you need an INTERPRETER, please tell us.

If you are unable to provide interpreters for the study, please clearly state this in the Participant Information Sheet

Please tick to indicate you consent to the following (Add or delete as appropriate)

I have read, or have had read to me in my first language, and I understand the Participant Information Sheet.

Yes $\square \quad$ No $\square$

I have been given sufficient time to consider whether or not to participate in this study.

Yes $\square \quad$ No $\square$

I have had the opportunity to use a legal representative, whanau/ family support or a friend to help me ask questions and understand the study.

Yes $\square \quad$ No $\square$

I am satisfied with the answers I have been given regarding the study and I have a copy of this consent form and information sheet.

Yes $\square \quad$ No $\square$

I understand that taking part in this study is voluntary (my choice) and that I may withdraw from the study at any time without this affecting my medical care.

Yes $\square \quad$ No $\square$

I consent to the research staff collecting and processing my information, including information about my health.

Yes $\square \quad$ No $\square$

If I decide to withdraw from the study, I agree that the information collected about me up to the point when I withdraw may continue to be processed.

Yes $\square \quad$ No $\square$

I understand that my participation in this study is confidential and that no material, which could identify me personally, will be used in any reports on this study.

Yes $\square \quad$ No $\square$

I understand the compensation provisions in case of injury during the study.

Yes $\square \quad$ No $\square$

I know who to contact if I have any questions about the study in general.

Yes $\square \quad$ No $\square$

\begin{tabular}{llc}
\hline I understand my responsibilities as a study participant. & Yes $\square$ & No $\square$ \\
\hline I wish to receive a summary of the results from the study. & Yes $\square$ & No $\square$
\end{tabular}

wish to receive a summary of the results from the study. 
Declaration by participant:

I hereby consent to take part in this study.

Participant's name:

Signature:

Date:

Declaration by member of research team:

I have given a verbal explanation of the research project to the participant, and have answered the participant's questions about it.

I believe that the participant understands the study and has given informed consent to participate.

Researcher's name:

Signature:

Date: 


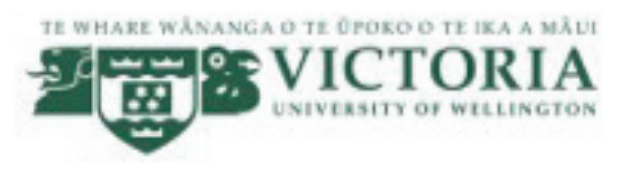

\section{Designing a System for Stroke Rehabilitation INFORMATION SHEET FOR PARTICIPANTS}

Thank you for your interest in this project. Please read this information before deciding whether or not to take part. If you decide to participate, thank you. If you decide not to take part, thank you for considering my request.

\section{Who am I?}

My name is William Duncan and I am a Masters student in the School of Design at Victoria University of Wellington. This research project is work towards my thesis.

\section{What is the aim of the project?}

This project aims to design a system of physical devices and videogames that help stroke patients carry out their physical rehabilitation. This research has been approved by the Victoria University of Wellington Human Ethics Committee [23011].

\section{How can you help?}

If you agree to take part I will interview you in your office, a meeting room in the School of Design's campus or in a public place, such as a café. I will ask you questions about stroke rehabilitation. I will audio record the interview and write it up later. We will construct a set of criteria and designs that facilitate stroke rehabilitation based on the findings from the research. In a second interview, we will seek your feedback about the new designs. Each interview will take 60 minutes. You can stop the interviews at any time, without giving a reason. You can withdraw from the study up to four weeks after the first interview. After this time, we will use the information you provide to design new objects. You can also withdraw your information for the second interview up to four weeks after it occurs. If you withdraw, the information you provided will be destroyed or returned to you.

\section{What will happen to the information you give?}

This research is confidential. I will not name you in any reports, and I will not include any information that would identify you. Only my supervisors and I will read the notes or transcript of the interview. The interview transcripts, summaries and any recordings will be kept securely and destroyed 3 years after the research ends.

\section{What will the project produce?}

The information from my research will be used in my Masters thesis. You will not be identified in my report. I may also use the results of my research for conference presentations, and academic reports. I will take care not to identify you in any presentation or report. 


\section{If you accept this invitation, what are your rights as a research participant?}

You do not have to accept this invitation if you don't want to. If you do decide to participate, you have the right to:

- choose not to answer any question;

- $\quad$ ask for the recorder to be turned off at any time during the interview;

- $\quad$ withdraw from the study up until four weeks after your interview;

- $\quad$ ask any questions about the study at any time;

- $\quad$ receive a copy of your interview recording (if it is recorded);

- $\quad$ read over and comment on a written summary of your interview;

- $\quad$ agree on another name for me to use rather than your real name;

- be able to read any reports of this research by emailing the researcher to request a copy.

If you have any questions or problems, who can you contact?

If you have any questions, either now or in the future, please feel free to contact either:

\section{Student:}

Name:

University email address:

\section{Supervisor:}

Name: Dr Edgar Rodriguez

Role: Programme Director Industrial Design

School: School of Design

Phone: 045636544

edgar.rodriguez@vuw.ac.nz

\section{Human Ethics Committee information}

If you have any concerns about the ethical conduct of the research you may contact the Victoria University HEC Convener: Associate Professor Susan Corbett. Email susan.corbett@vuw.ac.nz or telephone +64-4-463 5480. 


\section{STI}

\section{Designing a System for Stroke Rehabilitation CONSENT TO INTERVIEW}

Researcher: Dr Edgar Rodriguez, School of Design, Victoria University of Wellington.

- I have read the Information Sheet and the project has been explained to me. My questions have been answered to my satisfaction. I understand that I can ask further questions at any time.

- I agree to take part in an audio recorded interview.

I understand that:

- I may withdraw from this study up to four weeks after the first interview or up to four weeks after the second interview reviewing the designs, and any information that I have provided will be returned to me or destroyed.

- The information I have provided will be destroyed 5 years after the research is finished.

- $\quad$ Any information I provide will be kept confidential to the researcher and the supervisor. I understand that the results will be used for a Masters/PhD report and a summary of the results may be used in academic reports and/or presented at conferences.

- My name will not be used in reports, nor will any information that would identify me.

- I would like a summary of my interview:

Yes $\square$ No $\square$

- $\quad$ I would like to receive a copy of the final report and have added my Yes $\square \quad$ No $\square$ email address below.

Signature of participant:

Name of participant:

Date:

Contact details: 
Document A2 - Permission to be

Photographed

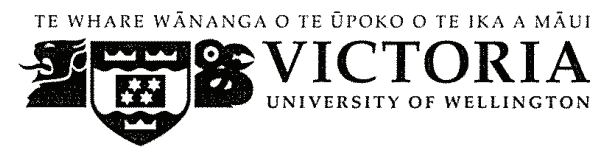

\section{Designing a System for Stroke Rehabilitation \\ CONSENT TO BE PHOTOGRAPHED}

Researchers: Scott Brebner and William Duncan, Master of Design Innovation Students, Victoria University of Wellington.

Supervisor: Dr Edgar Rodriguez-Ramirez, School of Design, Victoria University of Wellington.

- I have read the Information Sheet and the project has been explained to me. My questions have been answered to my satisfaction. I understand that I can ask further questions at any time.

- I agree to have my photo taken and used in any academic publications of this work.

I understand that:

- $\quad$ No photos will be taken of me in which I can be identified.

- My name will not be credited in the images to protect my privacy.

Signature of participant:

Name of participant:

Date:

Contact details: 


\section{Appendix A - Background Research}

\section{Additional Notes on a Research Session with clinician 2}

The Ideal Practitioner The role of the practitioner extends further beyond assessment and prescription of therapy. The practitioner must also represent certain ideals in order to help engage the patient with their rehabilitation. The practitioner must work to understand the subjective experience of the patient following their stroke and identify their hopes, aspirations and goals.

Aspiration > Goals (in rehabilitation) > Tasks (therapeutic tasks/exercises)

Aspiration: eg, being able to walk down the driveway to get the mail Rehabilitative Goals: Improve leg strength and improve gait Tasks: Complete 400 repetitions of toe ups and heel raises (Clinician 2, personal communication, August 10, 2015).

To facilitate patient engagement in rehabilitation, Clinician 2 described four ideals the practitioner needs to represent:

Entrusting - Patients need confidence in the skills and competence of their practitioner. The patient must be able to trust that they will do the right thing for them and that the practitioner has their best interests at heart.

Investing - Practitioners have a real emotional investment in the rehab process.

Reciprocating - The clinician is engaged and reciprocates in an emotional way so the patient knows that they are completely involved in the process.

Adaptability - Adapt, tailor, respond to a patients needs in the moment as they progress through rehab is one of the key elements.

Knowing - The practitioner has to understand who the patient is as a human being in order to adapt and be responsive. This is essential in order to know how to connect the aspirations.

Adaptability is probably the most relevant in terms of practitioner ideals that can be represented in an exergaming system (clinician 2, personal communication, August 10, 2015). Background research explored the way exergame media had facilitated adaptability through changing in-game parameters (Alankus et al., 2010; Flores et al., 2008; Levin, et al., 2015; Gil-Gomez et al., 2011; Alankus et al., 2010). However, as addressed in the background, there is an opportunity to explore how exergame hardware can also adapt to the patients needs as they progress through their rehabilitation. Strength for task training adapts load to ensure the strength-training portion of the programme is consistently intensive for the patient (Signal, 2014, p. 49). The task training portion uses progression across nine different parameters to increase the intensity of the task. One progression, part task/whole task, increases the difficulty of the part task from one single step forward (part task) to stepping up a stepladder (whole task) (Signal, 2014, p. 55). There could be potential for the hardware to facilitate intensity through adapting the load of the controller, and ensuring the form allows for part/whole tasks to be performed.

\section{Interview with nurse 1}

Nurse 1 was able to run us through the dayto-day experience of a few stroke patients she has worked with. There was also discussion about the major contributing factors that lead to the patient being able to live at home independently, needing parttime assistance or full-time assistance. Fulltime assistance usually required the patient to live in an assisted living home as the cost of full-time in-home care is expensive alongside the cost of adapting a domestic environment to cater for a stroke patient. Semi-assisted living 
may involve a caregiver helping the stroke patient in their home everyday with certain activities such as cooking and cleaning or can involve the patient being picked up into care everyday or several times a week. This would allow their primary caregiver, often a spouse or close family member time to work or complete other necessary activities.

If a person only has physical limitations, have adaptations to their home and they dont have the safety, balance and falling issues then they are ok to live at home.

\section{Balance is the first big factor in considering} a stroke patients independence. If they have trouble walking and/or are always tripping over things then they can become a fall risk and would be considered for assisted living or full time care.

Issues of neglect are major contributors to justify someone s need for assisted care. Patients that suffer hemiparesis may have the inability to visualise the affected part of their body. This makes tasks of independence such as cooking or cleaning dangerous as the patient would be at risk of burning themselves.

Continuing issues of neglect such as hygiene must also be taken into account. Adaption can be made to the patients home to allow them to adequately dress and clean themselves as well as giving them a certain amount of mobility around their home, however these can be costly.

Cognitive deficiencies as well as mood and depression are final factors when considering a patients ability to live unassisted. There becomes potential for the patient to cause harm to themselves when cognitive impairments detriment the individuals ability to assess risk. The patients mood is also taken into account because depression can cause the patient to become a risk to themselves. Mood management may also become too hard to mitigate for the patients spouse or family.
Spasticity is also considered but is not usually a major barrier to a persons independence. Small modifications can be made and implemented to the users clothes and objects to mitigate spasticity and contractures of the affected limbs. However, nurse 1 did address that it is a contributing factor towards having a higher quality of life and enjoying activities in a similar way to pre stroke. An example was that if you enjoy going for long walks but you dont have fine motor control (eg. you slightly drag your leg) you will fatigue very quickly. Nurse 1 addressed that there is wasted potential in how refined motor control can be of the lower limb. Contemporary attitudes towards rehabilitation are not getting people the most beneficial recovery they could be. Current priorities of lower limb rehabilitation focus on getting the patient mobile then working on rehabilitating the upper limb.

Nurse 1 then went on to describe two stroke patients she has worked with. Both with different ideologies, physiological and physiological factors pre- and post-stroke as well as having different cognitive ability.

The first stroke patient nurse 1 described was a Maori male in his mid 70s but is ten years post stroke (suffered his stroke mid 60s). His stroke caused hemiparesis to the left side of his body, contractures in his hand, chronic shoulder pain and depression which he takes anti-depressants for. Edema in the affected upper-limb makes him prone to skin conditions such as cellulitis. He takes antibiotics regularly for this. His comorbidities involved afribulation of the heart. Afribulation involves the desynchronisation of the four heart valves and results in the formation of small blood clots that lead to his stroke. He takes blood thinners for this. Environmental factors pre-stroke involved a lack of exercise, poor diet and smoking. Damage to his brain caused by the stroke has affected his mobility and he must now use a walking aid. He suffers a lot of frustrations as pre-stroke he was a highly functioning older adult who was well educated. He used to enjoy playing the guitar and a tin whistle but is unable to do so post-stroke. He now lives in assisted living full-time 
due to safety issues as well as his spouse finding his mood hard to manage.

Day-to-day living begins with someone assisting him to wash. His deficient balance causes him to be unsafe in the shower and contractures in his arm make it hard to clean one side of his body. Spasticity has also made it hard for him to independently wash one side of his hand. Adaptations are used on his clothing to help him remain as independent as possible in dressing himself. Velcro is used instead of buttons, longer and larger zips and grasping mechanisms on his socks. His cognitive inability to assess risks mean he has to be supervised when doing tasks such as making a tea and he is unable to cook a whole meal. He also finds it hard to concentrate for long periods of time making cognitively demanding exercises such as reading a book hard for him to do. These inabilities frustrate him as he enjoyed these rituals on a day-to-day basis pre-stroke.

\section{Personas}

Anika - Female - 82 - Mosgiel, Dunedin - 6 Months Post-stroke

Bio - Anika has always been determined to live independently in her own home even before her stroke six months ago. Her mind remains strong and her determination has enabled her to persist with early clinical rehabilitation. Her early progress developing mobility and balance after suffering hemiparesis has enabled her to remain living at home with the constant support of her children. Weekly clinical therapy sessions have been crucial to this positive outcome as Anika thrives off feedback with her clinicians whom she has a strong social bond with. The lack of feedback in practicing her exercises at home has caused her to lose interest quickly and subsequently fail to exert her affected limbs the same way as experienced in her assisted therapy. She lives on a large lifestyle block in rural Dunedin with her daughter and grandchildren. A reasonable about of walking around the property was part of her daily routine when maintaining her garden and supervising her grandchildren can be physically demanding. She is frustrated as she feels she has reached a plateau in her recovery and until she can increase her dose of rehabilitation daily she will fatigue quicker. This compromises her participation in her passions such as maintaining her prizewinning garden and tending to her homegrown fruit and vegetables.

Condition - Left hemiparesis with very small cognitive effect; muscle weakness in her lower extremity and contractures of the hand; sufficient balance and mobility however drags her foot when walking making her fatigue easily; and rheumatoid arthritis in her hands.

Passions - Playing with her grandchildren; gardening; and socialising at the local farmers market where she sells her produce.

Goals for rehabilitation - Anika is determined to regain as much of her former functionality as possible and allow her to continue to live in her home environment for as long as she is physically capable of doing so.

Rehabilitation needs - Anika needs a homebased rehabilitation system that can provide her with real time feedback about her form and micro/macro rehabilitation goals. She also needs constant feedback on maintaining correct form when completing exercises. Contractures in her affected upper limb mean that any interactions requiring both hands need to be ergonomically designed to accommodate for spasticity

Comorbidities - Rheumatoid arthritis in her hands.

Environmental Factors Pre/Post - Rural living on a lifestyle block means Anika must negotiate inconsistent terrain in order to complete her daily activities such as getting the mail from the letterbox or taking the rubbish out. Anika is still able to complete these tasks but she is severely fatigued by them now.

Ideological Factors - Anika believes that the outcome of her rehabilitation is the product of her own determination when adequately 
supported by her family and clinicians.

Nikau - Male 76 - Avonhead, Christchurch 18 Months Post-Stroke

Bio - Before his stroke last year Nikau was a highly functioning and successful architect well-known to the local Christchurch community of creatives. Both he and his wife lived completely independently maintaining full-time jobs and enjoyed the broad social circles they were involved with. The demand of his work caused Ernest to neglect his health in the later years of his career. Heavy smoking and a sedentary lifestyle caused atrial fibrillation of his heart and inevitably contributed to his stroke causing hemiparesis and the immobilization of one side of his body. This has caused massive cognitive and physiological impairment and he now must walk with the assistance of a walking aid. His inability to concentrate for long periods of time has forced him into retirement causing him to fall into depression. He has accepted that he will not be able to return to work full time but is determined to regain enough mental capacity to work on projects from home at his own pace. Nikau has major balance issues but his successful career as an architect has afforded him the ability to make the needed adjustments to continue living at home under the assistance of his wife. He goes to supervised therapy sessions twice a week but his engagement with the therapy is lacking as he is very judgmental of his peers and only enjoys the company of those who he can relate to directly. He completes his home therapies religiously but is unable to see the tangible benefits of the exercises and seeks quantitative feedback of his progress. He also finds that his home-based therapy is unable to adequately adapt to the small improvements he makes causing him to feel like he is repeating futile exercises. Nikau is very house proud and appreciates the subtleties of the furniture and decor he has invested in. He is very self-conscious of having too many clinical devices lying round his house and hates feeling like he lives in a hospital.
Condition - Muscle weakness in his affected limbs, severe spasticity and lack of balance.

Passions - Socialising with his friends, painting and sketching.

Goals for rehabilitation - Nikau wants to retain enough mobility to start exercising and leading a more active life to aid him in retaining his former level of cognition.

Rehabilitation needs - A system that compensates for his problems with balance. Aesthetically fits into his home environment. It must engage him cognitively as well as physically, adapt to his progress and give him feedback on how well he performed.

Comorbidities - Atrial fibrillation of his heart, Edema, Cellulitis.

Environmental Factors Pre/Post Stroke Negotiating cars and people in the car park when he goes grocery shopping, leading a reasonably sedentary life pre-stroke.

Ideological Factors considering rehabilitation - Nikau did not exercise regularly so the high exertion required to complete his rehabilitation is new to him and he is slowly learning to adjust through encouragement from his spouse.

Ernest - Male - 68 - Newtown, Wellington - 3 Years Post Stroke

Bio - After his stroke 3 years ago Ernests wife found it hard to cope with the fulltime assistance she had to give him. Ernest suffered severe balance issues and muscle weakness down the left side of his body. Effects to his cognition mean it is hard for Ernest to visualize the affected side of his body putting him at risk of injury himself when completing activities unsupervised. Ernest and his wife were able to afford certain adaptations to their home to carry out certain tasks such as getting Ernest washed and dressed but part-time assistance was decided on. Ernest is picked up at 9am every morning and taken to an assisted living facility where he partakes in activities and assisted 
rehabilitation and dropped back home at $4 \mathrm{pm}$. Ernest was initially bound to his bed after his stroke and has come a long way in regaining mobility. He worked for 40 years as a factory foreman so physical exertion is familiar to him. This has benefited his rehabilitation and got him to a point where he has a certain amount of mobility, however engagement with his home rehabilitation programme is lacking. His chronic shoulder pain restricts his range of motion making complex movements hard for him and his deteriorating eyesight makes it hard for him to follow instructions of new rehabilitative techniques from his occupational therapist. Ernest and his wife have had little to do with technology but Ernest is open to the idea of integrating it into his therapy programme but identifies with analog interfaces more than digital GUI.

Condition - Severe muscle weakness and cognitive deficiencies as well as chronic shoulder pain and deteriorating eyesight.

Passions - Bird watching, reading and taking his dogs on walks.

Goals for rehabilitation - To be able to walk unassisted so he can go on extended walks in the native bush surrounding Wellington.

Rehabilitation needs - User friendly and intuitive device that requires minimal amount of interaction (yak shaving) that compensates for is poor eyesight and portable enough to enable him to use the device in home and take it with him to the assisted living facility.

Comorbidities - Glaucoma is causing his deteriorating eyesight

Environmental Factors Pre/Post - Ideological Factors considering rehabilitation - Ernest believes his recovery is dictated by the clinician, the DHB and his familys investment in him. However, from his work as a foreman he is used to the feeling of high physical exertion. 


\section{Appendix B - Expanded Notes from Reviews}

Initial Concepts Review w/ Research Supervisors \& Peers - 17/09/15, 24/09/15, 1/10/15

- More priority needs to be given to the aesthetics of the devices

- Literature suggests that gamification of lower limb stroke rehabilitation could mitigate the need for splinting when attempting to treat spasticity. Therefore it could be counter intuitive to combine a wearable game controller with a splint

- Demographics need to be more clearly defined to start to narrow down what the device can/cannot address.

- The aesthetics of all devices are too clinical and utilitarian.

- When taking a designerly approach to the creation of lower limb home-based stroke rehabilitation a device's aesthetics can have a major effect on the patient's engagement with the device and subsequently their engagement with the rehabilitation.

- There is also opportunity to address the cultural stigmas associated with medical devices through the consideration of aesthetics.

- The context of the controller needs to be more clearly defined.

- Does the controller need to integrate splinting technology to mitigate spasticity, drop foot, lock knee, etc?

- The idea of combining a traditional splint with a game controller may not be valid as there is literature that suggests high and frequent doses of rehabilitation reduces spasticity.

- Concepts are too broad in their applications.
- Explore ways of facilitating load by adding weight.

- Ankle strap with sensors is the easiest way to track lower limb movement.

- What can other designs offer that a basic ankle strap cannot?

- Would the technical nature of a game controller make its use seem complicated to an older adult who is not used to technology.

Review 1: w/ clinician 1, clinician 3 \& clinician 4 - 14/10/15

Feedback:

The first review of concepts involved overview of the information identified through literature and design reviews and the initial workshop session with clinicians and how they have influenced design criteria for developing concepts. Criteria were not critiqued and it was suggested that they were inline with what the clinicians would consider important to the development of the controller's design. There was an important issue that clinician 1 brought to attention that I had not thoroughly addressed in my current research, that being skin integrity.

Skin integrity is the skin's natural ability to remain healthy, whole and intact. The ability of skin to retain its integrity decreases with age. Stroke does not necessarily cause problems with skin integrity but "comorbidities" (diseases co-occurring with the stroke) common with older adult stroke patients such as peripheral vascular disease can. Pressure from clothing, bed linen, pillows and even certain mattresses can cause pressure sores and tearing of the skin. This is a factor when considering the ergonomics of anything a patient could be wearing for extended amounts of time.

- Sensor placement needs to be defined and tech needs to be demoed to allow a digital visualisation of movements in real time. This will be achieved by resolving the software issues with Node, a Java Script protocol 
and the IMU. Concepts One, Two and Three were viewed to provide adaptability through changing load and salient to the context in which rehabilitation would take place.

- Consider the co-morbidities and skin integrity of the patient when designing devices worn on the skin.

- Concept 2 will have issues with skin integrity and the locomotive ability needed to put on a compression pant.

- Concept 2 is not clearly defined.

- Something with the great resistance would not be able to be put on with one hand so it does not address the spasticity of the affected limbs.

- Pressure in certain areas would be localised and could cause pressure sores or skin tearing in patients with poor skin integrity.

- An automated wrapping system would be more appropriate so pressure could be applied in the appropriate places and a simple pulling movement could suffice in engaging the device with the patient's physiology.

- Resistance is hard to achieve when applied directly to the physiology of the patient. Bandaging for resistance works only as a tactile cue, suggesting the body should move in a specific way. The use of weight to simulate resistance is more beneficial and is easier to quantify for adapting it to the patient's progress.

\section{Review 2 w/ clinician 1 - 16/03/16}

Feedback:

- Would the clinician set the receptions maximum and if so how do you inform the recommendations for the clinician?

- Regarding the STT parameters, there are 9, but each has a drop down menu on the digital version with 5-7 options each.
- You should be selective about what parameters to include for both game and shoe, focus on maybe 2 .

- What parameters to focus on:

- Load. Make sure it is sufficient load. If done with a resistance band, there should be no abnormal movement and this depends on how it is tied, what it is tied to.

- Check the line of pull on the shoe

- Resistance bands need to be distributed across the skin evenly, the more surface area the band can take up, the more comfortable the band will be on the skin of the patient.

- Soles: If they have different squishiness, the person has to rely more on their vestibular system and this may be a problem as they might fall.

- Shoe: Stronger and more obvious back bit to pull when putting on.

- Sitting on chair and tying resistance band to leg would work for knee extension but not for knee flexion.

- Inclusion criteria:

- Hemiplegic with walking disability.

- No significant musculoskeletal pain that would stop them from exercising.

- No cognitive or perceptual problems that would stop them from engaging.

- $\quad$ No massive visual neglect.

- $\quad$ Medically stable after stroke.

- $\quad$ Disregard the 12 months.

- $\quad$ Recruit from stroke clubs.

- Do purposeful sampling, 
at least one of each:

- $\quad$ left hemiplegia

- $\quad$ right hemiplegia

- $\quad$ severe walking disability

- $\quad$ almost close to normal walk speed

- $\quad$ no stable foot to test boot

- $\quad$ Have the caregiver along.

- $\quad$ Interviews are best

\section{Review 2.1 w/ clinician 1 - 06/04/16}

- Resistance band training is not facilitated effectively in the home due to the fall risk of being anchored to something and strong mounting points are needed.

- Most resistance band exercises when unsupervised are not intensive enough to warrant any benefit to the patient.

- Weighted soles may provide enough load for hip abduction due to the large torque forces involved versus the small muscle used in the exercise. Weighted soles and resistance bands will unlikely be able to replace the load provided by a westminster pulley during hip extension exercises as the gluts are large muscles.

\section{Review 3 w/ clinician 1 - 03/05/16}

- Velcro is a concern to FDA acceptance as it can house bacteria; a solution would be to encourage the user to wear socks.

- New weight device could provide load equal to that provided by the westminster pulley and resistance bands.

- Should be looking for a range of participants, male/female, left and right hemisphere with different ranges of deficits.
- Use two therapists to guide the process (old and young).

- The shoe should be intuitive enough to put on and use with no instruction needed.

Review 4 w/ Clinician 1 - 27/07/16

- The shoe looks good and especially to get on and off.

- Streamlining the design of the weighted component and removing as much bulk as possible would be good.

- Replacing resistance band is a valid outcome of the design. Using resistance bands unsupervised are a "nightmare" for patients. This system has mitigated this and has potential for strength training therapies beyond STT.

- Its unrealistic to have people lift the foot onto the opposite knee, many cannot do this. The release mechanism could be refined perhaps a back and up pull rather than back and down? Alternatively a push down action with the other foot.

- If the weighted sole causes the foot to be too high in a stationary position, hip hitching can occur as compensation.

- Highlights the impact of peripheral oedema and swelling on the foot.

- Performs abduction incorrectly (including external rotation with abduction) Can the IMU enable feedback about quality of movement?

- Hardness of the weighted sole must be considered. Does it have the potential to hit the other leg? Surface quality will make a difference in this respect. A smooth hard surface could bruise the patient. However a rough surface has the potential to break the skin and cause infection.

- Progression for priming: increase strength 
and decrease repetitions.

- Start at 15 progress to 12/10/8rm w/ more weight.

- Idealy 5 to $8 \mathrm{rm}$.

- Embed calculation for weight and rm into the system to indicate how much load to apply and how many repetitions they should do:

- Use age, weight, height and normative data to find an approx starting weight.

- Ask them to do a set at approx weight.

- Do as many as possible until failure.

- The system then calculates $1 \mathrm{rm}$.

- Each session record weight and rm plus get the user's feedback on how intensive it was (Easy/Med/Hard).

- "If you can individualise the programme you are more likely to be effective 'one size fits all' doesn't work" intensity must be right and dose must be right to be effective and engage the user. Hard work = sense of success. Do not underestimate the power of hard work."

- Potential fall risk with weight applied.

Clinical trials should look at how the user is instructed to set up the system and use the system versus how they actually follow the instructions to setup and use in their environment to encourage users to be safe.

- Further testing with patients who have other comorbidities such as diabetes that might further compromise skin integrity.

- Would likely facilitate hamstring-priming component.

- Further testing to see if intensive priming can be facilitated for hip flexion, hip extensor and quadriceps. These often requires more load than hip abduction and hamstrings. 


\section{Appendix C - User Testing}

\section{Document C1 - Over-the-Phone Questions}

(Inclusion Criteria)

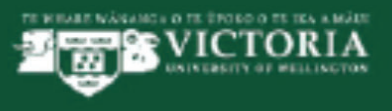

SCHOQ OF DEsIGN To Kura Hacho

FACURTY OF ARCATECTURE \& DEEICEN To Whanga Wh hanga thathas

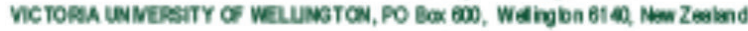

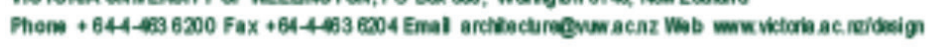

\section{INTERVIEW QUESTIONS (over the phone)}

Inclusion Criteria:

[ Have you experienced a strokebefore/have cared for someone who has?

口 Did you experience left or right hemiplegia?

Q What is your shoe size?

[ How has your stroke affected your arms or legs?

口. How has your stroke affected your walking?

๒ Can you stand independently and lift one foot while standing?

0 Do you have any muscular or skeletal related pain?

口 Can you tell me how fast you can walk?

a Will a caregiver be with you during the sessions and interviews?

Recovery:

v What are your recovery goals?

v What do you do for stroke therapy in your own bome?

v In the hast week, on average, how much time do you spend each day on this?

v Do you use any devioes to assist you with bome therapy?

Technology:

- How much time do you spend using computers, the internet, smartphones, or tablets each day?

- Do you find technology easy or difficult to use?

๑ Which bits are easy, which bits are difficult?

- Have you played digital games before? 


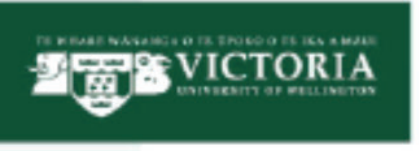

SCHOC OF DESION TO Kura Hoaho

FACU TY OF AACHTECTURE S OESICN To Whanga Whangationho

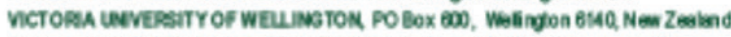

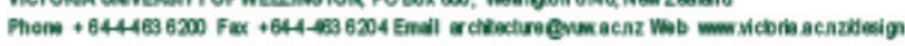

\section{USER TESTING INTERVIEW}

(For each question we will be looking for an answer in regards to the media and the device itself, prompting if necessary)
A. What parts of the experience did you enjoy? Why?
B. Was there anything you did not understand or enjoy? Why?
C. How do you think the system could be improved?
D. At any point, did you experience pain or discomfort? 
SCHOOL OF DESIGN Te Kura Hoahoa

FACULTY OF ARCHITECTURE \& DESIGN Te Wāhanga Waihanga-Hoahoa

VICTORIA UNIVERSITY OF WELLINGTON, PO Box 600, Wellington 6140, New Zealand

Phone + 64-4-463 6200 Fax +64-4-463 6204 Email architecture@vuw.ac.nz Web www.victoria.ac.nz/design

Participant:

\section{USER TESTING INTERVIEW 3}

(For each question we will be looking for an answer in regards to the footwear, prompting if necessary)

A. What parts of the experience did you enjoy? Why?

B. Was there anything you did not understand or enjoy? Why?

C. How do you think the footwear could be improved?

D. At any point, did you experience pain or discomfort? 
E. Please indicate your feelings towards the footwear's appearance using the Geneva Emotion Wheel below:

(you will be taken through an example first)

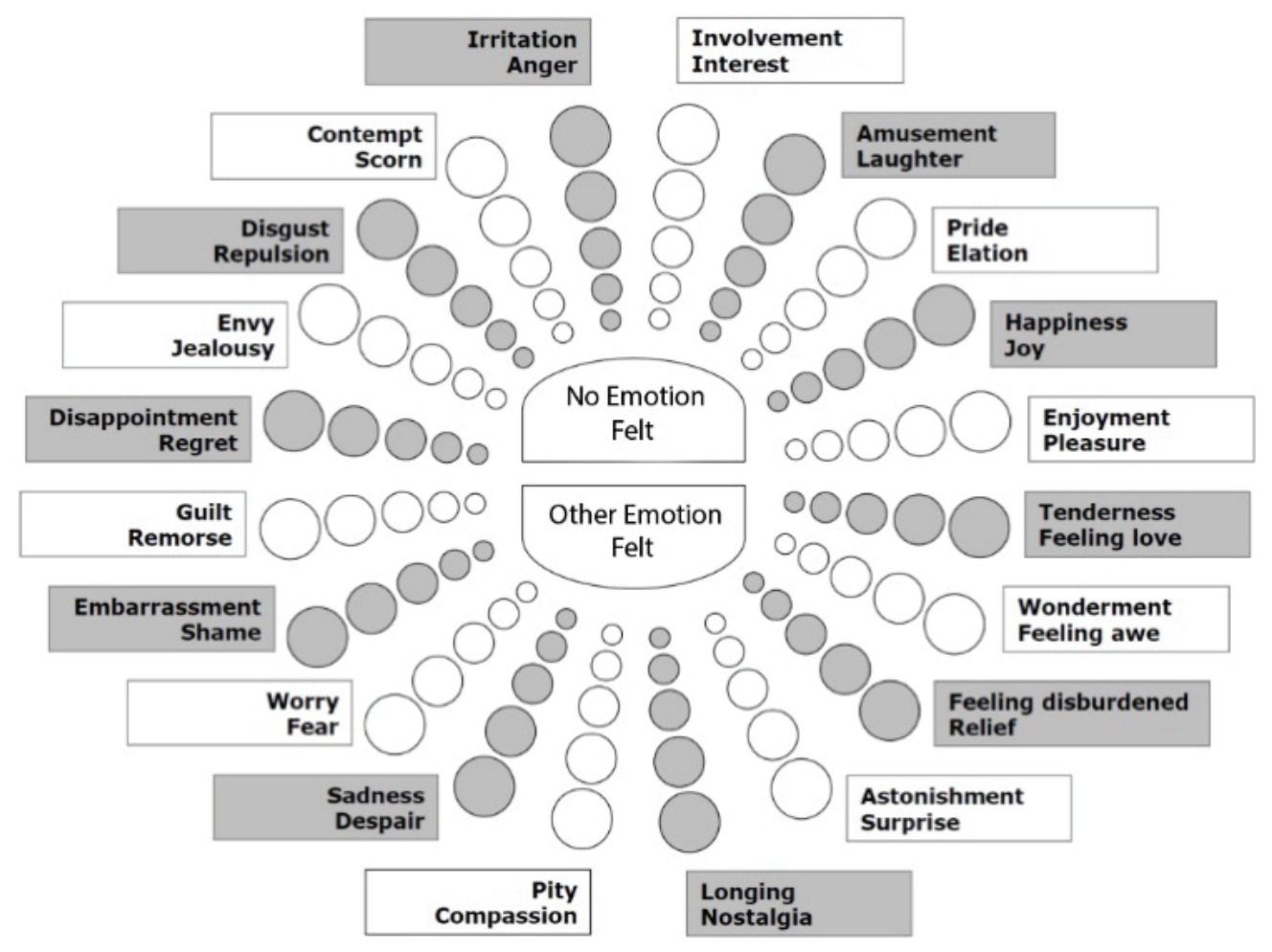

("You might decide for none, one, or two emotions first and then indicate each emotion's intensity independently by choosing a smaller circle for lower intensity or a bigger circle for higher intensity. If you do not feel any emotion towards the footwear/weighted sole's appearance make a cross in the centre of the wheel at "no emotion felt". If you feel an emotion which is not described by the presented emotions please write its name in the centre of the wheel below "other emotion felt").

F. Could you please comment on your choices? 
G. Please indicate your feelings towards the weighted sole's appearance using the Geneva Emotion Wheel below:

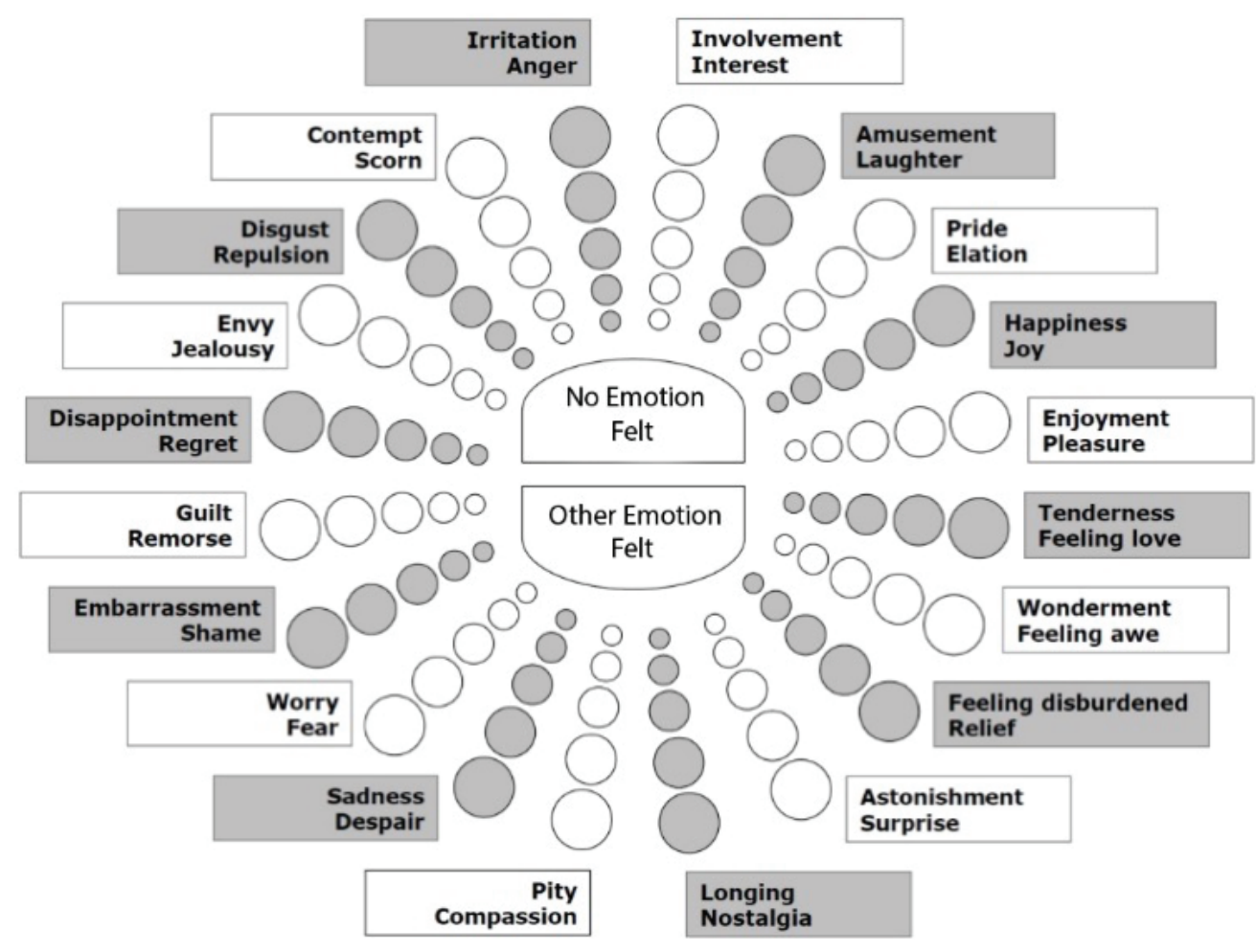

("You might decide for none, one, or two emotions first and then indicate each emotion's intensity independently by choosing a smaller circle for lower intensity or a bigger circle for higher intensity. If you do not feel any emotion towards the footwear/weighted sole's appearance make a cross in the centre of the wheel at "no emotion felt". If you feel an emotion which is not described by the presented emotions please write its name in the centre of the wheel below "other emotion felt").

H. Could you please comment on your choices? 


\section{Interview Notes (over the phone)}

\section{Participant 1: Ned}

- Has experienced stroke before

- Left hemiplegia with with left leg and left arm affected. Also has multiple sclerosis previous to stroke. This affected his left arm and leg with stroke worsening the effects.

- Shoe size U.S 8 but wears an AFO so one size up will be appropriate

- Walks with a limb and feels like his ankle is fused. Used an AFO

- Can stand on unaffected leg and move affected leg independently

- Experiences no pain

- Walks quickly but with a shuffle

- Can provide a caregiver for testing

- Started his recovery with major impairments only able to lie on his back, regained independence and eventually was able to go back to work.

- Yoga for one hour once a week and keeps active but has no home based therapy

- Uses no rehabilitative devices

- Uses an iPad daily to read news and watch tv shows. Some days uses it very little, but uses it frequently on rainy days

- Finds technology relatively easy to use

- Has played digital games but not into them

\section{Participant 2: Eve}

- Suffered Stroke

- Right side of body affected. Suffered a cerebellar stroke
- Mens US 7

- Following stroke used a wheelchair, then transitioned to a walker and was finally able to walk independently using a walking stick.

- Balance is affected, can walk independently but has to look straight forward. Turning head to the side while walking will cause her to turn in that direction

- Can stand and lift affected leg independently

- Experiences shoulder pain

- Moderate walking speed

- Can have neighbour present during testing

- Recovery goals were to be independent.

- No home based therapy, but finds keeping active to be good rehabilitation.

- Does not use a computer or tablet

- Finds computers and tablets hard to use but has used the "able $\mathrm{x}$ " rehab system

- Has played digital games before

\section{Participant 3: Nancy}

- Suffered Stroke

- Right hemiparesis

- Size 7 mens US

- Weakness in right hand leg

- Initially affected walking, but has recovered mobility

- Can stand independently and lift affected limb

- No pain 
- Can have a caregiver present during testing

- Recovery goal of getting independence back

- Basic home based exercises using a skipping rope and exercise ball

- Exercise ball and skipping rope

- Doesn't use much tech as stroke has affected memory so finds it hard to use

- Has played a few games during first rehabilitation

\section{User Testing 1: Extra Notes}

\section{Nancy}

- Offering gym memberships did not help because people could not afford them.

- Similarly, owning a personal computer system is too expensive for many.

- Was not confident enough to hold iPad and play at the same time; needed table nearby.

- Thought the system would be best suited for people who were recently in hospital from stroke.

- She likes being cognitively stimulated.

"You're not a dummy. You can still make your brain work."

- Thinks have a version available at the club would be competitive. "They love it at club when they have one another on. They love competition."

- The system needs to be brought on in stages. "Not bang all together."

"If you're expected to do it in a hurry I don't think it would be any good."
- Direction of motion for exercise needs to be clearly established.

- She could make cognitive connections between similar tasks. E.g. reading the game instructions vs. reading letters in her mail.

- A "you can do it" mentality would be beneficial. Users have no need to be afraid of the device.

- The whole experience was new and exciting. She was glad to see that somebody was try to help survivors of stroke.

- "We need to be able to work out the technology and be able to do it for yourself."

- There were points where she wasn't sure if she had done the right thing but she liked that it made her think. It put her out of her comfort zone. "We need to be pushed to get the brain to do these things."

- "The more that we can do for ourselves the better."

- Can relate aspects of the game to other real-world actions like using the telephone or the toaster. "The phone's not so scary after all."

- "Paperwork is scary." If she can read the instruction and play the game then she can read paperwork. It made her feel good about this. "I can do that... When the next piece of paper comes in, [l can do it]."

- In comparison to normal rehab - "This makes you feel like a normal person."

- "The more that we can do for ourselves the better."

- Need to be conscious of people with sensitive feet. Has to be warm. "Medication can make your hands and feet cold."

- "To me it's fashionable. Nowadays, everyone wants a boot. I've got a boot on." 
- "Colour please."

- "Mine would be red and green and yellow all together."

- Having detachable components to vary the colour and style would be interesting. "I could have black for going out and a coloured pair for going down to the beach."

\section{Ned}

- Bending over the iPad is uncomfortable.

Causes lower back pain.

- Should get a tablet stand.

- Didn't understand the connection between dominoes and rehabilitation.

- Prefers to put shoe on by himself

- A lot of early rehab was learning to stand upright unaided

- Often finds it easier to put on shoes by himself as he can feel where his hand and foot are.

\section{User Testing 2 - Extra Notes}

\section{Eve}

- Emphasised how some survivors of stroke may not have access to adequate facilities, meaning home-based rehabilitation is the only viable option they have.

- Would not have been able to perform the exercises without using the table for support

- Someone who is less able needs to start with less exercise, less weight, set by clinician

- Believed most important point to introduce the system was early on in the recovery process. "Get them in the most early stages of the rehab."

- Wanted to try again, despite initial difficulty.
"That's how you learn."

- "Once you got the hang of it it could grip you, you could enjoy it."

- Can't rush into things. It's okay to take your time. Make sure they feel that they are not rushed.

- Once you accomplished something in game, it felt like you'd learnt something.

- "You've got to take your time to read it. You can't rush it. Take your time to read the instructions."

- "I Found [the experience] stimulating. I wanted to try it again"

- Didn't find any parts of the experience disheartening, found her points of confusion part of the learning process

- "You had to stop and think. You didn't have to rush things"

- "Once you learnt, you felt like you had conquered it"

\section{Nancy}

- Having a physical version of the instructions (for both game and orthosis), printed on sturdy material, e.g. laminated card, would provide security. Users may not be confident trying to get help from the machine and having the card available as a fallback would avoid embarrassment.

- The card would "[remind the user that they] are okay to continue." "Just knowing that the card is there might remind me of what is going on. I might not even need to read it."

- Enjoyed the experience because it is "new, exciting and helpful." It allowed her to see where she is at (with her own capabilities).

- Looking down while concentrating made her feel dizzy. Had to sit down after tutorial and have a glass of water. 
- Before priming, break the exercise down into a step by step process: explain how it works with accompanying animation, add suggestions if needed (e.g. you can hold the edge of the table if it helps you keep your balance), let them practice the motion with supportive messages (e.g. "a little higher") and once they get it right it counts as their first repetition towards 15 . There should be the option to remove this functionality once the player feels they have mastered the exercise's form. A similar process would take place before the main phase as well. For something like sidestepping, mention to lead with the weaker foot (the foot that did the strength training reps.

- Addition supportive information should be included: "If you feel tired or dizzy, take your time to sit down and drink some water."

- Mixed mediums of communication is necessary. Nancy is more confident with written instruction but other people she knows are more dependent on diagrams or spoken instruction.

- By the end of the second game (non-tutorial) she was getting the hang of the game, making correct decisions before the prompting timed out.

- Expressed excitement to play. Used the game as a test to see where her abilities were at.

- Talked of how the offer to play a game made her feel wanted as a person."I can do it for me. I don't need people around."

- Everything comes back to independance.

- "We are not a forgotten cause. You're still a person and should be treated like a person."

- Don't put time pressure on anything. The player must know that they control the pace.

- The offer to play a game made her feel included - "It all boils down to feeling needed, wanted and independence."
- "Just because I've had a stroke doesn't mean I've lost the plot." "We're not a forgotten cause."

- Liked that she doesn't need people around to play the game - "[she] can do it for [her]."

- "It might be repetition, but every time you're doing it you're getting better, getting faster."

- "Let people know if they can't do it, it's okay", You can ask for help at any time.

- Initially walking with a walker, that aid gave her security. The shoe does the same. It comes back to security.

- "Having a shoe that designed for us (stroke patients) will benefit us because we will be mobile, improving muscles and circulation.

- "Why are you taking the bus? I thought you had a car?". Until you come comfortable with telling people about your stroke you tend to avoid it

\section{Ned}

- "It's stimulating in both ways" - in reference to cognitive and physically.

- Was tired after game - "starting to break out a sweat." Necessitates having a build up into more difficult exercises. Completed 30 leg raises and 55 sideways steps and believed the maximum he could accomplish would be roughly double.

\section{User Testing 3 - Extra Notes}

\section{Eve}

- Enjoyed the adaptability of the weight. The ability to gradually increase the weight.

- Weight was initially too heavy

- The movement of having to lift the leg up to midline to take off the weighted sole could 
become hard to do after the workout.

- Once she had been shown how to use it, and potentially under the guidance of an OT she would be confident using it independently.

\section{GEW Notes: Shoe}

- Tenderness/Feeling Love: The person inventing it is putting themselves in the position of who has to wear it.

- Enjoyment: Felt comfortable and secure wearing the shoe in comparison to the last version that wasn't as comfortable

- Relief: Making progress in your rehabilitation

GEW Notes: Weighted Sole

- Enjoyment: Illicites feeling of making progress

- Feeling love/tenderness: If you have that and they put it on you you would be glad that you have something that's going to help you improve and get independant. You feel "one step closer" to your independence

\section{Nancy}

- The shoe looks amazing, is soft and pliable yet strong

- Nice to have some colour

- Material is comfortable

- The merino is warm which is good because my feet are always cold

- Would be quite comfortable wearing them around the house

- The hierarchy of the order in the which the straps need to be affixed makes sense.

- The red and white tags indicate the top needs to be undone first

- Feels stable
- Width is good

- Left foot has a bit off supination so but the shoe made it easy to get into regardless.

- Weight feel secure and made her feel stable when moving with the weight on.

- Tag on heel was great for getting shoe on and off

GEW Notes: Shoe

- Wonderment: "It's pretty, it's nice, it's shaped right"

- Worry: How do I put it on and will I be able to do it?

- Relief: It was easy to put on.

- Proud: Proud and happy to wear them

- Sadness: About having the stroke

GEW Notes: Weighted Sole

- Fearful: I looked at it and straight away was fearful that I wouldn't be able to work it. The appearance makes it feel complicated. Its different to anything I have ever seen.

- Pride: As soon as I knew I could put it on $\mathrm{i}$ was proud of myself that I could do it.

- Surprised: That she felt good when it was on.

\section{Ned}

- Foot is twisted so it's always difficult doing things like putting shoes on.

- The material was a bit tight around the top of the foot on the affected leg.

- Felt comfortable and secure once the shoe was on

- With enough time he felt he could master putting on the shoe and attaching the weighted sole 
- Easy to get both sole and shoe off

- Weight was good and felt he could have increased the weight

- The shoe looks fashionable

GEW Notes: Shoe

- Pride/Elation: Wearing something that was useful and fashionable

GEW: Weighted Sole

- Interest: Anything that helps involve you in your therapy

- Happyness: Helps you with your therapy, "I guess it has to look a bit clumpy because of the weight" 
Appendix D - Process

Early Concepts Renders

1)
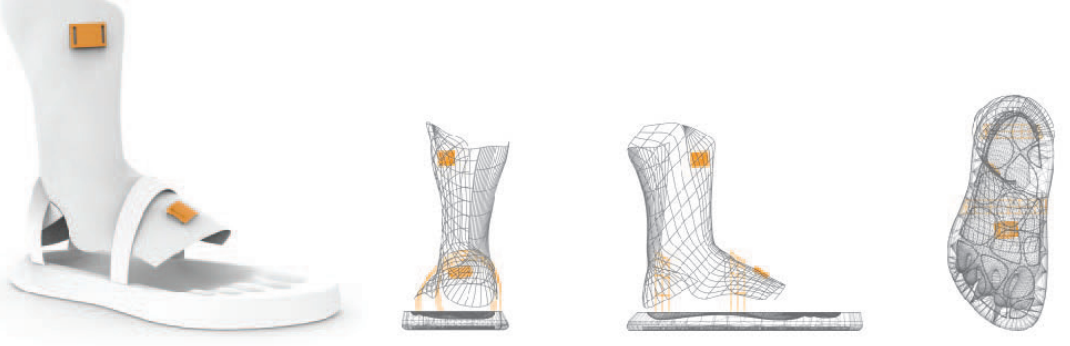

2)

3)
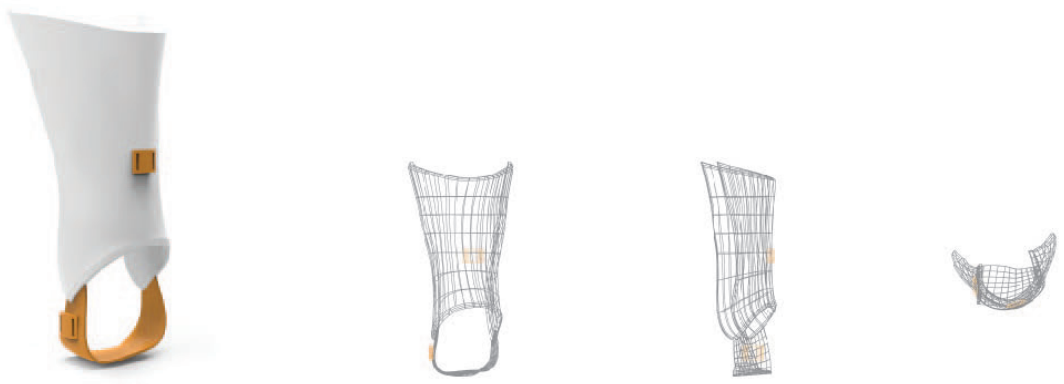

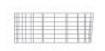

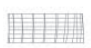

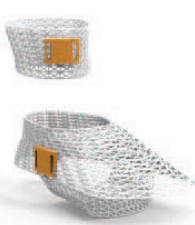

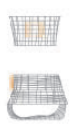
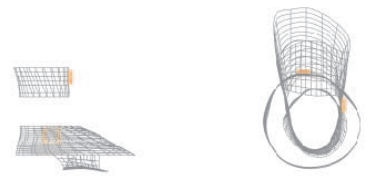

4)
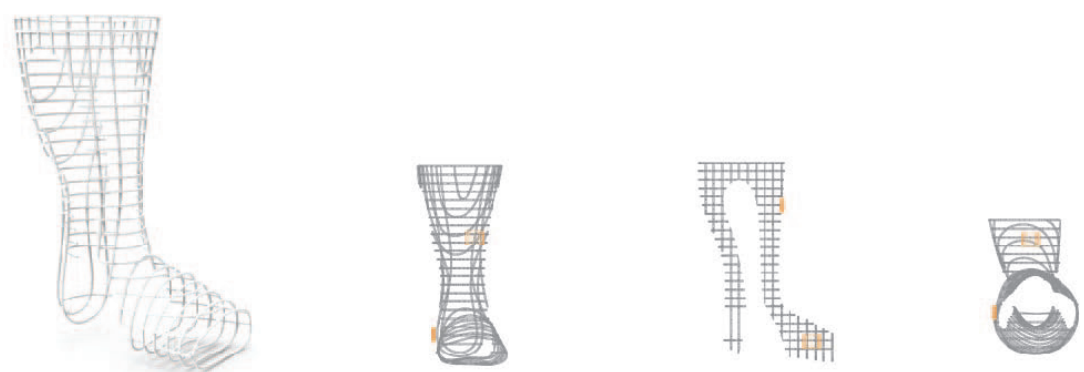


\section{Expanded Concepts}
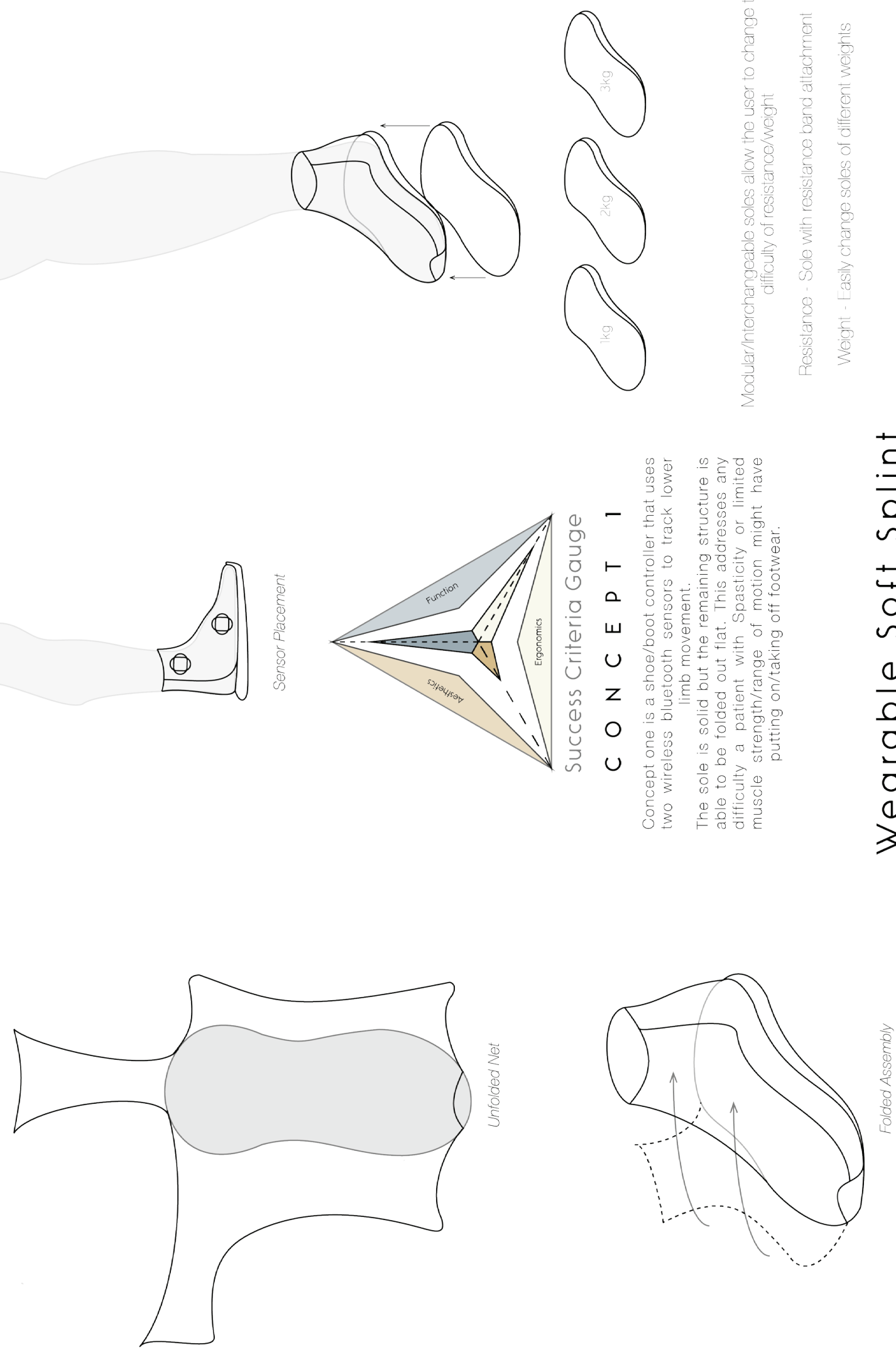

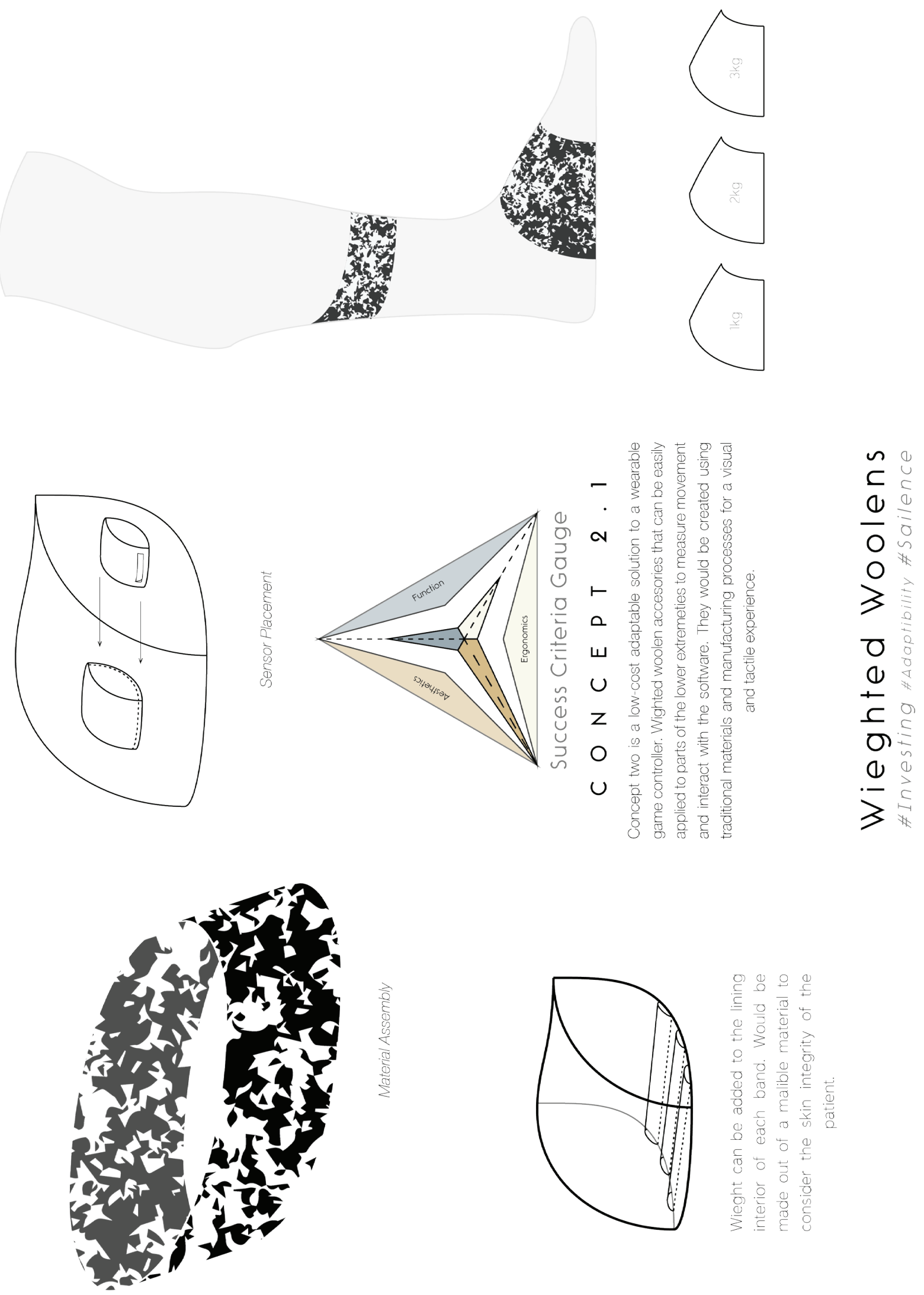

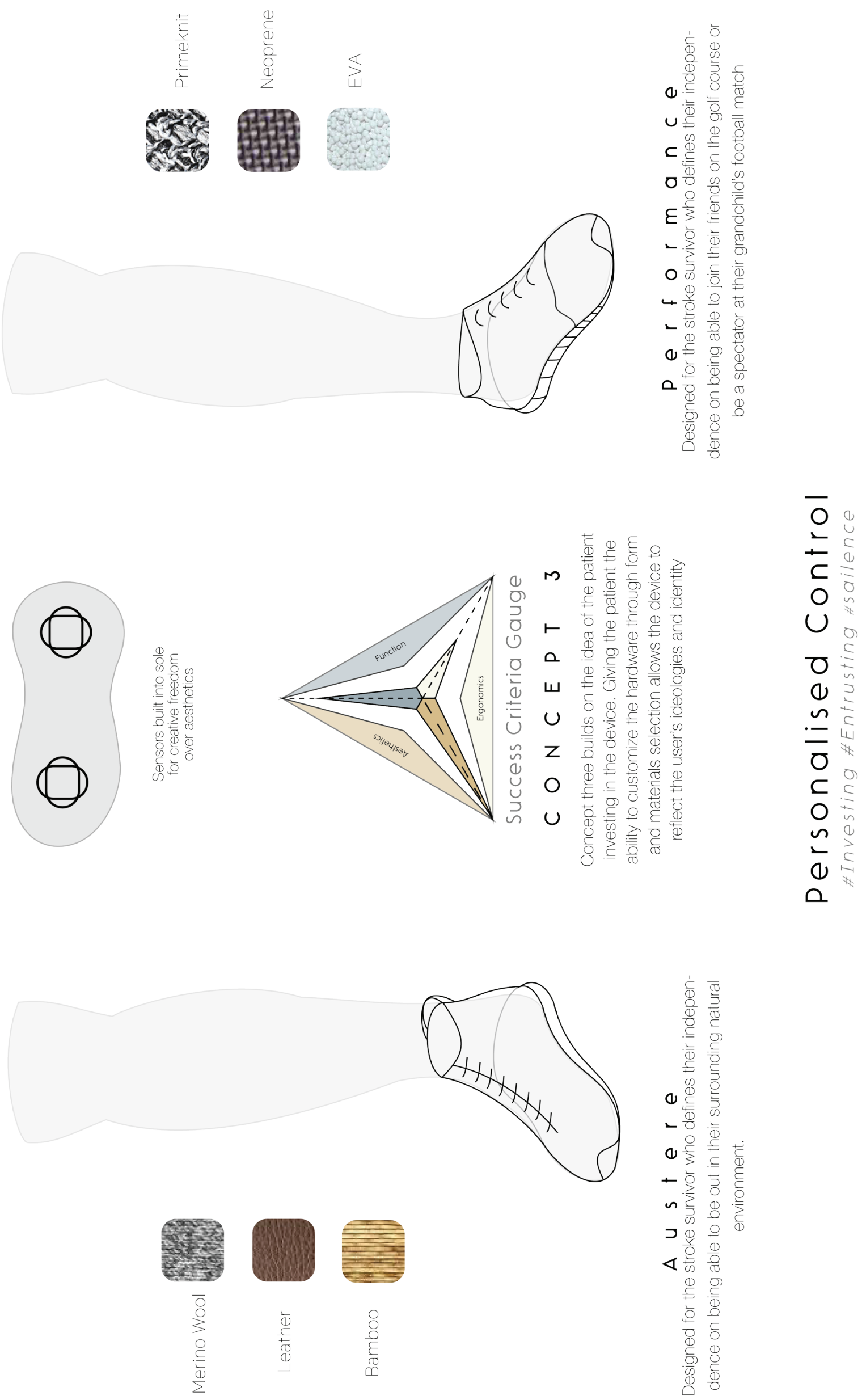

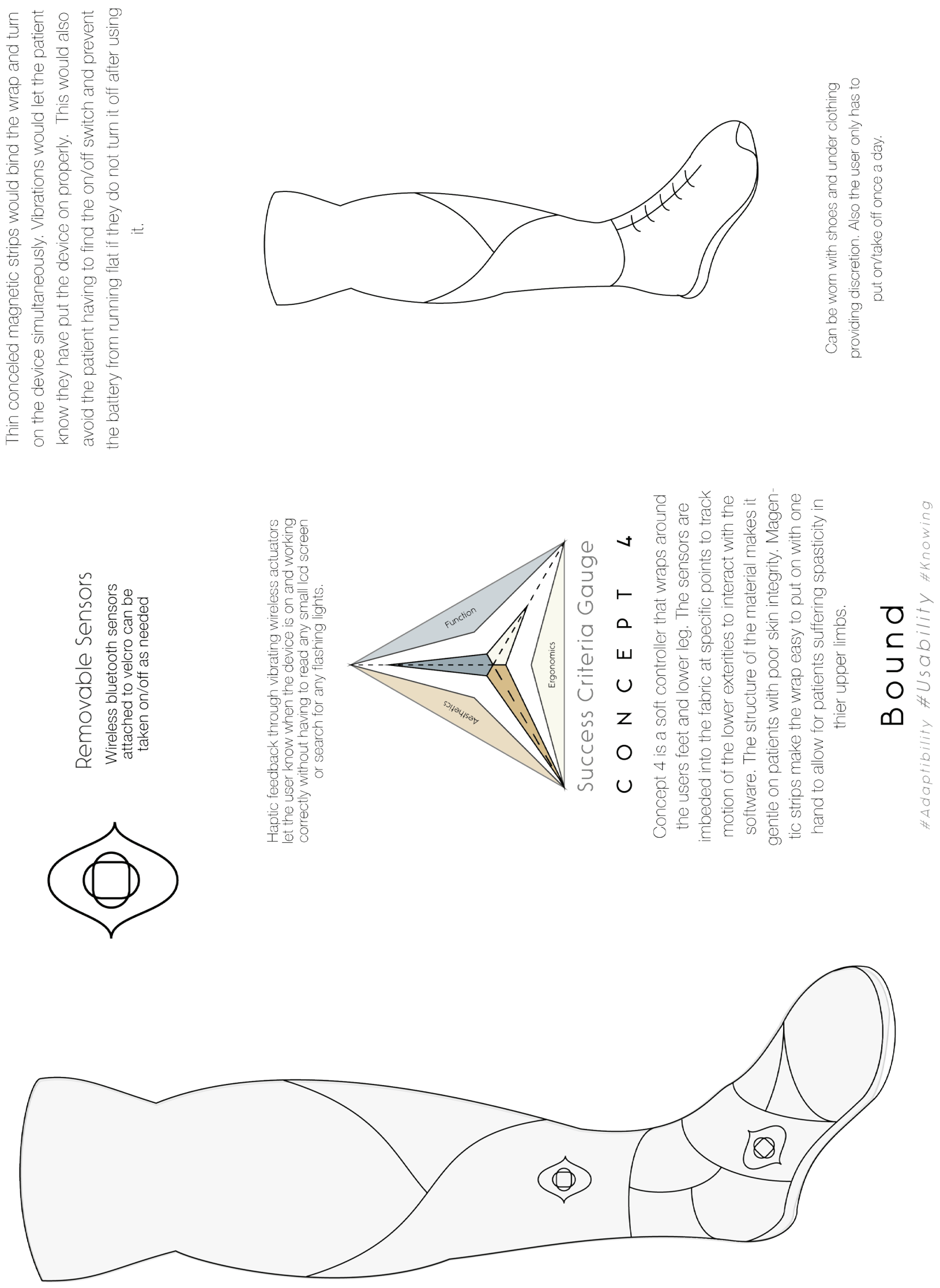


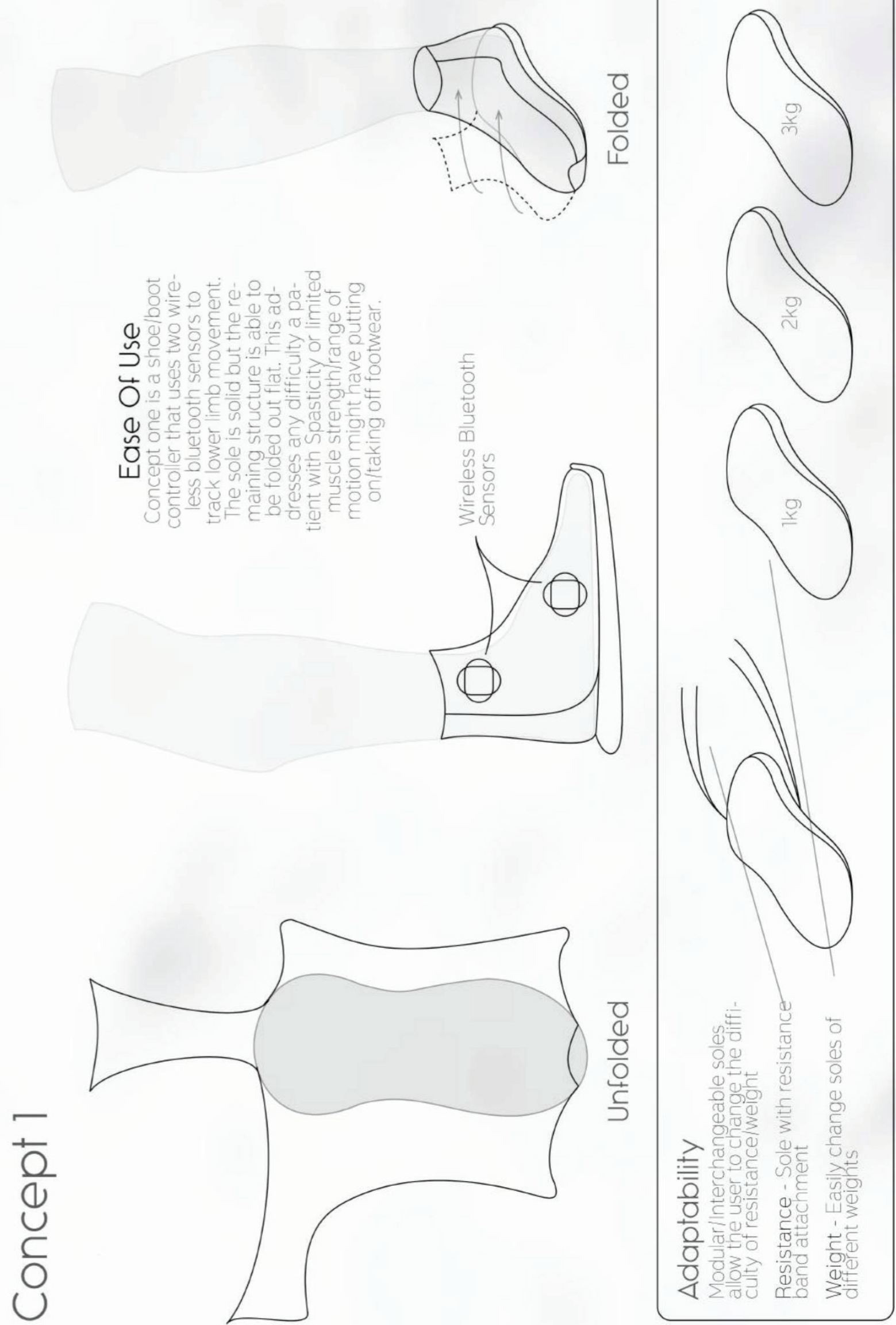



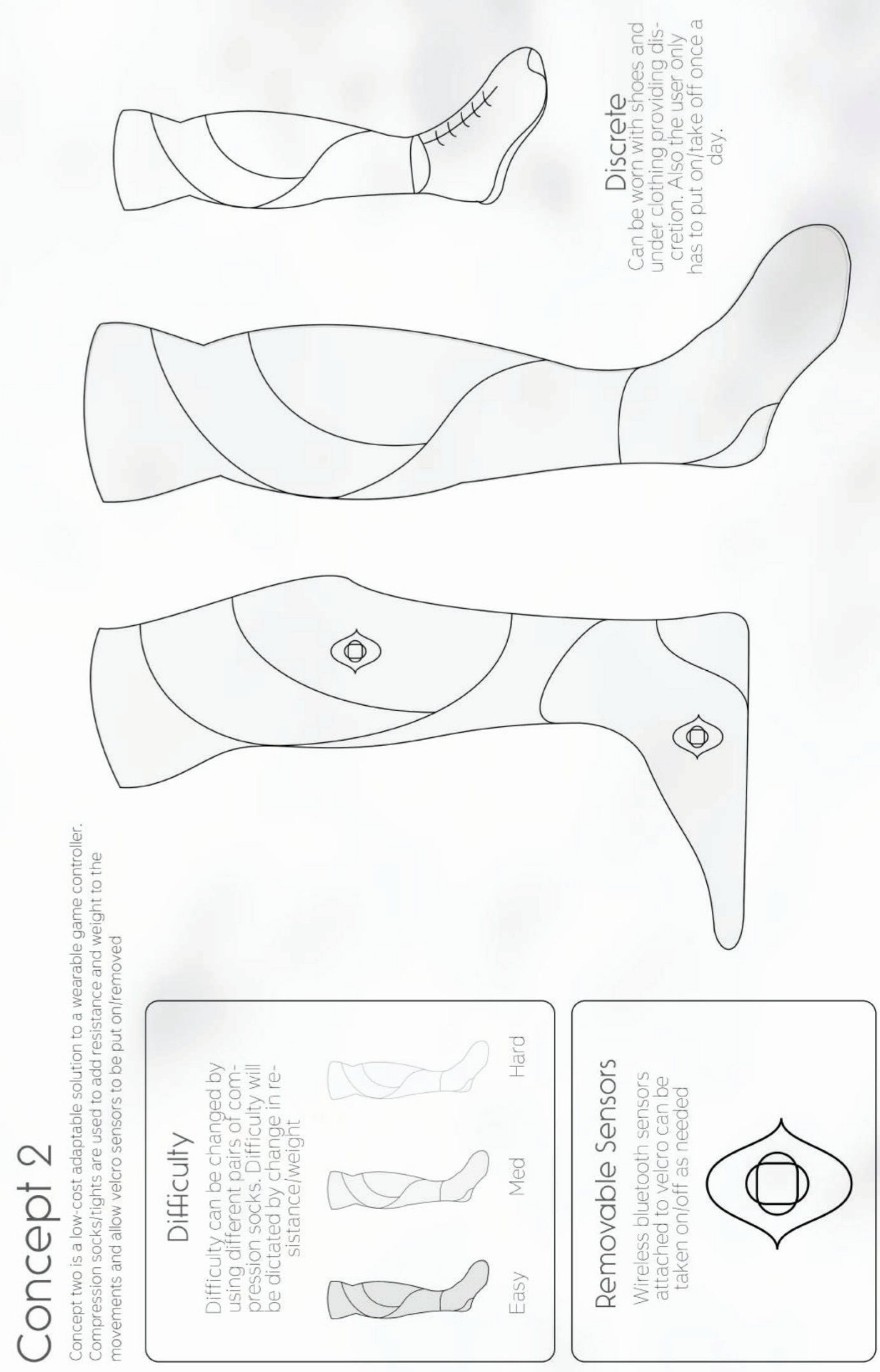


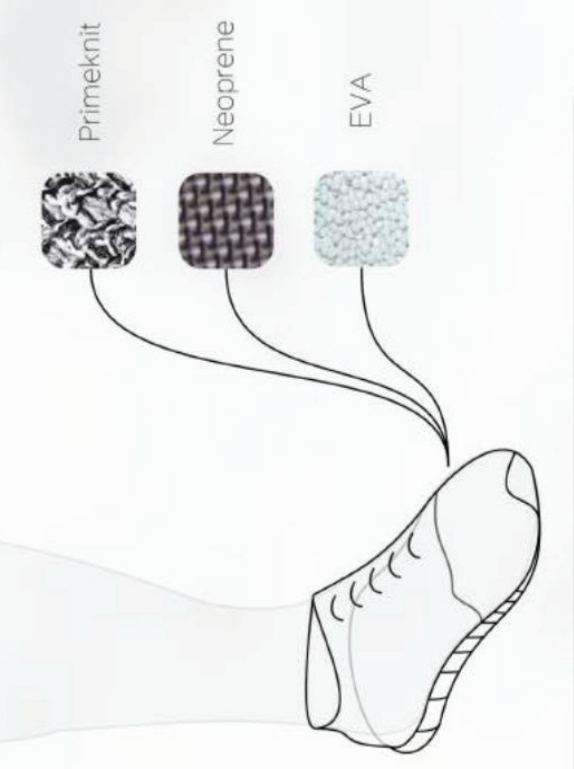

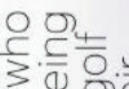
这 $\geq ᄃ \subsetneq$ (4)

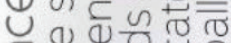

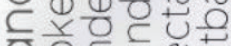
O०ᄃ (1) (1) E芯运运船 Oे (1) $+\div 0$ (1) (1)

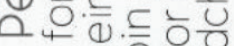
웜원 도원 돈등 ज㐫这

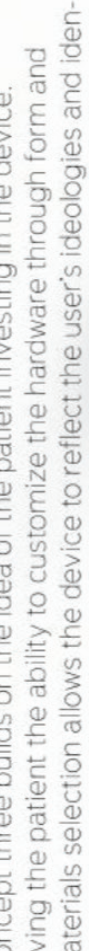

M

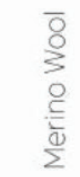

1
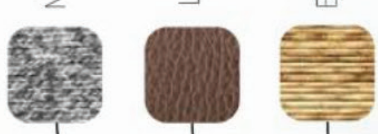

울잉 $3 \cdot \frac{1}{2} \cdot \frac{1}{0}$ $\geq \frac{5}{5}$

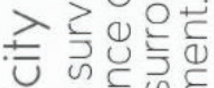
ज证 은드은등 트 윻둰 象 $\sqsubset$ (1) $\frac{1}{1} \div 0=$

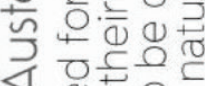
(1) 원웡 过
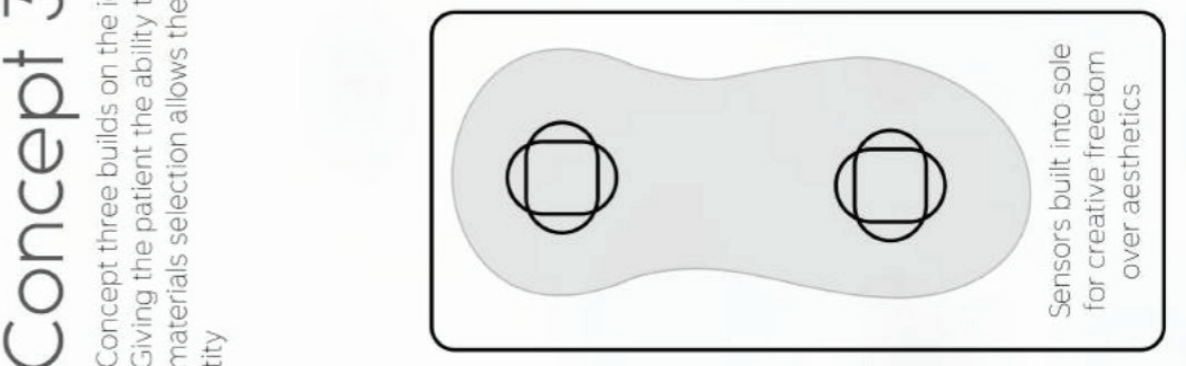
Aesthetic Exploration
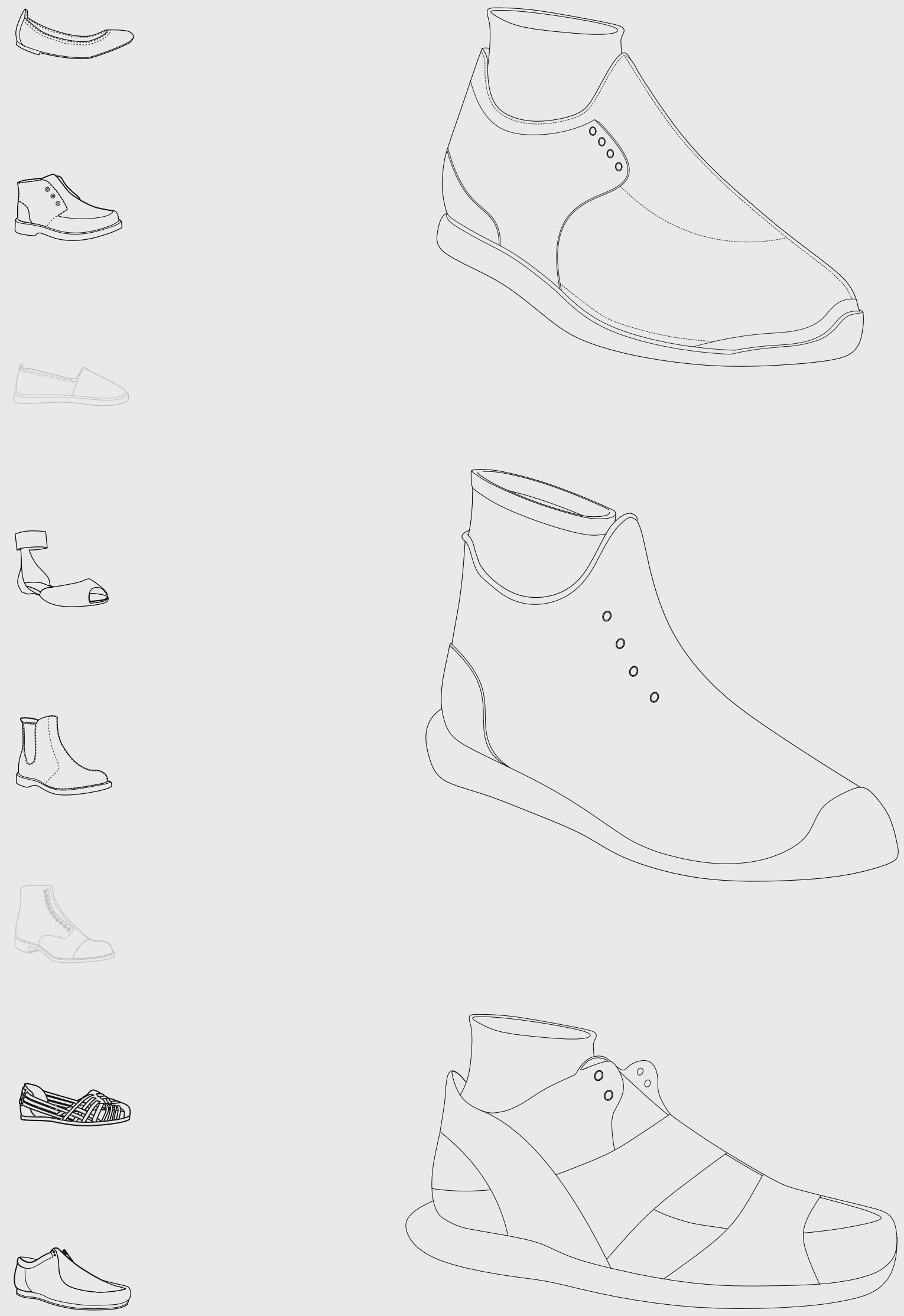

196

Appendix 


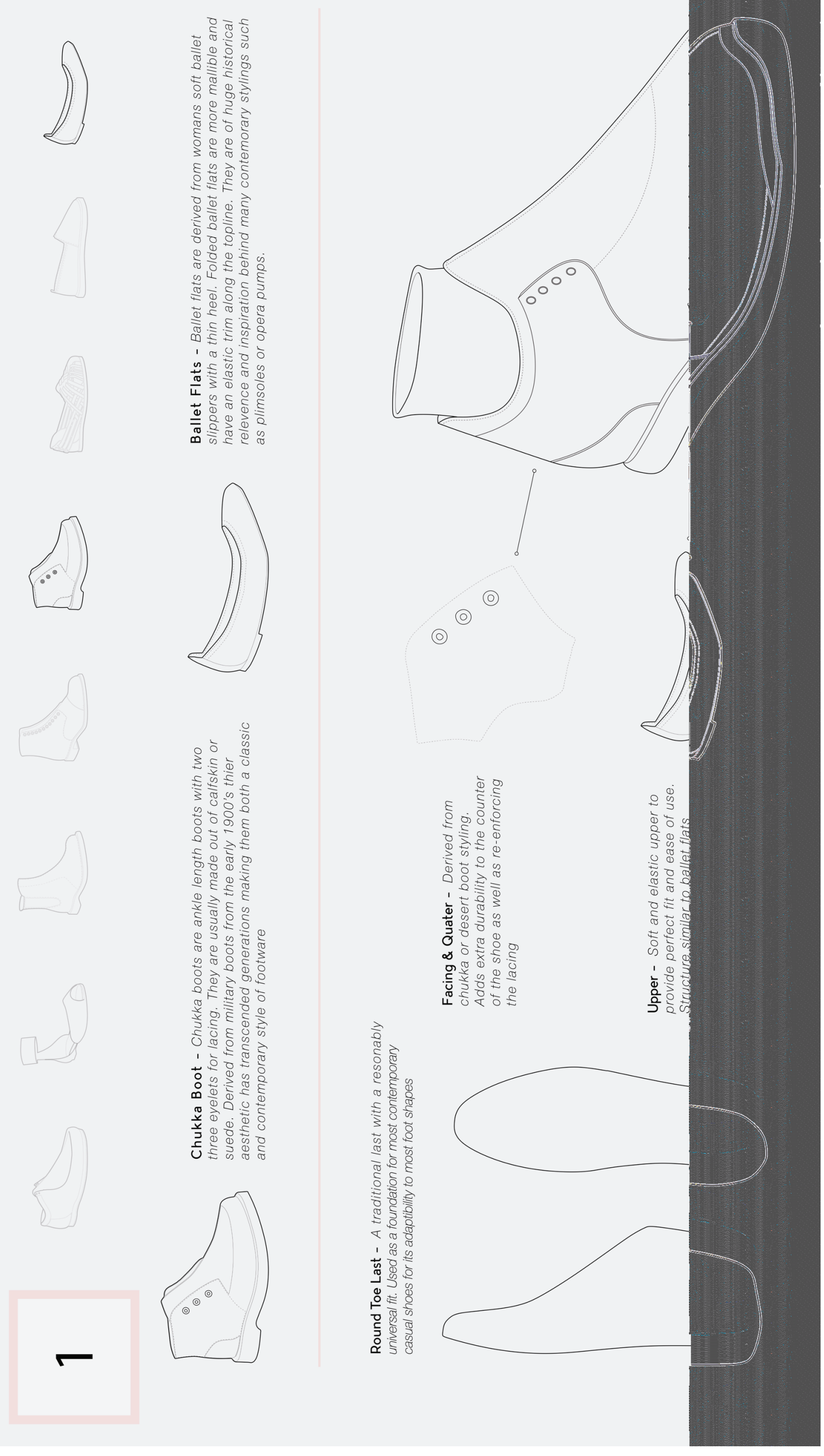




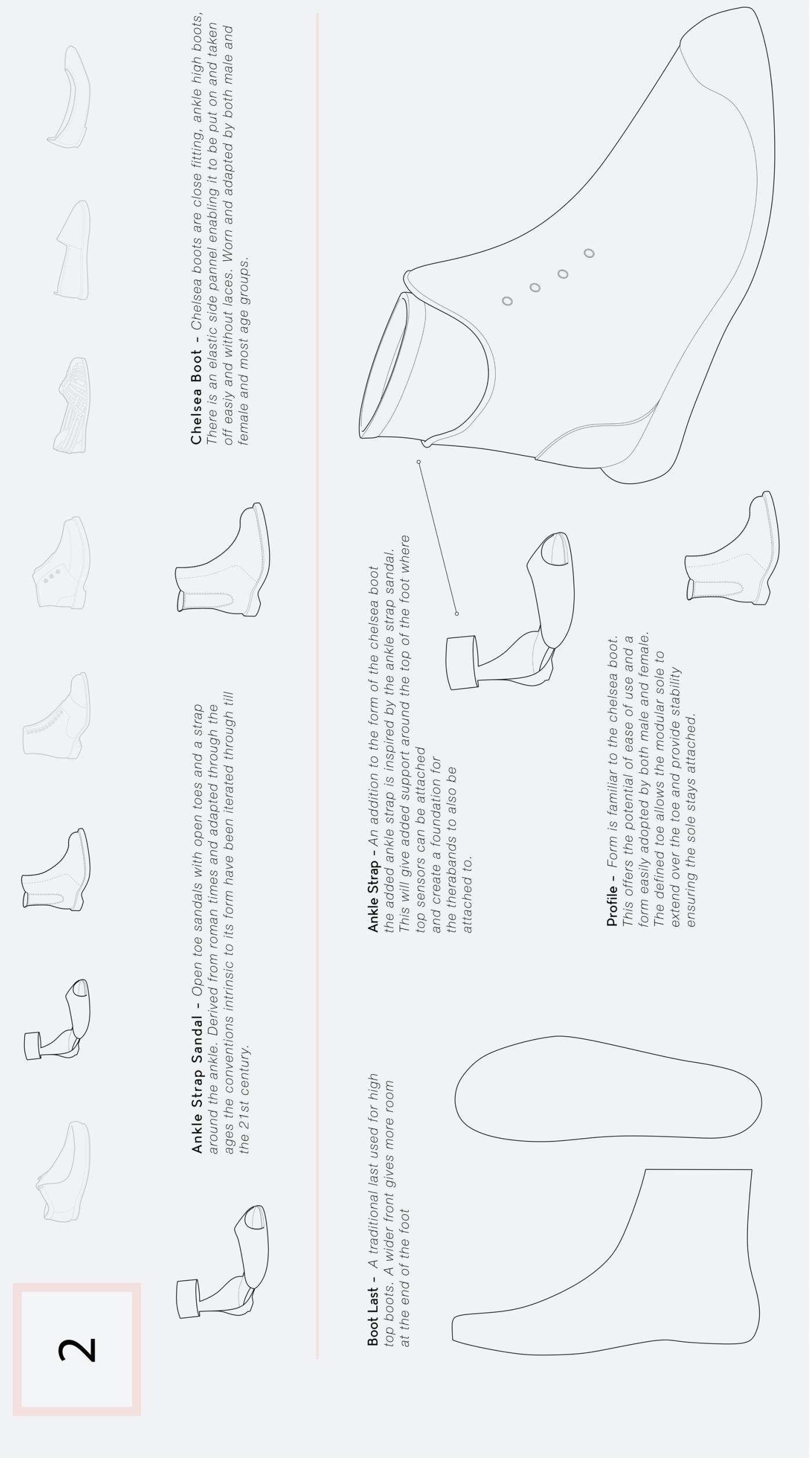




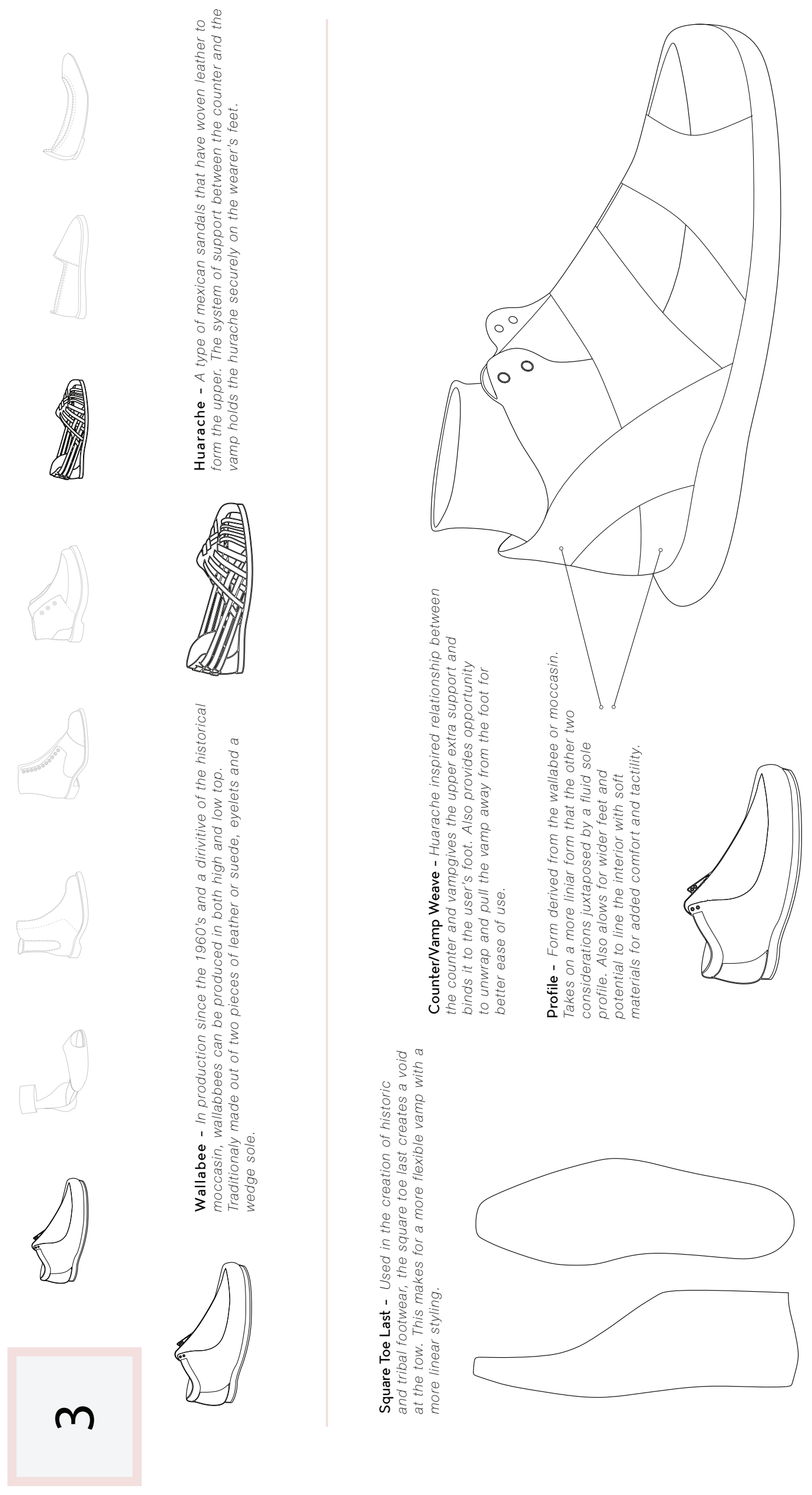


